\author{
UNIVERSIDADE DE SÃO PAULO \\ ESCOLA DE ENGENHARIA DE SÃO CARLOS \\ DEPARTAMENTO DE HIDRÁULICA E SANEAMENTO \\ PROGRAMA DE PÓS-GRADUAÇÃO EM ENGENHARIA HIDRÁULICA E \\ SANEAMENTO
}

\title{
ANÁLISE DO MATERIAL PARTICULADO ATMOSFÉRICO EM UMA REGIÃO DE SÃO CARLOS-SP
}

\section{VINÍCIUS MORI VÁLIO}

SÃO CARLOS - SP 



\title{
ANÁLISE DO MATERIAL PARTICULADO ATMOSFÉRICO EM UMA REGIÃO DE SÃO CARLOS-SP
}

VINÍCIUS MORI VÁLIO

\author{
Dissertação apresentada à Escola de \\ Engenharia de São Carlos, da \\ Universidade de São Paulo, como parte \\ dos requisitos para obtenção do título de \\ Mestre em Ciências: Engenharia \\ Hidráulica e Saneamento. \\ Orientador: Prof. Dr Wiclef Dymurgo \\ Marra Júnior.
}

\section{Versão Corrigida \\ SÃO CARLOS - SP}


AUTORIZO A REPRODUCÃO TOTAL OU PARCIAL DESTE TRABALHO, POR QUALQUER MEIO CONVENCIONAL OU ELETRONICO, PARA FINS DE ESTUDO E PESQUISA, DESDE QUE CITADA A FONTE.

Válio, Vinícius Mori

V172a Análise do material particulado atmosférico em uma região de são Carlos-sp / Vinícius Mori Válio; orientador Wic lef Dymurgo Marra Júnior. São Carlos, 2015 .

Dissertação (Mestrado) - Programa de Pós-Graduação e Área de Concentração em Hidráulica e Saneamento -Escola de Engenharia de São Carlos da Universidade de São Paulo, 2015.

1. Material Particulado. 2. Qualidade do Ar. 3. Precipitação. I. Título. 


\section{FOLHA DE JULGAMENTO}

Candidato: Engenheiro VINíCIUS MORI VÁLIO.

Título da dissertação: "Análise do material particulado atmosférico em uma região de São Carlos-SP".

Data da defesa: 29/05/2015

\section{Comissão Julgadora:}

Prof. Dr. Wiclef Dymurgo Marra Junior

(Orientador)

(Escola de Engenharia de São Carlos/EESC)

Prof. Titular Marcius Fantozzi Giorgetti

(Escola de Engenharia de São Carlos/EESC)

Profa. Dra. Kelen de Almeida Dornelles

(Instituto de Arquitetura e Urbanismo/IAU-USP)

\section{Resultado:}

Aprov $\triangle$ DO

AprovaDO

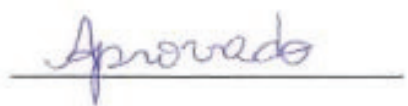

Coordenadora do Programa de Pós-Graduação em Engenharia Hidráulica e Saneamento:

Profa. Associada Maria Bernadete A. Varesche Silva 



\section{RESUMO}

VÁLIO, V.M. Análise do Material Particulado atmosférico em uma região de São Carlos-SP. 2015. 122 f. Dissertação (Mestrado) - Escola de Engenharia de São Carlos, Universidade de São Paulo. São Carlos, 2015.

O presente trabalho avaliou a qualidade do ar de uma área central da cidade de São Carlos-SP, mais precisamente no campus 1 da Universidade de São Paulo. Nessa região há grande movimentação de pessoas e veículos, principalmente durante o horário comercial. Esta avaliação foi feita com base na determinação de um dos parâmetros utilizados para verificar a qualidade do ar, o material particulado (MP) inalável em suspensão, ou seja, partículas que possuem diâmetro aerodinâmico menor ou igual a 10 $\mu \mathrm{m}$ e podem penetrar no sistema respiratório, sendo portanto, nocivas à saúde humana. $\mathrm{O}$ MP foi determinado em suas frações de 2,5 e $10 \mu \mathrm{m}$ de diâmetro $\left(\mathrm{MP}_{10}\right.$ e $\left.\mathrm{MP}_{2,5}\right)$. Duas metodologias diferentes foram utilizadas para determinar a concentração do material particulado em suspensão, fotometria por espalhamento de luz, através do equipamento ADR-1500 e gravimetria, através do PEM (Personal Enviromental Monitor). Os valores obtidos pelo método gravimétrico foram superiores aos resultados encontrados através da fotometria. As concentrações obtidas foram comparadas com os limites recomendados pela Organização Mundial da Saúde para o MP em suas frações de 2,5 e $10 \mu \mathrm{m}$, iguais respectivamente a 25 e $50 \mu \mathrm{g} / \mathrm{m}^{3}$. Além do material particulado foram obtidos dados para temperatura, umidade relativa e precipitação. As médias obtidas para as concentrações de $\mathrm{MP}_{10}$ e $\mathrm{MP}_{2,5}$, com o método gravimétrico, o qual fornece os resultados mais confiáveis, foram iguais respectivamente a 48,8 e 23,1 $\mu \mathrm{g} / \mathrm{m}^{3}$, muito próximas portanto, de seus limites correspondentes. As menores concentrações obtidas para o $\mathrm{MP}_{10}$ foram, em sua maioria, verificadas em dias chuvosos, tanto através do PEM como do ADR. As concentrações de $\mathrm{MP}_{2,5}$, obtidas somente através do PEM, também apresentaram os menores valores em dias com chuva. Foi desenvolvido um modelo matemático que prevê o comportamento do $\mathrm{MP}_{10}$ durante as precipitações, evento este que se mostrou o mais importante na influência da concentração de material particulado atmosférico.

Palavras Chave: Material Particulado, Qualidade do Ar, Precipitação. 


\begin{abstract}
VÁLIO, V.M. Analysis of atmospheric Particulate Matter in a region of São Carlos-SP. 2015. 122 f. Dissertação (Mestrado) - Escola de Engenharia de São Carlos, Universidade de São Paulo. São Carlos, 2015.

This study evaluated the air quality of a central area of the city São Carlos-SP, more precisely on the Campus 1 of the University of São Paulo. In this region there is a large movement of people and vehicles, manly during business hours. This evaluation was made based on determination of one parameter used to verify air quality, the inhalable particulate material (PM) suspended in the air, in other words, particles which have aerodynamic diameter les or equal to $10 \mu \mathrm{m}$ and can penetrate in the respiratory system, therefore, harmful to human health. The PM was determined in its fractions from 2,5 and $10 \mu \mathrm{m}$ of diameter $\left(\mathrm{PM}_{10}\right.$ e $\left.\mathrm{PM}_{2,5}\right)$. Two different methodologies were used to determinate the concentration of particulate suspended material, photometry by scattered light, using the equipment ADR-1500, and gravimetry, thru PEM (Personal Environmental Monitor). The data obtained from gravimetry were higher than the results found thru photometry. The concentrations found were compared to the limits recommended by World Health Organization for PM and its fractions of 2,5 and $10 \mu \mathrm{m}$, equal to 25 and $50 \mu \mathrm{g} / \mathrm{m}^{3}$. Besides PM, temperature, relative humidity and precipitation were measured. The average values for the concentrations of $\mathrm{PM}_{10}$ and $\mathrm{PM}_{2,5}$, using gravimetry, which provide more reliable results, it were equal to 48,8 and $23,1 \mu \mathrm{g} / \mathrm{m}^{3}$, therefore really close to their corresponding limits. The lower concentrations seen for $\mathrm{PM}_{10}$ were, mostly, verified on rainy days, using PEM and ADR. The concentrations of $\mathrm{PM}_{2,5}$, obtained just using PEM, also had the lowest values during rainy days. A mathematical model was developed to predict $\mathrm{PM}_{10}$ behavior during precipitations, this event has shown to have the most important influence on the concentration of atmospheric particulate matter.
\end{abstract}

Keywords: Particulate Matter, Air Quality, Precipitation. 
"Não vou me deixar embrutecer, eu acredito nos meus ideais. Podem até maltratar meu coração que meu espírito ninguém vai conseguir quebrar".

Renato Russo

"Podem matar uma, duas, até três rosas, mas nunca deterão a primavera".

Che Guevara

Dedico este trabalho a toda minha familia e a meus poucos, porém verdadeiros, amigos. 



\section{AGRADECIMENTOS}

Primeiramente agradeço a Deus, pela minha vida, pela minha família, amigos e tudo o que Ele me concedeu. Inclusive as oportunidades e ferramentas que colaboraram para a conquista de um lugar nesta Universidade.

Agradeço aos meus pais pela educação, apoio, ensino, amor e carinho. Ao meu irmão com quem cresci e me desenvolvi.

A minha tia, Rosário, pela oportunidade em estudar na sua escola. Aos meus avós pelo apoio e carinho. Em especial a José Carlos Mori (in memorian) e Iolanda Vellori Mori, que também estiveram sempre presentes na minha vida e cuja casa foi minha segundo moradia.

Agradeço ao meu orientador, professor Dr. Wiclef Dymurgo Marra Júnior, pela orientação, compreensão, auxílio e incentivo. A Coordenação de Aperfeiçoamento de Pessoal de Nível Superior (CAPES) pela concessão da bolsa de Mestrado, sem a qual este trabalho não seria realizado. Ao Departamento de Arquitetura e Urbanismo da USP de São Carlos por ter possibilitado o funcionamentos dos equipamentos dentro da estação meteorológica. Ao técnico Pedro Mathia pela ajuda e fornecimento dos dados da estação meteorológica.

Aos meus amigos de longa data e também aos novos que fiz em São Carlos. Aos amigos e companheiros das repúblicas Mão de Onze, onde morei durante o mestrado, e da Safari (UNESP- Rio Claro) e Barracão (Esalq-USP), onde tive o prazer de morar durante a graduação.

Em especial, agradeço a minha mãe, a minha tia, Tânia, a minha avó Iolanda, e a Lidya Beatriz dos Santos e Felipe Niero Costa, que me ajudaram durante um momento muito delicado e turbulento pelo qual passei em 2013-2014. 



\section{SUMÁRIO}

I. INTRODUÇÃ

II. OBJETIVO.

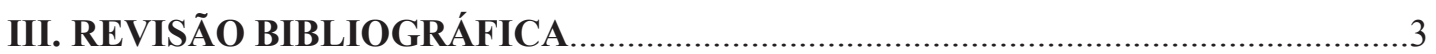

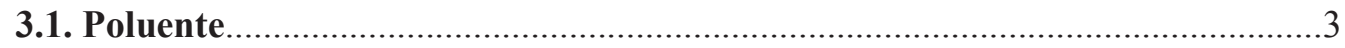

3.2. Poluentes Primários e Secundários...............................................................

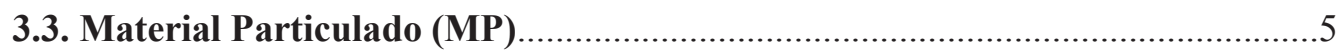

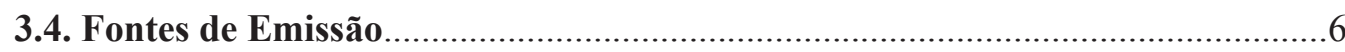

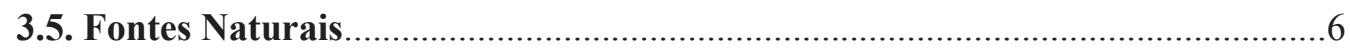

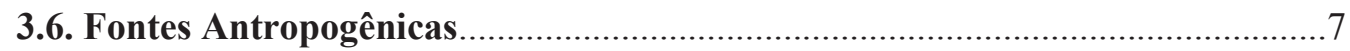

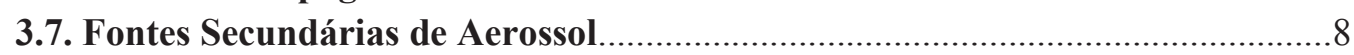

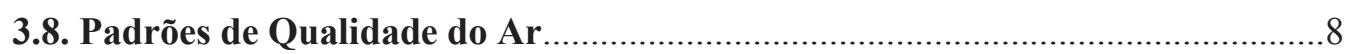

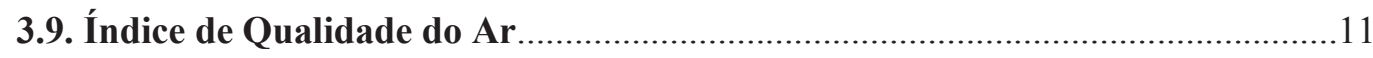

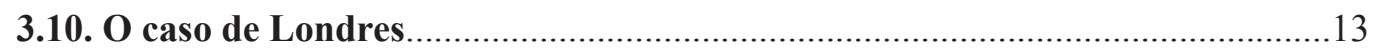

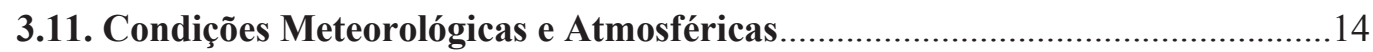

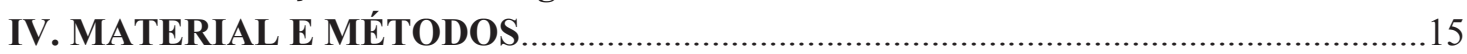

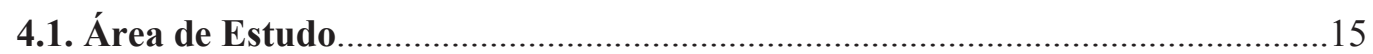

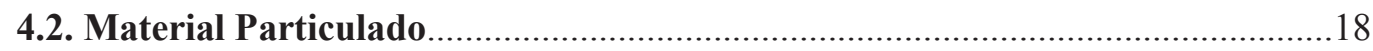

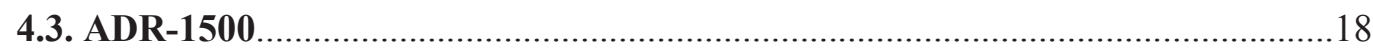

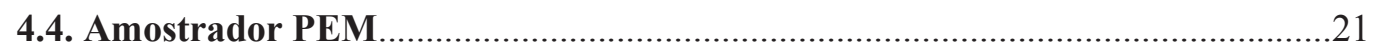

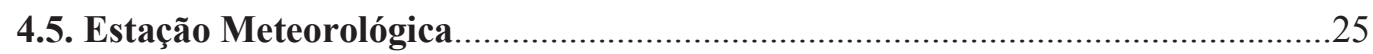

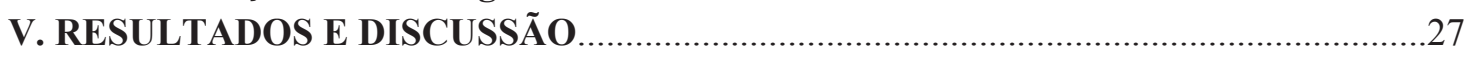

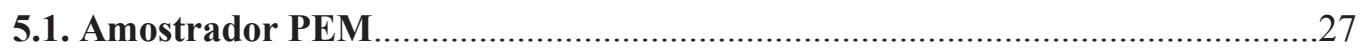

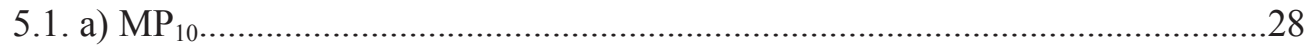

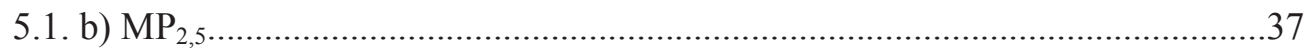

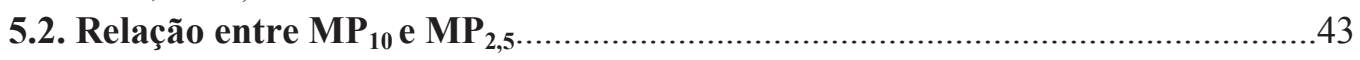

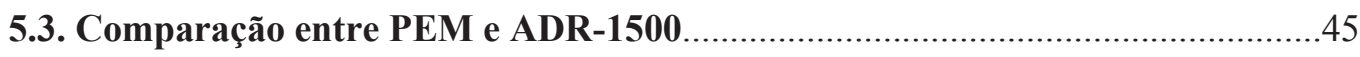

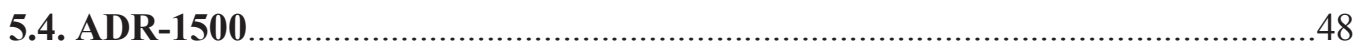

5.5. Influência das precipitações sobre a concentração de material particulado..59

5.6. Variação horária da concentração de MP-10 .......................................................83

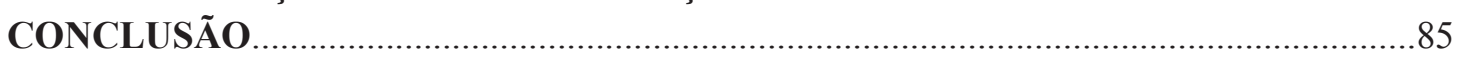

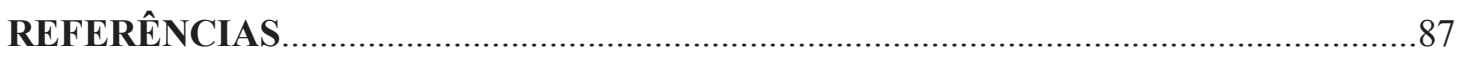

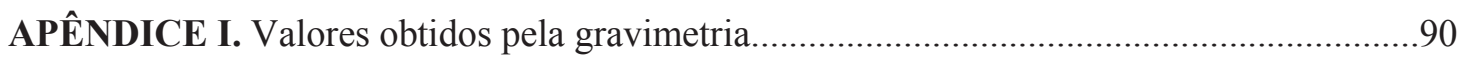

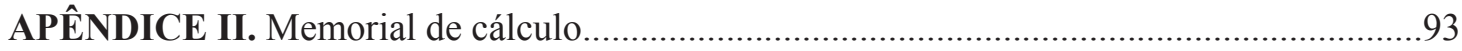




\section{LISTA DE FIGURAS}

Figura 1. Gráfico de mortes versus as concentrações de dióxido de enxofre e MP............................14

Figura 2. Mapa do Brasil, com destaque para o estado de São Paulo e a cidade de São Carlos.......15

Figura 3. Localização da área 1 da USP na cidade de São Carlos - SP.............................................16

Figura 4. Localização do ponto de amostragem dentro da área 1 da USP..........................................17

Figura 5. Vista do ADR 1500 em funcionamento......................................................................

Figura 6. ADR 1500 funcionando com o ciclone vermelho; (a) entrada de ar; (b) ciclone vermelho;

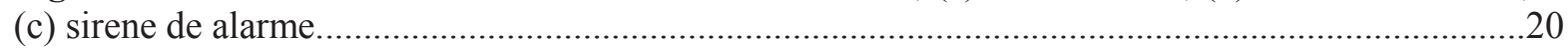

Figura 7. Vista interna do ADR 1500. (a) Vista do display digital do ADR exibindo as concentrações instantânea e média de $\mathrm{MP}_{10}$; (b) Ciclones vermelho e azul............................................................20

Figura 8. Esquema de montagem de um PEM (a) e amostrador PEM com bomba de sucção (b).....22

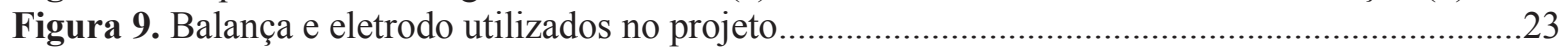

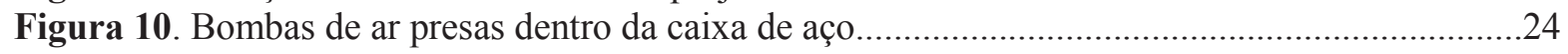

Figura 11. Caixa de aço com o conjunto bomba e PEM em funcionamento presa ao suporte do

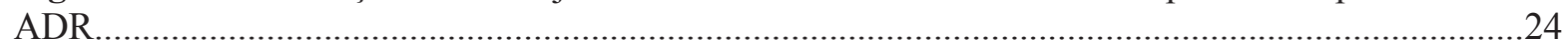

Figura 12. Local onde os amostradores PEM são posicionados na caixa; (a) $\mathrm{MP}_{10}$, (b) $\mathrm{MP}_{2,5} \ldots \ldots \ldots . .25$

Figura 13. Estação meteorológica e seus equipamentos; (a) direção e (b) intensidade dos ventos, (c)

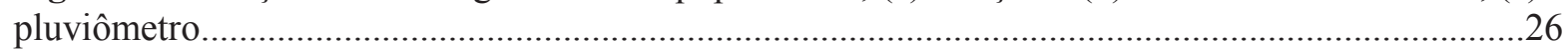

Figura 14. Gráfico de dispersão dos valores obtidos para as concentrações de $\mathrm{MP}_{10} \ldots \ldots \ldots \ldots \ldots \ldots \ldots \ldots . . . . . . .32$

Figura 15. Gráfico de dispersão dos valores obtidos em dias sem chuva para as concentrações de

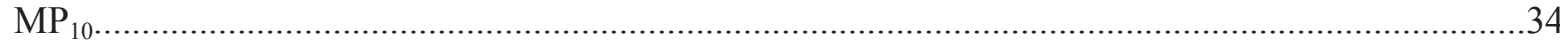

Figura 16. Gráfico de dispersão dos valores obtidos em dias com chuva para as concentrações de

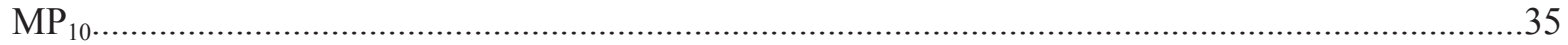

Figura 17. Gráfico das concentrações de $\mathrm{MP}_{10}$ e o valor máximo recomendado pela OMS...............36

Figura 18. Gráfico de dispersão dos valores obtidos para as concentrações de $\mathrm{MP}_{2,5} \ldots \ldots \ldots \ldots \ldots \ldots \ldots \ldots . . . . . . . . . . .39$

Figura 19. Gráfico de dispersão dos valores obtidos em dias sem chuva para as concentrações de

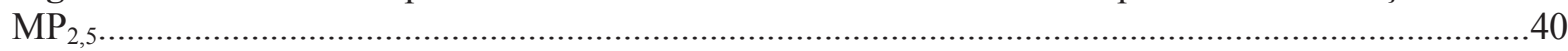

Figura 20. Gráfico de dispersão dos valores obtidos em dias com chuva para as concentrações de

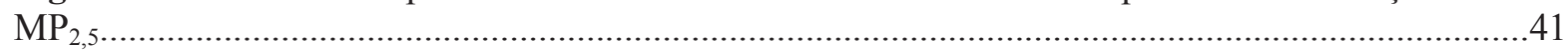

Figura 21. Gráfico das concentrações de $\mathrm{MP}_{2,5}$ e o limite recomendado pela OMS..............................42

Figura 22. Gráfico de distribuição da relação percentual entre as concentrações de $\mathrm{MP}_{2,5}$ e $\mathrm{MP}_{10} \ldots . .43$

Figura 23. Gráfico das concentrações de $\mathrm{MP}_{10}$ obtidas através do ADR e o limite recomendado pela

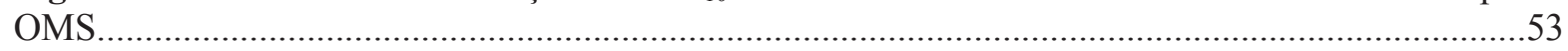

Figura 24. Gráfico das concentrações de $\mathrm{MP}_{10}$ obtidas através do ADR e o limite recomendado pela

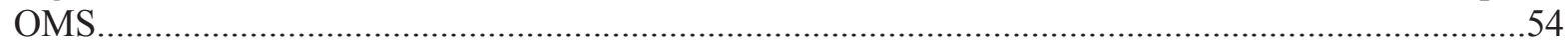

Figura 25. Gráfico das concentrações de $\mathrm{MP}_{10}$ obtidas através do ADR e o limite recomendado pela

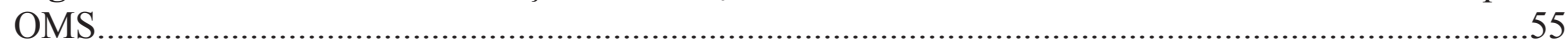

Figura 26. Gráfico das concentrações de $\mathrm{MP}_{10}$ obtidas através do ADR e o limite recomendado pela

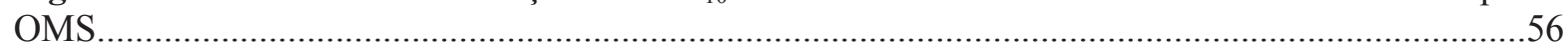

Figura 27. Gráfico das concentrações de $\mathrm{MP}_{10}$ obtidas através do ADR e o limite recomendado pela

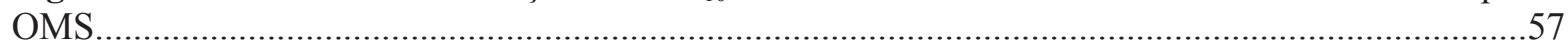

Figura 28. Gráfico das concentrações de $\mathrm{MP}_{10}$ obtidas através do ADR e o limite recomendado pela

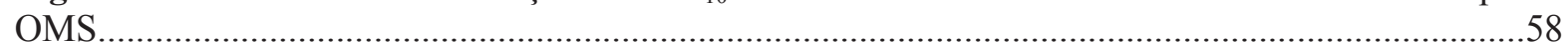

Figura 29. Gráfico de dispersão dos valores de $\alpha$ para as precipitações selecionadas.........................67

Figura 30. Gráfico de dispersão dos valores de $\alpha$ para as precipitações da Tabela 13........................70

Figura 31. Precipitação 1, linha de tendência exponencial do Excel e o valor de $\mathrm{R}^{2}$..........................73

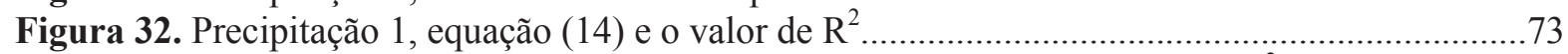

Figura 33. Precipitação 2, linha de tendência exponencial do Excel e o valor de $\mathrm{R}^{2}$.................................74

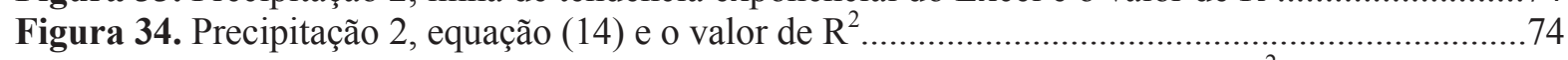

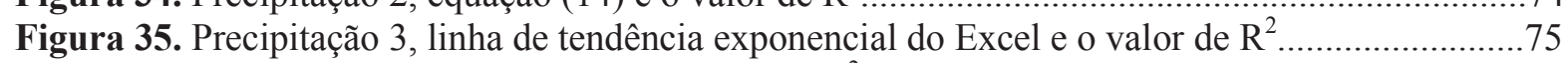

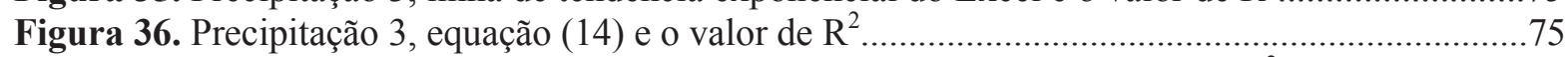

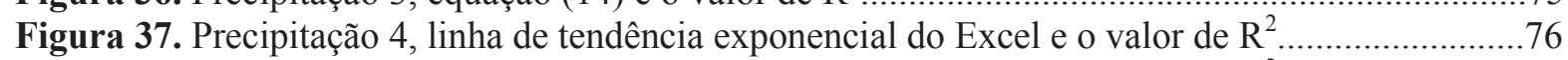

Figura 38. Precipitação 5, linha de tendência exponencial do Excel e o valor de $\mathrm{R}^{2}$................................77 
Figura 39. Precipitação 5, equação (14) e o valor de $\mathrm{R}^{2}$

Figura 40. Precipitação 6, linha de tendência exponencial do Excel e o valor de $\mathrm{R}^{2}$............................78

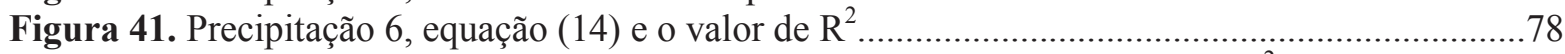

Figura 42. Precipitação 7, linha de tendência exponencial do Excel e o valor de $\mathrm{R}^{2}$.........................79

Figura 43. Precipitação 7, equação (14) e o valor de $\mathrm{R}^{2}$.............................................................79

Figura 44. Precipitação 8, linha de tendência exponencial do Excel e o valor de $\mathrm{R}^{2}$........................80

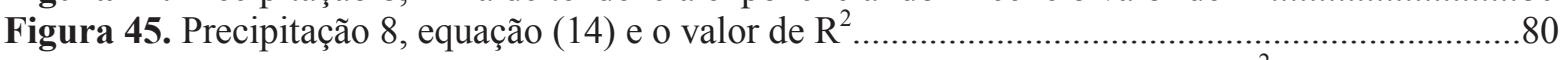

Figura 46. Precipitação 9, linha de tendência exponencial do Excel e o valor de $\mathrm{R}^{2}$......................81

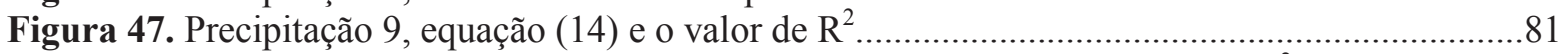

Figura 48. Precipitação 10, linha de tendência exponencial do Excel e o valor de $\mathrm{R}^{2}$.....................8.

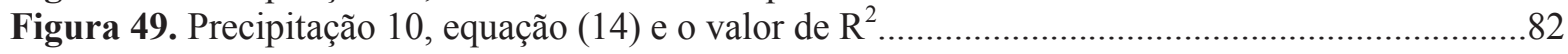




\section{LISTA DE TABELAS}

PÁGINA

Tabela 01. Fontes e características dos principais poluentes na atmosfera........................................04

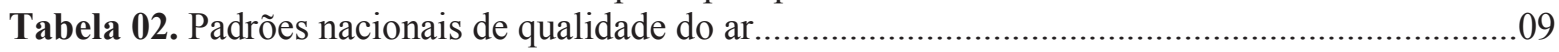

Tabela 03. Critérios para episódios agudos de poluição do ar............................................................. 10

Tabela 4. Valores propostos pela OMS como referência para a qualidade do ar..................................11

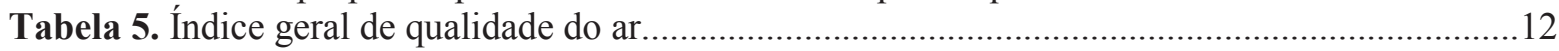

Tabela 6. Valores obtidos para os MP 10 e 2,5 através do PEM........................................................20

Tabela 7. Dias em que houve chuva e o valor precipitado, durante o período de amostragem..........31

Tabela 8. Concentrações de $\mathrm{MP}_{10}$ obtidas através do PEM e ADR e a relação entre as mesmas......46

Tabela 9. Concentrações de $\mathrm{MP}_{10}$ medidas através do ADR-1500 e suas respectivas datas...............49

Tabela 10. Precipitações que influenciaram na concentração de MP e informações relacionadas a

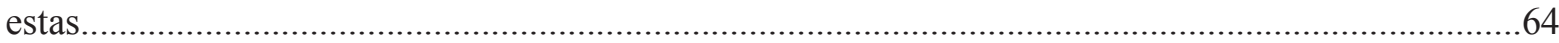

Tabela 11. Precipitações selecionadas para o cálculo de $\alpha$ médio...........................................................66

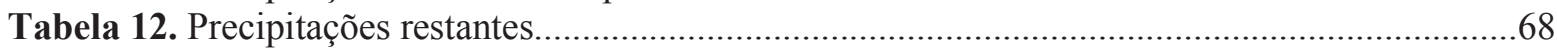

Tabela 13. Precipitações, o valor de $\alpha$, suas concentrações iniciais Ko1 e Ko2 e a razão entre as

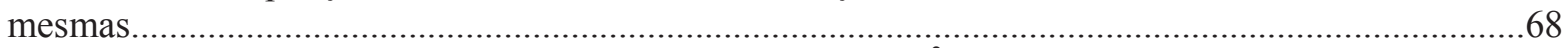

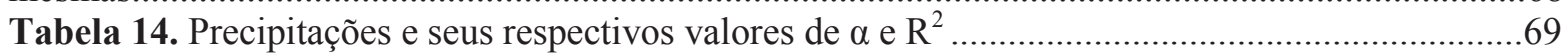

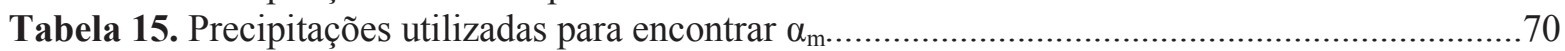

Tabela 16. Comparação entre a eficiência real na remoção de MP e a eficiência prevista utilizando-se

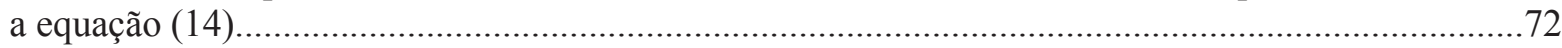

Tabela 17. Variação da concentração de $\mathrm{MP}_{10} \mathrm{em}$ um horário de pico em relação à média diária......84 


\section{INTRODUÇÃO}

Em 1950, Cubatão foi escolhida para sediar a Refinaria Presidente Bernardes (RPBC), que foi a maior obra industrial de seu tempo no Brasil. No seu encalço surgiram outras indústrias petroquímicas, siderúrgicas e de fertilizantes. Mas, em 1956, logo depois das primeiras refinarias entrarem em funcionamento, alguns estudantes foram atendidos no Pronto Socorro por intoxicação e, em 1957, ocorreu o primeiro caso documentado de intoxicação aguda por poluição. O que outrora era progresso tornarase agora decadência. Na década de 1980, Cubatão era a cidade mais poluída do mundo, ficando conhecida mundialmente pelo apelido de "vale da morte". De acordo com Couto (2003), de um pobre vilarejo a um dos maiores centros industriais do país, Cubatão pagaria um preço muito alto: a ruína do seu meio ambiente, pois em 20 anos a Serra do Mar tinha árvores sem folhas, rios sem vida e uma atmosfera poluída.

Observa-se, portanto que, tanto a saúde da população como as construções das cidades são diretamente afetadas pela poluição ambiental, de modo particular pela poluição atmosférica. Além dos gases presentes na atmosfera, destacam-se também as partículas suspensas no ar, constituídas de poeiras, fumaças e todo tipo de material sólido e líquido que se mantém suspenso na atmosfera por causa de seu pequeno tamanho, as quais têm um papel predominante nos processos regulados pela circulação atmosférica (WHO, 2003; BAIRD, 2002).

A qualidade do ar é diretamente influenciada pela distribuição e intensidade das emissões de poluentes atmosféricos de origem natural ou antrópica. Exercem papel fundamental a topografia e as condições meteorológicas, que se alteram de modo significativo nas várias regiões do Estado de São Paulo. As emissões veiculares desempenham um papel de destaque nos níveis de poluição do ar dos grandes centros urbanos, ao passo que as emissões industriais afetam significativamente a qualidade do ar em regiões mais especificas (CETESB, 2013). Deste modo, é a interação entre as condições atmosféricas e as fontes de poluição que vai definir o nível de qualidade do ar, que por sua vez determina o surgimento de efeitos adversos da poluição do ar sobre os receptores.

A determinação sistemática da qualidade do ar deve ser, por questões de ordem prática, definida em função de sua importância e dos recursos disponíveis. Com isso, neste trabalho, foi realizada a análise da concentração do material particulado atmosférico inalável em suas frações de até 2,5 e $10 \mu \mathrm{m}$ de diâmetro. 


\section{OBJETIVO}

Este trabalho quantificou o material particulado atmosférico em uma região da cidade de São Carlos - SP, através de medições realizadas na área 1 do campus da Universidade de São Paulo, localizado na região central do município, e também avaliou a influência de alguns fatores na concentração do MP. Para tal, foram realizados os seguintes procedimentos:

- Caracterizar fisicamente o material particulado inalável, por meio de distribuição de tamanho, nas suas frações de até 2,5 e $10 \mu \mathrm{m}$ de diâmetro.

- Verificar a influência das precipitações sobre a variabilidade das concentrações do material particulado.

- Verificar a influência das horas do dia sobre a variabilidade das concentrações do material particulado. 


\section{REVISÃO BIBLIOGRÁFICA}

\subsection{Poluente}

Conforme a Resolução CONAMA nº 3 de 28/06/1990, considera-se poluente atmosférico "qualquer forma de matéria ou energia com intensidade e em quantidade, concentração, tempo ou características em desacordo com os níveis estabelecidos, e que tornem ou possam tornar o ar impróprio, nocivo ou ofensivo à saúde, inconveniente ao bem-estar público, danoso aos materiais, à fauna e a flora ou prejudicial à segurança, ao uso e gozo da propriedade e as atividades normais da comunidade".

A medição sistemática da qualidade do ar é restrita a um número de poluentes, definidos em função de sua importância e dos recursos disponíveis para seu acompanhamento. $\mathrm{O}$ grupo de poluentes que servem como indicadores de qualidade do ar, adotados universalmente e que foram escolhidos em razão da frequência de ocorrência e de seus efeitos adversos, são: material particulado (MP), dióxido de enxofre $\left(\mathrm{SO}_{2}\right)$, monóxido de carbono $(\mathrm{CO})$, oxidantes fotoquímicos, como o ozônio $\left(\mathrm{O}_{3}\right)$, hidrocarbonetos $(\mathrm{HC})$ e óxidos de nitrogênio $\left(\mathrm{NO}_{\mathrm{x}}\right)$.

Quando se determina, para fins de legislação, a concentração de um poluente na atmosfera, mede-se o grau de exposição dos receptores (seres humanos, outros animais, plantas, materiais) como resultado final do processo de lançamento desse poluente na atmosfera a partir de suas fontes de emissão e suas interações na atmosfera, do ponto de vista físico (diluição) e químico (reações químicas).

A Tabela 1 mostra uma visão geral dos principais poluentes considerados indicadores da qualidade do ar, bem como suas características, quais suas principais origens e seus efeitos no meio ambiente. 
Tabela 01. Fontes e características dos principais poluentes na atmosfera.

\begin{tabular}{|c|c|c|c|}
\hline Poluente & Características & Fontes Principais & $\begin{array}{c}\text { Efeitos Gerais ao Meio } \\
\text { Ambiente }\end{array}$ \\
\hline $\begin{array}{l}\text { Partículas } \\
\text { Inaláveis } \quad \text { Finas } \\
\left(\mathbf{M P}_{2,5}\right)\end{array}$ & $\begin{array}{l}\text { Partículas de } \\
\text { sólido ou } \\
\text { suspensas no ar, na formal } \\
\text { de poeira, neblina, } \\
\text { aerossol, fumaça, fuligem } \\
\text { etc, que podem } \\
\text { permanecer no ar e } \\
\text { percorrer longas distâncias. } \\
\text { Faixa de tamanho }<2,5 \\
\text { micra. }\end{array}$ & $\begin{array}{l}\text { Processos de combustão } \\
\text { (industrial, veículos } \\
\text { automotores), aerossol } \\
\text { secundário (formado na } \\
\text { atmosfera) como sulfato } \\
\text { e nitrato, entre outros. }\end{array}$ & $\begin{array}{l}\text { Danos à vegetação, } \\
\text { deterioração } \\
\text { visibilidade, } \\
\text { contaminação do solo e } \\
\text { água. }\end{array}$ \\
\hline $\begin{array}{l}\text { Partículas } \\
\text { Inaláveis }\left(\mathrm{MP}_{10}\right) \text { e } \\
\text { Fumaça }\end{array}$ & $\begin{array}{l}\text { Partículas de material } \\
\text { sólido ou líquido que } \\
\text { ficam suspensas no ar, na } \\
\text { forma de poeira, neblina, } \\
\text { aerossol, fumaça, fuligem, } \\
\text { etc. Faixa de tamanho }<10 \\
\text { micra. }\end{array}$ & $\begin{array}{l}\text { Processos de combustão } \\
\text { (indústria e veículos } \\
\text { automotores), poeira } \\
\text { ressuspensa, aerossol } \\
\text { secundário (formado na } \\
\text { atmosfera). }\end{array}$ & $\begin{array}{lr}\text { Danos à } & \text { vegetação, } \\
\text { deterioração } & \text { da } \\
\text { visibilidade } & \text { e } \\
\text { contaminação do solo e } \\
\text { água. }\end{array}$ \\
\hline $\begin{array}{lr}\text { Partículas } & \text { Totais } \\
\text { em } & \text { Suspensão } \\
\text { (PTS) } & \end{array}$ & $\begin{array}{l}\text { Partículas de material } \\
\text { sólido ou líquido que } \\
\text { ficam suspensas no ar, na } \\
\text { forma de poeira, neblina, } \\
\text { aerossol, fumaça, fuligem, } \\
\text { etc. Faixa de tamanho }<50 \\
\text { micra. }\end{array}$ & 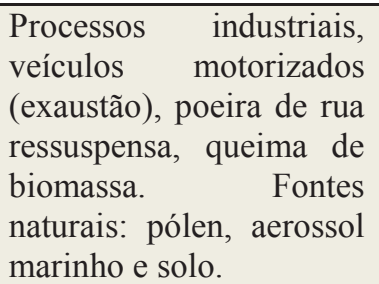 & $\begin{array}{lr}\text { Danos à } & \text { vegetação, } \\
\text { deterioração } & \text { da } \\
\text { visibilidade } & \text { e } \\
\text { contaminação do solo e } \\
\text { água. }\end{array}$ \\
\hline $\begin{array}{ll}\text { Dióxido } & \text { de } \\
\text { Enxofre }\left(\mathrm{SO}_{2}\right) & \end{array}$ & $\begin{array}{l}\text { Gás incolor, com forte } \\
\text { odor, semelhante ao gás } \\
\text { produzido na queima de } \\
\text { palitos de fósforos. Pode } \\
\text { ser transformado a } \mathrm{SO}_{3} \text {, } \\
\text { que na presença de vapor } \\
\text { de água, passa rapidamente } \\
\text { a } \mathrm{H}_{2} \mathrm{SO}_{4} \text {. É um importante } \\
\text { precursor dos sulfatos, um } \\
\text { dos principais } \\
\text { componentes das } \\
\text { partículas inaláveis. }\end{array}$ & $\begin{array}{l}\text { Processos que utilizam } \\
\text { queima de óleo } \\
\text { combustível, refinaria de } \\
\text { petróleo, veículos a } \\
\text { diesel, produção de polpa } \\
\text { e papel, fertilizantes. }\end{array}$ & $\begin{array}{l}\text { Pode levar à formação } \\
\text { de chuva ácida, causar } \\
\text { corrosão nos materiais e } \\
\text { danos à vegetação: } \\
\text { folhas e colheitas. }\end{array}$ \\
\hline $\begin{array}{l}\text { Dióxido de } \\
\text { Nitrogênio }\left(\mathrm{NO}_{2}\right)\end{array}$ & $\begin{array}{l}\text { Gás marrom avermelhado, } \\
\text { com odor forte e muito } \\
\text { irritante. Pode levar à } \\
\text { formação de ácido nítrico, } \\
\text { nitratos (o qual contribui } \\
\text { para o aumento das } \\
\text { partículas inaláveis na } \\
\text { atmosfera) e compostos } \\
\text { orgânicos tóxicos. }\end{array}$ & $\begin{array}{lr}\text { Processos de } & \text { combustão } \\
\text { envolvendo veículos } & \text { vacessos } \\
\text { automotores, } & \text { procesinas } \\
\text { industriais, } & \text { usiná } \\
\text { térmicas que } & \text { utilizam } \\
\text { óleo ou } & \text { gás, } \\
\text { incinerações. } & \end{array}$ & $\begin{array}{l}\text { Pode levar à formação } \\
\text { de chuva ácida, danos à } \\
\text { vegetação e à colheita. }\end{array}$ \\
\hline $\begin{array}{ll}\text { Monóxido } & \text { de } \\
\text { Carbono }(\mathrm{CO}) & \end{array}$ & $\begin{array}{l}\text { Gás incolor, inodoro e } \\
\text { insípido. }\end{array}$ & $\begin{array}{l}\text { Combustão incompleta } \\
\text { em veículos automotores. }\end{array}$ & \\
\hline Ozônio $\left(\mathrm{O}_{3}\right)$ & $\begin{array}{l}\text { Gás incolor, inodoro nas } \\
\text { concentrações ambientais e } \\
\text { o principal componente da } \\
\text { névoa fotoquímica. }\end{array}$ & $\begin{array}{l}\text { Não é } r \\
\text { diretamente para a } \\
\text { atmosfera. É produzido } \\
\text { fotoquimicamente pela } \\
\text { radiação solar sobre os } \\
\text { óxidos de nitrogênio e } \\
\text { compostos orgânicos } \\
\text { voláteis. }\end{array}$ & $\begin{array}{lr}\text { Danos às } & \text { colheitas, à } \\
\text { vegetação } & \text { natural, } \\
\text { plantações } & \text { agrícolas; } \\
\text { plantas ornamentais. }\end{array}$ \\
\hline
\end{tabular}

Fonte: CETESB, 2013. 


\subsection{Poluentes Primários e Secundários}

A grande variedade de substâncias que podem estar presentes na atmosfera pode ser classificada em poluentes primários e secundários, de acordo com suas origens. Os poluentes primários são aqueles emitidos diretamente pelas fontes de emissão à atmosfera. Já os poluentes chamados de secundários são aqueles formados na atmosfera através da reação química entre poluentes e/ou constituintes naturais na atmosfera.

\subsection{Material Particulado (MP)}

Sob a denominação geral de material particulado se encontra um conjunto de poluentes constituídos de poeiras, fumaças e todo tipo de material sólido e líquido que se mantém suspenso na atmosfera por causa de seu pequeno tamanho. As principais fontes de emissão de material particulado para a atmosfera são veículos automotores, processos industriais, queima de biomassa, ressuspensão de poeira do solo, entre outros. O material particulado pode também se formar na atmosfera a partir de gases como dióxido de enxofre $\left(\mathrm{SO}_{2}\right)$, óxidos de nitrogênio ( $\mathrm{NOx}$ ) e compostos orgânicos voláteis (COVs), que são emitidos principalmente em atividades de combustão, transformandose em partículas como resultado de reações químicas no ar.

O tamanho das partículas está diretamente associado ao seu potencial para causar problemas à saúde, sendo que quanto menor o tamanho destas, maiores serão os possíveis efeitos nocivos provocados, pois podem ser inaladas e chegar inclusive, até aos alvéolos pulmonares. O material particulado pode ser classificado como:

a) Partículas Totais em Suspensão (PTS)

Podem ser definidas de maneira simplificada como aquelas cujo diâmetro aerodinâmico é menor que $50 \mu \mathrm{m}$. Uma parte destas partículas é inalável e pode causar problemas à saúde, outra parte pode afetar desfavoravelmente a qualidade de vida da população, interferindo nas condições estéticas do ambiente e prejudicando as atividades normais da comunidade.

b) Partículas Inaláveis (MP $\underline{10})$

Podem ser definidas, grosso modo, como aquelas cujo diâmetro aerodinâmico é menor que $10 \mu \mathrm{m}$. Dependendo da distribuição de tamanho na faixa de 0 a $10 \mu \mathrm{m}$, podem ficar retidas na parte superior do sistema respiratório ou penetrar mais profundamente, alcançando os alvéolos pulmonares. 


\section{c) Partículas Inaláveis Finas $\left(\mathrm{MP}_{2,5}\right)$}

Possuem diâmetro aerodinâmico menor que 2,5 $\mu \mathrm{m}$. Devido ao seu tamanho diminuto, penetram profundamente no sistema respiratório, podendo atingir os alvéolos pulmonares.

d) Fumaça (FMC)

Está associada ao material particulado suspenso na atmosfera proveniente dos processos de combustão. O método de determinação da fumaça é baseado na medida de refletância da luz que incide na poeira (coletada em um filtro), o que confere a este parâmetro a característica de estar diretamente relacionado ao teor de fuligem na atmosfera.

\subsection{Fontes de emissão}

O material particulado na atmosfera pode se originar tanto de fontes naturais quanto de fontes antropogênicas. As partículas naturais podem vir de vulcões, queimadas, incêndios, sprays marinhos e plantas, e podem ser constituídas de pólen, sal marinho, bactérias, etc.

O material particulado antropogênico tem origem em várias fontes, como indústrias, processos extrativos de materiais - tais quais rochas e minérios -, bem como seu preparo e utilização, ou formação de sprays em torres de refrigeração, e também processos de combustão (LENZI \& FAVERO, 2009).

Em cidades do centro do estado de São Paulo, como São Carlos, Ribeirão Preto, Piracicaba, entre outras, onde a economia é dependente de atividades industriais e agrícolas além da poluição oriunda das atividades urbanas, a poluição atmosférica tem contribuição também destas atividades agrícolas, como as queimadas de cana-de-açúcar, que emitem grandes quantidades de gases precursores do efeito estufa como $\mathrm{NO}_{\mathrm{x}}, \mathrm{CO}_{2}$, metano, carbono orgânico volátil além de material particulado, que podem ser transportados até estas cidades, atingindo sua população (BOWER et al., 1994).

\subsection{Fontes Naturais}

Entre as principais fontes naturais de MP podem-se destacar emissões de partículas do solo, aerossol marinho e vulcões. Partículas de origem vegetal, como pólens das plantas, também estão presentes na troposfera, todavia em concentrações bem menores que as demais fontes (SEINFELD \& PANDIS, 1998). Em regiões remotas como a Floresta Amazônica, as emissões naturais são muito importantes (ARTAXO, 
1985). Todavia, nos grandes centros urbanos, as emissões antrópicas passam a ter a sua importância acentuada.

Em diversas áreas urbanas no litoral do Brasil, o aerossol marinho e o particulado de origem do solo se fazem presentes (ARTAXO, 1985). Em áreas remotas ou urbanas, a ação do vento sobre o solo levanta quantidades de poeira, que permanecem em suspensão no ar.

\subsection{Fontes antropogênicas}

Centros urbanos geralmente reúnem uma grande frota veicular, além de atividades industriais, o que torna a poluição antropogênica significativamente maior do que a natural nestes locais (WATSON et al., 2001).

Castanho \& Artaxo (2001) identificaram como sendo as principais fontes de $\mathrm{MP}_{2,5}$ atmosférico na região metropolitana de São Paulo, veículos, ressuspensão de partículas do solo, combustão e óleo combustível, além de sulfatos e emissões industriais. Segundo o mesmo autor, a ressuspensão de partículas do solo foi a principal fonte de $\mathrm{MP}_{2,5-10}$. Veículos apresentam como principais elementos emitidos o carbono orgânico e inorgânico, além de elementos como $\mathrm{Cu}$ (emissão devido à ação dos freios), Fe, Zn e S (WATSON et al., 2001; MOLNAR et al., 2002).

A queima de biomassa, utilizada desde a pré-história para produção de energia, tem sido uma das importantes fontes antropogênicas de poluição atmosférica. A queima de cana-de-açúcar como método de despalha, é uma atividade antiga, introduzida no Havaí e na Austrália durante a Segunda Guerra Mundial em razão da falta de mão de obra; tornou-se habitual na grande maioria dos estabelecimentos agrícolas dedicados ao seu cultivo, tendo como principal objetivo facilitar e baratear o corte manual da cana, que ainda prevalece no estado de São Paulo (SZMRECSÁNYI, 1994).

Ressalta-se que no Estado de São Paulo, a queima da cana coincide com período de baixas precipitações e piores condições de dispersão, agravando seus efeitos na qualidade do ar. Sendo assim, em 2002, foi aprovada, no Estado de São Paulo, a Lei $n^{0}$ 11.241, que dispõe sobre a eliminação da queima da palha de cana-de-açúcar e estabelece um cronograma do ano de 2002 a 2031, com porcentagens de áreas plantadas onde a queima deve ser eliminada, que vão de $20 \%$ no primeiro ano a $100 \%$ em 2021 , para áreas mecanizáveis, e até 2031 para áreas não mecanizáveis. Além disso, a lei proíbe queimadas em áreas localizadas a menos de um quilômetro do perímetro de áreas urbanas e de reservas indígenas, e exige dos plantadores um planejamento anual a ser 
entregue à Agência Ambiental do Estado de São Paulo (CETESB), adequando as áreas de produção ao plano de eliminação das queimadas.

\subsection{Fontes secundárias de aerossol}

Uma vez suspensas na atmosfera, as partículas podem variar de tamanho e composição química através de processos que incluem a coagulação com outras partículas, a condensação/evaporação de espécies voláteis e transformações dentro das nuvens. As partículas superfinas são originadas principalmente de mecanismos secundários, ou seja, resultante de processos de conversão gás/partícula (YNOUE, 2004).

\subsection{Padrões de Qualidade do Ar}

Os padrões de qualidade do ar (PQAr), segundo publicação da Organização Mundial da Saúde (OMS) em 2005, variam de acordo com a abordagem adotada para balancear riscos a saúde, viabilidade técnica, considerações econômicas e vários outros fatores políticos e sociais, que por sua vez dependem, entre outros fatores, do nível de desenvolvimento e da capacidade nacional de gerenciar a qualidade do ar. As diretrizes recomendadas pela OMS levam em conta esta heterogeneidade e, em particular, reconhecem que, ao formularem políticas de qualidade do ar, os governos devem considerar cuidadosamente suas circunstâncias locais antes de adotarem os valores propostos como padrões nacionais.

Através da Portaria Normativa $n^{\circ} 348$ de 14/03/90, o IBAMA estabeleceu os padrões nacionais de qualidade do ar e os respectivos métodos de referencia, ampliando o número de parâmetros anteriormente regulamentados através da Portaria GM n n 0231 de 27/04/76. Os padrões estabelecidos através dessa portaria foram submetidos ao CONAMA em 28/06/90 e transformados na Resolução CONAMA nº 03/90.

Os padrões de qualidade do ar podem ser divididos em primários e secundários. São padrões primários de qualidade do ar as concentrações de poluentes que, ultrapassadas, poderão afetar a saúde da população. Podem ser entendidos como níveis máximos toleráveis de concentração de poluentes atmosféricos, constituindo-se em metas de curto e médio prazo. São padrões secundários de qualidade do ar as concentrações de poluentes atmosféricos abaixo das quais se prevê o mínimo efeito adverso sobre o bem estar da população, assim como o mínimo dano a fauna e a flora, 
aos materiais e ao meio ambiente em geral. Podem ser entendidos como níveis desejados de concentração de poluentes, constituindo-se em meta de longo prazo.

Os padrões nacionais de qualidade do ar fixados na Resolução CONAMA $n^{\circ} 03 / 90$ são apresentados na Tabela 2.

Tabela 02. Padrões nacionais de qualidade do ar.

\begin{tabular}{|c|c|c|c|c|}
\hline Poluente & $\begin{array}{c}\text { Tempo de } \\
\text { Amostragem }\end{array}$ & $\begin{array}{c}\text { Padrão } \\
\text { Primário } \\
\mu \mathrm{g} / \mathrm{m}^{3}\end{array}$ & $\begin{array}{c}\text { Padrão } \\
\text { Secundário } \\
\mu \mathrm{g} / \mathrm{m}^{3}\end{array}$ & Método de medição \\
\hline \multirow{2}{*}{$\begin{array}{l}\text { Partículas totais } \\
\text { em suspensão }\end{array}$} & 24 horas $^{1}$ & 240 & 150 & \multirow{2}{*}{$\begin{array}{l}\text { Amostrador de } \\
\text { grandes volumes }\end{array}$} \\
\hline & $\mathrm{MGA}^{2}$ & 80 & 60 & \\
\hline \multirow{2}{*}{$\begin{array}{c}\text { Partículas } \\
\text { inaláveis }\left(\mathrm{PM}_{10}\right)\end{array}$} & 24 horas $^{1}$ & 150 & 150 & \multirow{2}{*}{$\begin{array}{c}\text { Separação } \\
\text { inercial/filtração }\end{array}$} \\
\hline & $\mathrm{MMA}^{3}$ & 50 & 50 & \\
\hline \multirow[t]{2}{*}{ Fumaça } & 24 horas $^{1}$ & 150 & 100 & \multirow[t]{2}{*}{ Refletância } \\
\hline & $\mathrm{MMA}^{3}$ & 60 & 40 & \\
\hline \multirow{2}{*}{$\begin{array}{c}\text { Dióxido de } \\
\text { Enxofre }\left(\mathrm{SO}_{2}\right)\end{array}$} & 24 horas $^{1}$ & 365 & 100 & \multirow[t]{2}{*}{ Pararosanilina } \\
\hline & $\mathrm{MMA}^{3}$ & 80 & 40 & \\
\hline \multirow{2}{*}{$\begin{array}{c}\text { Dióxido de } \\
\text { Nitrogênio }\left(\mathrm{NO}_{2}\right)\end{array}$} & 1 hora & 320 & 190 & \multirow[t]{2}{*}{ Quimiluminescência } \\
\hline & $\mathrm{MMA}^{3}$ & 100 & 100 & \\
\hline \multirow{4}{*}{$\begin{array}{l}\text { Monóxido de } \\
\text { carbono (CO) }\end{array}$} & 1 hora $^{1}$ & 40.000 & 40.000 & \multirow{4}{*}{$\begin{array}{l}\text { Infravermelho não } \\
\text { dispersivo }\end{array}$} \\
\hline & & $35 \mathrm{ppm}$ & $35 \mathrm{ppm}$ & \\
\hline & \multirow[t]{2}{*}{8 horas $^{1}$} & 10.000 & 10.000 & \\
\hline & & 9 ppm & $9 \mathrm{ppm}$ & \\
\hline Ozônio $\left(\mathrm{O}_{3}\right)$ & 1 hora $^{1}$ & 160 & 160 & Quimiluminescência \\
\hline
\end{tabular}

1. Não deve ser excedido mais que uma vez no ano; 2. Média geométrica anual; 3. Média aritmética anual. Fonte: Resolução CONAMA n ${ }^{\circ}$ 03/90.

A mesma resolução estabelece ainda os critérios para episódios agudos de poluição do ar, os quais são apresentados na Tabela 3. Ressalte-se que a declaração dos estados de Atenção, Alerta e Emergência requer, além dos níveis de concentração atingidos, a previsão de condições meteorológicas desfavoráveis à dispersão dos poluentes.

A legislação estadual (DE n 8.468 de 08/09/76) também estabelece padrões de qualidade do ar e critérios para episódios agudos de poluição do ar, mas abrange um numero menor de parâmetros. Os parâmetros fumaça, partículas inaláveis e dióxido de nitrogênio não tem padrões e critérios estabelecidos na legislação estadual. Os parâmetros comuns à legislação federal e estadual têm os mesmos padrões e critérios, com exceção dos critérios de episodio para ozônio. Neste caso a legislação estadual é mais rigorosa para o nível de atenção $\left(200 \mu \mathrm{g} / \mathrm{m}^{3}\right)$. 
Tabela 03. Critérios para episódios agudos de poluição do ar.

\begin{tabular}{|l|c|c|c|}
\hline \multicolumn{1}{|c|}{ Parâmetros } & Atenção & Alerta & Emergências \\
\hline $\begin{array}{l}\text { Partículas totais em suspensão }\left(\mu \mathrm{g} / \mathrm{m}^{3}\right) \\
-24 \mathrm{~h}\end{array}$ & 375 & 625 & 875 \\
\hline Partículas inaláveis $\left(\mu \mathrm{g} / \mathrm{m}^{3}\right)-24 \mathrm{~h}$ & 250 & 420 & 500 \\
\hline Fumaça $\left(\mu \mathrm{g} / \mathrm{m}^{2}\right)-24 \mathrm{~h}$ & 250 & 420 & 500 \\
\hline Dióxido de enxofre $\left(\mu \mathrm{g} / \mathrm{m}^{3}\right)-24 \mathrm{~h}$ & 800 & 1.600 & 2.100 \\
\hline $\mathrm{SO}_{2} \times \mathrm{PTS}\left(\mu \mathrm{g} / \mathrm{m}^{2}\right)\left(\mu \mathrm{g} / \mathrm{m}^{3}\right)-24 \mathrm{~h}$ & 65.000 & 261.000 & 393.000 \\
\hline Dióxido de nitrogênio $\left(\mu \mathrm{g} / \mathrm{m}^{3}\right)-1 \mathrm{~h}$ & 1.130 & 2.260 & 3.000 \\
\hline Monóxido de carbono $(\mathrm{ppm})-1 \mathrm{~h}$ & 15 & 30 & 40 \\
\hline Ozônio $\left(\mu \mathrm{g} / \mathrm{m}^{3}\right)-1 \mathrm{~h}$ & $400 *$ & 800 & 1.000 \\
\hline
\end{tabular}

* O nível de atenção é declarado pela CETESB com base na legislação estadual, que é mais restritiva $\left(200 \mu \mathrm{g} / \mathrm{m}^{3}\right)$. Fonte: Resolução CONAMA n ${ }^{\circ}$ 03/90.

Desde 1990 quando a resolução CONAMA 03/90 foi promulgada, os padrões nacionais de qualidade do ar permaneceram inalterados. Contudo, estudos recentes indicam prejuízos à saúde da população com concentrações bem abaixo dos limites considerados seguros pela legislação vigente. Episódio semelhante aconteceu com a legislação federal que tratava da classificação dos corpos hídricos e dos padrões para o lançamento de efluentes, dentre outros. A primeira lei federal sobre o assunto, resolução CONAMA $\mathrm{n}^{\circ} 20$ de 1986, foi atualizada somente após quase 20 anos, com a promulgação da resolução CONAMA n`357 de 2005, depois de estudos sugerirem que os limites estabelecidos eram pouco restritivos.

Em 2006, a Organização Mundial da Saúde (OMS) propôs novos limites (Tabela 4), mais restritivos, no que se refere às concentrações de material particulado, dióxido de nitrogênio, dióxido de enxofre e ozônio. Porém, é importante observar que, com a alteração do período de amostragem do ozônio de uma (1), para oito (8) horas, a média calculada das concentrações observadas no período de amostragem tende a diminuir, facilitando assim o seu enquadramento dentro do novo Valor Máximo Permitido (VMP) estabelecido pela OMS. 
Tabela 4. Valores propostos pela OMS como referência para a qualidade do ar.

\begin{tabular}{|c|c|c|}
\hline Poluente & $\begin{array}{c}\text { Tempo de } \\
\text { Amostragem }\end{array}$ & $\begin{array}{c}\text { Limites Propostos } \\
\left(\mu \mathrm{g} / \mathrm{m}^{3}\right)\end{array}$ \\
\hline \multirow{2}{*}{$\begin{array}{l}\text { Material Particulado } \\
\text { inalável }\left(\mathrm{PM}_{10}\right)\end{array}$} & 24 horas $^{1}$ & 50 \\
\hline & $\mathrm{MMA}^{2}$ & 20 \\
\hline \multirow{2}{*}{$\begin{array}{l}\text { Material Particulado } \\
\text { Fino }\left(\mathbf{P M}_{2,5}\right)\end{array}$} & 24 horas $^{1}$ & 25 \\
\hline & $\mathrm{MMA}^{2}$ & 10 \\
\hline \multirow{2}{*}{$\begin{array}{c}\text { Dióxido de Enxofre } \\
\left(\mathrm{SO}_{2}\right)\end{array}$} & 24 horas $^{1}$ & 365 \\
\hline & $\mathrm{MMA}^{2}$ & 80 \\
\hline \multirow{2}{*}{$\begin{array}{l}\text { Dióxido de Nitrogênio } \\
\left(\mathrm{NO}_{2}\right)\end{array}$} & 1 hora & 320 \\
\hline & $\mathrm{MMA}^{2}$ & 100 \\
\hline Ozônio $\left(\mathrm{O}_{3}\right)$ & 1 hora $^{1}$ & 160 \\
\hline
\end{tabular}

1. Não deve ser excedido mais que uma vez no ano; 2 . Média aritmética anual.

Os limites estabelecidos pela OMS são um avanço no que diz respeito à VMPs que garantam uma maior proteção do meio ambiente e consequentemente da saúde humana. Por tal motivo e devido à grande discrepância entre os seus valores e os obsoletos valores preconizados pela resolução nacional (mais tolerantes do que as normas da União Europeia e dos EUA, por exemplo), neste estudo serão utilizados os valores estabelecidos pela OMS para $\mathrm{PM}_{10}$ e $\mathrm{PM}_{2,5}$.

\section{9. Índice de Qualidade do Ar}

O índice de qualidade do ar (IQAr) é uma ferramenta matemática desenvolvida para simplificar o processo de divulgação da qualidade do ar é obtido através de uma função linear segmentada, onde os pontos de inflexão são os padrões de qualidade do ar (CETESB, 2011). Desta função, que relaciona a concentração do poluente com o valor do índice, resulta um número adimensional referido a uma escala com base nos padrões de qualidade do ar. Para efeito de divulgação, é utilizado o índice mais elevado dos poluentes medidos, portanto, a qualidade do ar é determinada diariamente pelo pior caso entre os poluentes monitorados. A relação entre índice, qualidade do ar e efeitos a saúde está apresentada na Tabela 5. A classificação da qualidade do ar também e representada segundo uma escala de cores. 


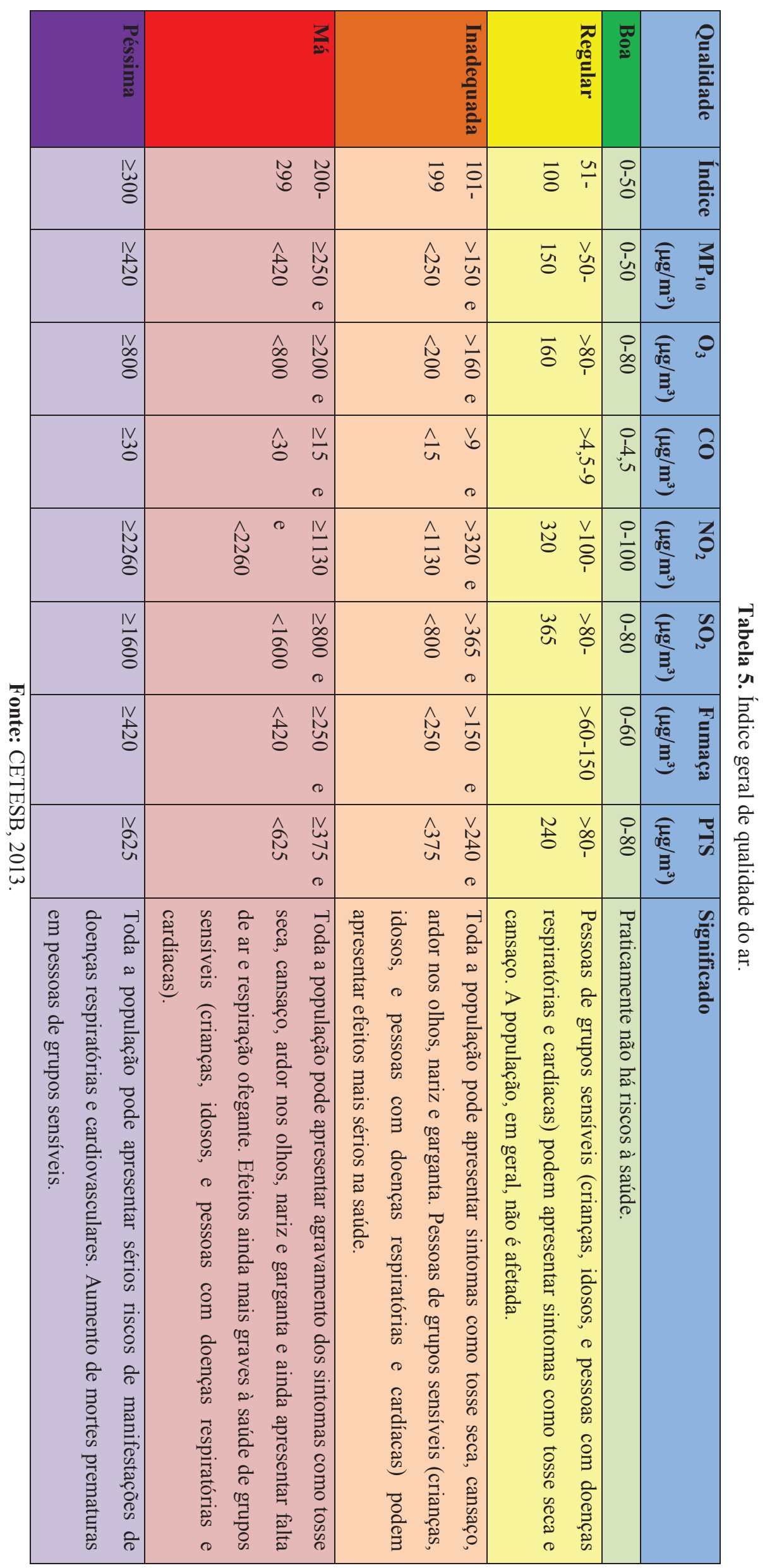




\subsection{0. $O$ caso de Londres}

Um dos primeiros casos de poluição aguda devido ao material particulado e ao dióxido de enxofre ocorreu na Inglaterra em 1952. Uma frente fria chegou a Londres e fez com que as pessoas queimassem mais carvão que o usual no inverno. O aumento na poluição atmosférica foi agravado por uma inversão térmica, causada pela densa massa de ar frio. $\mathrm{O}$ acúmulo de poluentes foi crescente, especialmente de fumaça e partículas do carvão que era queimado. Como consequência mais de 3 mil londrinos morreram entre os dias 5 e 9 de dezembro, período em que a concentração de poluentes no ar atingiu seu ápice.

A Figura 1 relaciona o número de mortes no período mencionado com a concentração de dióxido de enxofre e material particulado no ar. É possível notar que as curvas de material particulado, dióxido de enxofre e do número de mortes por dia, grosso modo, tem o comportamento similar a uma parábola com concavidade para baixo, sendo que a curva do número de mortes encontra-se deslocada para a direta em relação às outras duas curvas, provavelmente devido ao tempo de exposição que as pessoas com saúde mais vulnerável ficaram expostas antes de vir a óbito em decorrência das concentrações elevadas desses poluentes.

Isso também pode ser verificado à medida que as concentrações começam a diminuir no dia 08 de dezembro e retornam aos valores observados antes do episódio de poluição aguda, no dia 4, entretanto, o mesmo não ocorre com o número de mortes por dia, pois provavelmente devido aos efeitos nocivos à saúde causados pela exposição às concentrações elevadas de $\mathrm{SO}_{2}$ e MP nos dias anteriores. No dia 15 de dezembro, quatro dias após as concentrações de poluentes terem retornado aos valores encontrados antes deste episódio de poluição aguda, o número de mortes por dia ainda era quase o dobro do valor antes da elevação dos poluentes (EDINBURGH UNIVERSITY, 2013). 


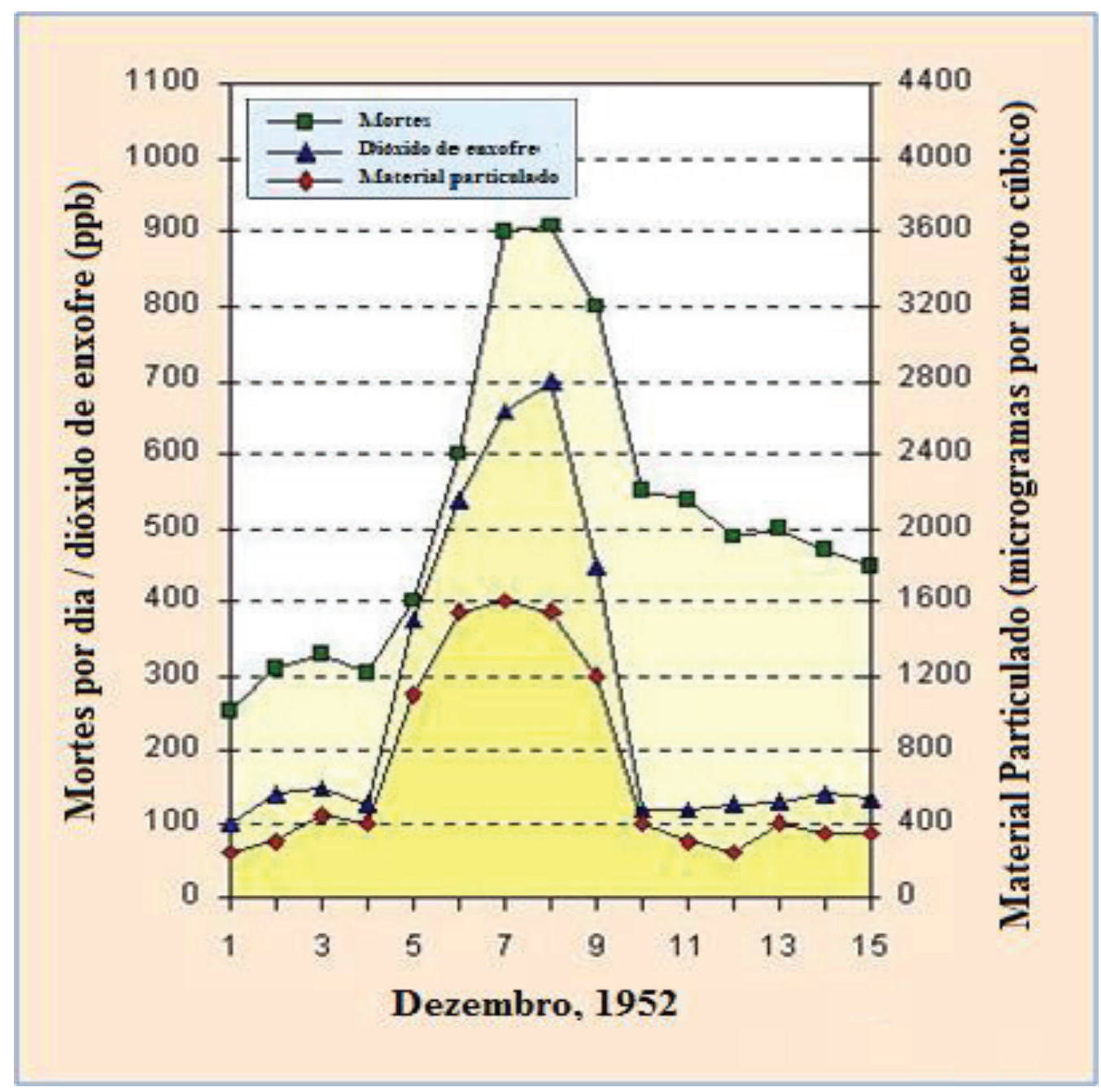

Figura 2. Gráfico da taxa de mortes versus concentrações de dióxido de enxofre e MP.

Fonte: Adaptado de (Edinburgh University, 2013).

\subsection{Condições Meteorológicas e Atmosféricas}

É importante frisar que, mesmo mantidas as emissões, a qualidade do ar pode mudar em função das condições meteorológicas que determinam uma maior ou menor "difusão" dos poluentes. São inúmeros os fatores meteorológicos que determinam o comportamento dos poluentes primários na atmosfera sendo que, dentre eles, o comportamento da precipitação pluviométrica permite verificar se a atmosfera foi menos estável ou mais, favorecendo ou não a dispersão desses poluentes.

Ademais os fenômenos de dispersão e remoção dos poluentes são comandados por diversos fatores, tais como localização, topografia, ilha de calor, solo, velocidade e direção do vento, precipitação, entre outros (TORRES \& MARTINS, 2005). Para partículas podemos destacar os processos de deposição seca (associados à remoção de material pela rugosidade da superfície, solubilidade das espécies em água, etc.), 
sedimentação (devido à ação gravitacional) e deposição úmida (associada ao processo de precipitação de material por água de chuva, neve e etc) (SEINFELD \& PANDIS, 1998).

\section{MATERIAL E MÉTODOS}

\section{1. Área de Estudo}

A cidade de São Carlos localiza-se na região central do estado de São Paulo (Figura 2). Segundo o censo realizado pelo Instituto Brasileiro de Geografia e Estatística (IBGE, 2010), a cidade possui uma população de 221.950 habitantes, sendo que $95 \%$ deles vivem em áreas urbanas.

O clima da região tem duas estações bem definidas: uma seca, de abril a setembro e outra chuvosa, de outubro a março (TOLENTINO, 1967). Apresenta temperatura média anual de $19,6^{\circ} \mathrm{C}$ e altitudes médias entre 800 e 1.000 metros.

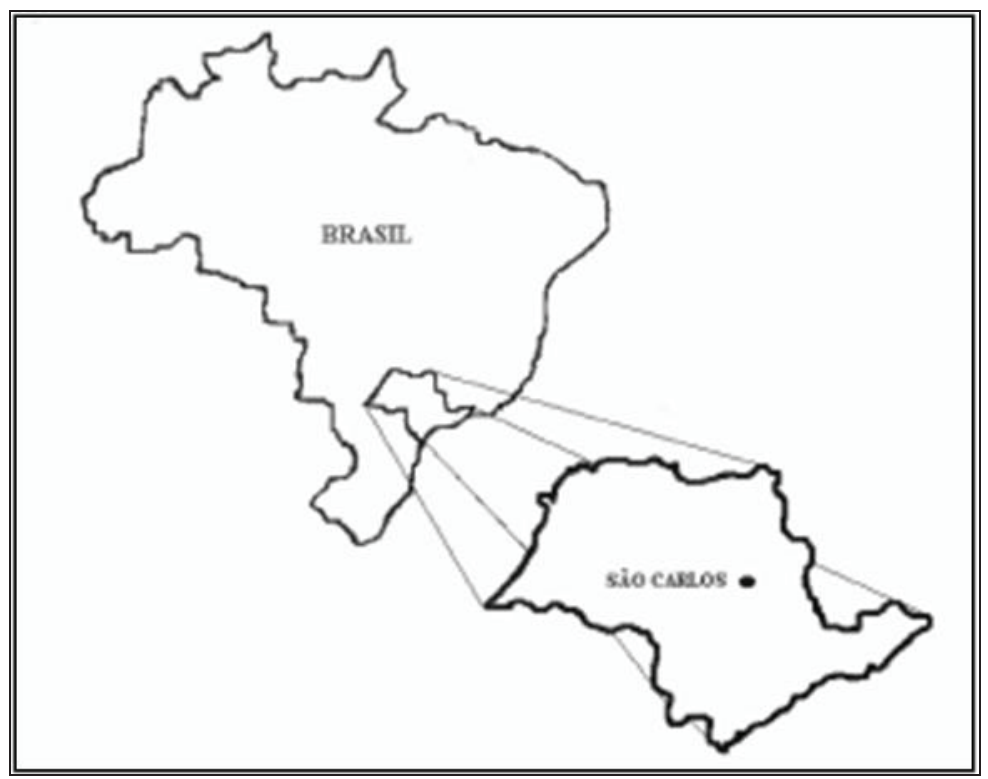

Figura 2. Mapa do Brasil, com destaque para o estado de São Paulo e a cidade de São Carlos.

Fonte: Bruno et al (2006).

As medições da concentração do material particulado em suas frações 2,5 e 10 $\mu \mathrm{m}$, bem como da temperatura e umidade relativa do ar foram realizadas na área $1 \mathrm{da}$ Universidade de São Paulo (Figuras 3 e 4), localizado no centro da cidade de São 
Carlos, mais precisamente na estação meteorológica do Instituto de Arquitetura e Urbanismo (IAU-USP).

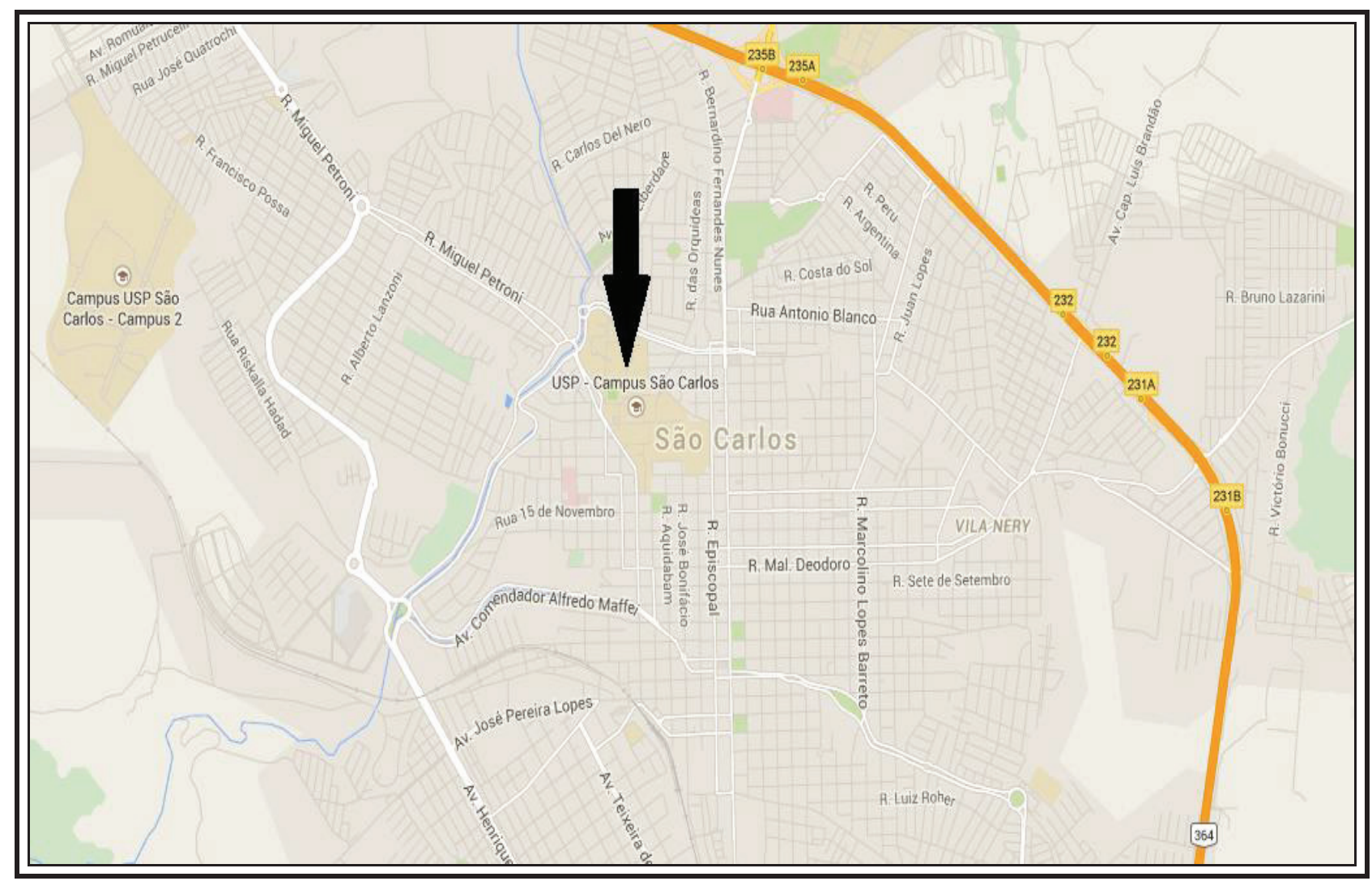

Figura 3. Localização da área 1 da USP na cidade de São Carlos - SP.

Fonte: (Google, 2015).

O ponto de medição das concentrações de MP tem uma localização estratégica. Situa-se próximo de uma marginal onde há grande movimentação de veículos, da entrada principal da área 1 USP, e de uma rua com subida e semáforos ao redor, onde os veículos ficam em marcha lenta, emitindo mais poluentes. 


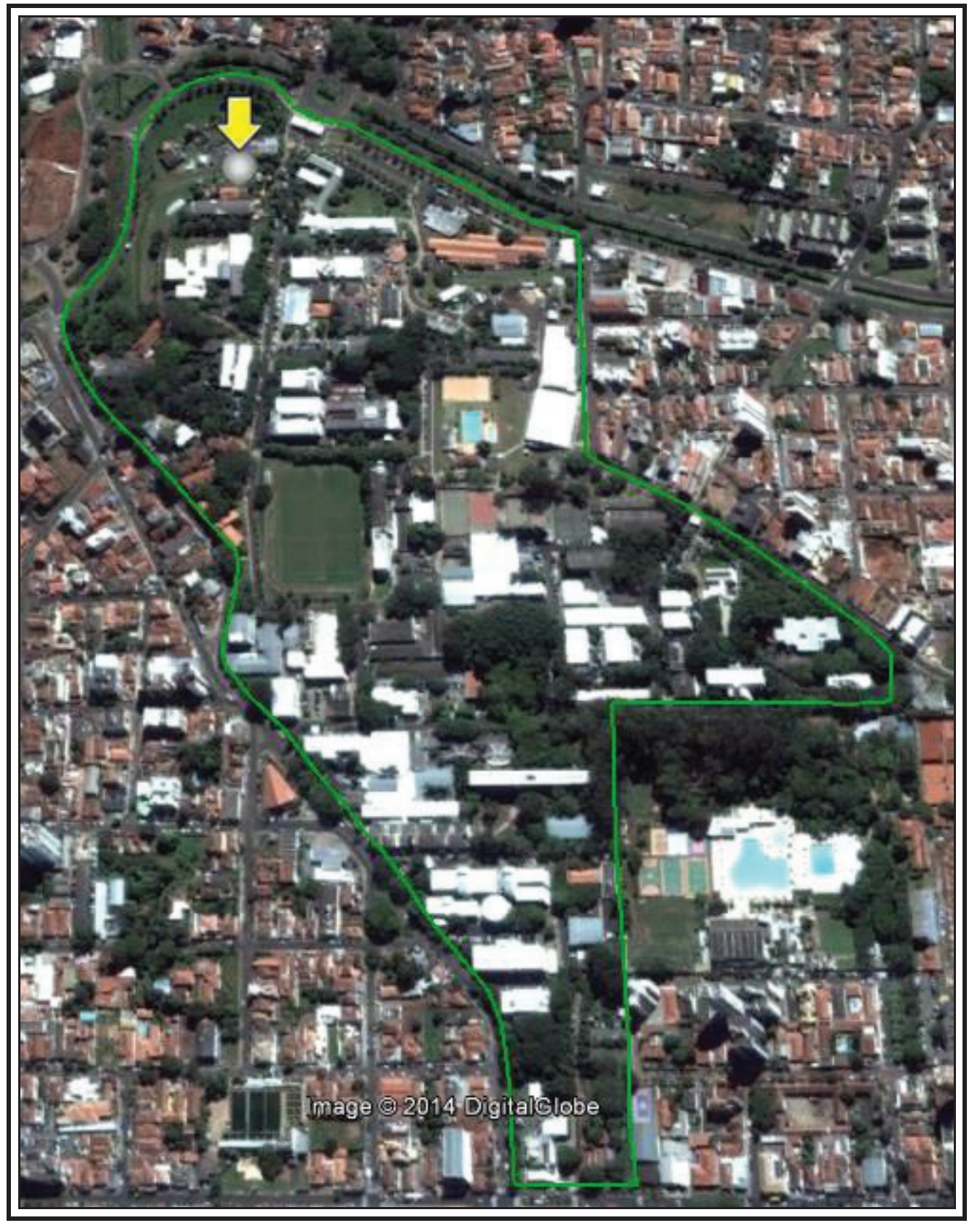

Figura 4. Localização do ponto de amostragem dentro da área 1 da USP.

Fonte: (Google, 2013).

A coleta de dados se deu durante os meses de julho a novembro de 2014. Além das medições realizadas, foram utilizados os dados referentes à precipitação fornecidos pela estação meteorológica já existente no local. 


\subsection{Material Particulado}

Para a medição do material particulado foram utilizados dois equipamentos: o ADR-1500 e o PEM (Personal Environmental Monitor). O primeiro, como será visto a seguir, não é baseado no método gravimétrico, o qual é reconhecido como o mais correto e que fornece os resultados mais confiáveis, por isso foi utilizado também neste estudo o PEM. Estes dois equipamentos se complementam. O ADR-1500 não utiliza o método gravimétrico, mas pode medir o MP continuamente quase em tempo real. $\mathrm{O}$ PEM só permite o cálculo da concentração média do material particulado durante o período de funcionamento deste, entretanto utiliza o método gravimétrico, que é o mais confiável.

\subsection{ADR-1500}

Este equipamento possui um sistema de monitoramento de partículas em tempo real. Isto é possível devido ao modo como ele funciona, qual seja, através de um sensor óptico que mede o espalhamento da luz no momento em que a partícula contida no ar amostrado atravessa um feixe de luz criado pelo ADR (Figuras 5, 6 e 7). Quanto maior for o diâmetro médio da partícula maior será a dispersão da luz, deste modo, o volume das partículas é calculado com base no diâmetro médio destas, o qual é obtido com base na taxa de dispersão da luz no momento em que a partícula atravessa o feixe luminoso. Atribuindo-se uma densidade média a estas partículas pode-se estimar a massa das mesmas. O cálculo do tamanho das partículas com base na dispersão na luz é chamado de fotometria por espalhamento de luz.

O ADR-1500 foi projetado para monitoramento automático e continuo, contando inclusive com a possibilidade de transmissão ininterrupta dos dados assim que estes são obtidos, bastando para isso, que o ADR esteja conectado via cabo, a um computador. Foi projetado para operar em ambientes externos, contando com uma estrutura a prova de sol, chuva, granizo e as demais intempéries climáticas.

Pode ser utilizado para o monitoramento de material particulado em suspensão de quatro tamanhos diferentes, porém, não é possível monitorar mais do que um tamanho de MP ao mesmo tempo. Para partículas com diâmetro menor ou igual a $10 \mu \mathrm{m}, 4 \mu \mathrm{m}, 2,5 \mu \mathrm{m}$ ou $1 \mu \mathrm{m}$. Isto é possível devido à seleção de um dos dois ciclones opcionais (Figura 7c) que podem equipar o aparelho. Estes ciclones são externamente 
similares, mas com cores diferentes, um vermelho, projetado para reter o material particulado de diâmetro maior que 10 ou $4 \mu \mathrm{m}$, dependendo da vazão de ar que o equipamento foi programado para amostrar, e o outro azul, que retém o material particulado de diâmetro maior que 2,5 ou $1 \mu \mathrm{m}$, também em função da vazão de ar amostrada. $\mathrm{O}$ ciclone é conectado à parte inferior do tubo de condução do ar aspirado pelo ADR.

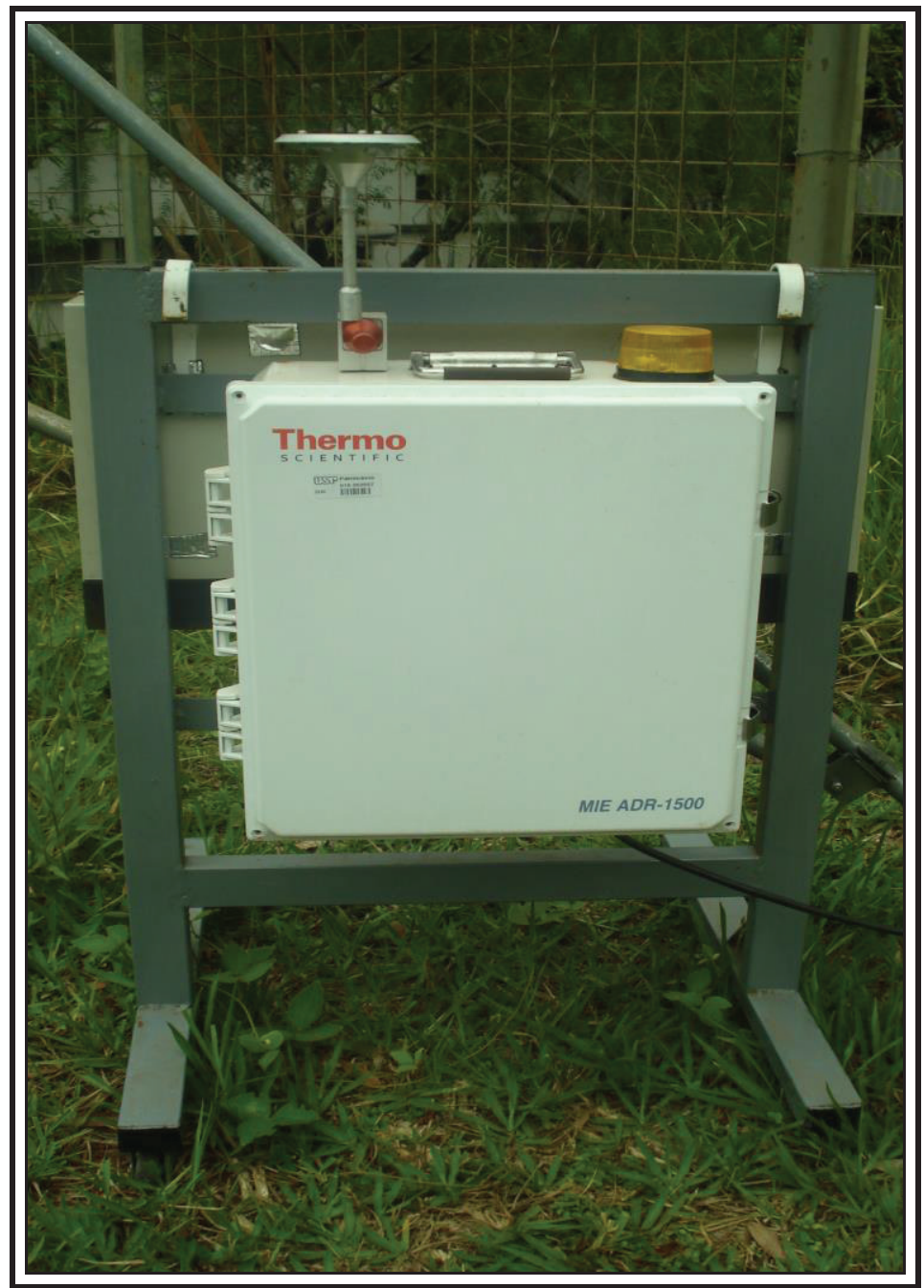

Figura 5. Vista do ADR 1500 em funcionamento. 


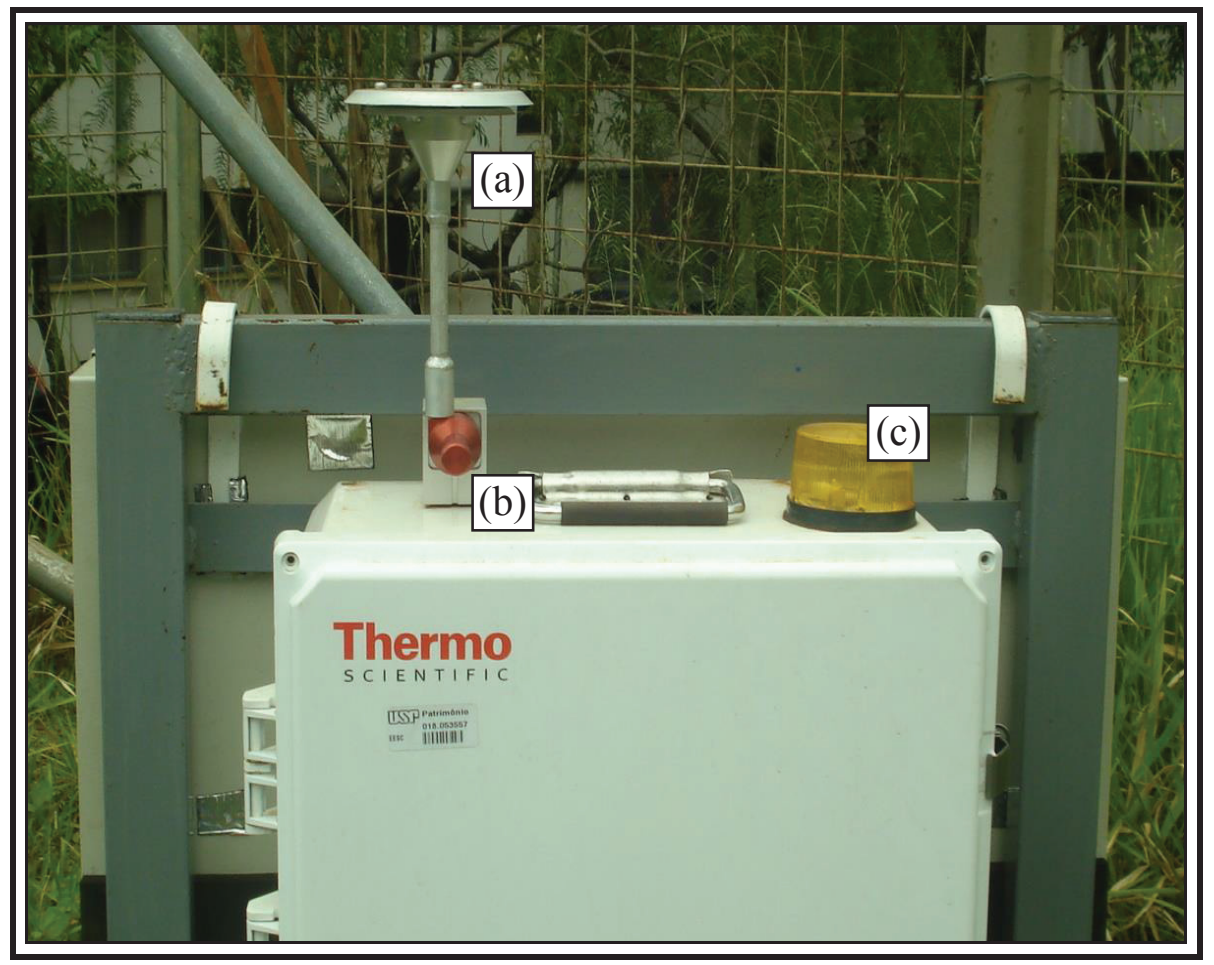

Figura 6. ADR 1500 funcionando com o ciclone vermelho; (a) entrada de ar; (b) ciclone vermelho; (c) sirene de alarme.

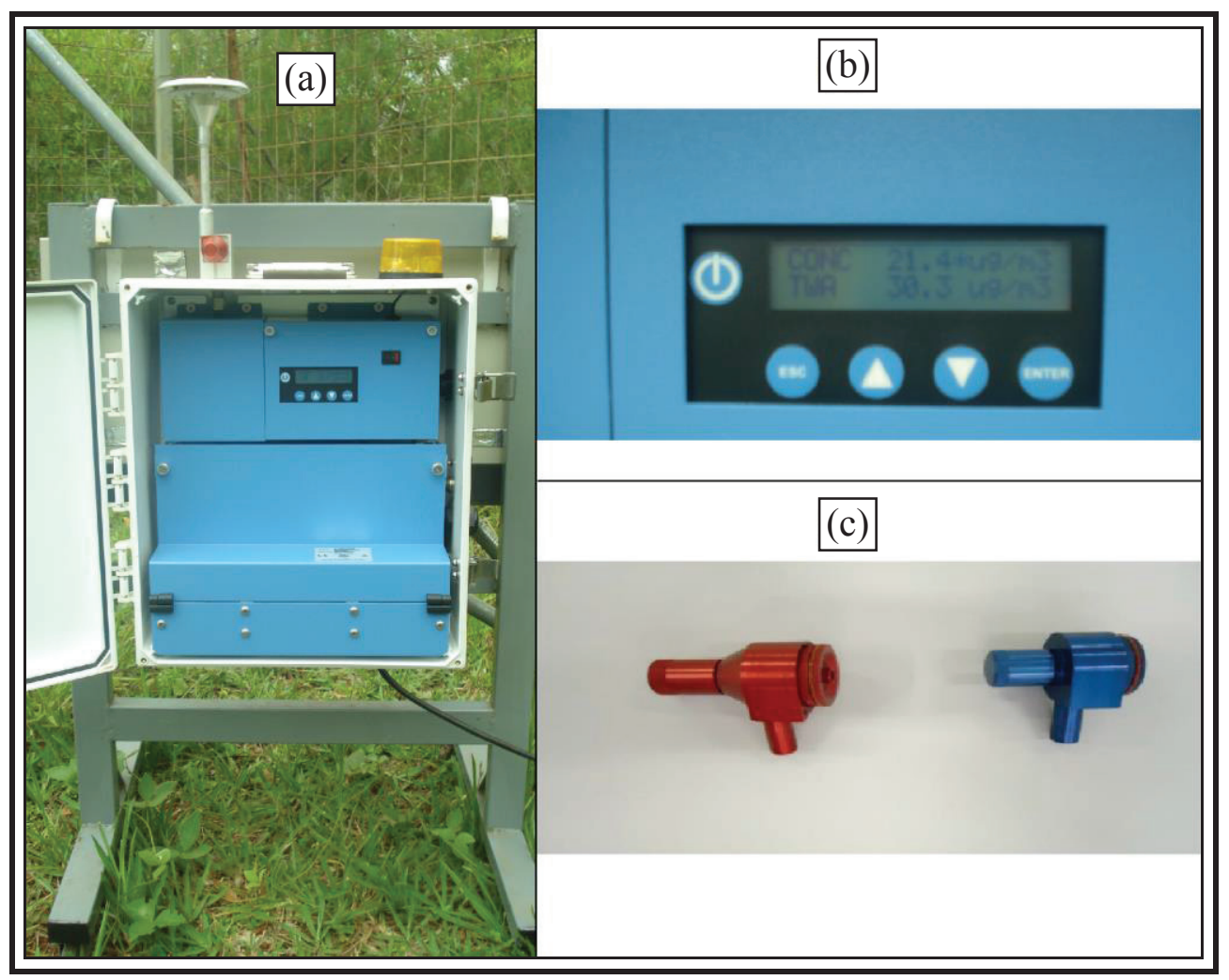

Figura 7. Vista interna do ADR 1500. (a) Vista do display digital do ADR exibindo as concentrações instantânea e média de $\mathrm{MP}_{10}$; (b) Ciclones vermelho e azul. Fonte: Rotirotti, 2013. 
O ADR 1500 registra a cada dois segundos uma nova medição da concentração de material particulado no ar. A cada 30 medições, ou seja, um intervalo de 1 minuto é calculado automaticamente pelo equipamento a concentração média de MP, a qual pode ser registrada na memória da máquina ou ser transmitida para um computador conectado ao equipamento. Além do material particulado este equipamento também analisa pressão atmosférica, temperatura e umidade relativa, parâmetros que são atualizados a cada minuto.

O ADR foi utilizado apenas com o ciclone vermelho acoplado e medindo a concentração de $\mathrm{MP}_{10}$, a qual era obtida através de uma vazão de ar igual a $1,19 \mathrm{~L} / \mathrm{min}$. Optou-se por mensurar o $\mathrm{MP}_{10}$ uma vez que esta fração contém indiretamente a fração menor, o $\mathrm{MP}_{2,5}$. Este equipamento permaneceu ligado durante todo o período de coleta de dados do projeto, de 5 de junho a 10 de novembro de 2014.

\subsection{Amostrador PEM}

O PEM (Personal Environmental Monitor) é um aparelho que consiste de um impactador em estágio único seguido de filtração. Ele deve ser acoplado a uma bomba portátil, neste caso foi utilizada uma bomba da SKC, a Leland Legacy Sample Pump, com vazão constante de $10 \mathrm{~L} / \mathrm{min}$. A etapa de impactação é realizada para coleta das

partículas maiores que o diâmetro de corte, que são retidas no anel de impactação do PEM untado com vaselina. Na filtração foram utilizadas membranas de celulose de 37 mm de diâmetro e $2 \mu \mathrm{m}$ de poro, onde são coletadas as partículas do $\mathrm{MP}_{2,5}$ ou $\mathrm{MP}_{10}$. A Figura 8 (a) mostra o esquema de montagem de um amostrador PEM. A Figura 8 (b) mostra o PEM já montado junto com a bomba de sucção. 
(a)

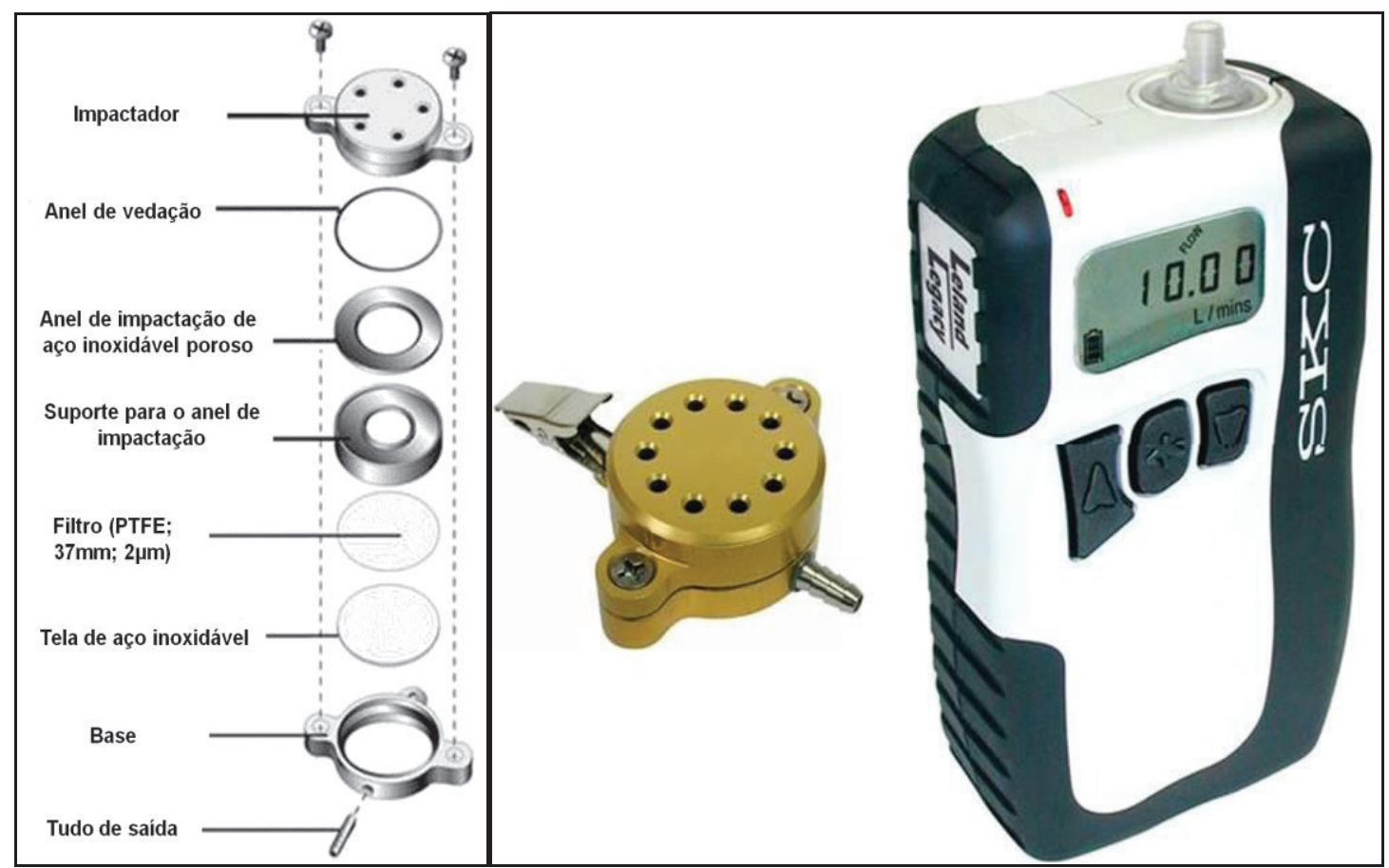

Figura 8. Esquema de montagem de um PEM (a) e amostrador PEM com bomba de sucção (b).

A massa de MP acumulada na membrana, conseguida por gravimetria, através da pesagem das membranas antes e após a coleta, é dividida pelo volume total amostrado, obtendo-se a concentração de material particulado.

A pesagem das membranas foi realizada no laboratório de controle ambiental do departamento de engenharia química da Universidade Federal de São Carlos (UFSCar). A balança (Figura 9) utilizada tinha sete (7) casas decimais após a vírgula, tendo, portanto, capacidade de medir até décimos de micrograma $(\mu \mathrm{g})$. As membranas eram pesadas três vezes antes de seu uso e três vezes depois. Após isto, o peso da membrana antes do uso era admitido com sendo a média aritmética da três primeiras pesagens, o mesmo processo vale para as ultimas três pesagens. Antes e após as pesagens as membranas eram acondicionadas em um dessecador por pelo menos 24 horas para eliminar qualquer umidade acumulada na membrana, o que poderia interferir nos resultados.

Além da balança foi utilizado um eletrodo (Figura 9) neutralizador de cargas eletrostáticas, resultantes do acúmulo de material particulado eletronegativamente carregado sobre a membrana. Essas cargas eletrostáticas poderiam interferir na massa auferida ao causar uma força magnética de repulsão entre a membrana e o prato de metal da balança, resultando em um peso inferior ao real. 
Para o funcionamento do conjunto de amostragem em ambiente externo foi adaptada uma caixa de aço (Figuras 10, 11 e 12).

Durantes as coletas foram utilizados dois amostradores PEM, um para a coleta do $\mathrm{MP}_{10}$ e outro para a coleta do $\mathrm{MP}_{2,5}$ (Figura 12), ambos acoplados a duas bombas da SKC, funcionando a uma vazão constante de $10 \mathrm{~L} \cdot \mathrm{min}^{-1}$. A bomba permanecia ligada durante 8 horas, das 11 às 19h, tempo que a carga da bateria da bomba dura trabalhando a uma vazão de 10 L.min ${ }^{-1}$, de acordo com o manual da SKC.

O objetivo do horário escolhido foi abranger os horários "de pico" do trânsito no final do dia, a saber, das $17 \mathrm{~h} 30 \mathrm{~min}$ às $19 \mathrm{~h}$, quando o movimento de veículos aumenta e a emissão de gases poluentes e material particulado também, de modo que as coletas feitas com o PEM tivessem "representatividade" amostral no que diz respeito ao fator temporal. Isto não ocorreria, por exemplo, se a coleta fosse realizada das $09 \mathrm{~h}$ às $17 \mathrm{~h}$, por exemplo, ou das $21 \mathrm{~h}$ às $05 \mathrm{~h}$ do dia seguinte, intervalos em que não há pico de trânsito.

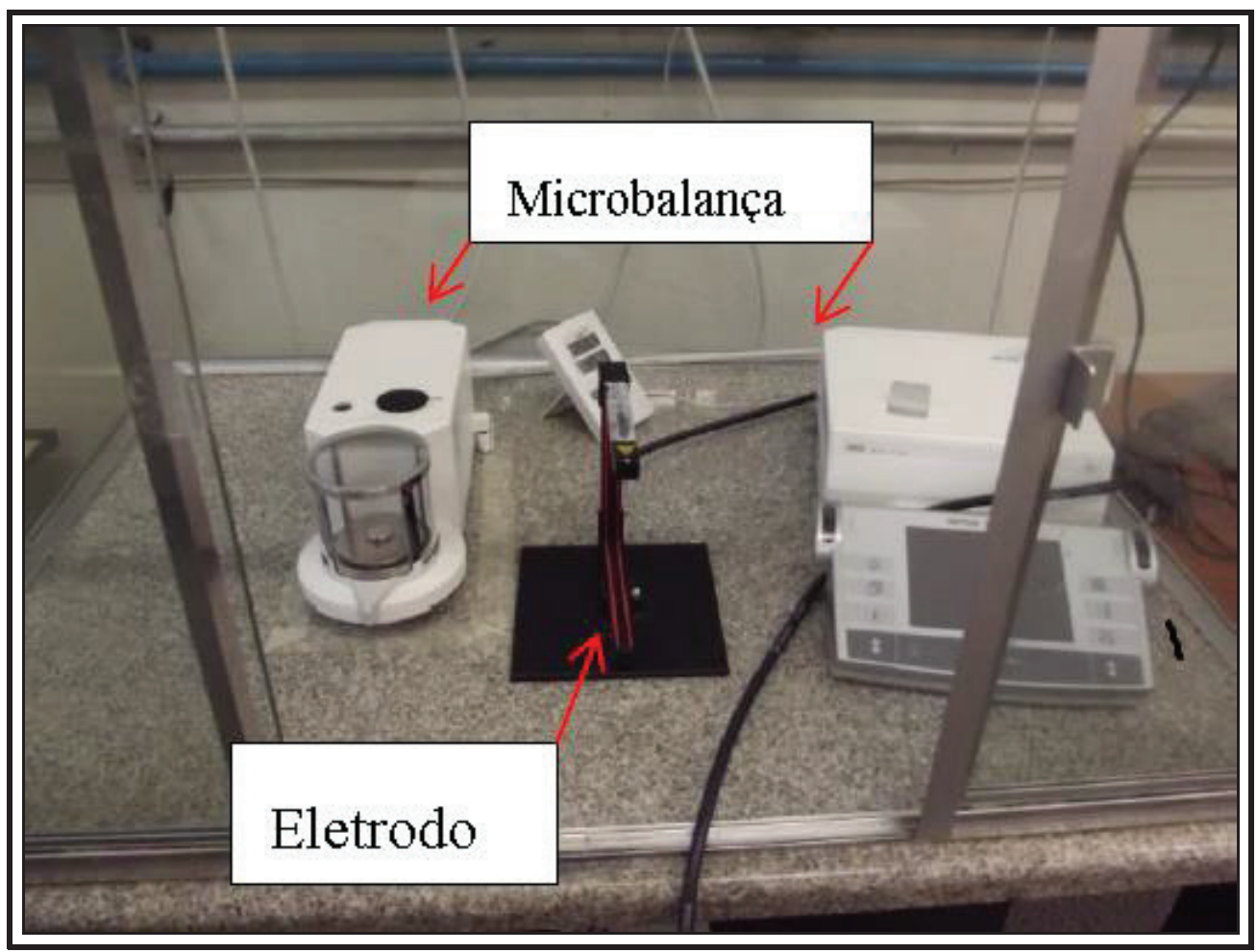

Figura 9. Balança e eletrodo utilizados no projeto. Fonte: Rotirotti, 2013. 


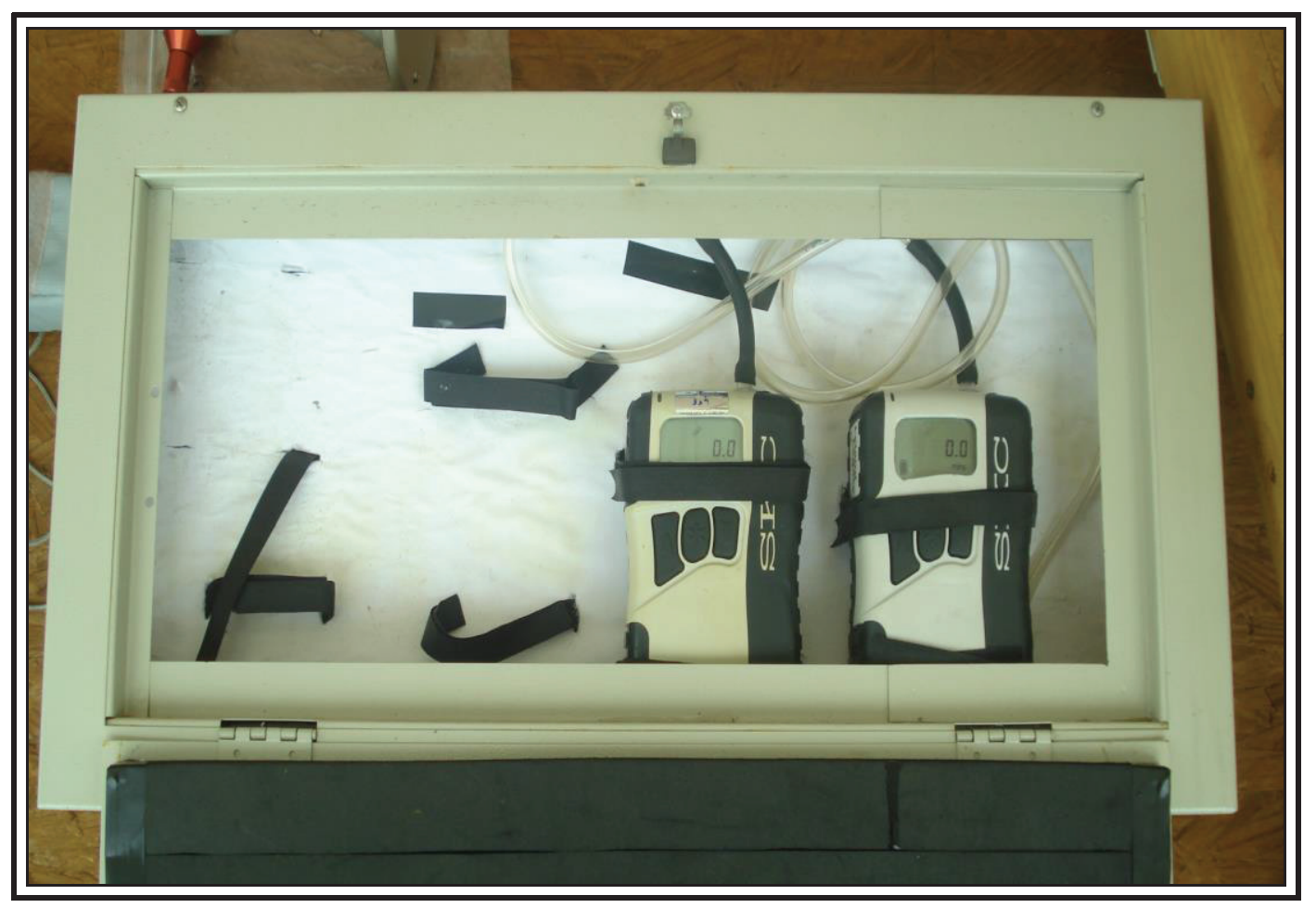

Figura 10. Bombas de ar presas dentro da caixa de aço.

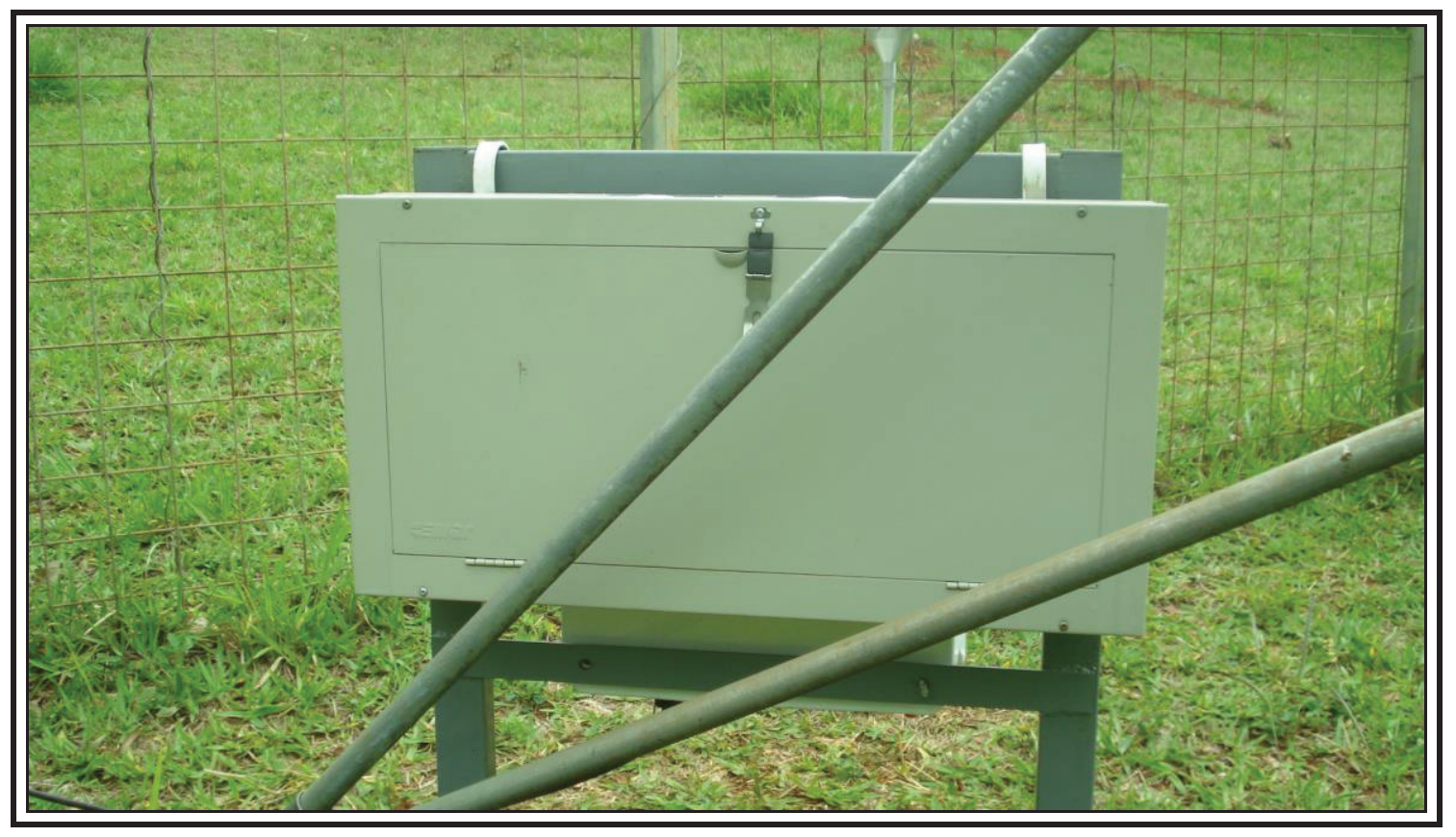

Figura 11. Caixa de aço com o conjunto bomba e PEM em funcionamento presa ao suporte do ADR. 


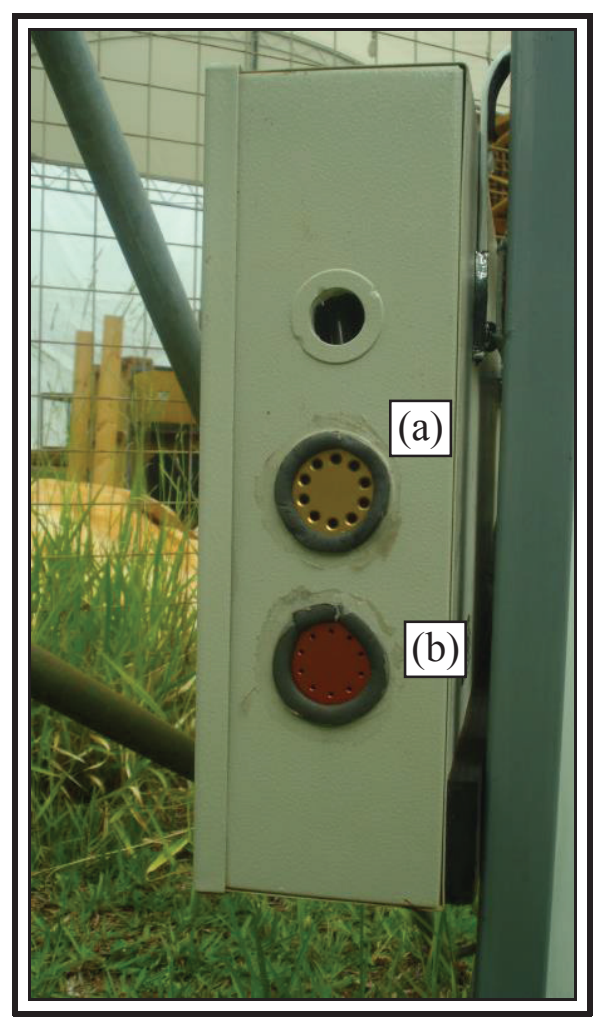

Figura 12. Local onde os amostradores $P E M$ são posicionados na caixa; (a) $\mathrm{MP}_{10}$, (b) $\mathrm{MP}_{2,5}$.

\subsection{Estação meteorológica}

A estação meteorológica (Figura 13) do Instituto de Arquitetura e Urbanismo da USP de São Carlos opera desde 2001 e coleta dados sobre precipitação, temperatura, radiação solar, umidade relativa, direção e intensidade dos ventos. Os dados se encontram disponíveis no seguinte endereço eletrônico:

http://sistemas.iau.usp.br/emeteorologica 


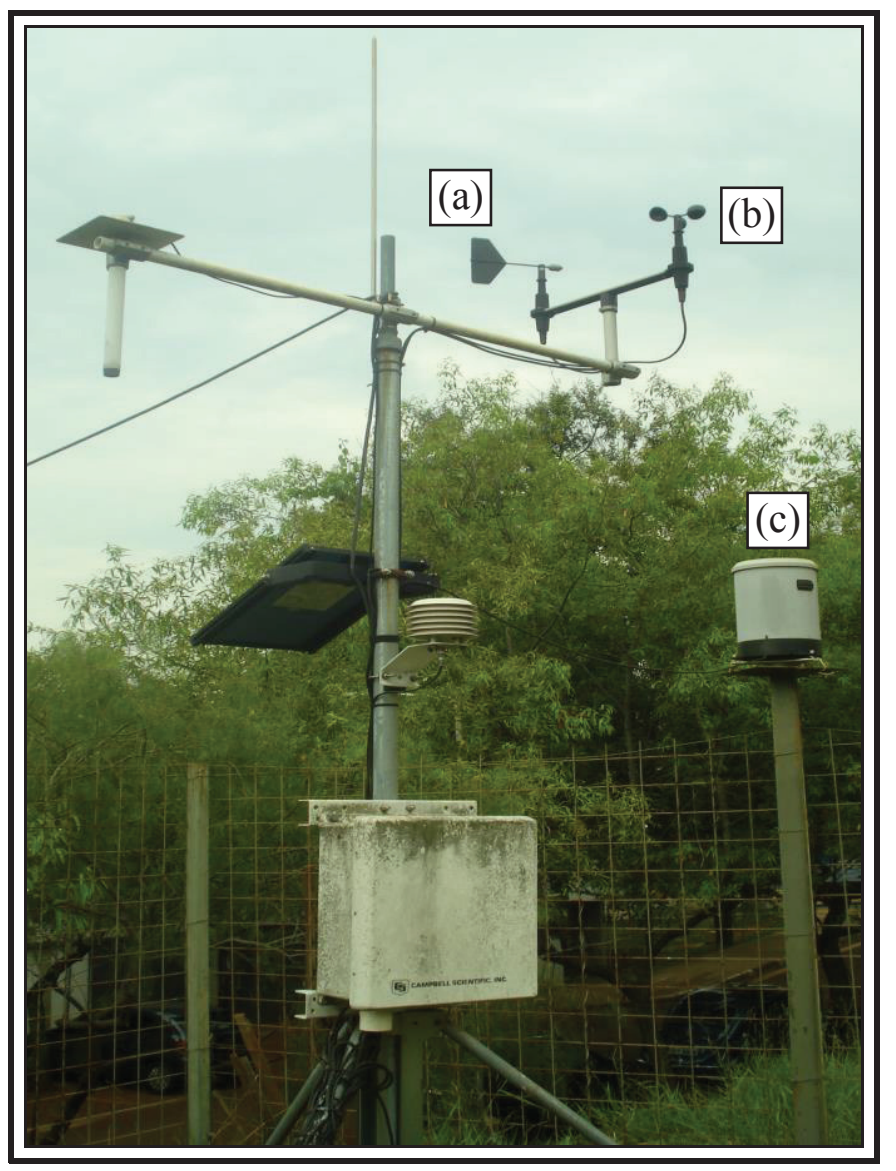

Figura 13. Estação meteorológica e seus equipamentos; (a) direção e (b) intensidade dos ventos, (c) pluviômetro.

Para a realização deste trabalho foram utilizados os dados de precipitação fornecidos por esta estação, os quais eram atualizados a cada 30 minutos. Portanto, em dias de chuva, por exemplo, foi possível saber não apenas quantos milímetros houve de precipitação, mas também calcular a intensidade média da mesma em $\mathrm{mm} / \mathrm{min}$ ou $\mathrm{mm} /$ hora. 


\section{RESULTADOS E DISCUSSÃO}

\subsection{Amostrador PEM}

$\mathrm{Na}$ tabela 6 estão os valores obtidos através do PEM para as concentrações de material particulado inalável grosso $\left(\mathrm{MP}_{10}\right)$, e material particulado inalável fino $\left(\mathrm{MP}_{2,5}\right)$.

Como já mencionado anteriormente, foram utilizados dois PEMs, um para a determinação da concentração de $\mathrm{MP}_{10}$ e outro para a concentração de $\mathrm{MP}_{2,5}$ (Figura 12). Também está presente na tabela a porcentagem das concentrações de $\mathrm{MP}_{2,5} \mathrm{em}$ relação as concentrações de $\mathrm{MP}_{10}$ obtidas em um mesmo dia.

Realizaram-se 23 coletas em dias diferentes, sendo que no dia 04 de novembro de 2014 não foi possível obter a concentração de $\mathrm{MP}_{10}$ e no dia 06 deste mesmo mês não foi possível obter a concentração de $\mathrm{MP}_{2,5}$. Resultando, portanto, em 22 coletas em que foi possível determinar os valores de $\mathrm{MP}_{10}$ e de $\mathrm{MP}_{2,5}$. Isto ocorreu devido a uma falha em um das bombas utilizada, a qual parou de funcionar, em ambos os casos, após poucos minutos de funcionamento.

Bruno (2005), em seu monitoramento do $\mathrm{MP}_{10}$ realizado no centro de São Carlos obteve a concentração média de material particulado grosso igual a $41 \mu \mathrm{g} / \mathrm{m}^{3}$ na estação seca, que vai de abril a outubro, e $23 \mu \mathrm{g} / \mathrm{m}^{3}$ na estação chuvosa. Já Silva (2012), em seu monitoramento no Mercado Municipal de São Carlos, obteve para a concentração de $\mathrm{MP}_{10}$ não estação chuvosa o valor de $35,6 \mu \mathrm{g} / \mathrm{m}^{3}$ e para o $\mathrm{MP}_{2,5} 25,91 \mu \mathrm{g} / \mathrm{m}^{3}$.

Rotiroti (2013), em seu trabalho de monitoramento também no Mercado Municipal, obteve para o $\mathrm{MP}_{10}$ em ambiente externo a média igual a $45,77 \mu \mathrm{g} / \mathrm{m}^{3}$ e $28,13 \mu \mathrm{g} / \mathrm{m}^{3}$ para o $\mathrm{MP}_{2,5}$. 
Tabela 6. Valores obtidos para os MP 10 e 2,5 através do PEM.

\begin{tabular}{|c|c|c|c|c|}
\hline Data das coletas & $\mathrm{MP}_{10}\left(\mu \mathrm{g} / \mathrm{m}^{3}\right)$ & $\mathrm{MP}_{2,5}\left(\mu \mathrm{g} / \mathrm{m}^{3}\right)$ & $\mathrm{MP}_{2,5} / \mathrm{MP}_{10}(\%)$ & Precipitação (mm) \\
\hline 16/junho & 47,9 & 23,0 & 48,0 & - \\
\hline 24/junho & 43,8 & 18,3 & 41,8 & - \\
\hline 27/junho & 58,2 & 29,4 & 50,5 & - \\
\hline 02/julho & 64,2 & 23,9 & 37,2 & - \\
\hline 04/julho & 79,4 & 31,4 & 39,5 & - \\
\hline 23/julho & 47,4 & 31,5 & 66,5 & - \\
\hline 24/julho & 34,5 & 16,5 & 47,8 & 56 \\
\hline 07/agosto & 47,6 & 22,1 & 46,4 & - \\
\hline 08/agosto & 49,5 & 24,6 & 49,7 & - \\
\hline 19/agosto & 24,0 & 15,9 & 66,3 & - \\
\hline 21/agosto & 48,5 & 20,4 & 42,1 & - \\
\hline 03/setembro & 23,2 & 8,7 & 37,5 & 111 \\
\hline 08/setembro & 47,7 & 30,4 & 63,7 & - \\
\hline 10/setembro & 73,7 & 37,2 & 50,5 & - \\
\hline 22/setembro & 28,3 & 19,1 & 67,5 & - \\
\hline 26/setembro & 39,3 & 19,4 & 49,4 & \\
\hline 06/outubro & 52,9 & 27,1 & 51,2 & - \\
\hline 09/outubro & 72,4 & 26,0 & 35,9 & - \\
\hline 20/outubro & 48,1 & 29,6 & 61,5 & 1 \\
\hline 21/outubro & 48,1 & 22,7 & 47,2 & - \\
\hline 03/novembro & 62,8 & 17,7 & 28,2 & 2 \\
\hline 04/novembro & - & 14,1 & - & 184 \\
\hline 06/novembro & 31,9 & - & - & 10 \\
\hline Média & 48,8 & 23,1 & 49,0 & - \\
\hline
\end{tabular}

\section{1. a) $\mathrm{MP}_{10}$}

Os menores valores obtidos para as concentrações de material particulado inalável grosso foram verificados em dias chuvosos, ou em dias em que havia chovido recentemente (Os dias em que houve chuva durante o período do estudo e a quantidade precipitada estão na Tabela 7). A única exceção ocorreu no dia 19 de agosto, no qual foi encontrada a segunda menor concentração para o $\mathrm{MP}_{10}$ considerando os valores obtidos através do PEM, igual a $24,0 \mu \mathrm{g} / \mathrm{m}^{3}$. A menor concentração, de $23,2 \mu \mathrm{g} / \mathrm{m}^{3}$, foi 
observada no dia 03 de setembro, em que ocorreu uma precipitação igual a $111 \mathrm{~mm}$, a maior considerando-se os dias em que o PEM estava monitorando as concentrações de $\mathrm{MP}_{10}$ e foi possível a sua determinação. No dia 04 de novembro houve uma precipitação igual a $184 \mathrm{~mm}$, mas só foi possível determinar a concentração do $\mathrm{MP}_{2,5}$.

$\mathrm{O}$ terceiro menor valor para o $\mathrm{MP}_{10}\left(28,3 \mu \mathrm{g} / \mathrm{m}^{3}\right)$ foi encontrado em um dia em que não ocorreu chuva, 22 de setembro, porém dois dias antes, em 20 de setembro, houve uma precipitação de $152 \mathrm{~mm}$, e no dia seguinte 21 , uma precipitação de $2 \mathrm{~mm}$. Portanto é provável que com esta chuva a concentração de $\mathrm{MP}_{10}$ atmosférico tenha diminuído significativamente e seu efeito perdurado, no mínimo, pelos próximos dois dias. Prosseguindo, a quarta menor concentração, igual a $31,9 \mu \mathrm{g} / \mathrm{m}^{3}$ foi observada no dia 06 de novembro, quando a altura da lâmina de água precipitada foi de $10 \mathrm{~mm}$, sendo que nos dias 04 e 05 de novembro, havia chovido 184 e $58 \mathrm{~mm}$, respectivamente. Por fim temos as quinta e sexta menores concentrações, 34,5 ( 24 de julho) e $39,3 \mu \mathrm{g} / \mathrm{m}^{3}$ (26 de setembro), com uma precipitação de $56 \mathrm{~mm}$ no dia em que foi obtida a primeira concentração e $45 \mathrm{~mm}$ na segunda. Pôde-se constatar que, de uma maneira geral, não só os menores valores foram obtidos em dias de chuva, mas que também quanto maior a precipitação no dia da coleta e nos dias anteriores a esta, menor fora a concentração obtida.

É importante observar que nos dias 20 de outubro e 03 de novembro, os valores obtidos para o $\mathrm{MP}_{10}$ não foram similares aos valores obtidos em outros dias com chuva, provavelmente porque a quantidade precipitada foi de apenas $1 \mathrm{~mm}$ no primeiro e de 2 mm no segundo dia. Com relação ao dia 20 de outubro houve uma chuva no dia anterior, mas de $8 \mathrm{~mm}$, já com relação ao valor obtido no dia 03 de novembro, houve uma precipitação igual a $67 \mathrm{~mm}$ no dia anterior, e é provável que as concentrações tenham diminuído neste dia (como ocorreu nos dias 24 de julho e 26 de setembro, que apresentaram valores de precipitação similares) porém os valores voltaram a subir no dia 03 de novembro. O que mostra que a chuva só começa a produzir um efeito significativo na redução das concentrações de $\mathrm{MP}_{10}$ a partir de uma quantidade mínima de precipitação em um intervalo de tempo.

Considerando-se o que ocorreu no dia 24 de julho, quando mesmo com a precipitação de $67 \mathrm{~mm}$ no dia anterior, a precipitação de $10 \mathrm{~mm}$ não foi suficiente para provocar uma diminuição nos valores de $\mathrm{MP}_{10}$, podemos supor que para concentrações similares às encontradas no dia em questão o valor de $10 \mathrm{~mm}$ ainda não é suficiente para promover uma redução na concentração de material particulado inalável grosso. No dia 
06 de novembro, houve uma precipitação igual a $10 \mathrm{~mm}$ e a concentração de $\mathrm{MP}_{10}$ obtida nesta data foi a quarta menor, entretanto nos dias 04 e 05 de novembro, havia chovido 184 e $58 \mathrm{~mm}$, respectivamente, o que influenciou o "baixo" valor obtido, pois a concentração obtida no dia 22 de setembro, como já visto, foi influenciada pela precipitação do dia 20, igual a $152 \mathrm{~mm}$.

Por outro lado, se esse valor de precipitação de $67 \mathrm{~mm}$, do dia 23 de julho, não foi suficiente para influenciar as concentrações de $\mathrm{MP}_{10}$ do dia seguinte, podemos propor que no dia 26 de setembro as concentrações de material particulado grosso não estavam sob a influência da chuva do dia anterior, igual a $16 \mathrm{~mm}$, mas apenas da precipitação do dia coleta, a qual foi igual a $45 \mathrm{~mm}$ e suficiente para que a concentração obtida estivesse entre os menores valores encontrados para o $\mathrm{MP}_{10}$, logo, grosso modo, podemos concluir que esse valor mínimo de precipitação capaz de provocar uma redução significativa e perceptível nas concentrações de $\mathrm{MP}_{10}$ encontra-se dentro do intervalo $10-45 \mathrm{~mm}$.

Em sete das 22 coletas em que foi possível determinar os valores de $\mathrm{MP}_{10}$, foi ultrapassado o valor máximo recomendado pela OMS, de $50 \mu \mathrm{g} / \mathrm{m}^{3}$, isso corresponde a aproximadamente $32 \%$ dos resultados obtidos para as concentrações de $\mathrm{MP}_{10}$ (A Figura 17 apresenta um gráfico de barras, com as concentrações obtidas para esta fração de material particulado e o limite recomendado pela OMS). Destes valores obtidos, três foram maiores que $70 \mu \mathrm{g} / \mathrm{m}^{3}$, sendo o maior igual a $79,4 \mu \mathrm{g} / \mathrm{m}^{3}$, quase $60 \%$ acima do limite recomendado.

Apesar de $68 \%$ dos valores obtidos estarem dentro do limite de $50 \mu \mathrm{g} / \mathrm{m}^{3}$, a média das concentrações obtidas para esta fração de material particulado foi de $48,8 \mu \mathrm{g} / \mathrm{m}^{3}$, apenas $1,2 \mu \mathrm{g} / \mathrm{m}^{3}$ ou $2,4 \%$, abaixo do limite recomendado pela OMS. Portanto a maior parte dos valores se encontrou dentro do limite, porém muito próximos a este. Caso o período de amostragem tivesse sido restrito a um intervalo de tempo menor e que englobasse apenas dias sem chuva com certeza a média se encontraria acima do limite. 
Tabela 7. Dias em que houve chuva e o valor precipitado, durante o período de monitoramento.

\begin{tabular}{|c|c|}
\hline Data & Precipitação (mm) \\
\hline 09/julho & 13 \\
\hline 10/julho & 13 \\
\hline 24/julho & 56 \\
\hline 25/julho & 13 \\
\hline 26/julho & 3 \\
\hline 27/julho & 1 \\
\hline 26/agosto & 32 \\
\hline 01/setembro & 14 \\
\hline 02/setembro & 29 \\
\hline 03/setembro & 111 \\
\hline 19/setembro & 150 \\
\hline $20 /$ setembro & 152 \\
\hline $21 /$ setembro & 2 \\
\hline $24 /$ setembro & 6 \\
\hline $25 /$ setembro & 16 \\
\hline $26 /$ setembro & 45 \\
\hline $27 /$ setembro & 20 \\
\hline 01/outubro & 4 \\
\hline 19/outubro & 8 \\
\hline 20/outubro & 1 \\
\hline 25/outubro & 3 \\
\hline 26/outubro & 102 \\
\hline 01/novembro & 2 \\
\hline 02/novembro & 67 \\
\hline 03/novembro & 2 \\
\hline 04/novembro & 184 \\
\hline 05/novembro & 58 \\
\hline 06/novembro & 10 \\
\hline 07/novembro & 19 \\
\hline 08/novembro & 117 \\
\hline
\end{tabular}

Como os valores obtidos para as concentrações de material particulado em dias chuvosos foram nitidamente inferiores aos resultados obtidos em dias em que não houve 
precipitação (salvo algumas exceções já mencionadas anteriormente), mostrou-se coerente trabalhar com esses números separadamente. Além dessa diferença, notou-se que os valores obtidos em dias chuvosos eram relativamente próximos entre si, o mesmo vale para os dias sem precipitação, porém isso não ocorre se as concentrações de $\mathrm{MP}_{10}$ obtidas nessas duas situações climáticas diferentes forem analisadas em conjunto.

Para exemplificar, a seguir temos o gráfico de dispersão (Figura 14) de todos os valores obtidos para as concentrações de $\mathrm{MP}_{10}$, bem como a equação da reta resultante da regressão linear aplicada a estes dados.

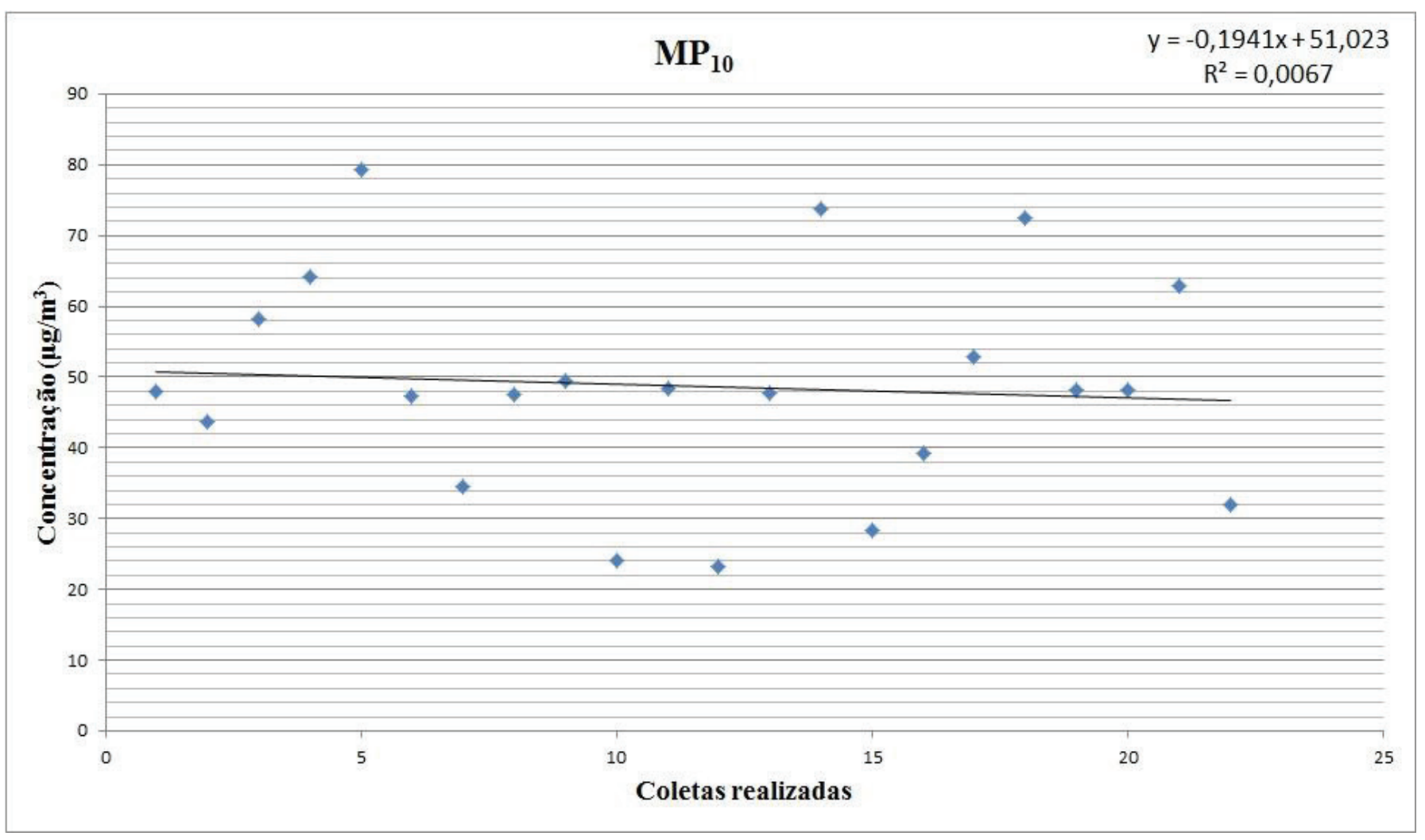

Figura 14. Gráfico de dispersão dos valores obtidos para as concentrações de $\mathrm{MP}_{10}$.

Nota-se visualmente que há uma dispersão muito grande dos dados. A maior parte destes está distante da reta que traduz o comportamento médio dos valores obtidos. Matematicamente isso é comprovado pelo baixo valor do coeficiente de determinação, $R^{2}$, igual a 0,0067 , este parâmetro expressa a precisão com que os dados obtidos são representados pela reta gerada através da regressão linear. Quanto mais próximo de 1 o valor de $\mathrm{R}^{2}$, maior a precisão da reta, de modo que se tomarmos pontos $(\mathrm{x}, \mathrm{y})$ pertencentes a uma determinada reta, a qual pode ser escrita como uma função do primeiro grau, a regressão linear nos levará a equação da mesma reta e o valor de $\mathrm{R}^{2}$ 
será 1 .

O critério utilizado para separação dos dados não foi a ocorrência de precipitação do ponto de vista conceitual, mas sim do ponto de vista prático, de sua influencia na concentração do material particulado. Por exemplo, para a construção do gráfico de dispersão das concentrações obtidas em dias chuvosos excluíram-se os valores obtidos nos dias, 20 de outubro e 3 novembro, pois nestas datas apesar de ter ocorrido a precipitação, esta foi de 1 e $2 \mathrm{~mm}$, respectivamente, valores que não exerceram uma influência significativa sobre a concentração de material particulado, como já foi verificado anteriormente (de modo que esses dias foram considerados para a finalidade de obtenção de uma média específica e construção do gráfico de dispersão, como dias não chuvosos). A terceira menor precipitação durante os dias em que o PEM estava funcionando ocorreu no dia 06 de novembro e foi igual a $10 \mathrm{~mm}$, este dia não foi excluído também, pois esta precipitação, embora ainda pequena, já não pode ser desconsiderada.

Para a construção do gráfico de dispersão das concentrações de material particulado obtido em dias sem chuva (Figura 15), foram considerados, além dos dias em que não houve precipitação, os dias 20 de outubro e 03 de novembro, como foi explicado anteriormente; e exclui-se o dia 19 de agosto, por estar sob influência de chuvas ocorridas nos dois dias anteriores a coleta de MP.

Analisando a Figura 15, percebe-se que os dados estão mais próximos da nova reta resultante da regressão linear aplicada apenas aos valores encontrados em dias com ausência de chuvas. Isso também pode ser constatado pelo valor de $\mathrm{R}^{2}$, igual a 0,0135 , o qual é maior que o valor de $\mathrm{R}^{2}$ obtido quando a regressão foi aplicada a todas as concentrações obtidas para o material particulado inalável grosso. Essa diferença entre os valores de $\mathrm{R}^{2}$ comprova que os resultados obtidos para as concentrações de material particulado em dias com ausência de chuvas tem uma distribuição restrita a um intervalo com menor amplitude do que o intervalo contendo todos os valores. Por fim, foi calculada a média das concentrações destes dias, a qual foi igual a $55,8 \mu \mathrm{g} / \mathrm{m}^{3}$, ou seja, acima da média geral obtida, o que já era esperado, e maior que o limite estabelecido pela OMS. 


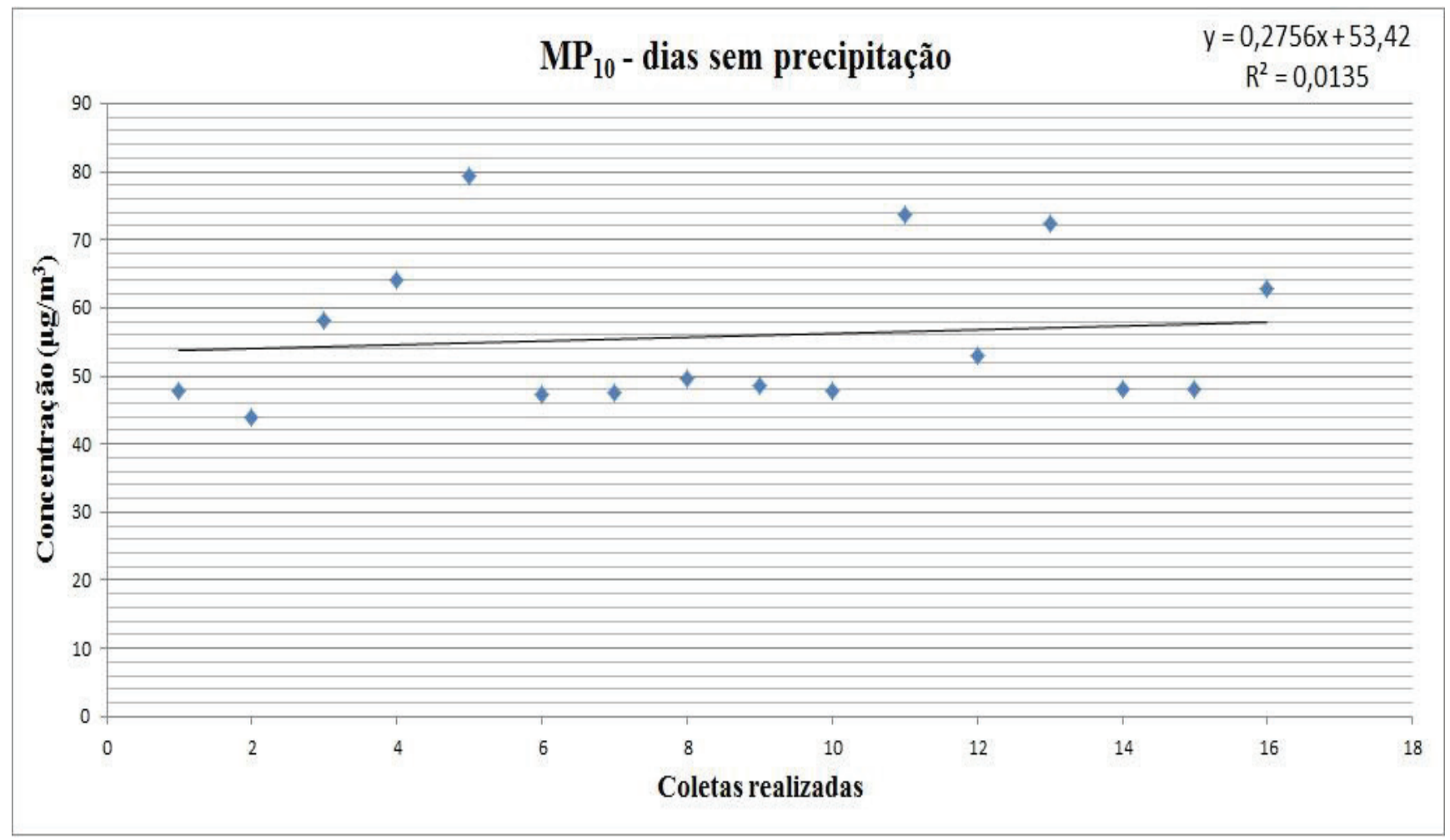

Figura 15. Gráfico de dispersão dos valores obtidos em dias sem chuva para as concentrações de $\mathrm{MP}_{10}$.

Foi construído também o gráfico de dispersão linear dos valores obtidos em dias chuvosos (Figura 16). Este gráfico, entretanto, possui apenas cinco valores, pois na maioria dos dias em que o PEM foi utilizado não houve chuva, e, como já mencionado anteriormente, dois dias onde o pluviômetro mediu 1 e $2 \mathrm{~mm}$, foram considerados como dias não chuvosos devido ao pequeno valor da precipitação, que não resultou em redução significativa na concentração de material particulado.

Este gráfico de dispersão apresentou o maior valor de $\mathrm{R}^{2}$, igual a 0,0797 , isto se deve a três fatores. O primeiro é estatístico, como foi o gráfico de dispersão com o menor número de valores (5), isto favorece a representatividade da reta obtida através da regressão linear, pois 5 ainda é um número muito próximo de 2, e, ao menos na geometria euclidiana, por dois pontos distintos passa-se apenas uma reta (isto implica que sempre que houver apenas dois pontos o valor de $\mathrm{R}^{2}$ será igual a 1), ou seja, considerando-se também a distribuição dos dados, o valor de $\mathrm{R}^{2}$ tende a ser cada vez menor que 1 a medida que o número de dados aumenta, e estes tendem a se distribuir em um intervalo comum, de menor amplitude se comparado ao intervalo constituído por todos os resultados, analogamente ao que ocorreu com os valores obtidos em dias não chuvosos (segundo fator), o terceiro fator e talvez o mais determinante, e que será 
provado posteriormente, é que todas as precipitações, com uma taxa de variação maior ou menor, fazem as concentrações de material particulado convergir para um intervalo com uma amplitude restrita. Esse comportamento pode ser modelado através de equações diferenciais de primeira ordem.

A média obtida para os dias chuvosos foi igual a $31,4 \mu \mathrm{g} / \mathrm{m}^{3}$, valor em torno de $44 \%$ menor do que a média obtida para os dias sem precipitação, de 55,8 $\mu \mathrm{g} / \mathrm{m}^{3}$. Com relação a média geral, igual a $48,8 \mu \mathrm{g} / \mathrm{m}^{3}$, esta ficou relativamente próxima a dos dias sem chuva, embora a diferença entre as duas primeiras médias seja grande, porque o número de dias sem chuva foi da ordem de três vezes maior que o número destes com chuva.

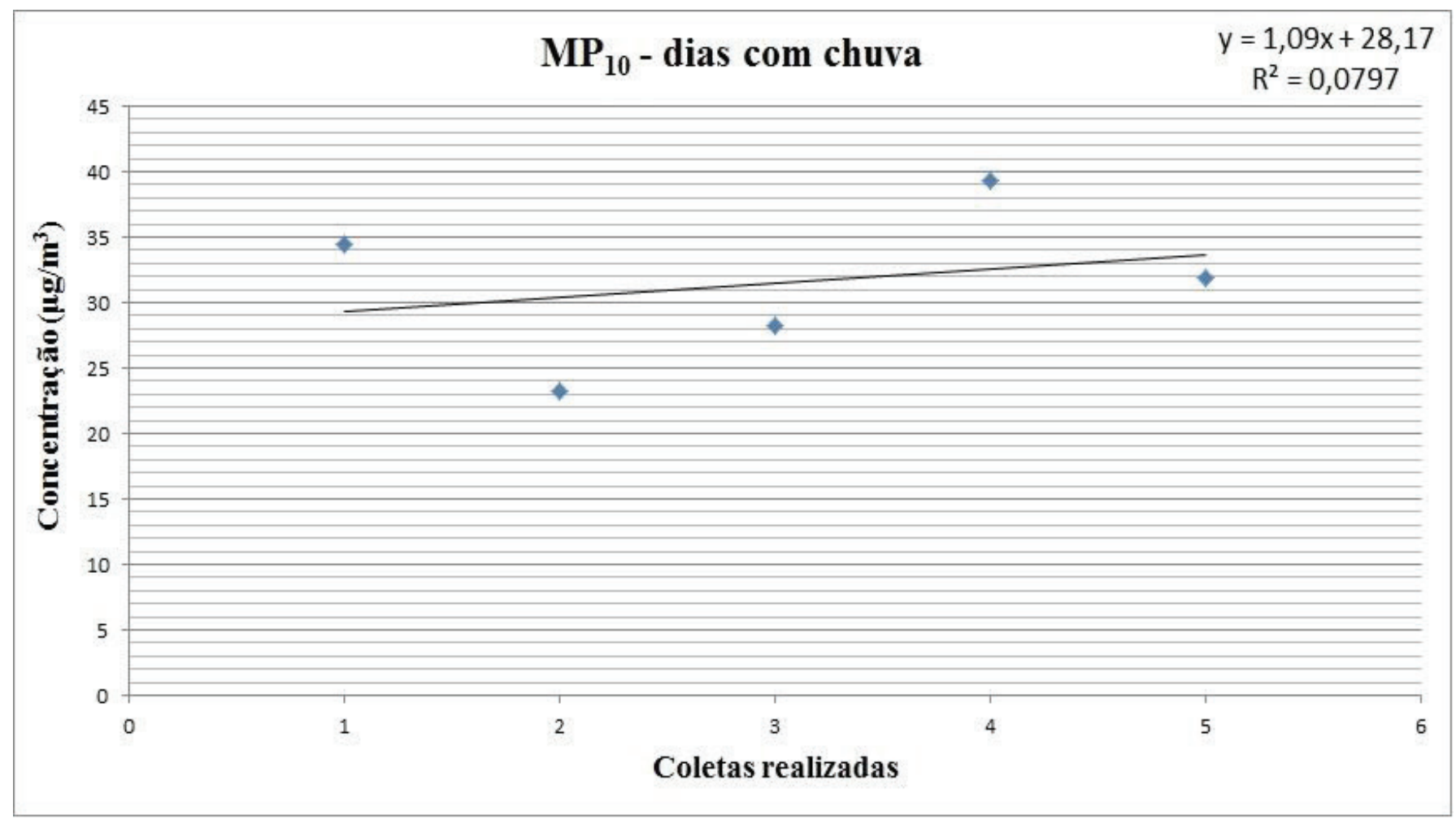

Figura 16. Gráfico de dispersão dos valores obtidos em dias com chuva para as concentrações de $\mathrm{MP}_{10}$. 


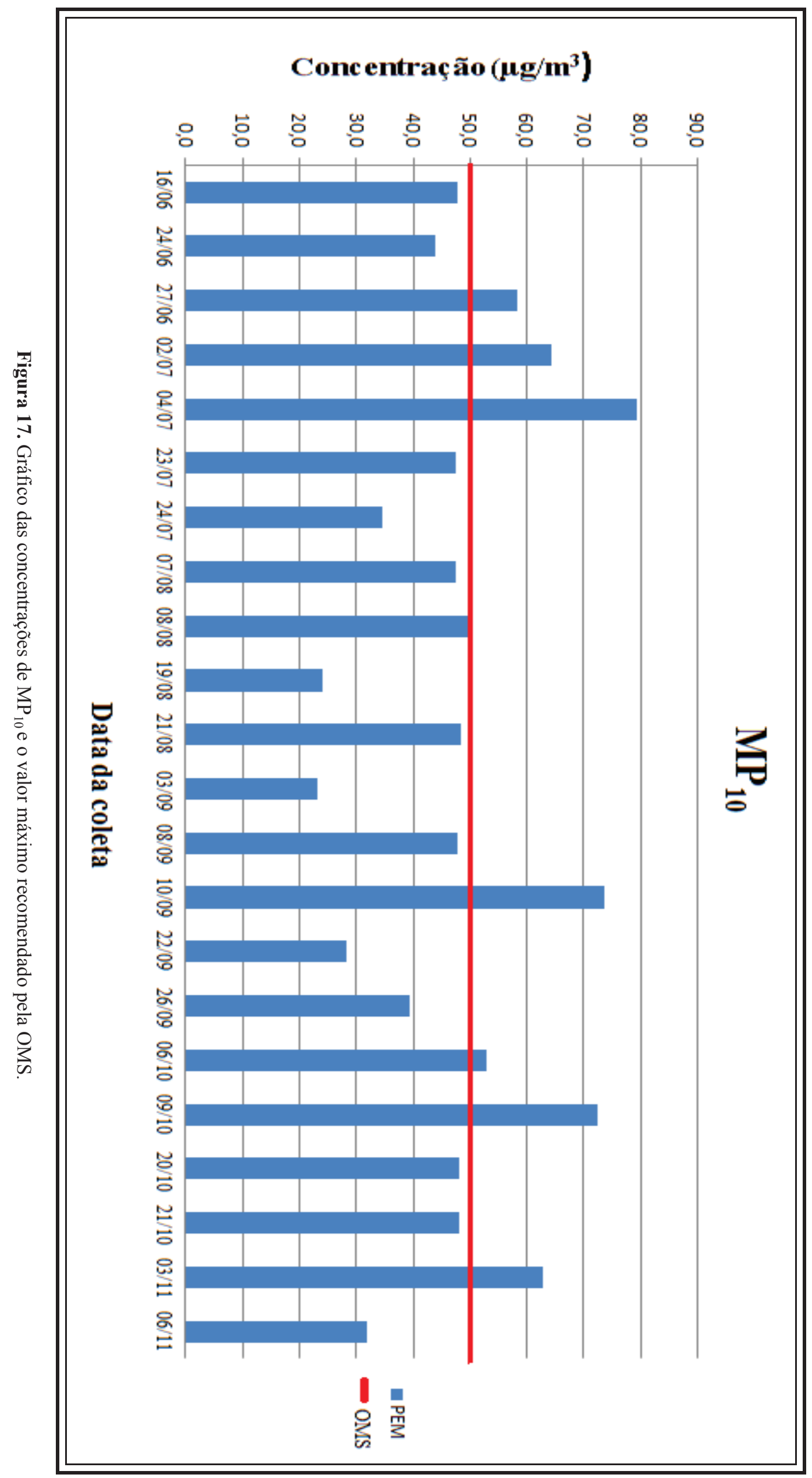




\section{1. b) $\mathrm{MP}_{2,5}$}

Dos 22 valores obtidos para a concentração de material particulado inalável fino, 8 ultrapassaram o limite recomendado pela OMS, que é de $25 \mu \mathrm{g} / \mathrm{m}^{3}$, isso corresponde a aproximadamente $36 \%$ dos resultados obtidos para as concentrações de $\mathrm{MP}_{2,5}$, porcentagem maior que a obtida para valores de $\mathrm{MP}_{10}$ acima do limite, que foi de $32 \%$. (A Figura 21 apresenta as concentrações obtidas para esta fração de material particulado e o limite recomendado pela OMS).

O maior valor para o $\mathrm{MP}_{2,5}, 37,2 \mu \mathrm{g} / \mathrm{m}^{3}$, aproximadamente $50 \%$ acima do limite, foi encontrado no dia 10 de setembro, data em que se verificou também o segundo maior valor para o $\mathrm{MP}_{10}, 73,7 \mu \mathrm{g} / \mathrm{m}^{3}$. Já a segunda maior concentração, igual a 31,5 $\mu \mathrm{g} / \mathrm{m}^{3}$, foi observada no dia 23 de julho, não sendo acompanhada, porém, de valores de $\mathrm{MP}_{10}$ também elevados nem acima do limite (ver seção 5.2). A terceira maior concentração foi observada no dia 24 de julho, com o valor de $31,4 \mu \mathrm{g} / \mathrm{m}^{3}$, no qual também foi verificada a maior concentração de $\mathrm{MP}_{10}, 79,4 \mu \mathrm{g} / \mathrm{m}^{3}$, conforme citado anteriormente. O quarto maior valor, $30,4 \mu \mathrm{g} / \mathrm{m}^{3}$, ocorreu no dia 8 de setembro não sendo acompanhado de uma concentração de $\mathrm{MP}_{10}$ também acima do limite. Os demais resultados em desacordo com a recomendação da OMS foram inferiores a $30 \mu \mathrm{g} / \mathrm{m}^{3}$.

Assim como verificado com o $\mathrm{MP}_{10}$, os menores valores obtidos para as concentrações de material particulado inalável fino foram observados em dias chuvosos, ou em dias em que havia chovido recentemente (Tabela 7), as exceções foram os dias 24 de junho e 19 de agosto. No primeiro, foi encontrada a sexta menor concentração para o $\mathrm{MP}_{2,5}$ e igual a $18,3 \mu \mathrm{g} / \mathrm{m}^{3}$, já o segundo foi o responsável pela terceira menor concentração, $15,9 \mu \mathrm{g} / \mathrm{m}^{3}$, lembrando que neste dia também foi verificada a segunda menor concentração para o $\mathrm{MP}_{10}$.

A menor concentração, de $8,7 \mu \mathrm{g} / \mathrm{m}^{3}$, foi observada em 03 de setembro, dia no qual também foi encontrada a menor concentração de $\mathrm{MP}_{10}$ e que apresentou uma precipitação igual a $111 \mathrm{~mm}$. A segunda menor concentração para o $\mathrm{MP}_{2,5}, 14,1 \mu \mathrm{g} / \mathrm{m}^{3}$, foi verificada no dia 04 de novembro, quando houve a maior precipitação, igual a 184 mm, considerando não só os dias em que o PEM estava em funcionamento mas também todo o período de monitoramento, pois como já mencionado anteriormente, o ADR 1500 permaneceu ligado ininterruptamente.

O quarto menor valor para o $\mathrm{MP}_{2,5}\left(16,5 \mu \mathrm{g} / \mathrm{m}^{3}\right)$ foi encontrado no dia $24 \mathrm{de}$ julho, quando a chuva foi de $56 \mathrm{~mm}$. A quinta menor concentração $\left(17,7 \mu \mathrm{g} / \mathrm{m}^{3}\right)$, por sua vez, foi verificada no dia 03 de novembro, que apresentou uma chuva de apenas 2 
mm, entretanto no dia anterior houve uma precipitação de $67 \mathrm{~mm}$; é importante observar que o valor obtido para o $\mathrm{MP}_{10}$ nesta data, apesar da chuva do dia anterior, foi um dos maiores observados, portanto é possível que a precipitação tenho exercido efeito apenas sobre o MP de menor diâmetro. É mister salientar que no dia 20 de outubro, o valor obtido para o $\mathrm{MP}_{2,5}$ não foi similar aos valores obtidos em outros dias com chuva (o mesmo ocorreu com o $\mathrm{MP}_{10}$ ), porque a quantidade precipitada foi de apenas $1 \mathrm{~mm}$; houve uma chuva no dia anterior, mas de parcos $8 \mathrm{~mm}$.

A média geral das concentrações de $\mathrm{MP}_{2,5}$ foi menor que o limite acima citado e igual a $23,1 \mu \mathrm{g} / \mathrm{m}^{3}$, ou seja $1,9 \mu \mathrm{g} / \mathrm{m}^{3}$ ou $7,6 \%$ abaixo deste. A média geral para as concentrações de $\mathrm{MP}_{10}$, porém, como já foi visto anteriormente, apesar de se encontrar dentro do limite, esteve muito próximo a este. Logo, tanto a média para as concentrações de $\mathrm{MP}_{10}$ como para de $\mathrm{MP}_{2,5}$, ficaram muito próximas dos seus respectivos limites recomendado pela OMS, apesar de não chegarem a atingi-los.

Os dados obtidos para as concentrações de $\mathrm{MP}_{2,5}$ foram analisados separadamente em dois grupos, contemplando duas condições meteorológicas: com e sem precipitação. Os motivos para esta análise separada bem como os critérios aplicados para a segregação dos dados são os mesmos aplicados a análise dos valores de $\mathrm{MP}_{10}$, os quais já foram explicados anteriormente.

A seguir temos o gráfico de dispersão (Figura 18) de todos os valores obtidos para as concentrações de $\mathrm{MP}_{2,5}$, bem como a equação da reta resultante da regressão linear obtida com esses dados. 


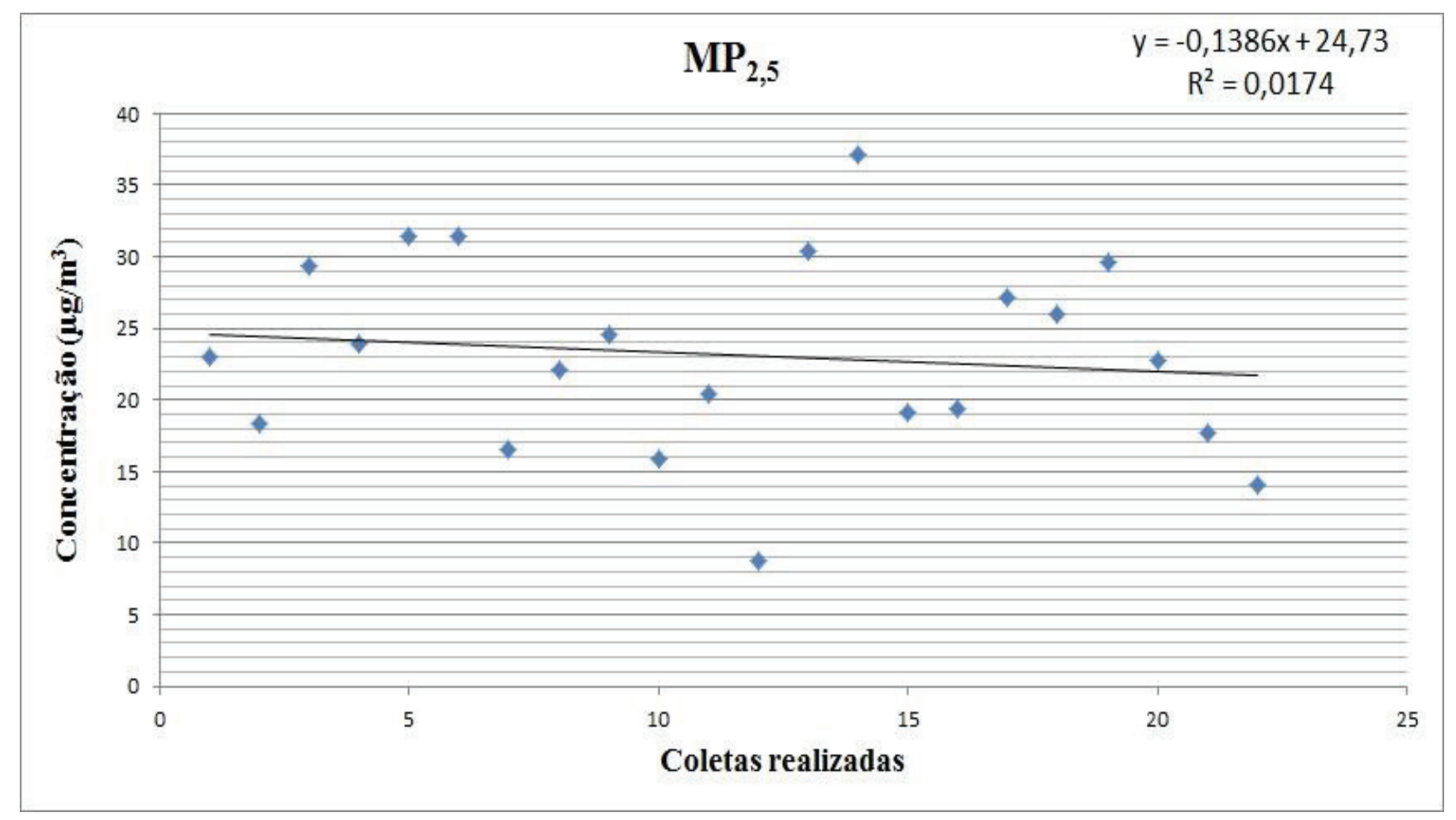

Figura 18. Gráfico de dispersão dos valores obtidos para as concentrações de $\mathrm{MP}_{2,5}$.

Nota-se visualmente que há uma grande dispersão dos dados. A maior parte destes está distante da reta que traduz o comportamento médio dos valores obtidos. Matematicamente, como já comentado, isso é comprovado pelo baixo valor do coeficiente de determinação, igual a 0,0174 , porém maior que o valor de $\mathrm{R}^{2}$ obtido para o mesmo gráfico só que com os valores de $\mathrm{MP}_{10}$, isto indica que os valores de $\mathrm{MP}_{2,5} \mathrm{se}$ distribuíram por um intervalo mais restrito se comparado ao da fração maior de material particulado. $\mathrm{O}$ intervalo cujos dados de $\mathrm{MP}_{10}$ se distribuíram, mesmo desconsiderando o resultado maior $\left(79,4 \mu \mathrm{g} / \mathrm{m}^{3}\right)$, está situado entre 20 e $75 \mu \mathrm{g} / \mathrm{m}^{3}$ aproximadamente, já o intervalo abrangendo as concentrações de material particulado fino está entre 8 e 38 $\mu \mathrm{g} / \mathrm{m}^{3}$.

Para a construção do gráfico de dispersão das concentrações de $\mathrm{MP}_{2,5}$ obtido em dias sem chuva (Figura 19), além dos dias em que não houve precipitação, foi considerado o dia 20 de outubro, pois este não exerceu uma influência significativa sobre a concentração de material particulado uma vez que a precipitação foi de apenas 1 mm; e foi excluído o dia 19 de agosto, porque o valor estava muito abaixo dos outros observados em dias sem chuva. 


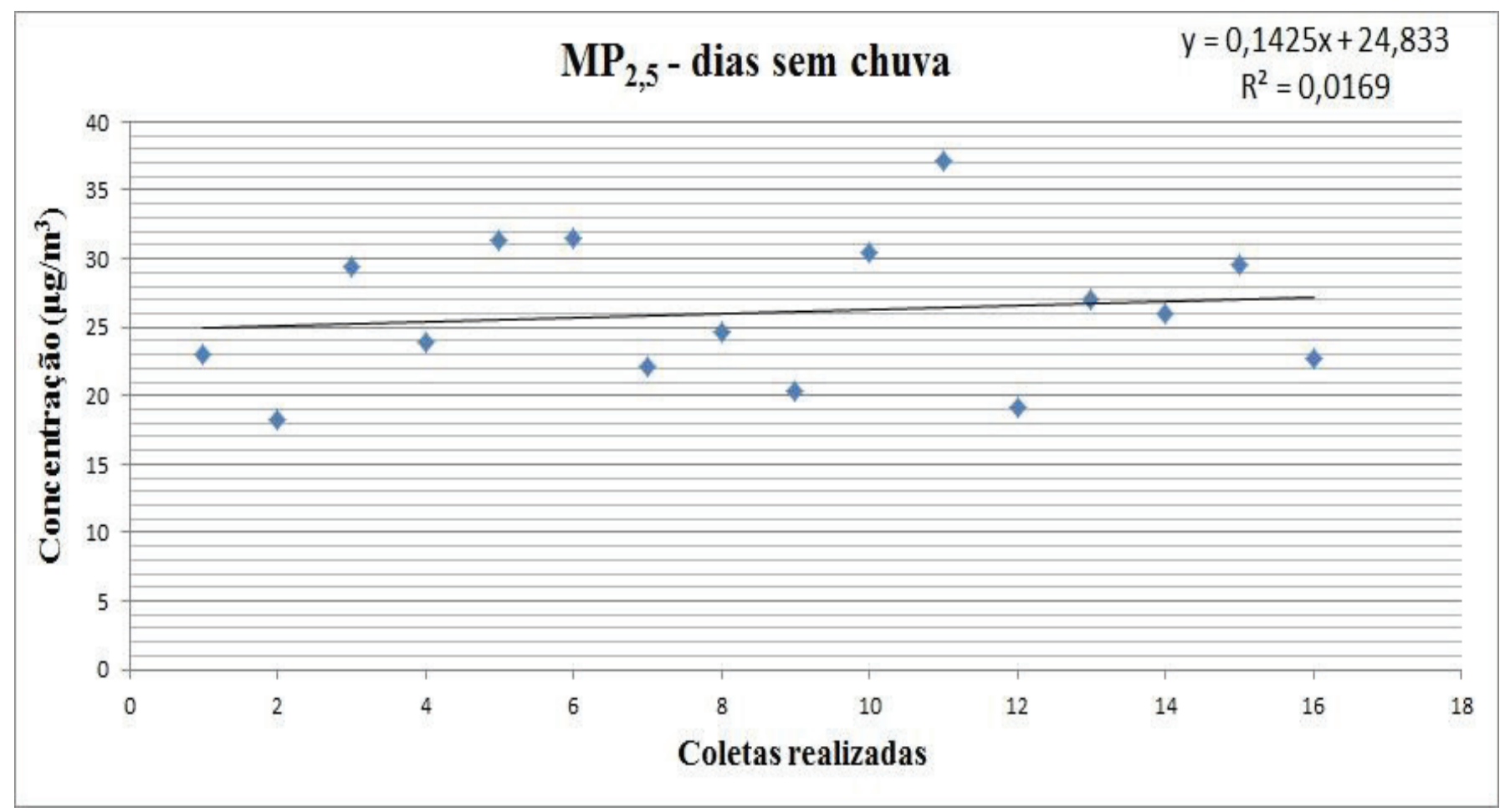

Figura 19. Gráfico de dispersão dos valores obtidos em dias sem chuva para as concentrações de $\mathrm{MP}_{2,5}$.

Analisando a Figura 19, percebemos que os valores obtidos para as concentrações de material particulado em dias com ausência de chuvas tem uma distribuição restrita a um intervalo com menor amplitude do que o intervalo contendo todos os valores, apesar disso os dados não estão mais próximos da nova reta resultante da regressão linear. Isso pode ser constatado pelo valor de $\mathrm{R}^{2}$, igual a 0,0169 , o qual é muito próximo, porém menor que o valor de $\mathrm{R}^{2}$ obtido quando a regressão foi aplicada a todas as concentrações obtidas para o material particulado inalável fino, 0,0174. Por fim, foi calculada a média das concentrações destes dias, a qual foi igual a $26,0 \mu \mathrm{g} / \mathrm{m}^{3}$, ou seja, acima da média geral obtida, e maior que o limite estabelecido pela OMS.

Foi construído também o gráfico de dispersão linear dos valores obtidos em dias chuvosos (Figura 20). Este gráfico de dispersão possui o maior valor de $\mathrm{R}^{2}(0,0256)$ dentre os três gráficos construídos com as concentrações de $\mathrm{MP}_{2,5}$, a explicação para isto é a mesma do $\mathrm{MP}_{10}$. A média obtida para os dias chuvosos foi igual a $15,3 \mu \mathrm{g} / \mathrm{m}^{3}$, concentração em torno de $41 \%$ menor do que a obtida para os dias sem precipitação. Com relação a média geral, igual a $23,1 \mu \mathrm{g} / \mathrm{m}^{3}$, esta ficou relativamente próxima a dos dias sem chuva, assim como verificado para o $\mathrm{MP}_{10}$, pois os dois $\mathrm{PEMs}$ funcionaram nos mesmos dias, cuja maioria, como já foi dito anteriormente, caracterizou-se pela ausência de chuvas. 


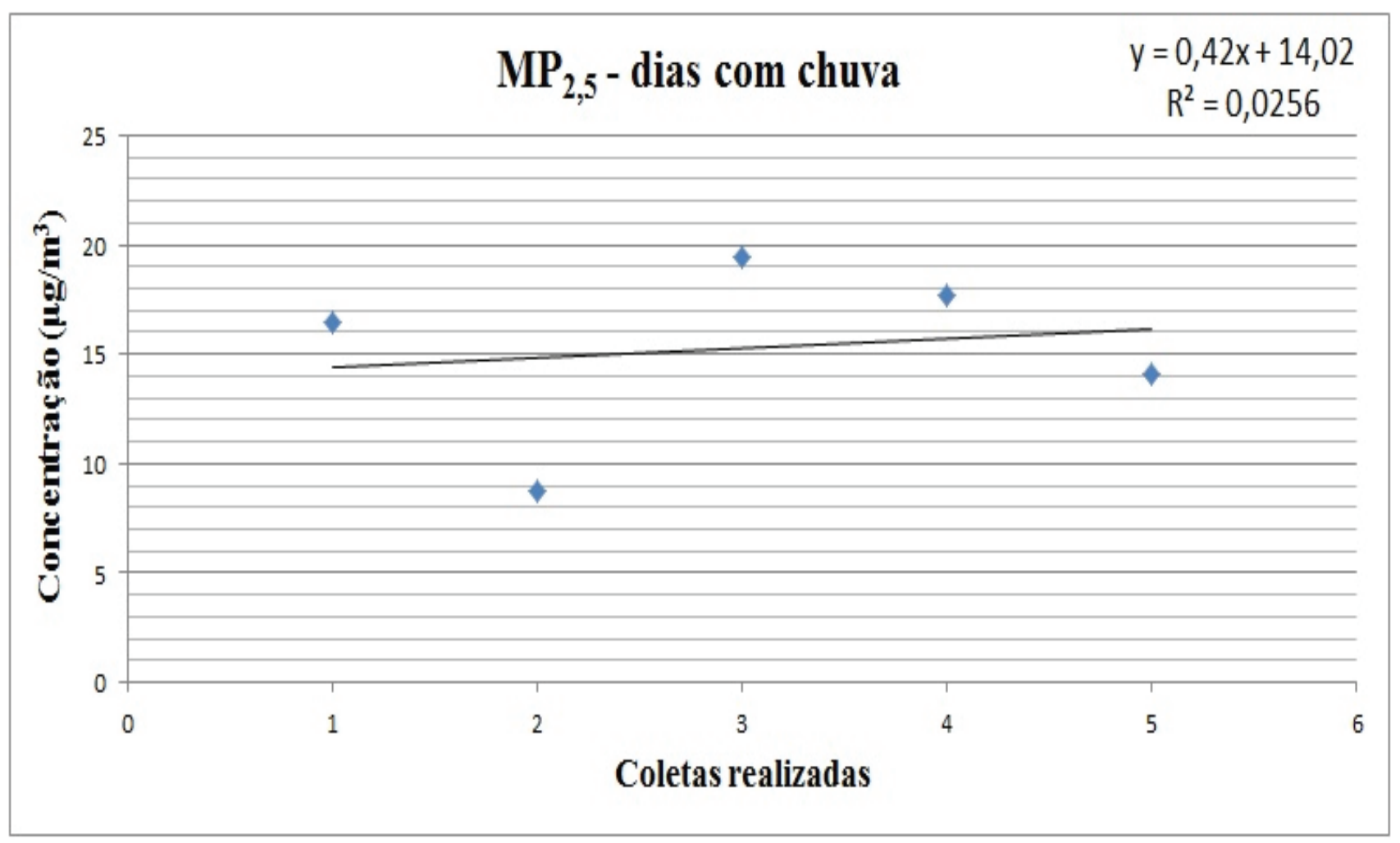

Figura 20. Gráfico de dispersão dos valores obtidos em dias com chuva para as concentrações de $\mathrm{MP}_{2,5}$. 


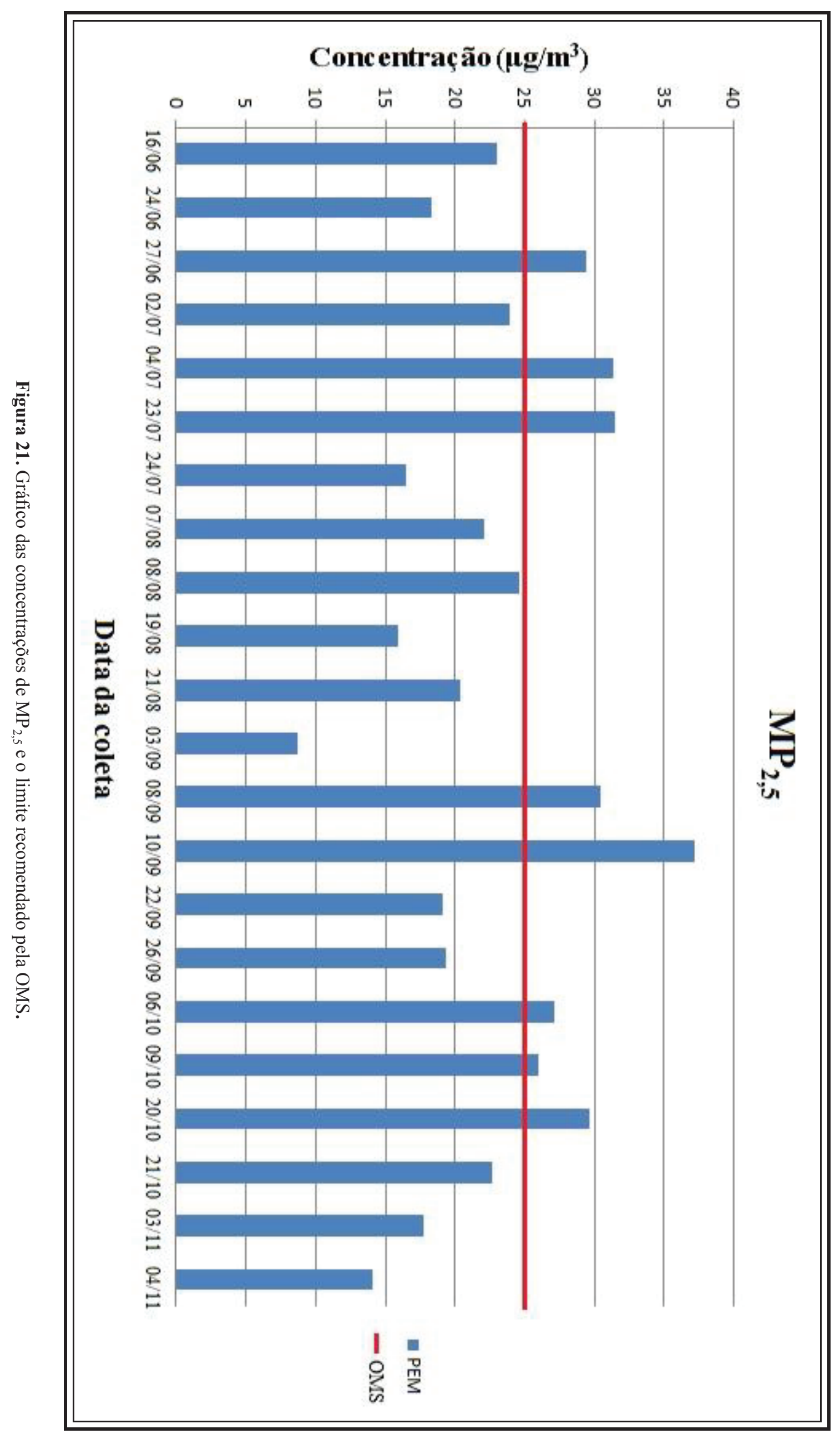




\subsection{Relação entre $M P_{10}$ e $M P_{2,5}$}

Apesar de o intervalo de diâmetros abrangido pelo material particulado fino $(0-2,5 \mu \mathrm{m})$ corresponder a um quarto do intervalo do material particulado grosso $(0-10 \mu \mathrm{m})$, a porcentagem correspondente a massa do $\mathrm{MP}_{2,5}$ na concentração do $\mathrm{MP}_{10}$ não obedeceu a essa razão. A média das relações entre as concentrações dessas duas frações de MP (Tabela 6), na mesma ordem, foi de aproximadamente 49\%, ou seja, praticamente o dobro da porcentagem resultante da relação entre os tamanhos dos intervalos dessas duas frações de material particulado. Essa constatação de uma participação “maior" do $\mathrm{MP}_{2,5}$ no $\mathrm{MP}_{10}$ não é algo bom do ponto de vista dos possíveis efeitos nocivos à saúde humana, pois esta fração menor de MP é a mais perigosa por ser a única capaz de chegar e se alojar nos alvéolos pulmonares.

Na Figura 22 temos o gráfico de distribuição dos valores obtidos para a relação entre as concentrações de $\mathrm{MP}_{2,5}$ e $\mathrm{MP}_{10}$, em porcentagem.

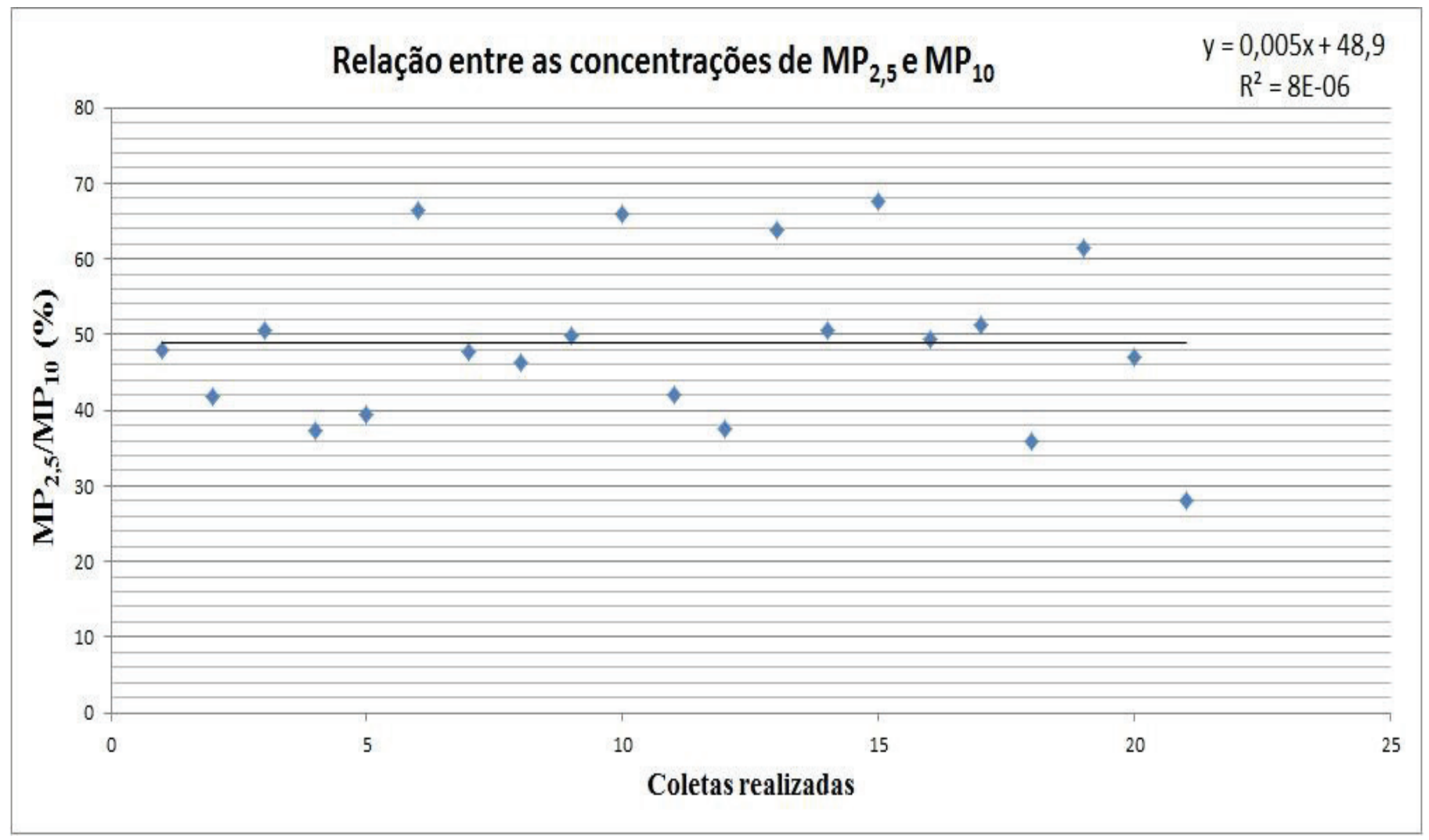

Figura 22. Gráfico de distribuição da relação percentual entre as concentrações de $\mathrm{MP}_{2,5} \mathrm{e} \mathrm{MP}_{10}$. 
A reta obtida através da regressão linear dos dados, e exibida no gráfico, é praticamente a própria média obtida, pois se desprezando o coeficiente angular, que é muito pequeno, tem-se $\mathrm{y}=48,9$, lembrando que o valor exato obtido para a média porcentual entre as relações é igual a 48,96\%. A distribuição dos dados em relação a reta equivale, portanto, a distribuição destes em relação a média.

Através do valor de $\mathrm{R}^{2}$, igual a $8 \times 10^{-6}$, e também analisando visualmente $\mathrm{o}$ gráfico pode-se perceber que existem valores muito próximos, mas também valores muito distantes da média, ou seja, houve dias em que foi grande a diferença entre a média e a relação entre as concentrações de $\mathrm{MP}_{2,5}$ e $\mathrm{MP}_{10}$, obtidas através do PEM.

Os menores valores para a relação $\mathrm{MP}_{2,5} / \mathrm{MP}_{10}$ foram: $28,19 \%$, no dia 03 de novembro, 35,95\% no dia 09 de outubro e 37,25\% no dia 02 de julho. Já os maiores, foram observados nos dias: 22 de setembro, igual a 67,69\%, 23 de julho com 66,5\% e $66,01 \%$ em 19 de agosto.

O limite recomendado pela OMS para a concentração de $\mathrm{MP}_{2,5}$, de $25 \mu \mathrm{g} / \mathrm{m}^{3}$, corresponde a metade do limite recomendado para o $\mathrm{MP}_{10}$, igual a $50 \mu \mathrm{g} / \mathrm{m}^{3}$, além disso, como já foi visto, a média das relações entre as concentrações dessas duas frações de MP também é igual a aproximadamente $50 \%$. Desse modo, nas ocasiões em que o $\mathrm{MP}_{10}$ ultrapassou $50 \mu \mathrm{g} / \mathrm{m}^{3}$ o mesmo ocorreu com o $\mathrm{MP}_{2,5}$, ou este último ficou pelo menos próximo ao limite, a exceção foi em casos onde a razão $\mathrm{MP}_{2,5} / \mathrm{MP}_{10}$ estava muito abaixo de $50 \%$. O contrário também foi verificado, quando apenas o $\mathrm{MP}_{2,5}$ ultrapassou o limite e o $\mathrm{MP}_{10}$ não ficou próximo da concentração máxima recomendada, estando a razão $\mathrm{MP}_{2,5} / \mathrm{MP}_{10}$ nestes casos muito acima de $50 \%$.

A concentração de material particulado inalável fino ultrapassou o limite recomendado pela OMS em 8 dos 22 dias em que foi possível determinar a sua a concentração, sendo que em 5 destes 8 dias a concentração de material particulado inalável grosso também estava acima do limite. Os dias em que apenas o $\mathrm{MP}_{2,5}$ ultrapassou o limite foram: 23 de julho, com a concentração igual a $31,5 \mu \mathrm{g} / \mathrm{m}^{3}, 08 \mathrm{de}$ setembro, 30,4 $\mu \mathrm{g} / \mathrm{m}^{3}$ e 20 de outubro com 29,6 $\mu \mathrm{g} / \mathrm{m}^{3}$. A respectivas relações $\mathrm{MP}_{2,5} / \mathrm{MP}_{10}$ nesses dias foram iguais a 61,$47 ; 66,50$ e $63,71 \%$. Em contrapartida, nos dias 02 de julho e 03 de novembro apenas o $\mathrm{MP}_{10}$ ultrapassou o limite, sendo as respectivas concentrações e relações $\mathrm{MP}_{2,5} / \mathrm{MP}_{10}$ iguais a 64,2 e $62,8 \mu \mathrm{g} / \mathrm{m}^{3} ; 37,25$ e $28,19 \%$. 


\subsection{Comparação entre PEM e ADR-1500}

Será feito aqui uma comparação dos resultados obtidos através do PEM e do ADR-1500 para a concentração de material particulado inalável grosso. Este tópico antecede uma apresentação mais abrangente dos dados do ADR e se restringe apenas aos valores fornecidos por este nos dias em que o PEM também estava funcionando, uma vez que apenas estes dados são passíveis de comparação.

Como já foi abordado nas páginas anteriores, estes dois aparelhos possuem métodos diferentes para medir a concentração de material particulado atmosférico; o PEM utiliza o tradicional e confiável método gravimétrico, o ADR funciona através da fotometria por espalhamento de luz. Além disso, a "natureza" do resultado fornecido por esses dois equipamentos é diferente. A concentração do PEM é obtida através de um cálculo simples, porém manual, e representa a média obtida durante o período de funcionamento. O ADR, por outro lado, calcula automaticamente as concentrações de MP e fornece a cada minuto um novo valor.

Para possibilitar a comparação dos resultados foi necessário encontrar a concentração média de $\mathrm{MP}_{10}$ para o ADR. Isso foi feito por meio da soma das concentrações fornecidas a cada minuto pelo ADR, durante o período em que o PEM estava em funcionamento, e posterior divisão por 480 (número de concentrações registradas pelo ADR durante as oito horas de funcionamento do PEM). Não foi possível obter a relação entre PEM e ADR no dia 03 de setembro, pois o ADR parou de funcionar, provavelmente devido a uma queda de energia.

A Tabela 8 contem as médias para o $\mathrm{MP}_{10}$, encontradas através do PEM e do ADR, bem como a relação entre as mesmas. Todos os valores obtidos através do PEM foram superiores aos encontrados com o ADR, e em alguns dias a relação entre a concentração obtida através do PEM e a concentração obtida através do ADR (PEM/ADR) foi maior que quatro. Em 11 dos 21 dias comparados (52\% dos casos), os resultados do PEM foram no mínimo três vezes maiores que os obtidos pelo ADR; considerando os dias em que a relação (PEM/ADR) foi no mínimo maior que dois, esse número sobe para 18 dos 21 dias comparados, o que corresponde a aproximadamente $86 \%$ dos casos. 
Tabela 8. Concentrações de $\mathrm{MP}_{10}$ obtidas através do PEM e ADR e a relação entre as mesmas.

\begin{tabular}{|c|c|c|c|}
\hline Dia & PEM (MP $_{\mathbf{1 0}}$ ) & ADR (MP $_{\mathbf{1 0}}$ ) & PEM/ADR \\
\hline 16/junho & 47,9 & 12,2 & 3,93 \\
\hline 24/junho & 43,8 & 13,2 & 3,32 \\
\hline 27/junho & 58,2 & 24 & 2,43 \\
\hline 02/julho & 64,2 & 13,1 & 4,90 \\
\hline 04/julho & 79,4 & 18,9 & 4,20 \\
\hline 23/julho & 47,4 & 14,1 & 3,36 \\
\hline 24/julho & 34,5 & 14,9 & 2,32 \\
\hline 07/agosto & 47,6 & 15 & 3,17 \\
\hline 08/agosto & 49,5 & 21,5 & 2,30 \\
\hline 19/agosto & 24 & 14 & 1,71 \\
\hline 21/agosto & 48,5 & 18,8 & 2,58 \\
\hline 03/setembro & 23,2 & - & - \\
\hline 08/setembro & 47,7 & 22,4 & 2,13 \\
\hline 10/setembro & 73,7 & 47,6 & 1,55 \\
\hline 22/setembro & 28,3 & 11,8 & 2,40 \\
\hline 26/setembro & 39,3 & 25,4 & 1,55 \\
\hline 06/outubro & 52,9 & 15,4 & 3,44 \\
\hline 09/outubro & 72,4 & 16,8 & 4,31 \\
\hline 20/outubro & 48,1 & 19,1 & 2,52 \\
\hline 21/outubro & 48,1 & 10,5 & 4,58 \\
\hline 03/novembro & 62,8 & 8,3 & 7,57 \\
\hline 06/novembro & 31,9 & 7,5 & 4,25 \\
\hline Média & $\mathbf{4 8 , 8}$ & $\mathbf{1 7 , 4}$ & $\mathbf{3 , 2 6}$ \\
\hline \hline
\end{tabular}

Mesmo os três menores resultados obtidos para essa razão, a saber: 1,$55 ; 1,55$ novamente e 1,71; já evidenciam uma diferença mais do que significativa entre os dados obtidos por esses dois equipamentos. Essa constatação é corroborada pela média calculada para as razões (PEM/ADR) igual a 3,26, o que significa que os resultados obtidos pelo método gravimétrico foram, em média, três vezes maiores que os obtidos através da fotometria. Considerando todos esses valores, a conclusão é inexorável: a discrepância entre os resultados é muito grande, e, com certeza, um destes métodos está errado. 
O método reconhecido como mais correto e que fornece os resultados mais confiáveis, como já dito anteriormente, é o gravimétrico, do qual faz uso o PEM. Portanto assumir-se-á aqui que os resultados "incompatíveis" com os reais valores de $\mathrm{MP}_{10}$ na área de estudo, foram os obtidos através do ADR.

Rotiroti (2013), utilizando não só os mesmos modelos, mas literalmente os mesmos equipamentos deste estudo, também observou maiores valores para a concentração de $\mathrm{MP}_{10}$ com o PEM, se comparados aos números obtidos por equipamentos de medição não gravimétricos, sendo um destes o ADR-1500. A média obtida por ele para a razão PEM/ADR foi igual a 4,17, seu estudo, entretanto, foi realizado em ambientes externos e internos.

Os erros de mensuração pelo ADR podem advir de vários fatores, como a posição em que uma partícula de esfericidade pequena adentra o feixe de luz, de modo que o diâmetro calculado através do espalhamento de luz seja menor ou maior que o diâmetro real da partícula. Entretanto como os valores calculados foram consideravelmente menores é de se supor que estes erros não estão se "neutralizando", ou seja, a medição de um diâmetro menor que o real está prevalecendo sobre a medição de um diâmetro maior, o que ocasiona uma sub-avaliação da massa de MP ao calcular um volume menor que o real através do valor inferior do diâmetro. Considerando uma posição simplificada do feixe de luz, e a partícula passando ao centro do feixe e uma rotação de $360^{\circ}$ ao longo de seu centro de massa, supondo este coincidir com o centro geométrico, é fácil verificar que na maior parte dos casos o valor calculado será menor que o real (o valor será igual ao real apenas quando o ângulo entre a partícula e o feixe for igual a $90^{\circ}$ ).

Também pode ocorrer um erro devido às partículas que não são computadas ao passarem pela "sombra" de outras partículas que entram no mesmo momento no feixe de luz. Outro possível erro pode ser a densidade média que é atribuída às partículas, a qual pode estar abaixo da real densidade média do MP, parâmetro que necessitaria de equipamentos muito sofisticados para fazer apenas uma estimativa do mesmo, uma vez que seria necessário o conhecimento do número de partículas envolvidas na concentração de MP. No ADR a mesma densidade é atribuída a todas as partículas detectadas através do espalhamento da luz, entretanto, as partículas são de composições variadas, pois podem ser compostas por diversos elementos químicos diferentes, o que faz com que a densidade varie muito de uma partícula sólida componente do MP para outra. 
Rotirotti (2013), como já mencionado anteriormente, encontrou o valor de correção para $\mathrm{PEM} / \mathrm{ADR}$, igual a 4,17, para o $\mathrm{MP}_{10}$, já para $\mathrm{o} \mathrm{MP}_{2,5}$, o valor de correção foi igual a 2,73. Os respectivos desvios padrão também foram menores para o $\mathrm{MP}_{2,5} \mathrm{em}$ relação ao $\mathrm{MP}_{10}$. Considerando que as medidas efetuadas pelo método gravimétrico através da utilização do PEM são as corretas, podemos afirmar que o "erro" diminui à medida que a fração comparada de MP diminui e com base nisso inferir que uma parcela do "erro" nas concentrações obtidas pelo ADR está relacionada com a dimensão e consequente massa que é atribuída ao MP, em função de uma densidade fixa previamente definida pelo equipamento, o que corrobora algumas das hipóteses que foram levantadas sobre esses possíveis erros.

\subsection{ADR-1500}

A fim de encontrar a concentração média diária de $\mathrm{MP}_{10}$ através dos valores obtidos com o ADR, lançou-se mão do mesmo processo utilizado para comparar as concentrações obtidas por este equipamento e as obtidas pelo PEM; a única diferença é que neste caso o tempo considerado passou a ser de 24 e não 8 horas. Logo, a média foi calculada por meio da soma das concentrações fornecidas a cada minuto pelo ADR, durante o período de 24 horas, e a divisão do valor obtido por 1.440, que é o número de minutos e consequentemente de concentrações registradas pelo ADR durante o período de um dia.

Como visto anteriormente, os resultados obtidos através do ADR foram os considerados "incompatíveis" com os reais valores de $\mathrm{MP}_{10}$ na área de estudo e os valores obtidos através do PEM como os mais corretos. Além disso, a média calculada para as razões entre os valores obtidos através do PEM e do ADR (PEM/ADR) foi igual a 3,26; portanto, para possibilitar a comparação das concentrações diárias obtidas através do ADR com a legislação vigente, estas foram multiplicadas por essa média.

A Tabela 9 apresenta os valores obtidos através do ADR durante o período em que este permaneceu ligado. Os valores já estão multiplicados por 3,26; número esse que pode ser considerado um fator médio de correção para os valores obtidos através deste equipamento, que utiliza o método da fotometria. 
Tabela 9. Concentrações de $\mathrm{MP}_{10}$ medidas através do ADR-1500 e suas respectivas datas.

\begin{tabular}{|c|c|c|c|c|c|c|c|}
\hline Dia & $\begin{array}{c}\text { Concentração } \\
\left(\mu \mathrm{g} / \mathrm{m}^{3}\right)\end{array}$ & Dia & $\begin{array}{c}\text { Concentração } \\
\left(\mu \mathrm{g} / \mathrm{m}^{3}\right)\end{array}$ & Dia & $\begin{array}{c}\text { Concentração } \\
\left(\mu \mathrm{g} / \mathrm{m}^{3}\right)\end{array}$ & Dia & $\begin{array}{c}\text { Concentração } \\
\left(\mu \mathrm{g} / \mathrm{m}^{3}\right)\end{array}$ \\
\hline 05/junho & 32,6 & 15/julho & 41,9 & 24/agosto & 84,3 & 03/outubro & 50,0 \\
\hline 06/junho & 34,9 & 16/julho & 41,7 & 25/agosto & 152,2 & 04/outubro & 43,0 \\
\hline 07/junho & 38,2 & 17/julho & 48,1 & 26/agosto & 211,6 & 05/outubro & 52,0 \\
\hline 08/junho & 38,7 & 18/julho & 33,1 & 27/agosto & 78,4 & 06/outubro & 57,5 \\
\hline 09/junho & 67,7 & 19/julho & 42,3 & 28/agosto & 95,5 & 07/outubro & 68,0 \\
\hline 10/junho & 56,3 & 20/julho & 75,7 & 29/agosto & 119,4 & 08/outubro & 70,4 \\
\hline 11/junho & 36,0 & 21/julho & 80,7 & 30/agosto & 117,7 & 09/outubro & 47,0 \\
\hline 12/junho & 34,5 & 22/julho & 62,6 & 31/agosto & 101,5 & 10/outubro & 80,6 \\
\hline 13/junho & 36,8 & 23/julho & 54,2 & 01/setembro & 49,1 & 11/outubro & 84,0 \\
\hline 14/junho & 39,3 & 24/julho & 57,6 & 02/setembro & 72,2 & 12/outubro & 53,8 \\
\hline 15/junho & 46,0 & 25/julho & 28,9 & 03/setembro & 29,2 & 13/outubro & 65,6 \\
\hline 16/junho & 66,7 & 26/julho & 51,3 & 04/setembro & 35,2 & 14/outubro & 76,7 \\
\hline 17/junho & 56,5 & 27/julho & 68,1 & 05/setembro & 37,2 & 15/outubro & $* 2$ \\
\hline 18/junho & 57,8 & 28/julho & 38,6 & 06/setembro & 49,9 & 16/outubro & $* 2$ \\
\hline 19/junho & 42,7 & 29/julho & 31,4 & 07/setembro & 56,2 & 17/outubro & $* 2$ \\
\hline 20/junho & 61,3 & 30/julho & 24,6 & 08/setembro & 82,5 & 18/outubro & $* 2$ \\
\hline 21/junho & 89,0 & 31/julho & 32,7 & 09/setembro & 52,5 & 19/outubro & $* 2$ \\
\hline 22/junho & 68,7 & 01/agosto & 37,1 & 10/setembro & 100,9 & 20/outubro & 63,1 \\
\hline 23/junho & 33,0 & 02/agosto & 53,9 & 11/setembro & 86,9 & 21/outubro & 52,5 \\
\hline 24/junho & 59,1 & 03/agosto & 72,0 & 12/setembro & 98,2 & 22/outubro & 99,0 \\
\hline 25/junho & 76,6 & 04/agosto & 59,9 & 13/setembro & 122,3 & 23/outubro & 55,0 \\
\hline 26/junho & 65,7 & 05/agosto & 61,8 & 14/setembro & $* 1$ & 24/outubro & 89,8 \\
\hline 27/junho & 78,2 & 06/agosto & 54,3 & $15 /$ setembro & $* 1$ & 25/outubro & 43,0 \\
\hline 28/junho & 68,8 & 07/agosto & 65,5 & 16/setembro & $* 1$ & 26/outubro & 30,7 \\
\hline 29/junho & 48,2 & 08/agosto & 105,3 & 17/setembro & $* 1$ & 27/outubro & 50,4 \\
\hline 30/junho & 41,1 & 09/agosto & 54,5 & $18 /$ setembro & $* 1$ & 28/outubro & $* 1$ \\
\hline 01/julho & 44,2 & 10/agosto & 57,3 & 19/setembro & $* 1$ & 29/outubro & 77,4 \\
\hline 02/julho & 55,6 & 11/agosto & 65,3 & 20/setembro & $* 1$ & 30/outubro & 56,9 \\
\hline 03/julho & 60,4 & 12/agosto & 77,5 & 21/setembro & $* 1$ & 31/outubro & 46,0 \\
\hline 04/julho & 72,5 & 13/agosto & 79,0 & 22/setembro & 49,4 & 01/novembro & 29,4 \\
\hline 05/julho & 47,4 & 14/agosto & 42,4 & 23/setembro & 56,1 & 02/novembro & 25,9 \\
\hline 06/julho & 51,5 & 15/agosto & 47,3 & $24 /$ setembro & 69,8 & 03/novembro & 26,8 \\
\hline 07/julho & 58,1 & 16/agosto & 52,3 & $25 /$ setembro & 46,1 & \begin{tabular}{|l|}
$04 /$ novembro \\
\end{tabular} & 16,2 \\
\hline 08/julho & 99,0 & 17/agosto & 105,9 & 26/setembro & 69,0 & 05/novembro & 11,5 \\
\hline 09/julho & 51,2 & 18/agosto & $* 1$ & 27/setembro & 65,7 & 06/novembro & 26,3 \\
\hline 10/julho & 27,8 & 19/agosto & 67,2 & 28/setembro & 82,4 & 07/novembro & 30,6 \\
\hline 11/julho & 36,2 & 20/agosto & 99,9 & 29/setembro & 70,6 & 08/novembro & 17,8 \\
\hline 12/julho & 31,2 & 21/agosto & 83,3 & $30 /$ setembro & 55,4 & 09/novembro & 43,7 \\
\hline 13/julho & 30,0 & 22/agosto & 84,7 & 01/outubro & 50,6 & \begin{tabular}{|l|}
$10 /$ novembro \\
\end{tabular} & 32,3 \\
\hline 14/julho & 36,4 & 23/agosto & 90,5 & 02/outubro & 51,5 & Média & 59,6 \\
\hline
\end{tabular}

\footnotetext{
*1 - ADR desligado $\quad * 2$ - ADR apresentou valores negativos
}

Em 88 dos 144 dias em que foi possível determinar as concentrações médias diárias de $\mathrm{MP}_{10}$ estas ficaram acima do valor máximo recomendado pela OMS, de $50 \mu \mathrm{g} / \mathrm{m}^{3}$, isso corresponde a aproximadamente $61 \%$ dos resultados obtidos, ou seja, 
mais da metade dos resultados estão em desconformidade com esse limite (Figuras 23, 24, 25, 26, 27 e 28). Fazendo coro a estes resultados ruins, do ponto de vista dos prováveis efeitos nocivos a saúde humana, a média geral das concentrações obtidas para esta fração de material particulado também ficou acima do limite, e foi igual a 59,6 $\mu \mathrm{g} / \mathrm{m}^{3}$, ou seja, quase $20 \%$ acima do valor de referência.

A maior concentração, observada no dia 25 de agosto, foi igual a 211,6 $\mu \mathrm{g} / \mathrm{m}^{3}$, mais de quatro vezes maior que o limite de $50 \mu \mathrm{g} / \mathrm{m}^{3}$, ou $323 \%$ acima deste. A segunda maior concentração, verificada no dia anterior, 24 de agosto, já significativamente menor que a primeira, foi de $152,2 \mu \mathrm{g} / \mathrm{m}^{3}$, valor $204 \%$ acima do limite. A terceira maior concentração foi verificada no dia 13 de setembro e igual a $122,4 \mu \mathrm{g} / \mathrm{m}^{3}$, seguida pelos valores de 119,5 e $117,7 \mu \mathrm{g} / \mathrm{m}^{3}$, obtidos respectivamente nos dias 29 e 30 de agosto. Mais quatro concentrações apresentaram resultados acima de $100 \mu \mathrm{g} / \mathrm{m}^{3}$, porém, todas relativamente menores que o quinto maior valor e muito próximas entre si.

Aproximadamente $70 \%$, ou 62 das 88 concentrações acima do limite, situaramse entre o intervalo de 50 a $80 \mu \mathrm{g} / \mathrm{m}^{3}$. Dos 26 resultados restantes e maiores que 50 $\mu \mathrm{g} / \mathrm{m}^{3}$, nove apresentaram valores acima de $100 \mu \mathrm{g} / \mathrm{m}^{3}$, como já mencionado antes, seis apresentaram concentrações entre 90 e $100 \mu \mathrm{g} / \mathrm{m}^{3}$ e outros onze dentro do intervalo de 80 a $90 \mu \mathrm{g} / \mathrm{m}^{3}$.

No mês de agosto de 2014, mês esse que é sempre líder no número de queimadas envolvidas na colheita de cana de açúcar dentre todos os meses do período em que tal prática é realizada, que vai de junho a outubro, em 26 dos 30 dias em que foi possível obter as concentrações médias de $\mathrm{MP}_{10}$, estas ficaram acima do limite recomendado pela OMS, sendo que quatro dos cinco maiores valores obtidos durante todo o período de monitoramento pelo ADR também foram observados em agosto; a saber, os três maiores e o quinto valor mais alto.

Os maiores valores obtidos para o $\mathrm{MP}_{10}$ através do PEM, foram de 79,4; 73,7 e $72,4 \mu \mathrm{g} / \mathrm{m}^{3}$, portanto muito inferiores aos obtidos pelo ADR, já multiplicados pelo fator de correção. O PEM, no entanto, efetuou coletas de material particulado durante 23 dias, dos quais foi possível obter 22 valores para o $\mathrm{MP}_{10}$, já o $\mathrm{ADR}$ teve um período de funcionamento de pouco mais de cinco meses e 144 valores de concentração para essa mesma fração de material particulado, portanto a probabilidade deste último encontrarse ligado em dias em que os níveis de $\mathrm{MP}_{10}$ atmosférico estavam elevados foi muito maior. O que pode explicar porque o ADR encontrou valores bem mais elevados. 
É de suma importância salientar que ao multiplicar os valores de $\mathrm{MP}_{10}$ obtidos com o ADR pelo fator de correção, igual a 3,26; as concentrações podem ter sido superestimadas. Supondo, por exemplo, que nos dias 24 e 25 de agosto, detentores das maiores concentrações obtidas, a relação PEM/ADR tenha sido igual a 1,55 (a menor encontrada dentre os dias em que ambos os equipamentos funcionaram) ao multiplicar o valor obtido pelo ADR por 3,26 tem-se:

$$
\begin{array}{cc}
\frac{[P E M]}{[A D R]}=1,55 & {[A D R]=\frac{[P E M]}{1,55}} \\
3,26 \times[A D R]=3,26 \times \frac{[P E M]}{1,55} & {[A D R]=2,1 \times[P E M]}
\end{array}
$$

Nesse caso específico, onde se supôs o valor do PEM 55\% maior que o obtido pelo ADR, já que neste dia apenas este último estava em operando, ao multiplicar-se o número encontrado pelo fator de correção, o resultado seria 2,1 vezes maior que o valor que seria fornecido pelo PEM, caso este estivesse ligado.

Prosseguindo, ao "corrigir-se" as concentrações obtidas nestes dias, dividindo-as por 2,1; lembrando que o valor fornecido pelo PEM é o considerado correto, obtêm-se a concentração de $72,5 \mu \mathrm{g} / \mathrm{m}^{3}$ para o dia 24 de outubro, e a de $100,8 \mu \mathrm{g} / \mathrm{m}^{3}$ para o dia 25 do mesmo mês. Ainda assim, estas concentrações estão acima do limite recomendado, sendo que uma delas ainda é maior que o maior valor encontrado pelo PEM e a outra está na faixa das maiores concentrações obtidas por este equipamento. Portanto, se mesmo supondo que a relação entre PEM/ADR nesses dois dias foi a menor (o que resulta na maior diminuição possível para os valores encontrados pelo ADR e multiplicados por 3,26 ), os valores corrigidos ainda foram elevados, conclui-se que estes dias apresentaram de fato concentrações elevadas de $\mathrm{MP}_{10}$.

Supondo também que a relação PEM/ADR tenha sido igual a 2,32 para estes mesmos dias, 24 e 25 de agosto, o resultado seria $40 \%$ maior que o valor seria fornecido pelo PEM, caso este estivesse ligado. As concentrações corrigidas seriam iguais a 150,6 $\mu \mathrm{g} / \mathrm{m}^{3}$ para o dia 25 e $108,3 \mu \mathrm{g} / \mathrm{m}^{3}$ para o dia anterior, relativamente maiores que no exemplo anterior.

A menor concentração, de $11,5 \mu \mathrm{g} / \mathrm{m}^{3}$, foi observada no dia 05 de novembro, o qual apresentou uma precipitação igual a $58 \mathrm{~mm}$, sendo que no dia anterior foi 
registrada a maior precipitação durante o período de monitoramento com o ADR, 184 $\mathrm{mm}$, e também a segunda menor concentração, igual a $16,2 \mu \mathrm{g} / \mathrm{m}^{3}$.

O terceiro menor valor para o $\mathrm{MP}_{10}\left(17,8 \mu \mathrm{g} / \mathrm{m}^{3}\right)$ foi encontrado no dia $08 \mathrm{de}$ novembro dia em que ocorreu, coincidentemente, também a terceira maior precipitação, de $117 \mathrm{~mm}$. A quarta menor concentração, igual a $31,9 \mu \mathrm{g} / \mathrm{m}^{3}$ foi observada no dia 30 de julho, o qual não apresentou chuva na ocasião e nem dias anteriores próximos. Por fim temos as quinta e sexta menores concentrações, 25,9 (02 de novembro) e $26,3 \mu \mathrm{g} / \mathrm{m}^{3}$ (06 de novembro), com uma precipitação de $67 \mathrm{~mm}$ no dia em que foi obtida a primeira concentração e $10 \mathrm{~mm}$ na segunda, entretanto com relação a esta última, já havia chovido 58 e $184 \mathrm{~mm}$ nos dois dias anteriores.

A concentração média de material particulado grosso obtida através do ADR para dias sem chuva foi igual a $62 \mu \mathrm{g} / \mathrm{m}^{3}, 24 \%$ acima do limite de $50 \mu \mathrm{g} / \mathrm{m}^{3}$ recomendado pela OMS, e maior, mas muito próximo, da média geral, que foi de 59, 6 $\mu \mathrm{g} / \mathrm{m}^{3}$. Em relação ao valor encontrado com o PEM para essa fração de MP em dias sem chuva, igual a $55,8 \mu \mathrm{g} / \mathrm{m}^{3}$, o resultado produzido através do método fotométrico foi $11 \%$ superior.

Já a concentração média de $\mathrm{MP}_{10}$ obtida para dias chuvosos foi igual a 47,3 $\mu \mathrm{g} / \mathrm{m}^{3}$, aproximadamente $24 \%$ menor que a média para dias sem chuva, porém, muito próximo ao limite recomendado pela OMS para essa fração de material particulado, e bem superior ao valor encontrado através do PEM para o $\mathrm{MP}_{10}$ em dias de chuva, que foi de $31,4 \mu \mathrm{g} / \mathrm{m}^{3}$, o que representa uma diferença de $50 \%$.

A média geral, assim como observado para os valores encontrados através do $\mathrm{PEM}$, ficou próxima à média obtida para os dias sem chuva, pois dentre os 144 dias em que foi possível determinar as concentrações médias de $\mathrm{MP}_{10}$ através do ADR, houve precipitação em 23 destes (desconsiderando duas precipitações com valores diários de apenas $1 \mathrm{~mm}$, já que as mesmas não influenciaram na redução de MP), ou seja, houve precipitações significativas em apenas $16 \%$ dos 144 dias.

Pôde-se constatar novamente, que, de uma maneira geral, não só os menores valores foram obtidos em dias de chuva, mas que também quanto maior a precipitação menor a concentração obtida. 


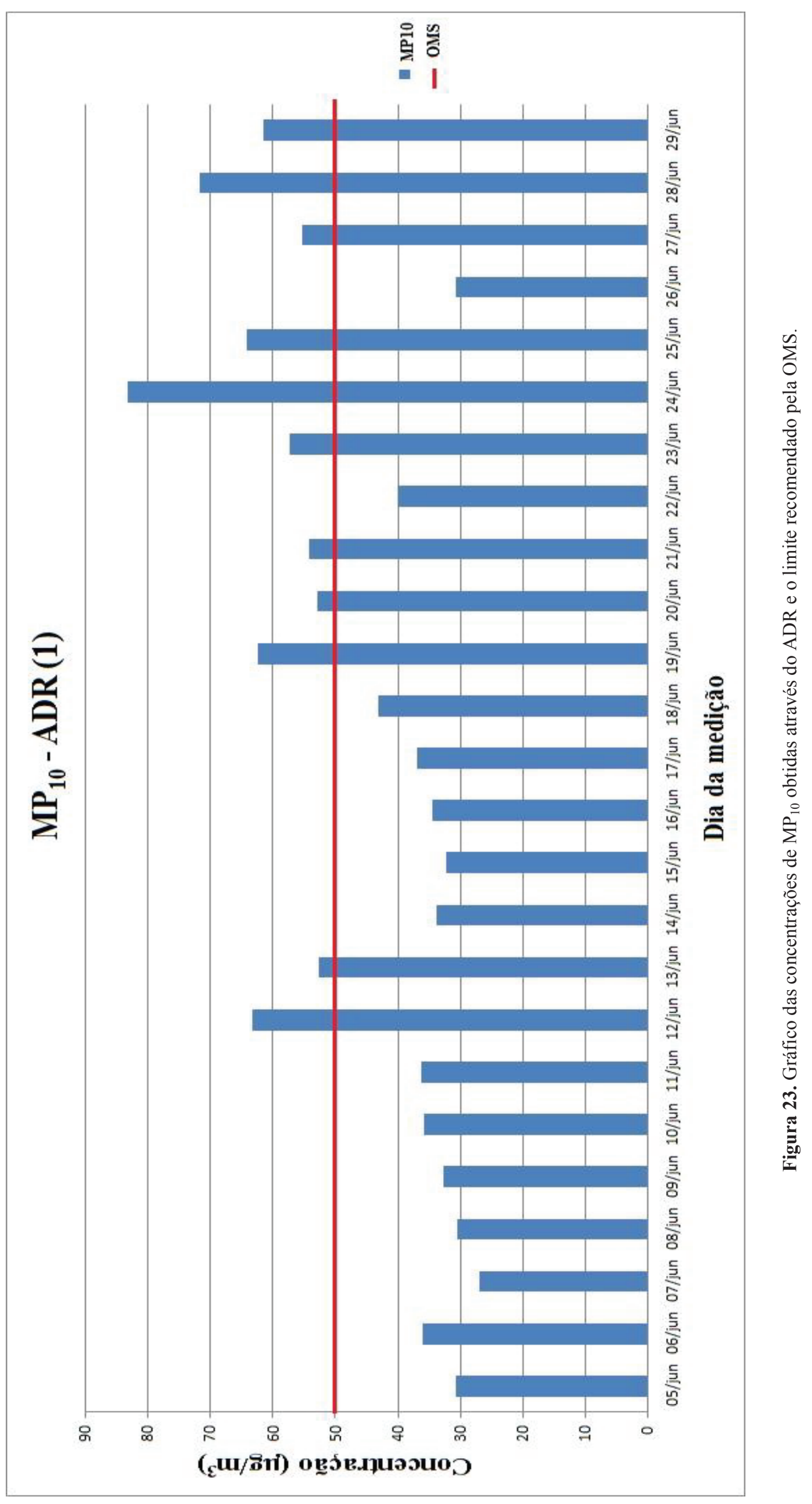




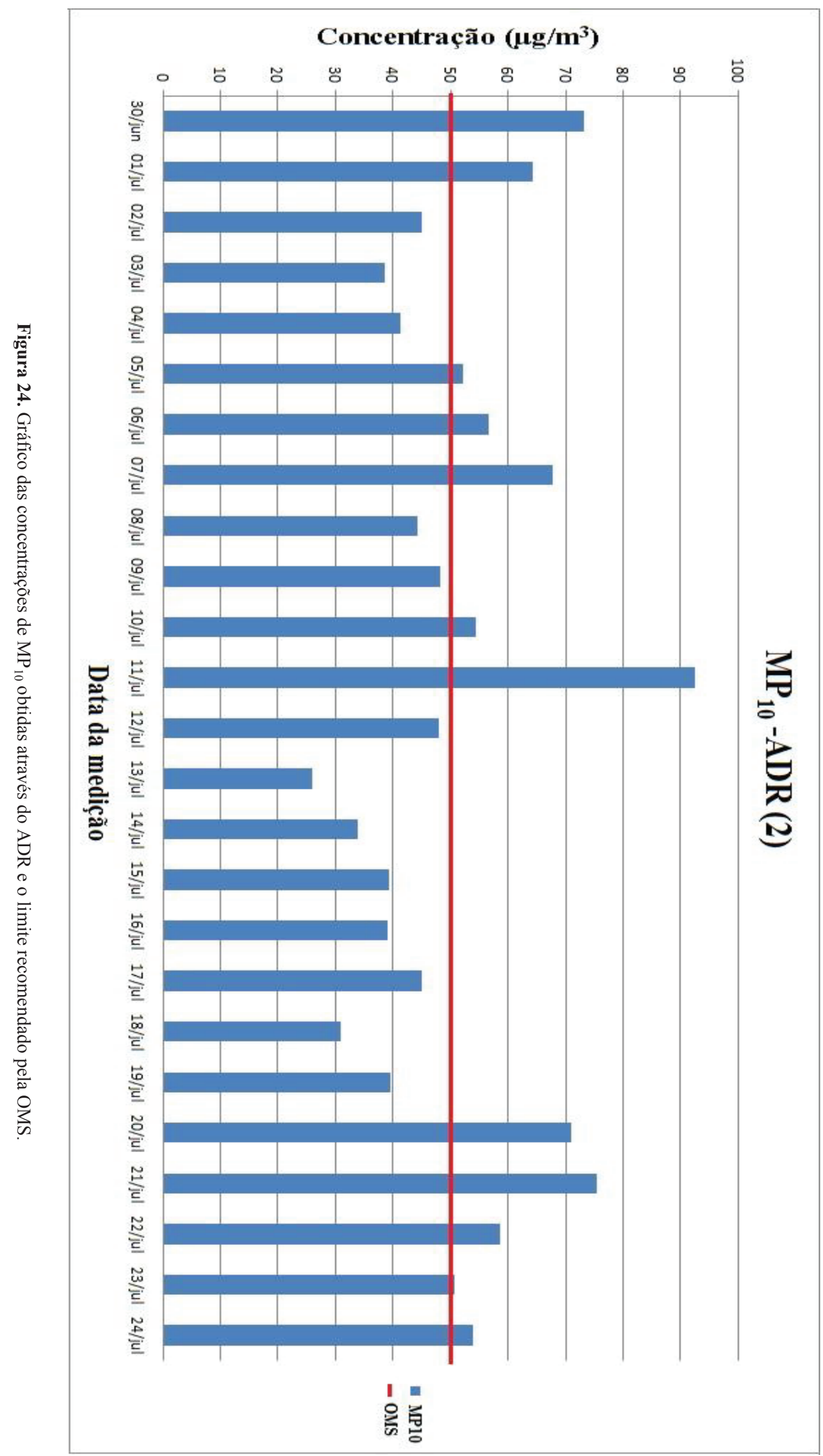




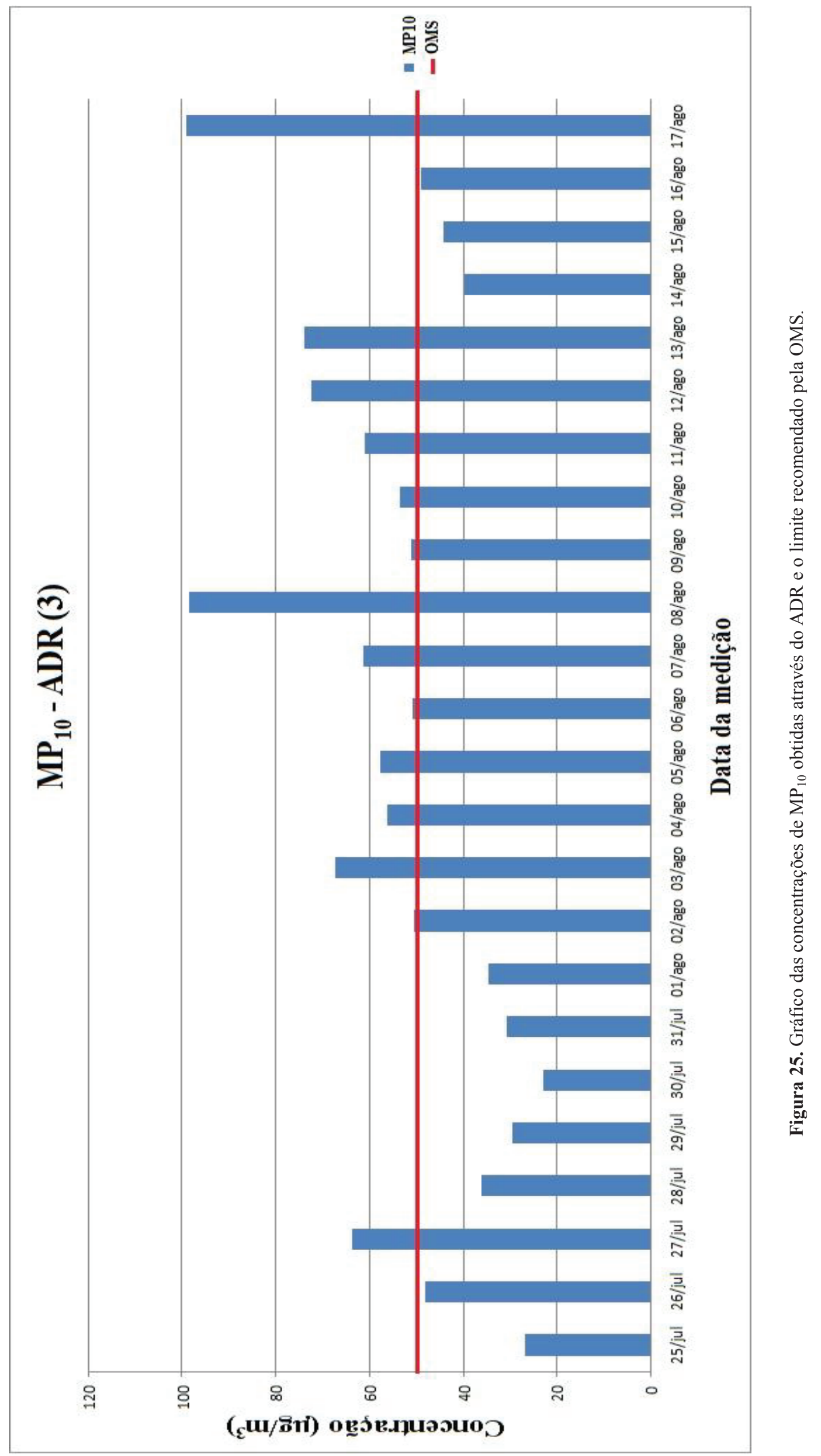




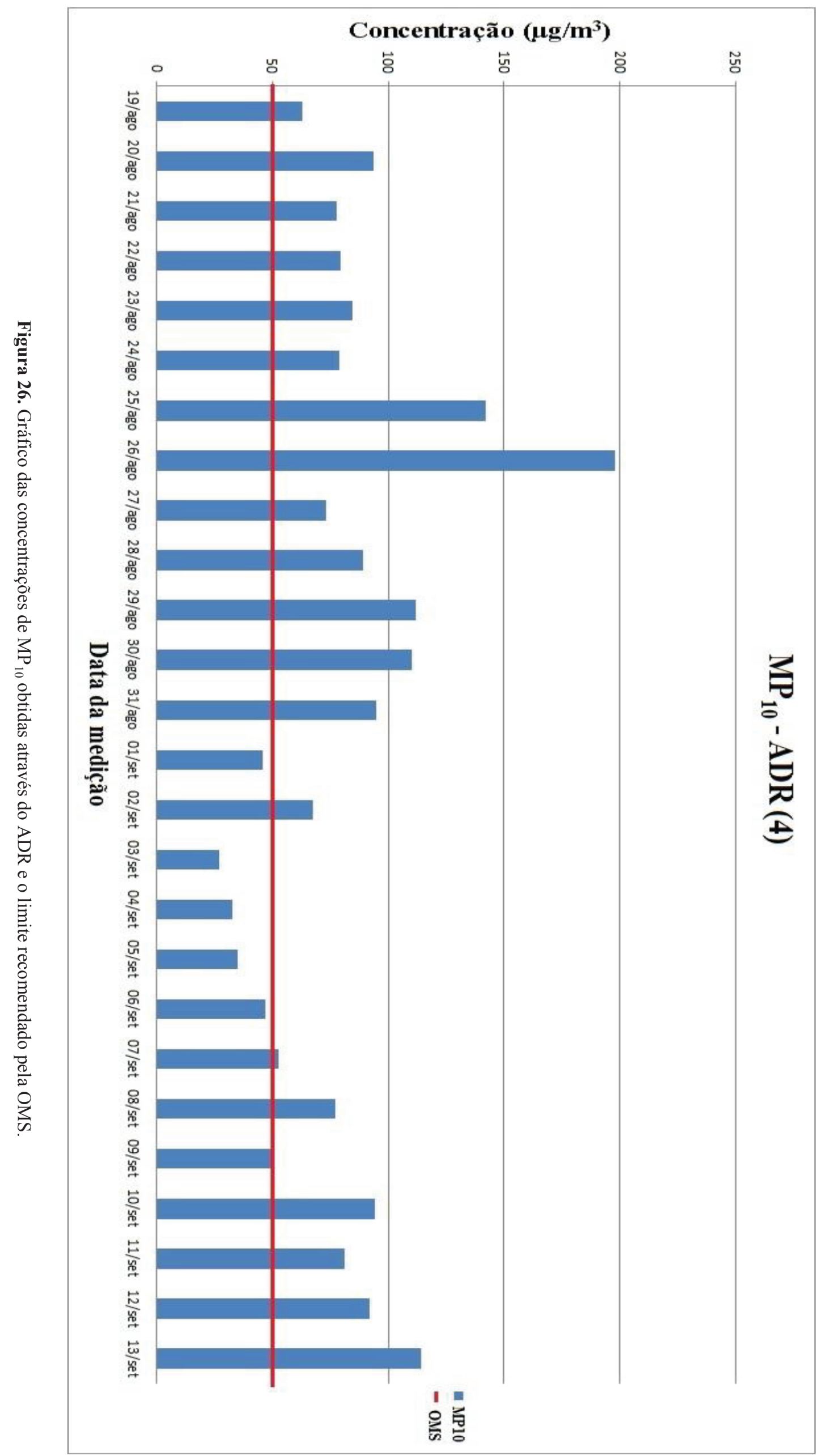




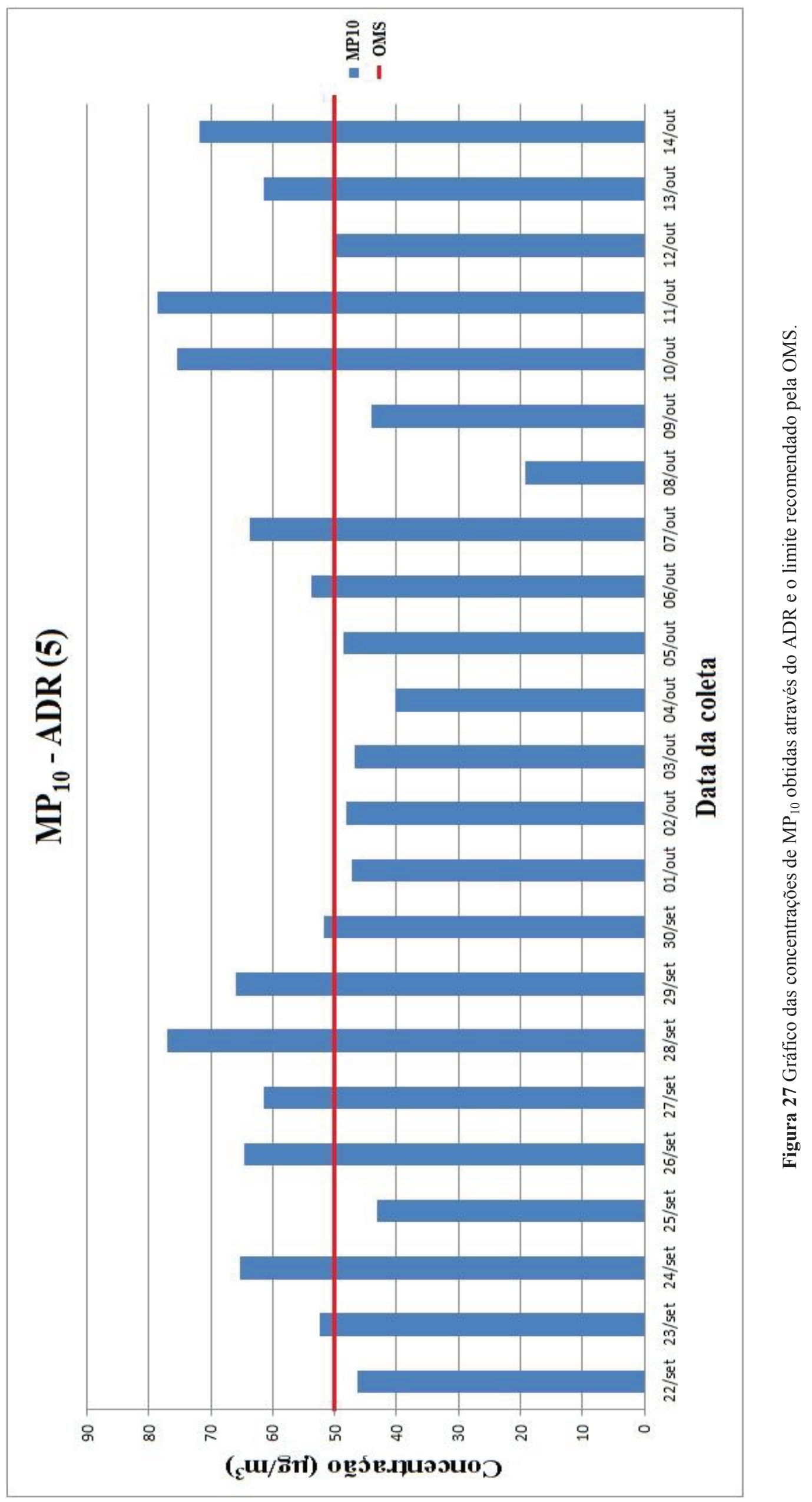




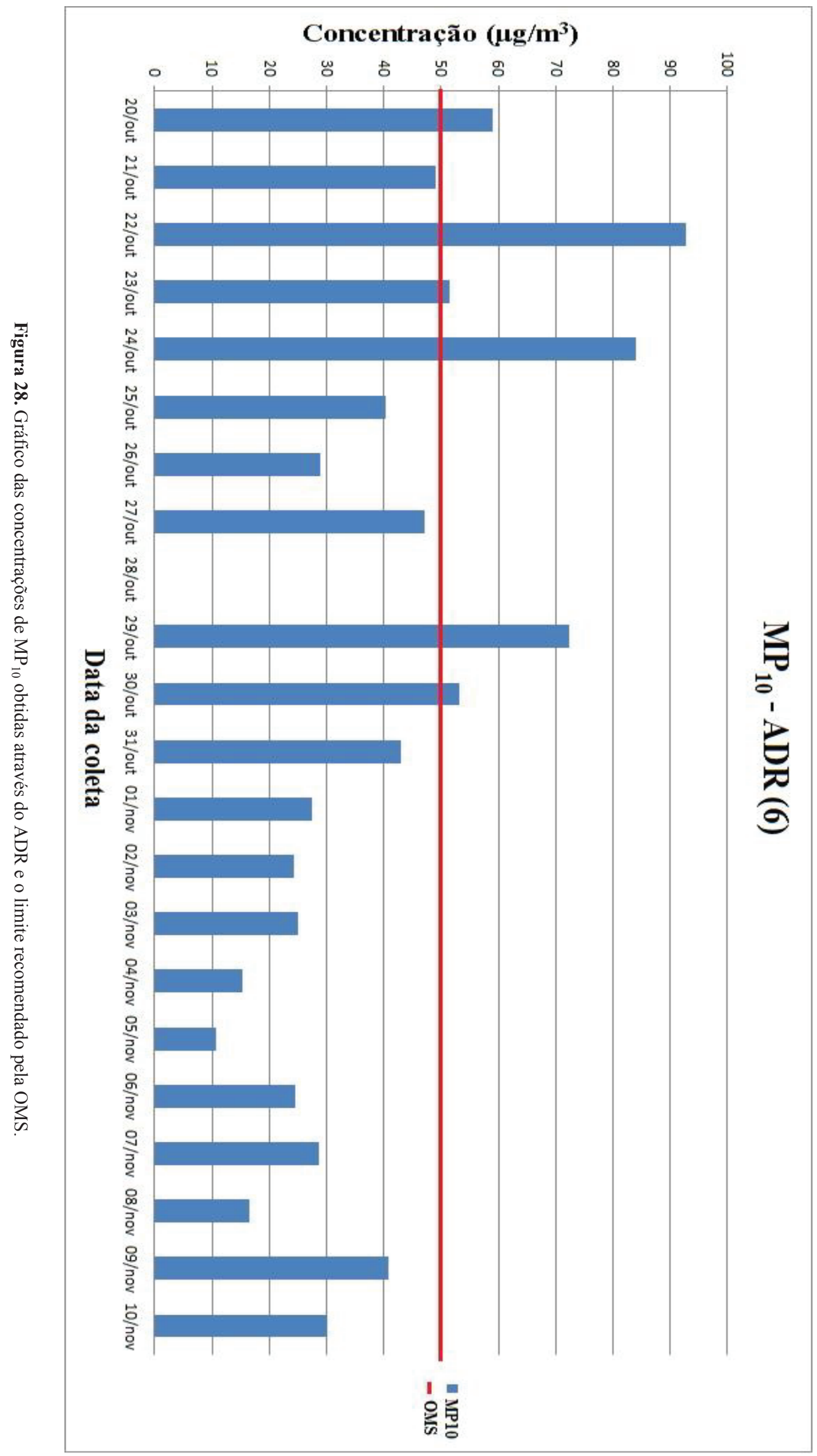




\subsection{Influência das precipitações sobre a concentração de material particulado}

Sendo $\mathrm{K}$ a concentração, em $\mu \mathrm{g} / \mathrm{m}^{3}$, de $\mathrm{MP}_{10}$, esse parâmetro representa a massa total que seria obtida caso fosse possível pesar separadamente todas as partículas suspensas com diâmetro aerodinâmico menor que $10 \mu \mathrm{m}$ em um volume de $1 \mathrm{~m}^{3}$ de ar. Portanto, a concentração de material particulado está relacionada com o número dessas partículas em certo volume de ar.

Quando ocorre uma precipitação, a probabilidade de uma gota de chuva interceptar uma dessas partículas antes de atingir o solo está relacionada com a quantidade de material particulado na atmosfera; quanto maior a quantidade dessas partículas em um determinado volume de ar, ou seja, quanto maior a concentração de $\mathrm{MP}_{10}$, maior será a probabilidade de uma gota de chuva "se chocar" com uma dessas partículas.

Assim que a precipitação começa, o material particulado passa a ser interceptado por uma parcela das gotas de chuva, sendo removido da atmosfera. Com a diminuição no número de partículas suspensas e consequentemente na concentração de material particulado, a probabilidade das próximas gotas se chocarem com uma das partículas que ainda estão em suspensão na atmosfera diminui, e à medida que mais partículas são removidas essa probabilidade fica cada vez menor, resultando em um número menor de interceptações e menor remoção de MP.

Pode-se dizer que a taxa de variação da concentração de $\mathrm{MP}_{10}$ em relação ao tempo $(\mathrm{dK} / \mathrm{dt})$ é diretamente proporcional ao valor negativo da concentração de material particulado (1), pois a concentração diminui ao longo do tempo. Essa relação de proporcionalidade pode ser transformada em uma equação inserindo-se uma constante de igualdade $\gamma$ (2). Essa constante por sua vez é diretamente proporcional à intensidade média da precipitação, que é o valor precipitado dividido pelo intervalo de tempo de duração da chuva $(\mathrm{P} / \Delta \mathrm{t})$. Essa relação de proporcionalidade (3) também pode ser transformada em uma equação inserindo-se outra constante de igualdade $\alpha$ (4).

(1) $\frac{d K}{d t} \propto-K$

$$
\frac{d K}{d t}=-\gamma K
$$



(3) $\gamma \propto \frac{P}{\Delta t}$
(4) $\gamma=\alpha \frac{P}{\Delta t}$

Substituindo (4) em (2) tem-se uma EDO (Equação Diferencial Ordinária) de $1^{\underline{a}}$ ordem (5). Integrando essa equação e aplicando os respectivos limites de integração, onde Ko é a concentração inicial de material particulado no tempo $t=0$, obtêm-se uma função (6) que fornece a concentração de material particulado em função do tempo.

$$
\begin{aligned}
& \text { (5) } \frac{d K}{d t}=-\alpha \frac{P}{\Delta t} K \\
& \int \frac{1}{K} d K=\int-\alpha \frac{P}{\Delta t} d t \\
& \int \frac{1}{K} d K=-\alpha \frac{P}{\Delta t} \int d t \\
& \int_{K o}^{K} \frac{1}{K} d K=-\alpha \frac{P}{\Delta t} \int_{0}^{t} d t \\
& {[\ln K]_{K o}^{K}=\left[-\alpha \frac{P}{\Delta t} t\right]_{0}^{t}} \\
& {[\ln K]-[\ln K o]=-\alpha \frac{P}{\Delta t} t} \\
& \ln \frac{K}{K o}=-\alpha \frac{P}{\Delta t} t \\
& e^{-\alpha \frac{P}{\Delta t} t}=\frac{K}{K o} \\
& \text { (6) } K=\text { Ko. } e^{-\alpha \frac{P}{\Delta t} t}
\end{aligned}
$$


Os valores da concentração inicial (Ko) e da intensidade média da precipitação $(\mathrm{P} / \Delta \mathrm{t})$ são constantes intrínsecas a cada ocorrência de chuva. Falta, portanto, determinar a constante $\alpha$, a qual está relacionada à equação e não aos episódios de chuva, e que representa numericamente qual a proporcionalidade entre a taxa de variação da concentração de material particulado em função do tempo e o produto da concentração de MP pela intensidade média da precipitação (5).

\section{5 a) Determinação de $\alpha$}

Para a determinação desta constante, os valores fornecidos pelo ADR para a concentração de MP, nos horários em que ocorreram as precipitações, foram transformados em gráficos através de um programa de planilhas eletrônicas, considerando a concentração inicial de MP aquela a partir da qual os valores começavam a diminuir em função do tempo. Após a inserção do gráfico era selecionado no programa a ferramenta para adicionar uma linha de tendência aos valores plotados, sendo escolhida a linha de tendência do tipo exponencial e a exibição de seu respectivo coeficiente de determinação $\left(\mathrm{R}^{2}\right)$.

As funções exibidas pelo

Excel para as linhas de tendência são do tipo:

$$
y=M \cdot e^{-\beta x}
$$

Onde:

$\mathrm{y}$ - valor da concentração em um instante $\mathrm{x}$

$\mathrm{x}$ - tempo em minutos

$\mathrm{M}$ - valor igual ou próximo à concentração inicial no tempo $\mathrm{x}=1$ minuto

$\beta$ - Valor numérico

Portanto a estrutura da função exponencial que descreve a linha de tendência é a mesma da função obtida analiticamente através da resolução da EDO de $1^{\mathrm{a}}$ ordem (6). A diferença reside no fato de que o tempo inicial considerado pelo Excel é $\mathrm{t}=1$ e não $\mathrm{t}=0$, que foi o limite de integração inferior utilizado anteriormente na resolução da EDO e que além de ser o mais comumente utilizado para a escala de tempo também é o mais 
coerente com a descrição do fenômeno, pois o tempo inicial nesse caso quando começa a precipitação é 0 . Isso ocorre porque o primeiro valor fornecido é associado pelo Excel como sendo da célula 1 , ou seja atribuída ao $\mathrm{x}=1$. Chamando a escala de tempo do Excel de $t_{1}$ e a do tempo da função analítica de $t_{2}$, tem-se que:

$$
\text { (7) } \quad t_{1}=t_{2}+1
$$

Fazendo $\mathrm{y}=\mathrm{K}$, a função da linha de tendência pode ser escrita da seguinte forma:

$$
\text { (8) } \quad K=M \cdot e^{-\beta t_{1}}
$$

Substituindo (7) em (8) tem-se:

$$
\begin{gathered}
K=M \cdot e^{-\beta\left(t_{2}+1\right)} \\
K=M \cdot e^{-\beta t_{2}-\beta} \\
\text { (9) } K=\frac{M}{e^{\beta}} e^{-\beta t_{2}}
\end{gathered}
$$

Onde $M / \mathrm{e}^{\beta}$ é a concentração no tempo $\mathrm{t}_{2}=0$, o mesmo valor que seria obtido em (8) para $t_{1}=1$. Portanto temos a mesma função, porém expressa na mesma escala de tempo da EDO que foi deduzida. Ou seja, embora com escalas de tempo diferentes, a constante exponencial é a mesma.

Como $M / e^{\beta}$ é a concentração inicial Ko, e chamando $t_{2}$ apenas de $t$, tem-se:

$$
\text { (10) } K=K o \cdot e^{-\beta t_{2}}
$$

Igualando (10) a (6), obtêm-se:

$$
\begin{aligned}
\text { Ko. } e^{-\alpha \frac{P}{\Delta t} t} & =\text { Ko. } e^{-\beta t} \\
e^{-\alpha \frac{P}{\Delta t}} & =e^{-\beta}
\end{aligned}
$$




$$
\begin{gathered}
\alpha \frac{P}{\Delta t}=\beta \\
\text { (11) } \alpha=\beta / \frac{P}{\Delta t}
\end{gathered}
$$

O valor $\beta$, como já foi dito, é fornecido pelo Excel, e a intensidade média da precipitação pode ser calculada, desse modo, obtêm-se o valor de $\alpha$ através da equação (11).

Fazendo uso da equação 11, o valor de $\alpha$ foi determinado para todas as precipitações em que houve redução na concentração de material particulado inalável grosso. A Tabela 10 apresenta essas precipitações, o valor inicial da concentração de $\mathrm{MP}_{10}$ antes da precipitação, o valor final, a eficiência, em porcentagem, na "remoção" do $\mathrm{MP}_{10}$ atmosférico, o valor precipitado, o horário de inicio e término da chuva, o valor do coeficiente de determinação e o valor de $\alpha$. 
Tabela 10. Precipitações que influenciaram na concentração de MP e informações relacionadas a estas.

\begin{tabular}{|c|c|c|c|c|c|c|c|}
\hline Dia & Hora & $\begin{array}{l}\text { Valor } \\
(\mathrm{mm})\end{array}$ & $\begin{array}{c}\text { Valor antes } \\
\left(\mu \mathrm{g} / \mathrm{m}^{3}\right)\end{array}$ & $\begin{array}{c}\text { Valor depois } \\
\left(\mu \mathrm{g} / \mathrm{m}^{3}\right)\end{array}$ & $\begin{array}{l}\text { Eficiência na } \\
\text { remoção (\%) }\end{array}$ & $\alpha$ & $\mathbf{R}^{2}$ \\
\hline 09/julho & $8: 12-8: 30 h$ & 1 & 27,21 & 18,24 & 32,97 & 0,5040 & 0,9489 \\
\hline 24/julho & $13: 07-15: 30 h$ & 37 & 34,49 & 6,16 & 82,14 & 0,0535 & 0,9259 \\
\hline 24/julho & $20: 00-21: 30 \mathrm{~h}$ & 8 & 10,54 & 6,65 & 36,91 & 0,0675 & 0,7878 \\
\hline 24-25/julho & $23: 50-01: 30 \mathrm{~h}$ & 14 & 7,08 & 0,51 & 93,78 & 0,2164 & 0,8783 \\
\hline 26/julho & $23: 00-23: 30 \mathrm{~h}$ & 1 & 26,2 & 19,42 & 25,88 & 0,33 & 0,8579 \\
\hline 01/setembro & $06: 30-07: 00 \mathrm{~h}$ & 1 & 18,27 & 15,34 & 16,04 & 0,208 & 0,7967 \\
\hline 01/setembro & 09:06-10:00h & 5 & 19,61 & 11,97 & 38,96 & 0,0972 & 0,8439 \\
\hline 01/setembro & $10: 30-11: 23 h$ & 2 & 15,55 & 9,05 & 41,80 & 0,243 & 0,8553 \\
\hline $02 /$ setembro & $21: 44-22: 58 \mathrm{~h}$ & 27 & 46,88 & 21,25 & 54,67 & 0,0225 & 0,8898 \\
\hline 03/setembro & $0: 15-02: 00 \mathrm{~h}$ & 95 & 23,01 & 3,73 & 83,79 & 0,0166 & 0,7385 \\
\hline $25 /$ setembro & $0: 00-02: 00 \mathrm{~h}$ & 9 & 12,27 & 8,93 & 27,22 & 0,0533 & 0,9167 \\
\hline $25 /$ setembro & 05:11-06:00h & 4 & 16,31 & 11 & 32,56 & 0,1225 & 0,8119 \\
\hline $27 /$ setembro & 04:30-05:00h & 1 & 19,37 & 13,57 & 29,94 & 0,27 & 0,7879 \\
\hline $27 /$ setembro & $08: 36-11: 00 \mathrm{~h}$ & 17 & 27,01 & 14,99 & 44,50 & 0,0265 & 0,7432 \\
\hline 26/outubro & $15: 00-15: 51 \mathrm{~h}$ & 41 & 14,05 & 3,48 & 75,23 & 0,0734 & 0,7982 \\
\hline 26/outubro & $16: 16-16: 42 \mathrm{~h}$ & 33 & 13,51 & 2,93 & 78,31 & 0,0494 & 0,8559 \\
\hline 26/outubro & $20: 44-21: 30 \mathrm{~h}$ & 25 & 13,7 & 3,25 & 76,28 & 0,0564 & 0,9702 \\
\hline 01/novembro & $23: 00-23: 45 h$ & 2 & 16,97 & 8,25 & 51,38 & 0,4275 & 0,9049 \\
\hline $02 /$ novembro & $0: 30$ às $1: 00 \mathrm{~h}$ & 1 & 8,43 & 6 & 28,83 & 0,33 & 0,808 \\
\hline 04/novembro & $01: 00-01: 44 h$ & 19 & 11,56 & 3,3 & 71,45 & 0,0672 & 0,9193 \\
\hline 04/novembro & $03: 14-03: 55 \mathrm{~h}$ & 31 & 9,35 & 3,65 & 60,96 & 0,0312 & 0,806 \\
\hline 04/novembro & $05: 11-05: 30 \mathrm{~h}$ & 5 & 5,54 & 4,32 & 22,02 & 0,116 & 0,8822 \\
\hline 04/novembro & $16: 36-17: 30 \mathrm{~h}$ & 5 & 5,49 & 2,71 & 50,64 & 0,165 & 0,5203 \\
\hline 04/novembro & $20: 36-21: 30 h$ & 11 & 4,33 & 0,16 & 96,30 & 0,34 & 0,9507 \\
\hline 04/novembro & $22: 37-23: 00 \mathrm{~h}$ & 5 & 2,41 & 1,31 & 45,64 & 0,1584 & 0,7802 \\
\hline 04/novembro & $23: 30-23: 54 \mathrm{~h}$ & 5 & 1,96 & 0,05 & 97,45 & 0,6864 & 0,6382 \\
\hline 05/novembro & 01:04-01:30h & 5 & 3,55 & 1,01 & 71,55 & 0,2808 & 0,8479 \\
\hline 05/novembro & $04: 30-05: 00 \mathrm{~h}$ & 8 & 2,96 & 0,02 & 99,32 & 0,3525 & 0,3239 \\
\hline 06/novembro & $17: 11-17: 51 \mathrm{~h}$ & 10 & 13,45 & 4,75 & 64,68 & 0,0656 & 0,3914 \\
\hline 08/novembro & $0: 10-01: 30 \mathrm{~h}$ & 52 & 10,76 & 2,07 & 80,76 & 0,0450 & 0,7932 \\
\hline 08/novembro & $03: 30-03: 55 h$ & 3 & 6,43 & 1,95 & 69,67 & 0,48 & 0,9733 \\
\hline
\end{tabular}

Observando os valores de $\alpha$ obtidos percebe-se que os maiores estão relacionados às ocorrências de pequenas precipitações. Esses episódios também apresentaram as menores eficiências de remoção de MP, o que já era esperado. Obviamente as maiores precipitações provocaram uma diminuição mais acentuada na 
concentração de $\mathrm{MP}_{10}$ e consequentemente tiveram as maiores eficiências de remoção.

Comparando as precipitações, entretanto, as eficiências na remoção não aumentaram na mesma proporção que a quantidade precipitada, o que comprova a relação não linear entre as mesmas. Um exemplo são as precipitações dos dias 26 de julho e 27 de setembro, ambas com concentrações parecidas de material particulado antes de chuva, 26,2 e $27,01 \mu \mathrm{g} / \mathrm{m}^{3}$, respectivamente; na primeira a precipitação foi de apenas $1 \mathrm{~mm}$, já na última de $17 \mathrm{~mm}$, as remoções na concentração de MP entretanto, não foram tão discrepantes, 25,88 e 44,5\%, também respectivamente.

Além disso, apesar da eficiência na remoção para pequenas precipitações ser menor, esta já corresponde a uma boa parcela da eficiência de remoção constatada para as precipitações maiores (como pode ser visto no exemplo acima), de modo que a medida que o nível da lâmina precipitada aumenta, a eficiência na remoção aumenta mas não só de maneira não linear, como também com uma taxa de variação $(\mathrm{dK} / \mathrm{dt})$ cada vez menor em módulo. Esse comportamento do material particulado corrobora a explicação físico-estatística que foi proposta na página 60 e expressa matematicamente por (1) e (2). Além do mais, isso indica que a derivada segunda da concentração em função do tempo é negativa. Matematicamente, derivando-se a equação (2) em relação ao tempo tem-se:

$$
\begin{aligned}
& \text { (2) } \frac{d K}{d t}=-\gamma K \\
& \text { (12) } \frac{d K^{2}}{d t^{2}}=-\gamma
\end{aligned}
$$

Condição, portanto, que é satisfeita pelo modelo proposto como consequência "natural" de (2).

Para que o valor de $\alpha$ seja encontrado é necessário analisar chuvas com uma quantidade mínima de água precipitada, pois quantidades menores de precipitação, onde a remoção do material particulado é "pequena", porém como uma taxa de variação da concentração de MP em função tempo (dK/dt) mais acentuada (em módulo), não representam o mecanismo de remoção do material particulado por completo mas apenas a parte inicial deste, onde a remoção é maior devido aos maiores valores da concentração $(\mathrm{K})$. Prova disto são os valores de $\alpha$ até dez vezes maiores encontrados para as pequenas precipitações, que se substituídos em (6) representariam uma curva 
exponencial mais acentuada se comparada aos valores menores dessa constante, entretanto, ainda de acordo com (6) essa constante não depende da precipitação média.

Os valores de $(\alpha)$ encontrados não seriam obviamente iguais por uma série de fatores, mas nesse processo de determinação empírica para essa constante, valores tão distantes não podem ser analisados no mesmo grupo. Portanto selecionando-se da Tabela 10 apenas as precipitações com mais de $10 \mathrm{~mm}$ de chuva, chega-se a Tabela 11, a qual serviu de ponto de partida para encontrar o valor médio $\alpha_{\mathrm{m}}$.

Tabela 11. Precipitações selecionadas para o cálculo de $\alpha$ médio.

\begin{tabular}{|l|c|c|c|c|c|c||}
\hline \multicolumn{1}{|c|}{ Dia } & Hora & $\begin{array}{c}\text { Número da } \\
\text { precipitação }\end{array}$ & $\begin{array}{c}\text { Expoente } \\
\text { equação Excel }\end{array}$ & $\begin{array}{c}\text { Remoção de } \\
\text { MP. }_{\mathbf{1 0}}(\mathbf{\%})\end{array}$ & $\begin{array}{c}\text { Precipitação } \\
(\mathbf{m m})\end{array}$ & $\boldsymbol{\alpha}$ \\
\hline 24/julho & $13: 07-15: 30 \mathrm{~h}$ & 1 & 0,011 & 84,16 & 34 & 0,04626 \\
\hline 24-25/julho & $23: 50-01: 30 \mathrm{~h}$ & 2 & 0,03 & 93,78 & 14 & 0,2164 \\
\hline 02/setembro & $21: 44-22: 58 \mathrm{~h}$ & 3 & 0,007 & 56,70 & 27 & 0,02190 \\
\hline 03/setembro & $0: 15-01: 30 \mathrm{~h}$ & 4 & 0,021 & 83,79 & 94 & 0,01680 \\
\hline 27/setembro & $08: 36-10: 54 \mathrm{~h}$ & 5 & 0,003 & 48,35 & 17 & 0,02440 \\
\hline 26/outubro & $15: 03-15: 51 \mathrm{~h}$ & 6 & 0,024 & 76,77 & 41 & 0,02810 \\
\hline 26/outubro & $16: 15-16: 39 \mathrm{~h}$ & 7 & 0,06 & 80,98 & 33 & 0,04360 \\
\hline 26/outubro & $20: 43-21: 27 \mathrm{~h}$ & 8 & 0,029 & 76,28 & 25 & 0,05640 \\
\hline 04/novembro & $01: 03-01: 43 \mathrm{~h}$ & 9 & 0,003 & 73,48 & 19 & 0,06320 \\
\hline 04/novembro & $03: 14-03: 48 \mathrm{~h}$ & 10 & 0,027 & 65,06 & 31 & 0,02960 \\
\hline 04/novembro & $20: 36-21: 30 \mathrm{~h}$ & 11 & 0,068 & 96,30 & 11 & 0,34 \\
\hline 08/novembro & $0: 10-01: 24 \mathrm{~h}$ & 12 & 0,034 & 89,77 & 52 & 0,04500 \\
\hline
\end{tabular}

Através das precipitações selecionadas e seus respectivos valores de $\alpha$, construiu-se o gráfico de dispersão das constantes obtidas para cada episódio de chuva (Figura 29). Para tal, as precipitações foram enumeradas como consta na Tabela 11. 


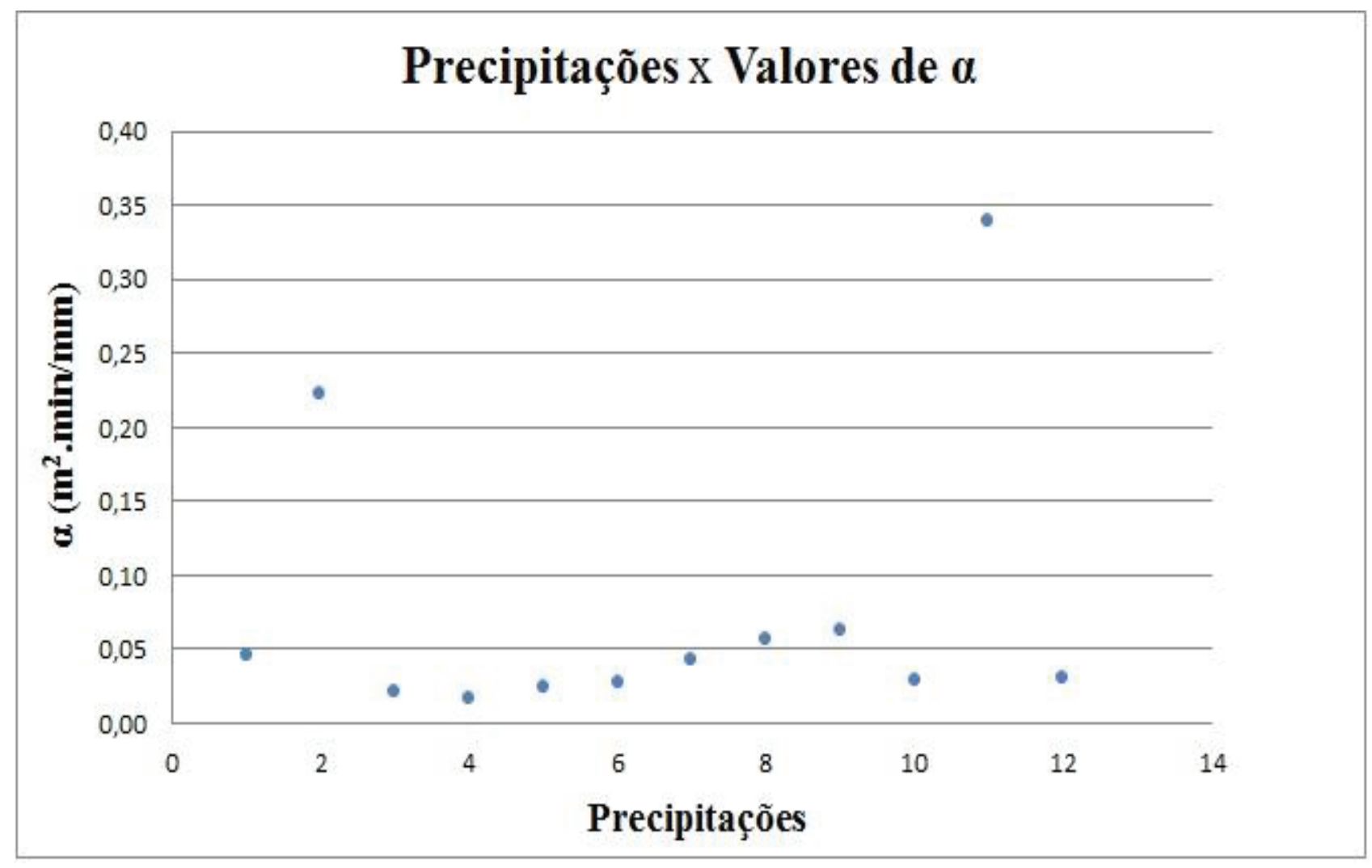

Figura 29. Gráfico de dispersão dos valores de $\alpha$ para as precipitações selecionadas.

Analisando o gráfico conclui-se que os valores encontrados distribuem-se dentro de um estreito intervalo, com exceção de dois destes, os valores de $\alpha$ representados pelos números 2 e 11, iguais respectivamente a 0,2164 e 0,34 .

Em uma série com grande número de valores para $\alpha$ é provável que estes ficassem, na sua maioria, dentro do intervalo acima verificado, com alguns poucos valores visivelmente distantes dessa faixa de distribuição. Todavia, numa série com grande quantidade de números, esses valores muito acima do provável padrão da série não influiriam significativamente no cálculo da média. Não é o que ocorre aqui haja vista que se dispõe apenas de 12 valores para $(\alpha)$, portanto esses dois valores, apesar de corresponderem a chuvas acima de $10 \mathrm{~mm}$ não serão considerados para o cálculo de $\alpha_{\mathrm{m}}$.

A Tabela 12 apresenta os dez episódios de chuva restantes. A Tabela 13 mostra a diferença relativa, em porcentagem, entre as concentrações Ko1, a qual é obtida fazendo $\mathrm{x}=1$ na linha de tendência exponencial traçada pelo Excel, e Ko2, que é o valor medido pelo ADR e utilizado como concentração inicial da função (6). 
Tabela 12. Precipitações restantes.

\begin{tabular}{||c|c|c|c|c|c|c||}
\hline \multicolumn{1}{|c|}{ Dia } & Hora & $\begin{array}{c}\text { Número da } \\
\text { precipitação }\end{array}$ & $\begin{array}{c}\text { Expoente } \\
\text { equação Excel }\end{array}$ & $\begin{array}{c}\text { Precipitação } \\
\text { (mm) }\end{array}$ & $\begin{array}{c}\text { Precipitação } \\
\text { média (mm/min) }\end{array}$ & $\boldsymbol{\alpha}$ \\
\hline 24/julho & $13: 07-15: 30 \mathrm{~h}$ & 1 & 0,011 & 34 & 0,23776 & 0,04626 \\
\hline 02/setembro & $21: 44-22: 58 \mathrm{~h}$ & 2 & 0,007 & 27 & 0,36986 & 0,02190 \\
\hline 03/setembro & $0: 15-01: 30 \mathrm{~h}$ & 3 & 0,021 & 94 & 1,25333 & 0,01680 \\
\hline 27/setembro & $08: 36-10: 54 \mathrm{~h}$ & 4 & 0,003 & 17 & 0,12319 & 0,02440 \\
\hline 26/outubro & $15: 03-15: 51 \mathrm{~h}$ & 5 & 0,024 & 41 & 0,85417 & 0,02810 \\
\hline 26/outubro & $16: 15-16: 39 \mathrm{~h}$ & 6 & 0,06 & 33 & 1,375 & 0,04360 \\
\hline 26/outubro & $20: 43-21: 27 \mathrm{~h}$ & 7 & 0,029 & 25 & 0,54348 & 0,05640 \\
\hline 04/novembro & $01: 03-01: 43 \mathrm{~h}$ & 8 & 0,003 & 19 & 0,475 & 0,06320 \\
\hline 04/novembro & $03: 14-03: 48 \mathrm{~h}$ & 9 & 0,027 & 31 & 0,91176 & 0,02960 \\
\hline 08/novembro & $0: 10-01: 24 \mathrm{~h}$ & 10 & 0,034 & 52 & 0,75556 & 0,04500 \\
\hline
\end{tabular}

Tabela 13. Precipitações, o valor de $\alpha$, suas concentrações iniciais Ko1 e Ko2 e a razão entre as mesmas.

\begin{tabular}{|l|c|c|c|c|c|c||}
\hline \multicolumn{1}{|c|}{ Dia } & Hora & $\boldsymbol{\alpha}$ & Ko1 & Ko2 & (Ko1-Ko2)/Ko2 (\%) & (Ko2-Ko1)/Ko1 (\%) \\
\hline 24/julho & $13: 07-15: 30 \mathrm{~h}$ & 0,04626 & 35,12 & 34,98 & 0,40 & - \\
\hline 02/setembro & $21: 44-22: 58 \mathrm{~h}$ & 0,02190 & 37,35 & 42,23 & - & 13,07 \\
\hline 03/setembro & $0: 15-01: 30 \mathrm{~h}$ & 0,01680 & 14,74 & 27,01 & - & 83,24 \\
\hline 27/setembro & $08: 36-10: 54 \mathrm{~h}$ & 0,02440 & 26,28 & 27,01 & - & 2,78 \\
\hline 26/outubro & $15: 03-15: 51 \mathrm{~h}$ & 0,02810 & 12,11 & 14,98 & - & 23,70 \\
\hline 26/outubro & $16: 15-16: 39 \mathrm{~h}$ & 0,04360 & 10,51 & 13,51 & - & 28,54 \\
\hline 26/outubro & $20: 43-21: 27 \mathrm{~h}$ & 0,05640 & 11,35 & 11,25 & 0,89 & - \\
\hline 04/novembro & $01: 03-01: 43 \mathrm{~h}$ & 0,06320 & 12,47 & 12,18 & 2,38 & - \\
\hline 04/novembro & $03: 14-03: 48 \mathrm{~h}$ & 0,02960 & 8,15 & 9,56 & - & 17,30 \\
\hline 08/novembro & $0: 10-01: 24 \mathrm{~h}$ & 0,04500 & 7,35 & 7,91 & - & 7,62 \\
\hline
\end{tabular}

A igualdade expressa por (11) e utilizada para encontrar $\alpha$ foi obtida considerando-se que os valores de Ko da função (6) e da linha de tendência exponencial do Excel eram iguais. Como se trata de um método empírico para obter uma constante de igualdade (lembrando que a função foi deduzida de maneira analítica), não será utilizado de rigor matemático excessivo, pois nesse caso nenhum dos valores de $\alpha$ poderia ser utilizado já que em todos os episódios de chuva as concentrações inicias Ko1 e Ko2 tiveram alguma diferença, mesmo que muito pequena, todavia, em alguns casos a diferença entre essas concentrações não pode ser desprezada. 
No dia 03 de setembro, por exemplo, valor da concentração inicial medida pelo ADR e utilizada pela função (6), Ko2, foi quase $84 \%$ superior ao valor de Ko1, o que faz com que o erro envolvido na utilização da equação (11) para encontrar $\alpha$ seja muito grande e desse modo o valor obtido não deve ser considerado. $\mathrm{O}$ mesmo aplica-se à precipitação do dia 2 de setembro, às primeiras duas chuvas ocorridas em 26 de outubro e à segunda precipitação do dia 04 de novembro.

Excluindo esses dias, chega-se por fim a Tabela 14, a qual exibe os valores de $\alpha$ e seus respectivos coeficientes de determinação $\left(R^{2}\right)$, para cada episódio de chuva restante.

Tabela 14. Precipitações e seus respectivos valores de $\alpha$ e $\mathrm{R}^{2}$.

\begin{tabular}{||l|c|c|c|c||}
\hline \multicolumn{1}{|c|}{ Dia } & Hora & $\begin{array}{c}\text { Número da } \\
\text { precipitação }\end{array}$ & $\boldsymbol{\alpha}$ & $\mathbf{R}^{\mathbf{2}}$ \\
\hline 24/julho & $13: 07-15: 30 \mathrm{~h}$ & 1 & 0,04626 & 0,8832 \\
\hline 27/setembro & $08: 36-10: 54 \mathrm{~h}$ & 2 & 0,02440 & 0,7101 \\
\hline 26/outubro & $20: 43-21: 27 \mathrm{~h}$ & 3 & 0,05640 & 0,9705 \\
\hline 04/novembro & $01: 03-01: 43 \mathrm{~h}$ & 4 & 0,06320 & 0,908 \\
\hline 08/novembro & $0: 10-01: 24 \mathrm{~h}$ & 5 & 0,04500 & 0,7728 \\
\hline
\end{tabular}

Analisando os valores de $\alpha$ da Tabela 14 nota-se que há um valor relativamente abaixo dos demais, o qual possui justamente o menor coeficiente de determinação. Isso fica mais evidente no gráfico de dispersão construído com esses valores de $\alpha$ (Figura 30). Portanto esse valor de $\alpha(0,0244)$ também será excluído.

Chega-se por fim a Tabela 15 , a qual exibe os valores de $\alpha$ utilizados para encontrar o valor de $\alpha_{\mathrm{m}}$, seus respectivos coeficientes de determinação $\left(\mathrm{R}^{2}\right)$, estes mesmos coeficientes elevados ao quadrado, e o produto destes pelos seus correspondentes valores de $\alpha$. Essas informações estão presentes porque o valor médio para essa constante foi calculado a partir de uma média ponderada, cuja fórmula utilizada está expressa pela equação (13). 


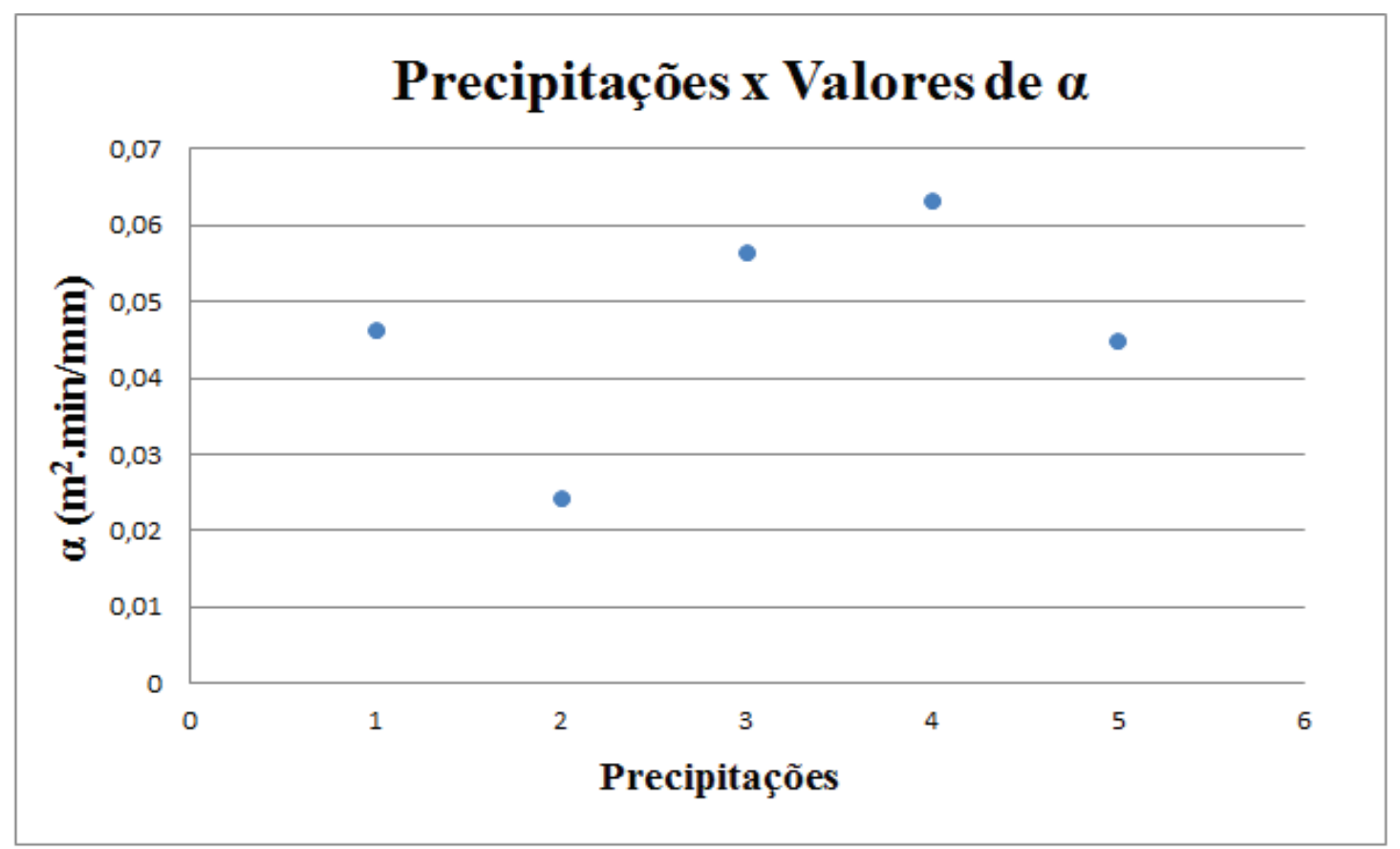

Figura 30. Gráfico de dispersão dos valores de $\alpha$ para as precipitações da Tabela 13.

Utilizou-se uma média ponderada porque valores de $\alpha$ obtidos por linhas de tendência que possuem maiores coeficientes de determinação tem um "peso" maior do que valores relacionados a coeficientes de determinação menores. Na média ponderada o coeficiente de determinação foi elevado ao quadrado para aumentar seu peso no cálculo de $\alpha_{\mathrm{m}}$.

Tabela 15. Precipitações utilizadas para encontrar $\alpha_{\mathrm{m}}$.

\begin{tabular}{|l|c|c|c|c|c|}
\hline \multicolumn{1}{|c|}{ Dia } & Hora & $\boldsymbol{\alpha}$ & $\mathbf{R}^{\mathbf{2}}$ & ${\left(\mathbf{R}^{\mathbf{2}} \mathbf{2}^{\mathbf{2}}\right.}$ & $\boldsymbol{\alpha} \mathbf{x}\left(\mathbf{R}^{\mathbf{2}} \mathbf{2}^{\mathbf{2}}\right.$ \\
\hline 24/julho & $13: 07-15: 30 \mathrm{~h}$ & 0,04626 & 0,8832 & 0,78 & 0,0361 \\
\hline 26/outubro & $20: 43-21: 27 \mathrm{~h}$ & 0,05640 & 0,9705 & 0,9419 & 0,0503 \\
\hline 04/novembro & $01: 03-01: 43 \mathrm{~h}$ & 0,06320 & 0,908 & 0,8245 & 0,0521 \\
\hline 08/novembro & $0: 10-01: 24 \mathrm{~h}$ & 0,04500 & 0,7728 & 0,5972 & 0,0269 \\
\hline
\end{tabular}

$$
\alpha_{m}=\frac{\sum_{i=1}^{n} \alpha_{i} \times\left(R_{i}^{2}\right)^{2}}{\sum_{i=1}^{n}\left(R_{i}^{2}\right)^{2}} \quad \alpha_{m}=\frac{0,1654}{3,1436}=0,052615
$$

Substituindo o valor de $\alpha_{m}$ calculado por (13) na equação (6) chega-se a:

$$
\text { (14) } K=K o \cdot e^{-0,052615 \frac{P}{\Delta t} t}
$$


Foram feitas duas simulações no Excel, uma utilizando a constante obtida através de uma média ponderada "simples", calculada utilizando o produto $\alpha \times \mathrm{R}^{2}$, e outra que utilizou o mesmo produto, mas com o coeficiente de determinação elevado ao quadrado (13), sendo que este última apresentou os melhores resultados, ou seja, os melhores coeficientes de determinação comparando os valores obtidos pelo ADR com a equação (14), a qual utiliza a constante obtida por (13).

Nas próximas páginas há uma comparação entre as linhas de tendência exponencial fornecidas pelo Excel e a equação (14) aplicada a todas as precipitações da Tabela 12, com exceção da 4 , pois os valores nesta ocasião estão muito dispersos (Figuras 31 a 49). O coeficiente de determinação não é o mais indicado para avaliar o ajuste de regressões não lineares, entretanto, ele foi utilizado para se comparar com os valores de $\mathrm{R}^{2}$ fornecidos pelo Excel.

É importante observar que os valores do coeficiente de determinação calculados para a linha de tendência exponencial fornecida pelo Excel serão, na grande maioria dos casos, maiores que os valores de $\mathrm{R}^{2}$ obtidos para a equação (14), poia a linha de tendência é calculada pelo programa com base nos valores de $\mathrm{MP}_{10}$ fornecidos. Já a equação desenvolvida neste estudo utiliza apenas a concentração inicial (Ko) e a precipitação média $(\mathrm{P} / \Delta \mathrm{t})$ para modelar o comportamento da concentração de material particulado grosso ao longo da chuva. Com o intuito de fornecer mais um meio para avaliar a precisão da equação (14), e que seja menos suscetível a "flutuação" das concentrações devido a imprecisões do ADR e possíveis erros amostrais ocasionados pela baixa vazão deste equipamento, foi construída a Tabela 16. 
Tabela 16. Comparação entre a eficiência real na remoção de MP e a eficiência prevista utilizando-se a equação (14).

\begin{tabular}{||l|c|c|c|c||}
\hline \multicolumn{1}{|c|}{ Dia } & Hora & $\begin{array}{c}\text { Número da } \\
\text { precipitação }\end{array}$ & $\begin{array}{c}\text { Eficiência real na } \\
\text { remoção de MP (\%) }\end{array}$ & $\begin{array}{c}\text { Eficiência prevista na } \\
\text { remoção de MP (\%) }\end{array}$ \\
\hline 24/julho & $13: 07-15: 30 \mathrm{~h}$ & 1 & 84,2 & 83,1 \\
\hline 02/setembro & $21: 44-22: 58 \mathrm{~h}$ & 2 & 51,9 & 75,4 \\
\hline 03/setembro & $0: 15-01: 30 \mathrm{~h}$ & 3 & 82,7 & 99,2 \\
\hline 27/setembro & $08: 36-10: 54 \mathrm{~h}$ & 4 & 48,4 & 50,5 \\
\hline 26/outubro & $15: 03-15: 51 \mathrm{~h}$ & 5 & 76,8 & 87,9 \\
\hline 26/outubro & $16: 15-16: 39 \mathrm{~h}$ & 6 & 81,0 & 81,1 \\
\hline 26/outubro & $20: 43-21: 27 \mathrm{~h}$ & 7 & 71,1 & 72,4 \\
\hline 04/novembro & $01: 03-01: 43 \mathrm{~h}$ & 8 & 73,5 & 62,3 \\
\hline 04/novembro & $03: 14-03: 48 \mathrm{~h}$ & 9 & 65,1 & 79,5 \\
\hline 08/novembro & $0: 10-01: 24 \mathrm{~h}$ & 10 & 81,2 & 82,6 \\
\hline
\end{tabular}




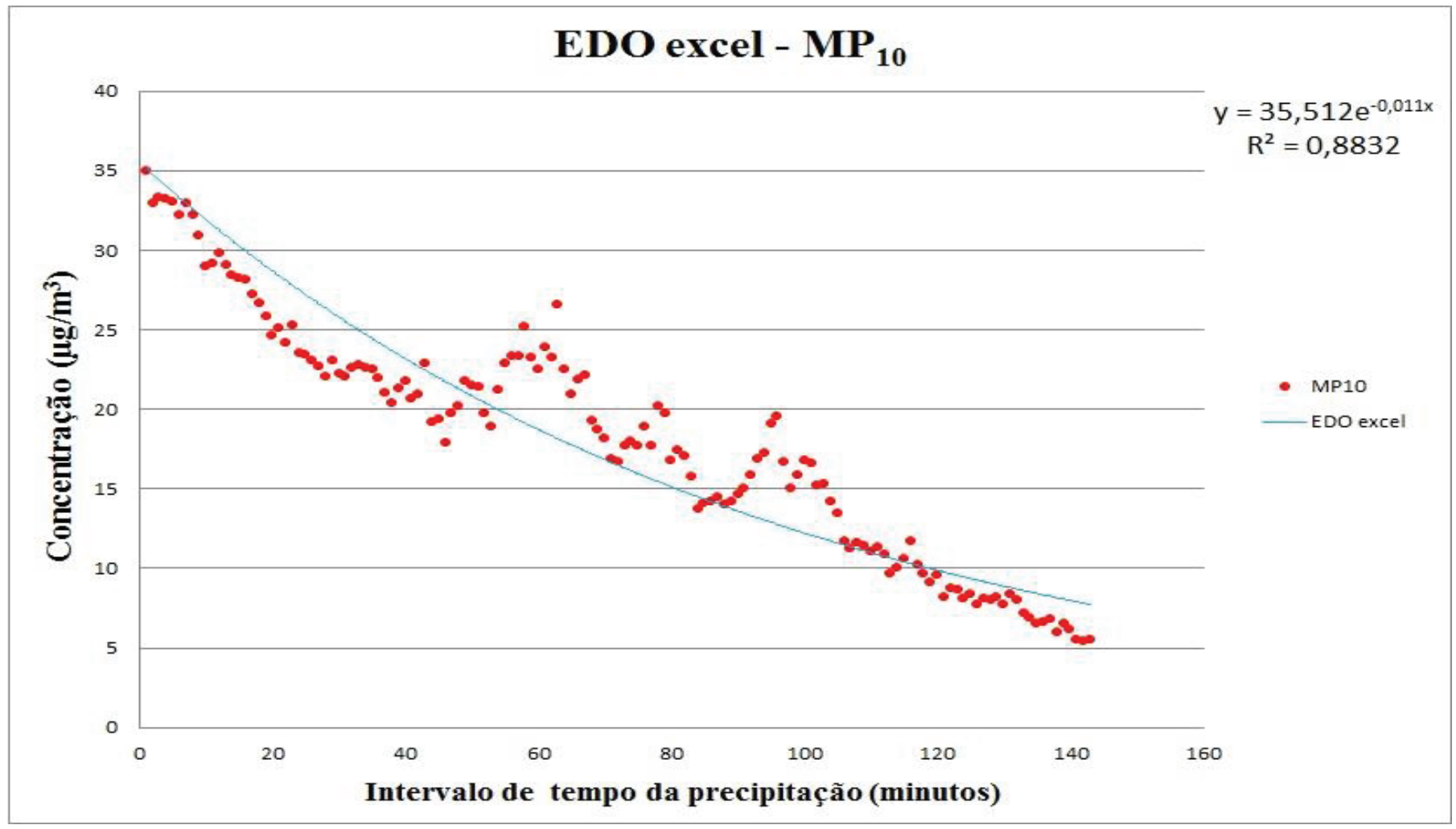

Figura 31. Precipitação 1, linha de tendência exponencial do Excel e o valor de $\mathrm{R}^{2}$.

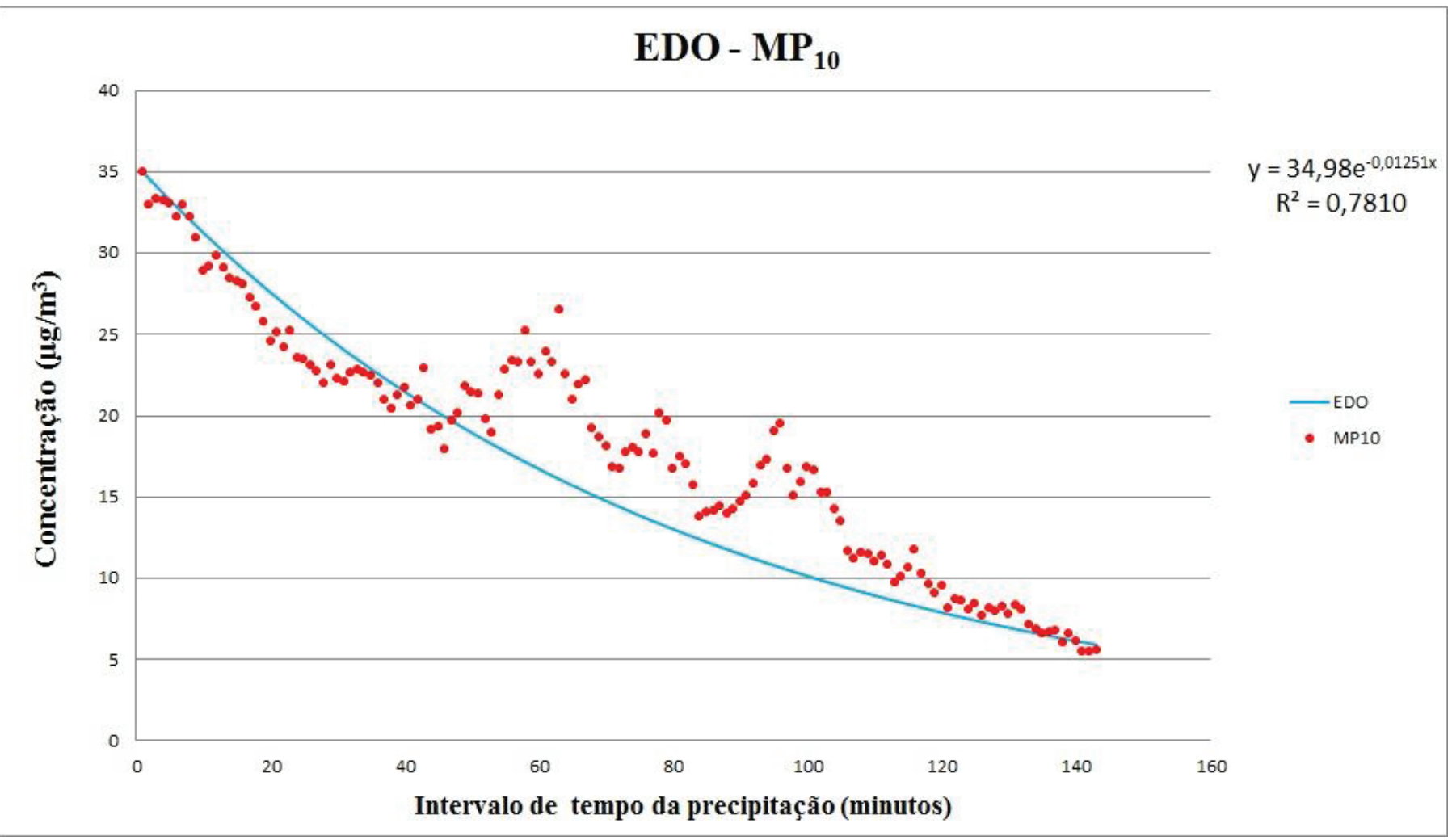

Figura 32. Precipitação 1 , equação (14) e o valor de $\mathrm{R}^{2}$. 


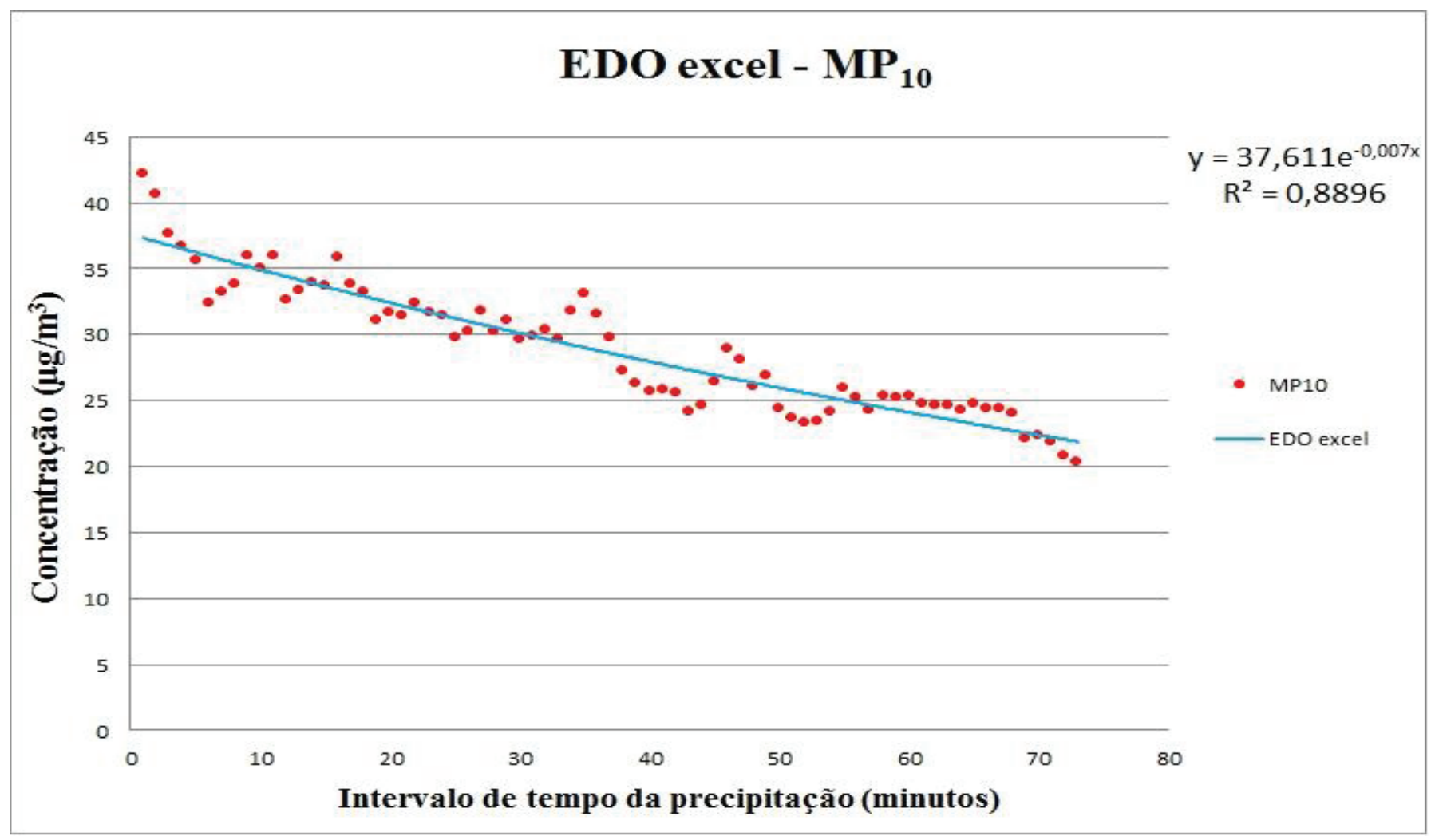

Figura 33. Precipitação 2, linha de tendência exponencial do Excel e o valor de $\mathrm{R}^{2}$.

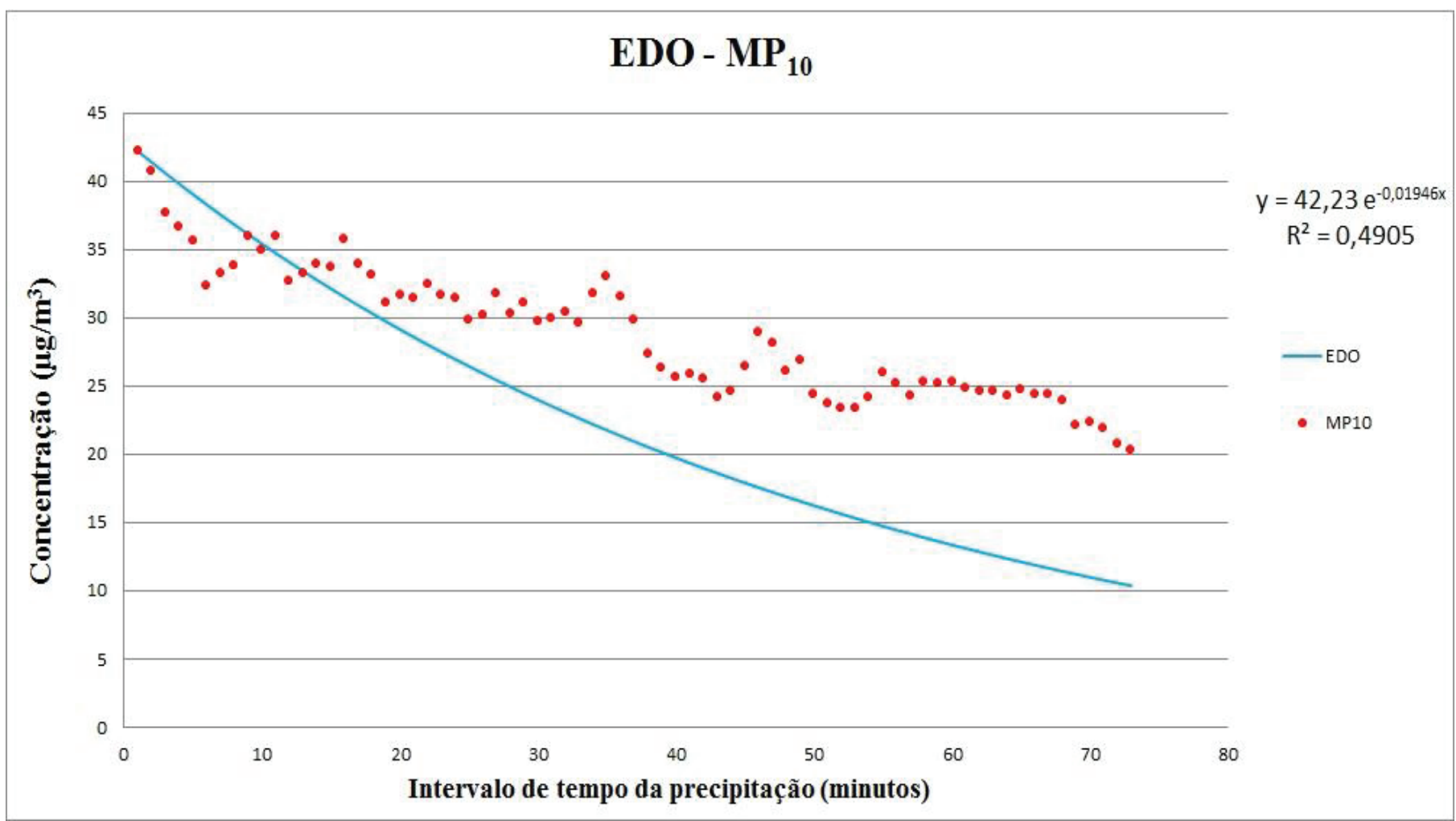

Figura 34. Precipitação 2, equação (14) e o valor de $\mathrm{R}^{2}$. 


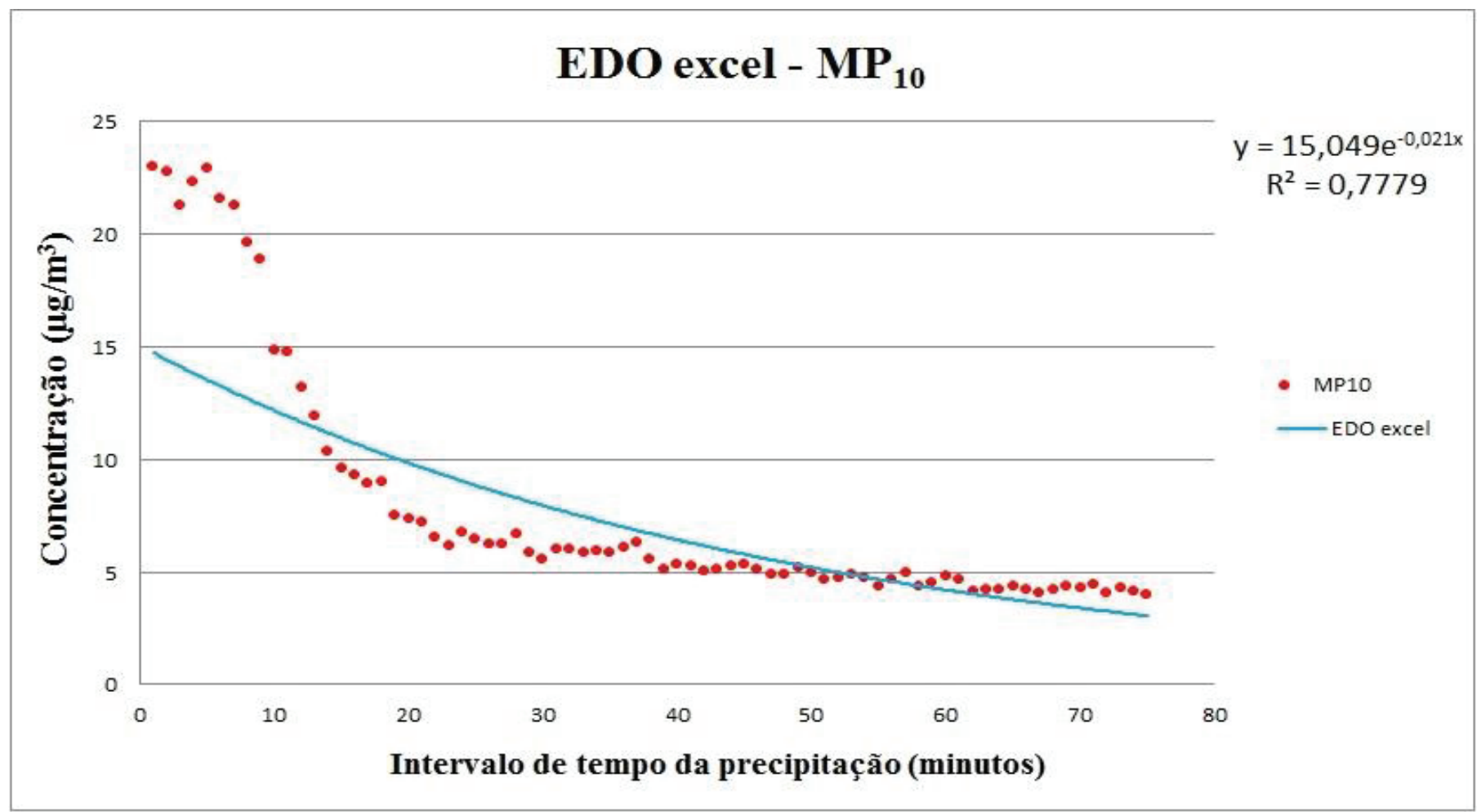

Figura 35. Precipitação 3, linha de tendência exponencial do Excel e o valor de $\mathrm{R}^{2}$.

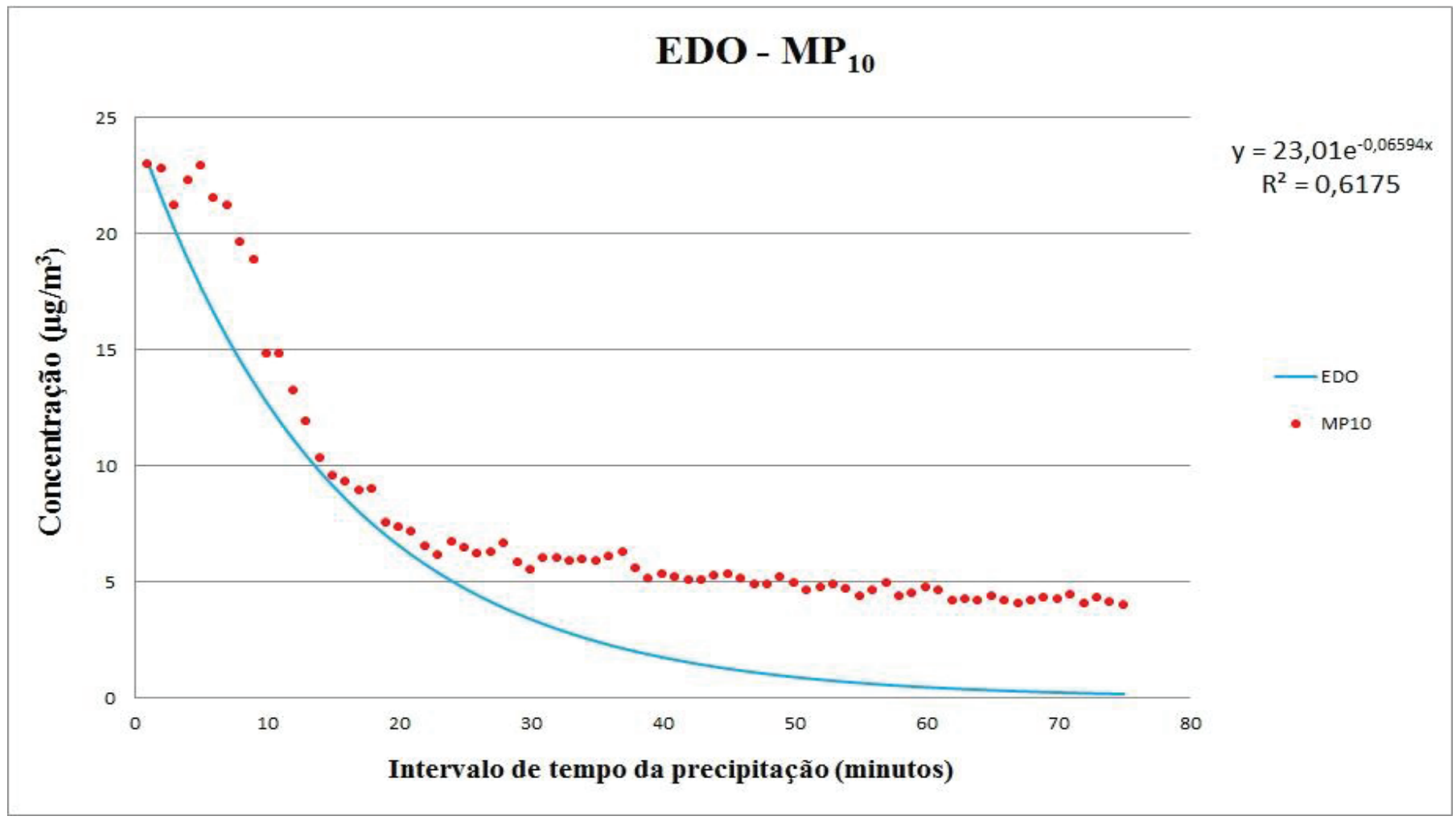

Figura 36. Precipitação 3, equação (14) e o valor de $\mathrm{R}^{2}$. 


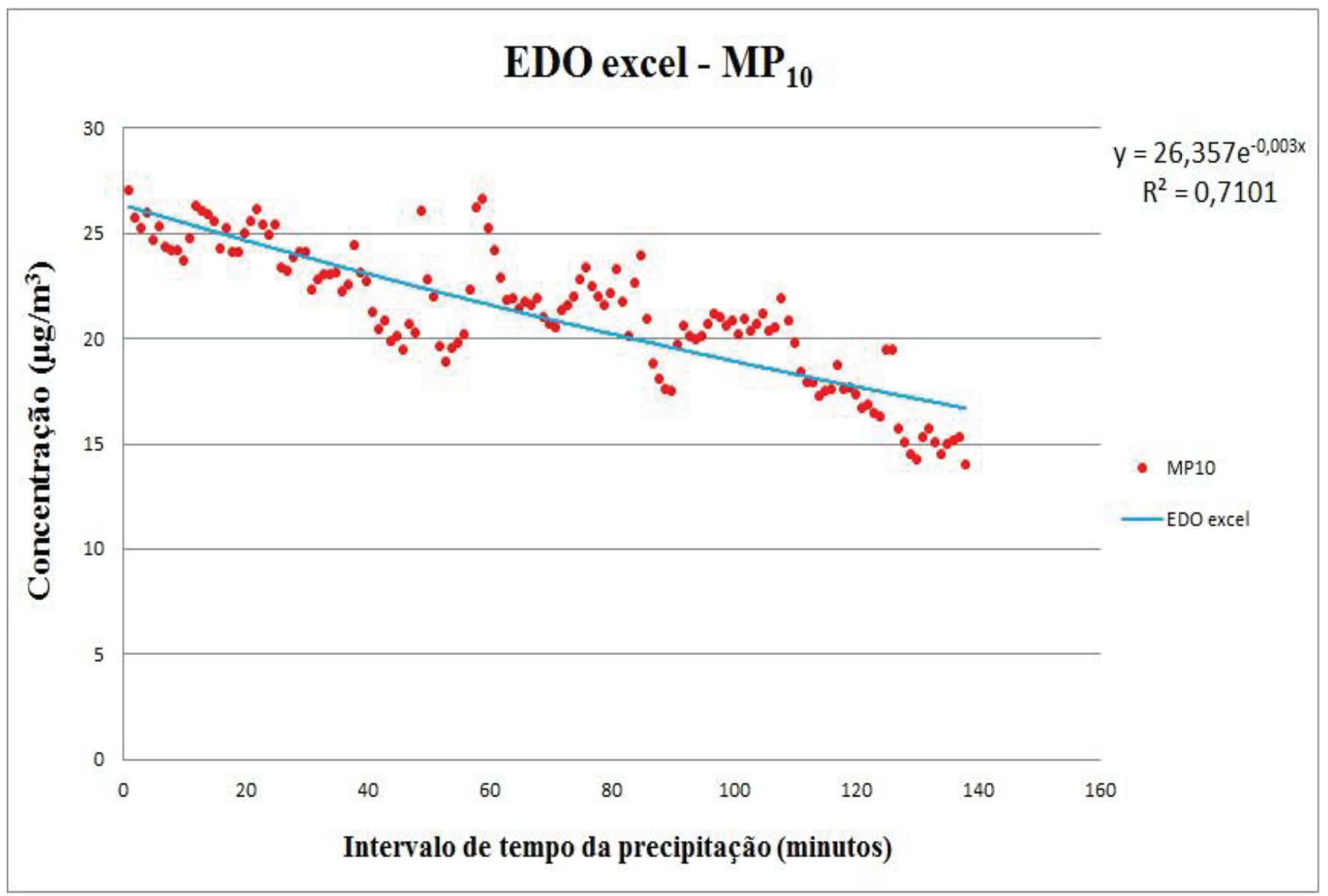

Figura 37. Precipitação 4, linha de tendência exponencial do Excel e o valor de $\mathrm{R}^{2}$. 


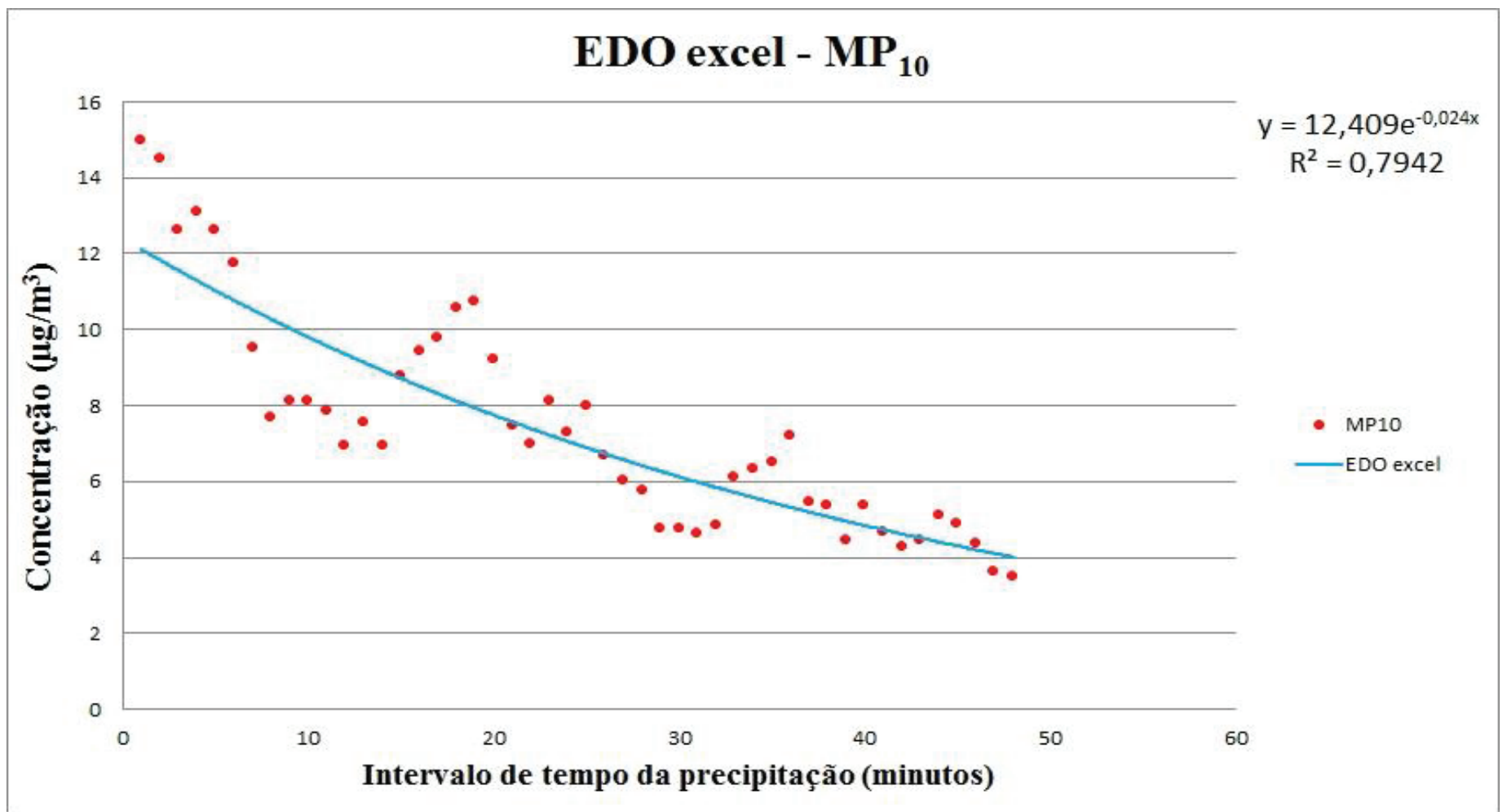

Figura 38. Precipitação 5, linha de tendência exponencial do Excel e o valor de $\mathrm{R}^{2}$.

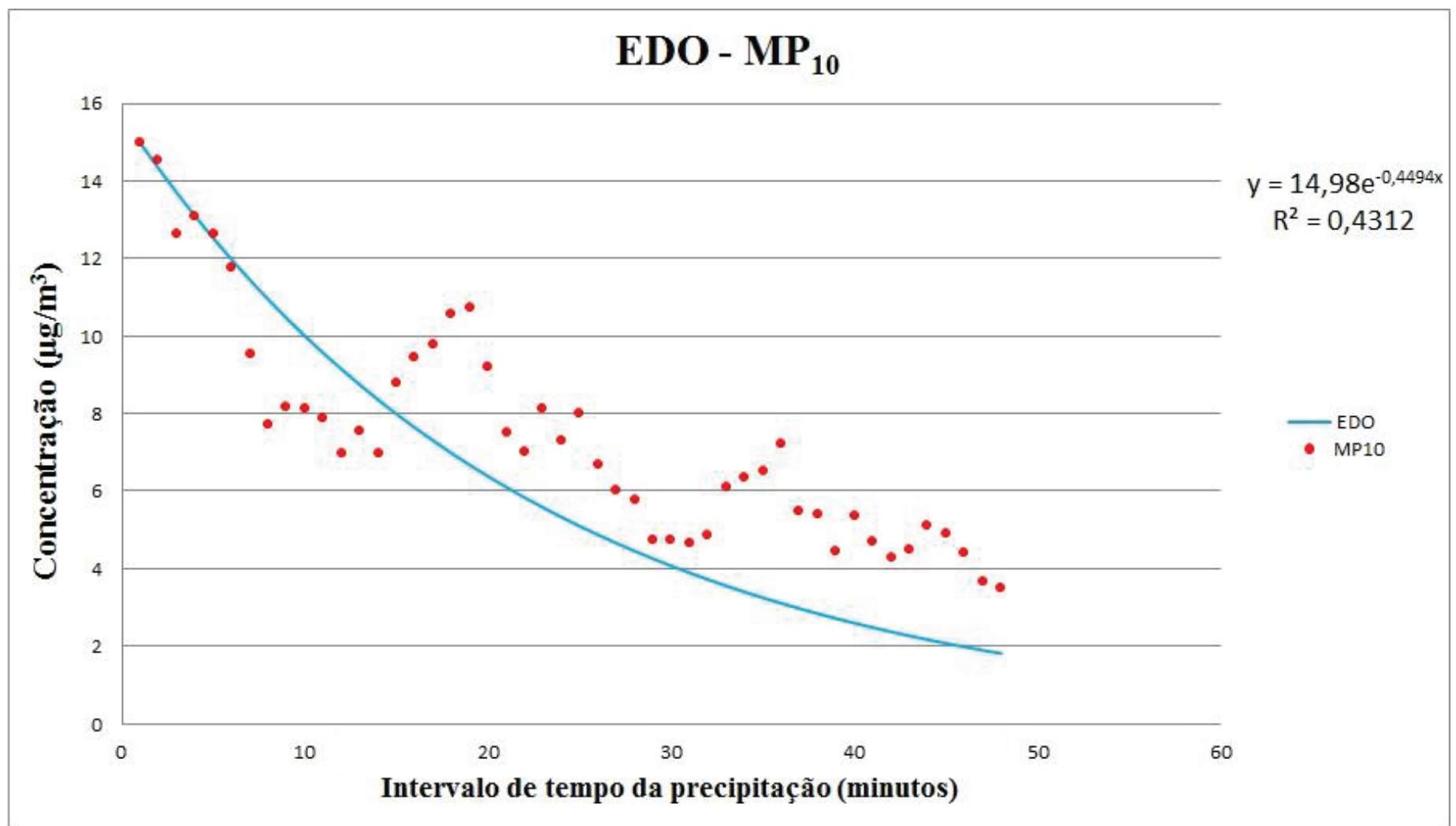

Figura 39. Precipitação 5, equação (14) e o valor de $\mathrm{R}^{2}$. 


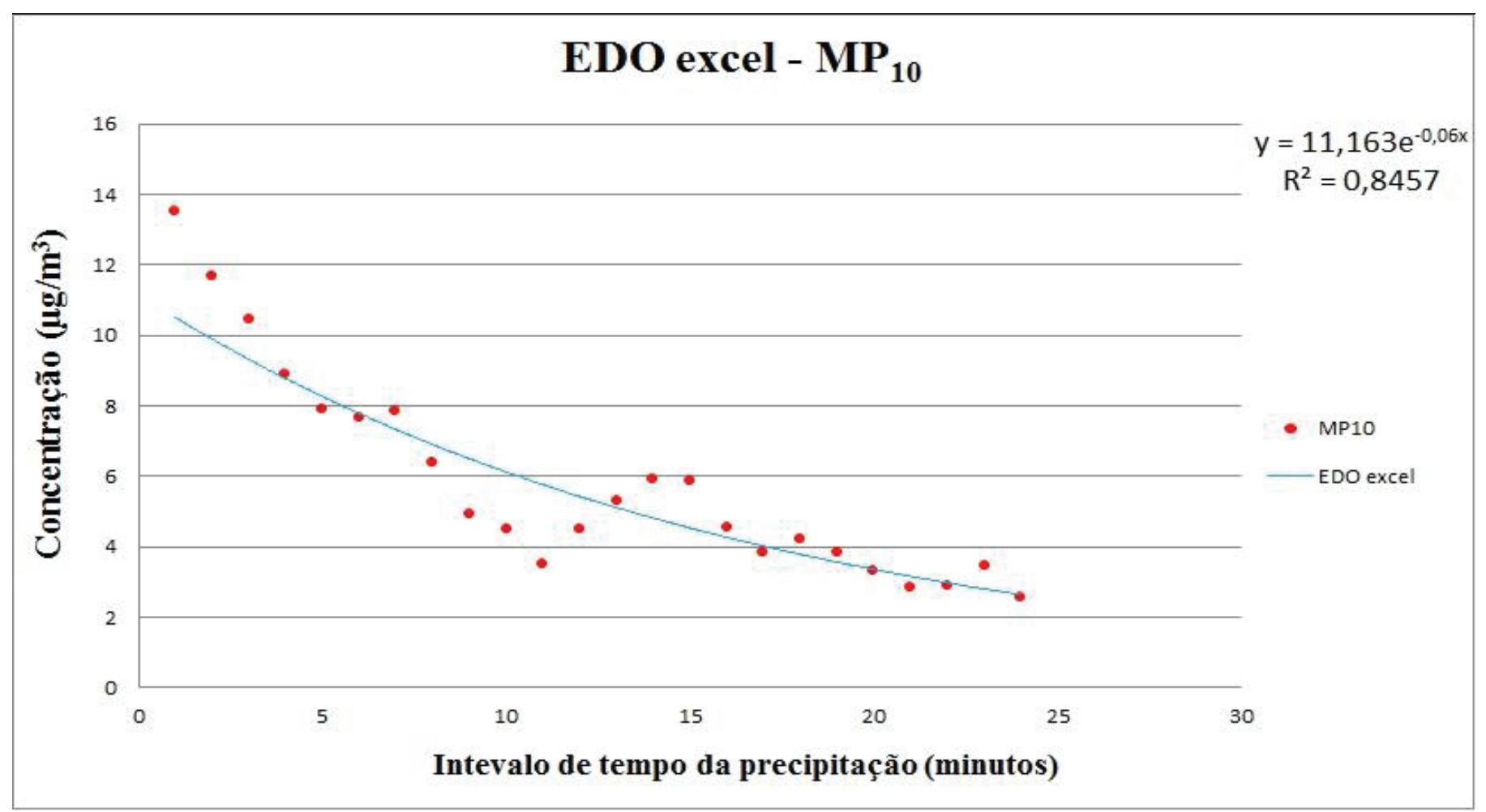

Figura 40. Precipitação 6, linha de tendência exponencial do Excel e o valor de $\mathrm{R}^{2}$.

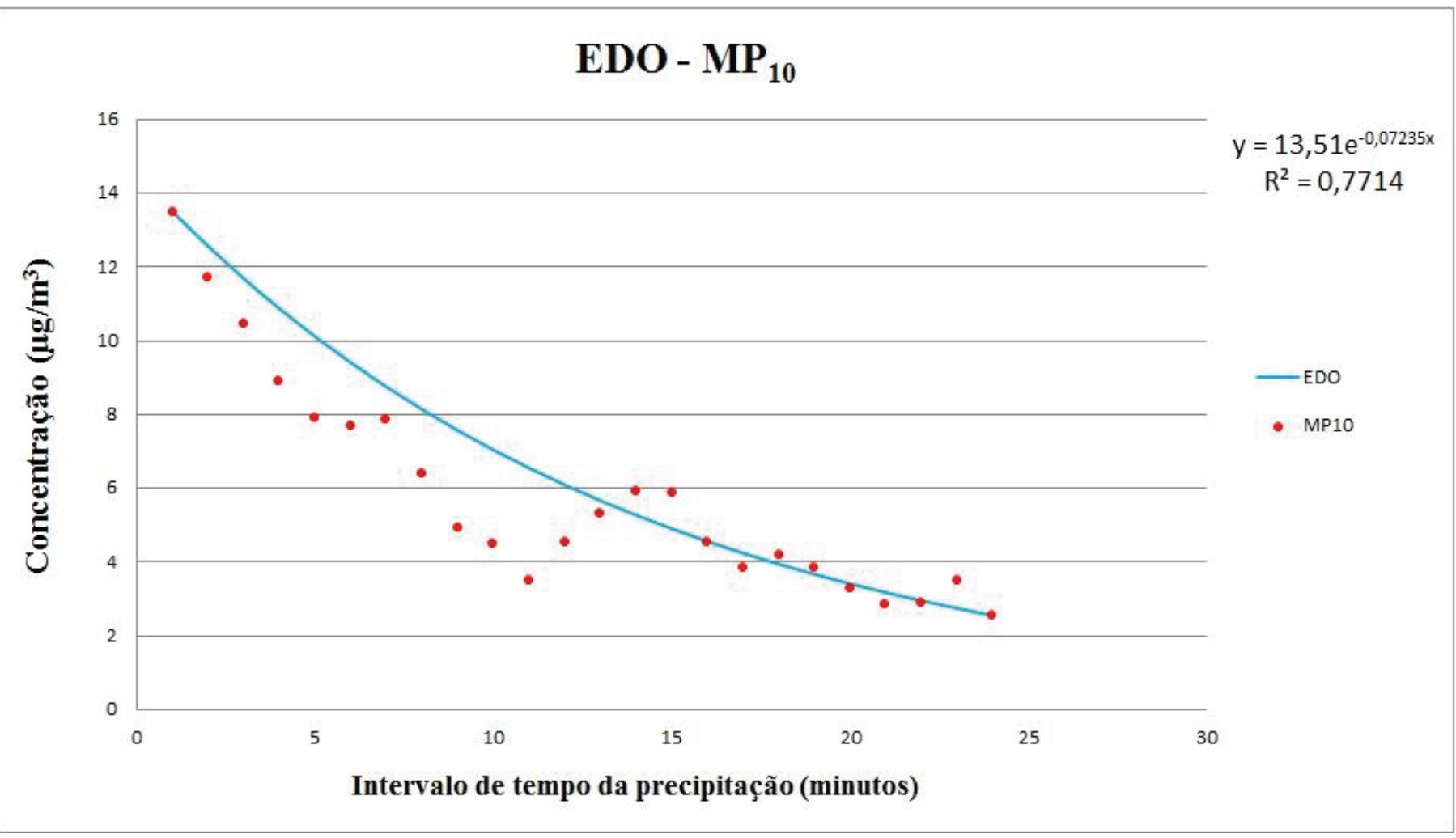

Figura 41. Precipitação 6, equação (14) e o valor de $\mathrm{R}^{2}$. 


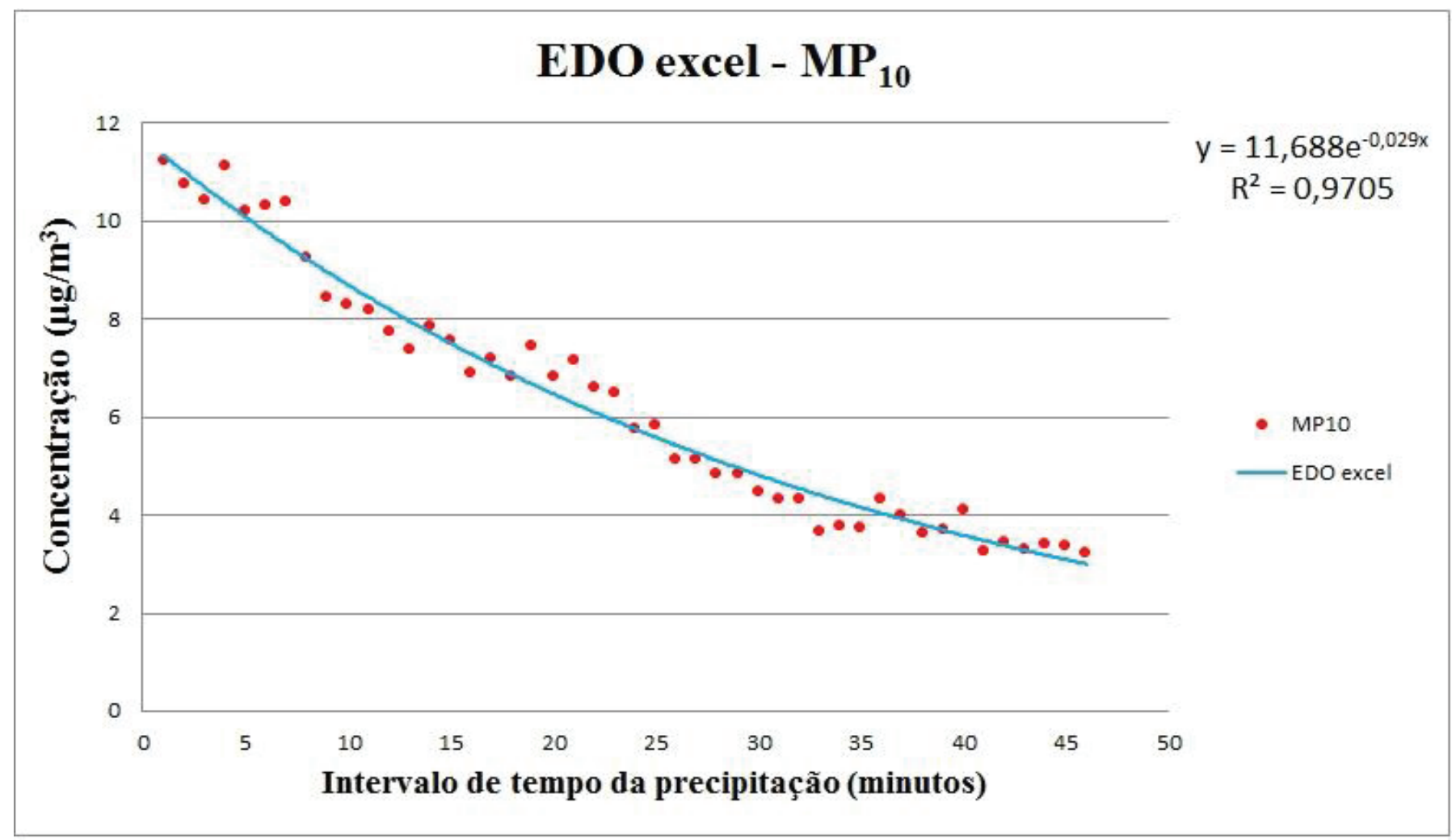

Figura 42. Precipitação 7, linha de tendência exponencial do Excel e o valor de $\mathrm{R}^{2}$.

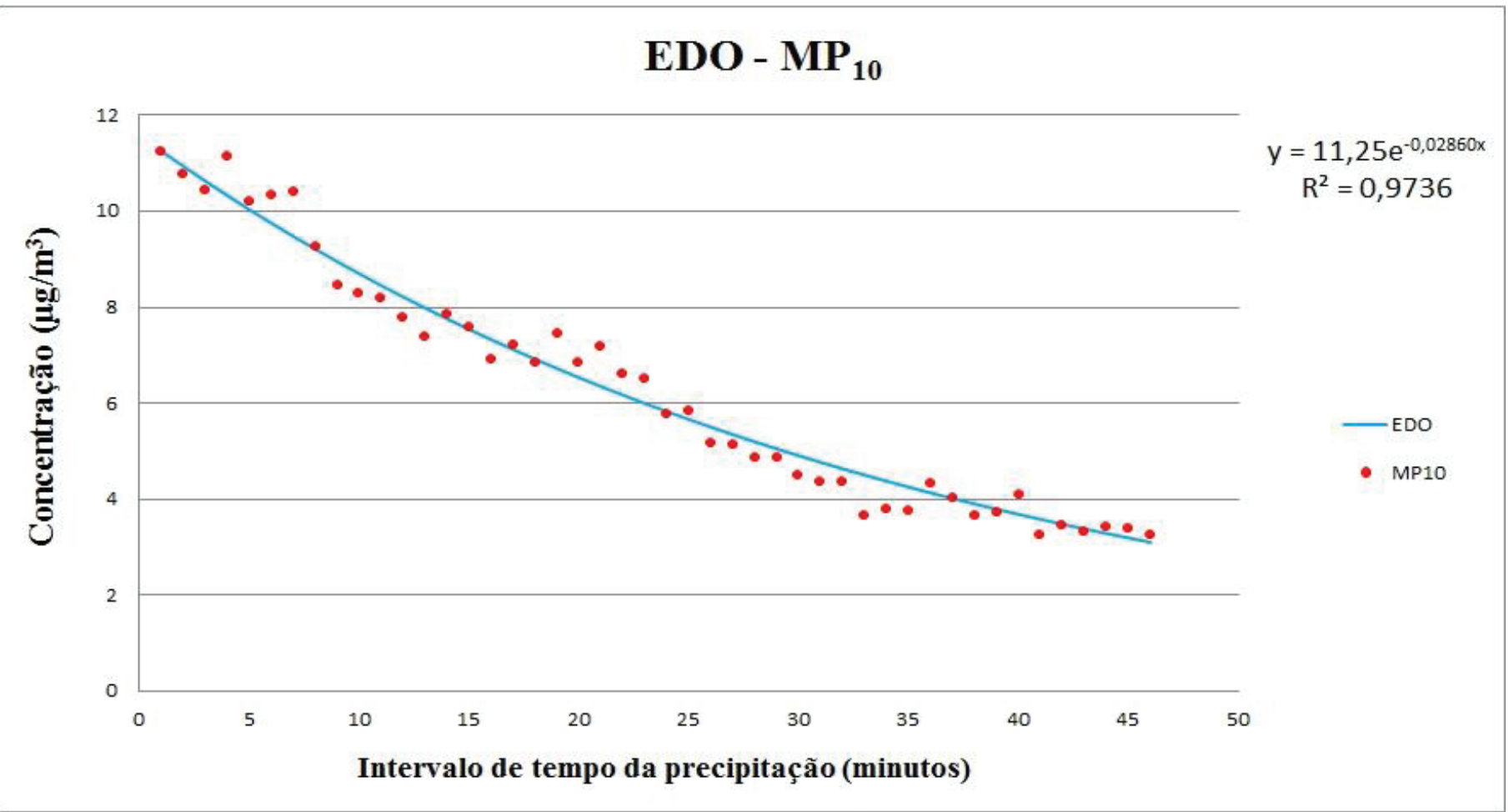

Figura 43. Precipitação 7, equação (14) e o valor de $\mathrm{R}^{2}$. 


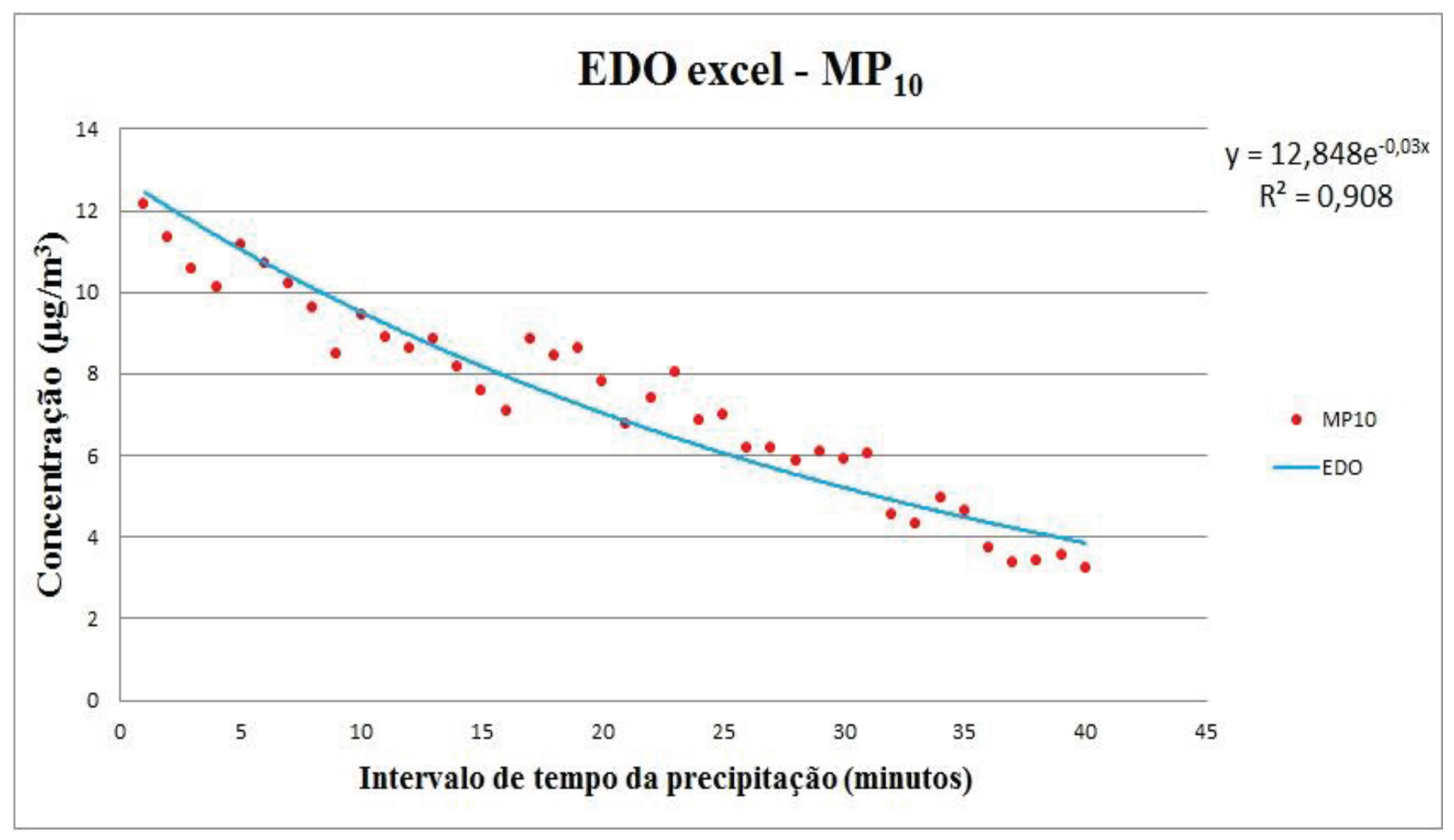

Figura 44. Precipitação 8, linha de tendência exponencial do Excel e o valor de $\mathrm{R}^{2}$.

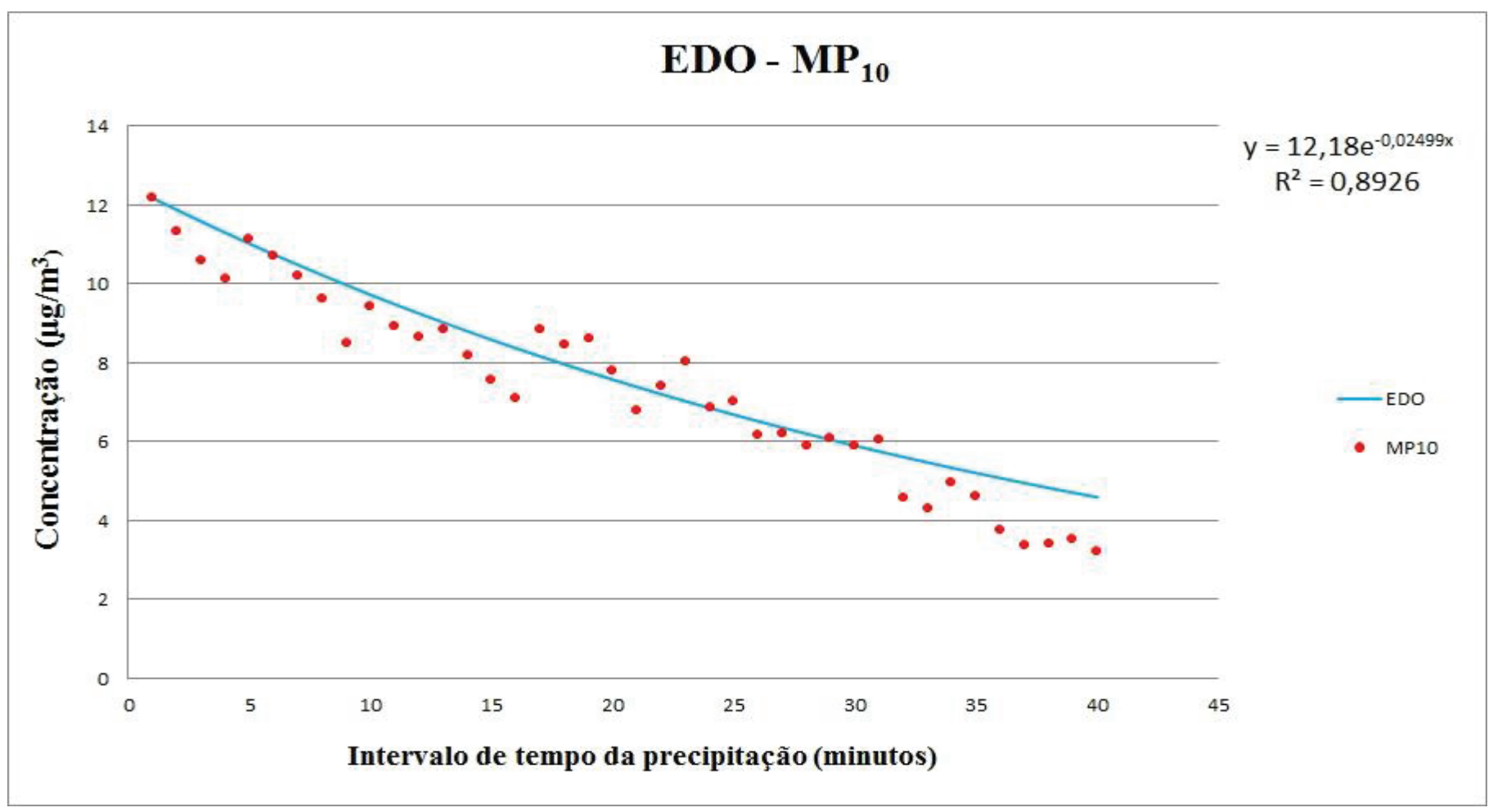

Figura 45. Precipitação 8, equação (14) e o valor de $\mathrm{R}^{2}$. 


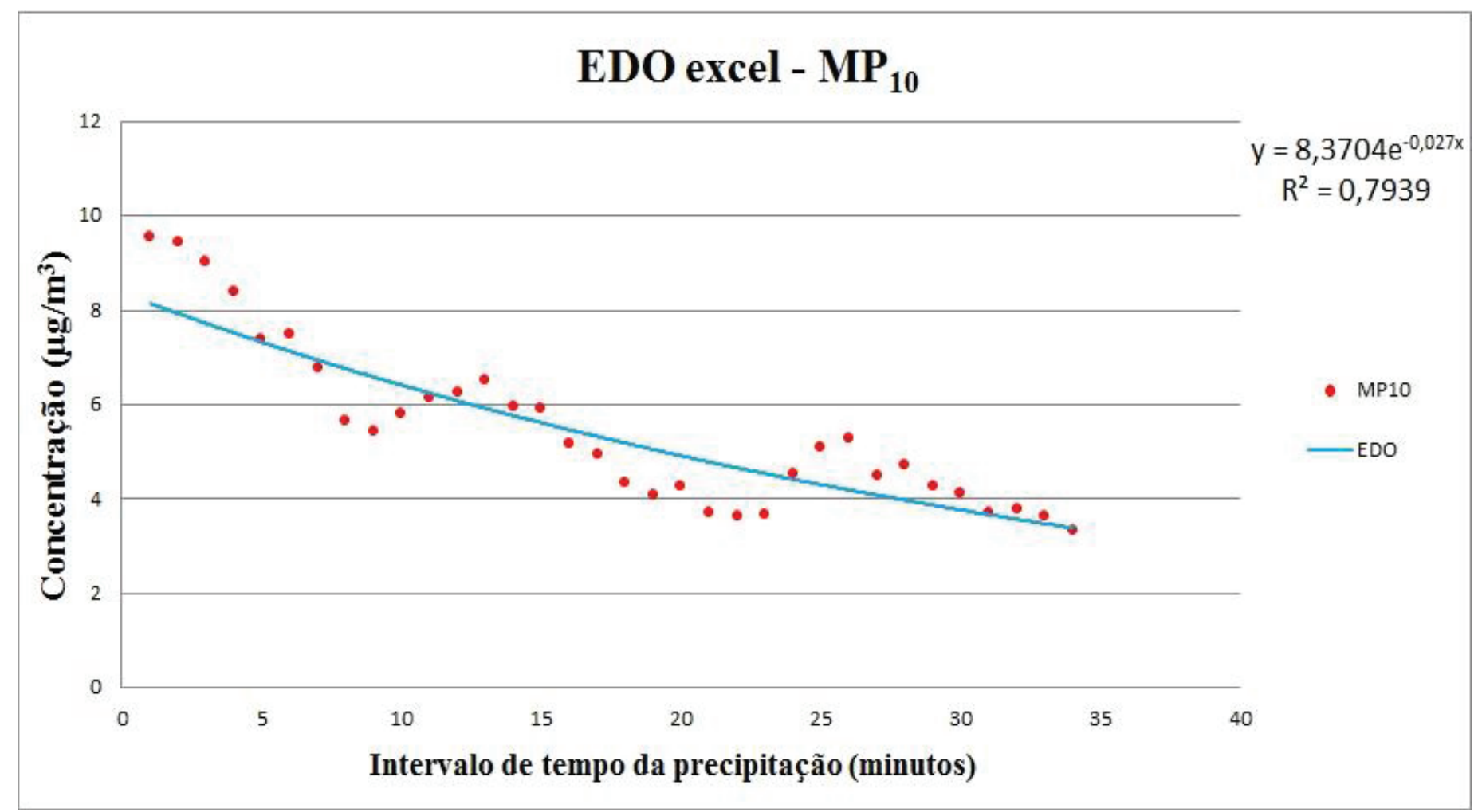

Figura 46. Precipitação 9, linha de tendência exponencial do Excel e o valor de $\mathrm{R}^{2}$.

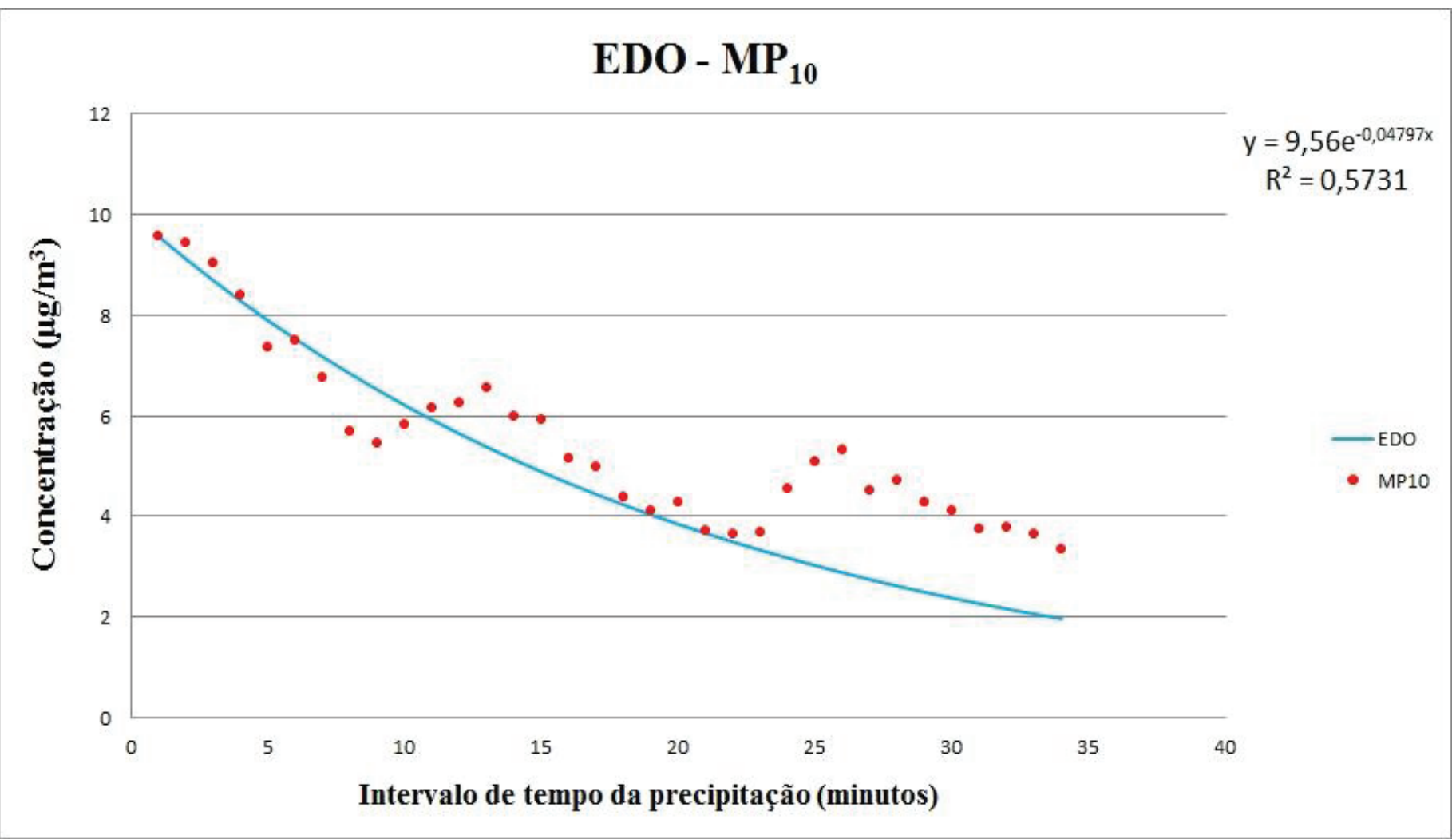

Figura 47. Precipitação 9, equação (14) e o valor de $\mathrm{R}^{2}$. 


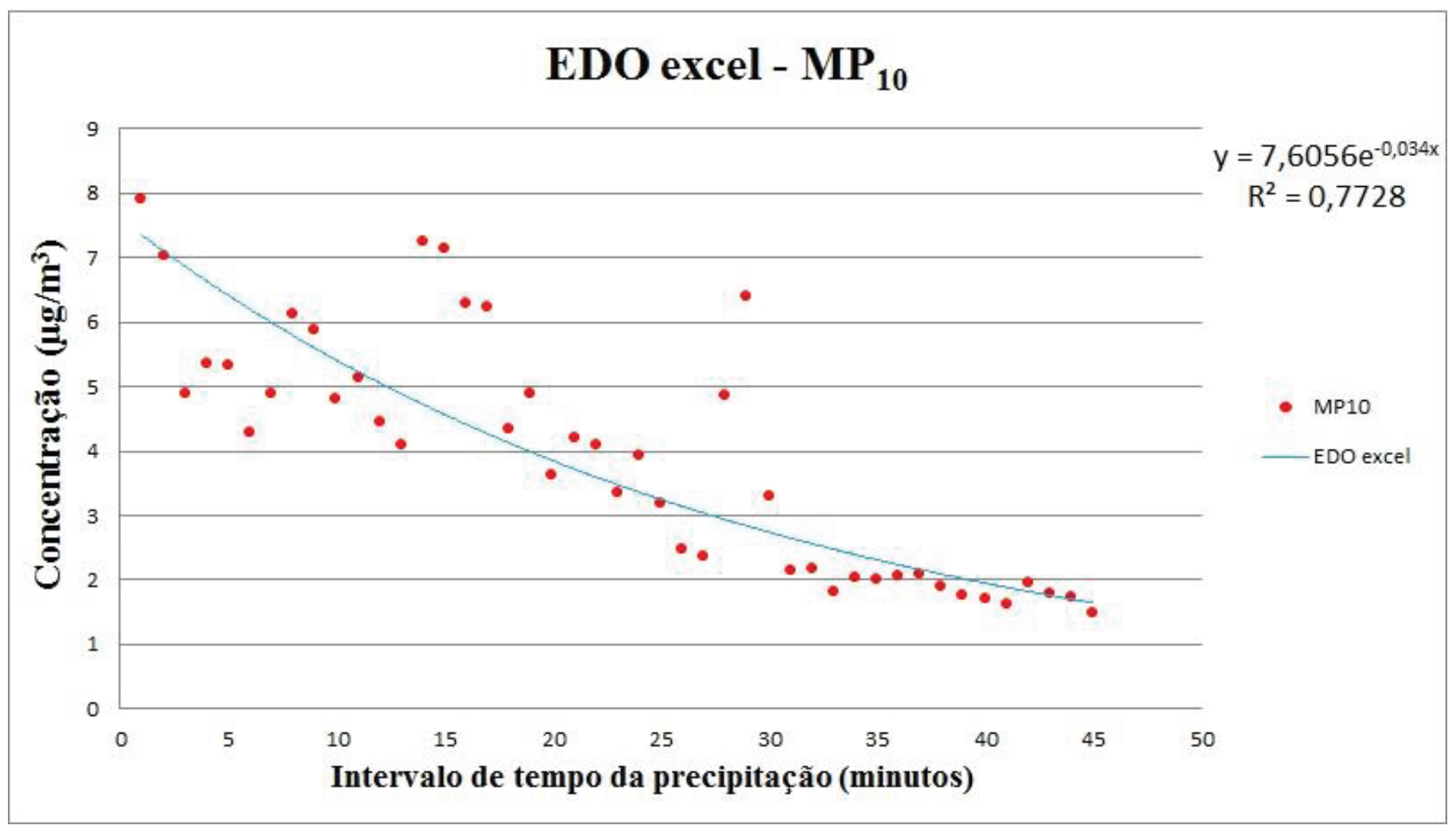

Figura 48. Precipitação 10, linha de tendência exponencial do Excel e o valor de $\mathrm{R}^{2}$.

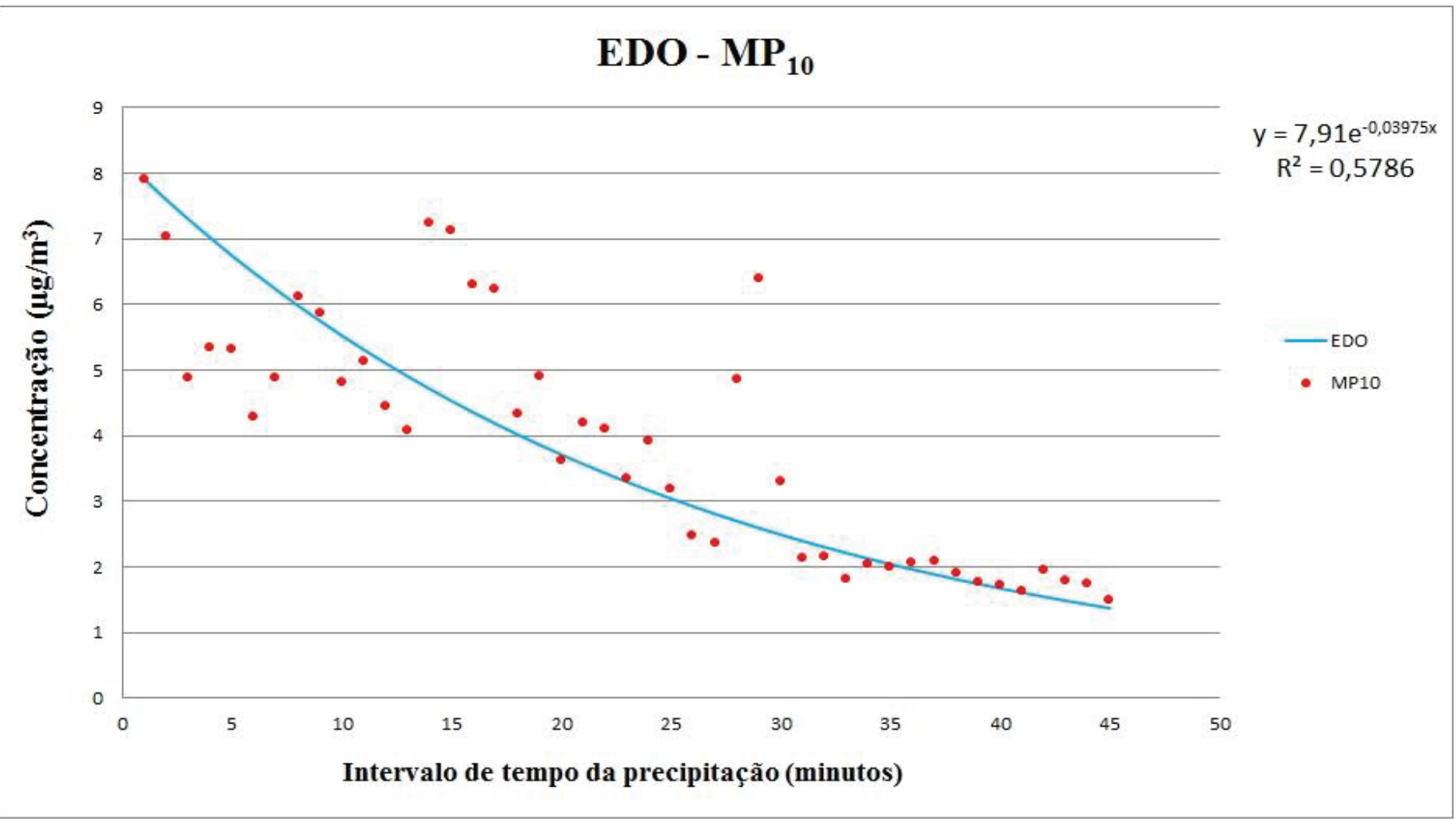

Figura 49. Precipitação 10, equação (14) e o valor de $\mathrm{R}^{2}$. 


\subsection{Variação horária da concentração de $M P_{10}$}

Para verificar se, e quanto a concentração de material particulado varia nos horários de pico, foram calculadas as concentrações de $\mathrm{MP}_{10}$ obtidas através do ADR no horário entre as 17:30h e 19h, quando há grande trânsito de veículos na região da área 1 da USP. Esses valores foram comparados com as médias diárias obtidas pelo ADR (Tabela 9), resultando na Tabela 17, a qual apresenta a variação percentual entre os valores obtidos durante o horário de pico e a média diária.

$\mathrm{O}$ maior valor foi obtido no dia 16 de julho, quando a concentração de $\mathrm{MP}_{10}$ no horário de pico foi 560\% superior à média diária, seguido pelas razões iguais a 369,6 e $311,1 \%$, encontradas respectivamente nos dias 13 e 17 de julho. O quarto maior valor foi igual a $292,5 \%$ e verificado no dia 12 de julho. Em mais quatro dias foram observados resultados onde a concentração de $\mathrm{MP}_{10}$ no horário de pico foi mais de 200\% superior a concentração diária; a saber, nos dias 14, 04, 15 e 10 de julho, cujos valores obtidos foram respectivamente de 243,$8 ; 239,3 ; 210$ e 209,9\%.

Por outro lado, também foram verificados em inúmeros dias valores negativos, ou seja, quando a concentração obtida no horário de pico foi menor que a concentração diária. Nesses dias, entretanto, a diferença porcentual não foi tão pronunciada, como na situação contrária. O maior valor negativo encontrado, em módulo, foi no dia 09 de julho, quando a concentração de $\mathrm{MP}_{10}$ no horário de pico foi $52,9 \%$ menor que a concentração diária. Os segundo e terceiro maior valores, sempre em módulo, foram iguais a 46,2 e 44,7\%, obtidos respectivamente nos dias 04 de novembro e 13 de agosto.

No mês de agosto, onde a grande maioria das concentrações diárias de MP esteve acima do limite recomendado pela OMS, provavelmente devido as queimadas em plantações de cana-de-açúcar na região, não houve concentrações registradas no horário de pico tão acima das concentrações diárias, sendo o maior valor igual a 78,6\%, obtido no dia 15 de agosto. A provável explicação para isso é que nesse mês a influencia do horário de pico no aumento da concentração de $\mathrm{MP}_{10}$ tenha sido menor devido a grande quantidade de MP que já havia sido lançada na atmosfera da região pelas queimadas.

Entre esses resultados negativos e positivos a média geral calculada foi de $20,7 \%$, o que significa que a concentração de $\mathrm{MP}_{10}$ no horário de pico é em média $20 \%$ maior que a concentração diária. Esse resultado já era esperado, entretanto havia a necessidade de confirmar essa hipótese e quantificar a diferença entre as concentrações diária e quando há grande movimentação de pessoas e veículos. 
Tabela 17. Variação da concentração de $\mathrm{MP}_{10} \mathrm{em}$ um horário de pico em relação à média diária.

\begin{tabular}{|c|c|c|c|c|c|c|c|}
\hline Dia & $\begin{array}{c}\text { Variação da } \\
\text { concentração } \\
(\%)\end{array}$ & Dia & $\begin{array}{c}\text { Variação da } \\
\text { concentração } \\
(\%)\end{array}$ & Dia & $\begin{array}{c}\text { Variação da } \\
\text { concentração } \\
(\%)\end{array}$ & Dia & $\begin{array}{c}\text { Variação da } \\
\text { concentração } \\
(\%)\end{array}$ \\
\hline 05/junho & $-5,1$ & 15/julho & 210,0 & 24/agosto & 22,1 & 03/outubro & 19,4 \\
\hline 06/junho & 22,4 & 16/julho & 560,2 & 25/agosto & 36,7 & 04/outubro & 7,6 \\
\hline 07/junho & 0,2 & 17/julho & 311,1 & 26/agosto & $-27,9$ & 05/outubro & $-12,2$ \\
\hline 08/junho & 10,2 & 18/julho & $-13,4$ & 27/agosto & $-15,6$ & 06/outubro & 3,1 \\
\hline 09/junho & $-10,1$ & 19/julho & $-6,0$ & 28/agosto & $-17,3$ & 07/outubro & $-8,4$ \\
\hline 10/junho & $-15,2$ & 20/julho & $-31,1$ & 29/agosto & $-23,9$ & 08/outubro & - \\
\hline 11/junho & 30,0 & 21/julho & $-9,1$ & 30/agosto & $-22,4$ & 09/outubro & $-19,2$ \\
\hline 12/junho & $-22,3$ & 22/julho & $-15,1$ & 31/agosto & 44,3 & 10/outubro & $-22,0$ \\
\hline 13/junho & 37,8 & 23/julho & 30,4 & 01/setembro & 7,6 & 11/outubro & $-5,7$ \\
\hline 14/junho & 50,3 & 24/julho & $-40,0$ & 02/setembro & 23,3 & 12/outubro & 39,3 \\
\hline 15/junho & 37,4 & 25/julho & 5,5 & 03/setembro & - & 13/outubro & 3,4 \\
\hline 16/junho & $-9,7$ & 26/julho & 1,0 & 04/setembro & 23,3 & 14/outubro & $-21,0$ \\
\hline 17/junho & $-40,0$ & 27/julho & $-27,1$ & 05/setembro & 7,7 & 15/outubro & $* 2$ \\
\hline 18/junho & 34,6 & 28/julho & $-20,9$ & 06/setembro & $-8,6$ & 16/outubro & $* 2$ \\
\hline 19/junho & $-2,4$ & 29/julho & $-39,3$ & 07/setembro & 2,1 & 17/outubro & $* 2$ \\
\hline 20/junho & $-7,7$ & 30/julho & $-33,7$ & 08/setembro & 83,6 & 18/outubro & $* 2$ \\
\hline 21/junho & $-44,2$ & 31/julho & 30,7 & 09/setembro & $-9,3$ & 19/outubro & $* 2$ \\
\hline 22/junho & $-25,6$ & 01/agosto & 15,9 & 10/setembro & $-29,6$ & 20/outubro & - \\
\hline 23/junho & 133,4 & 02/agosto & 31,2 & 11/setembro & $-15,6$ & 21/outubro & - \\
\hline 24/junho & 13,7 & 03/agosto & $-42,1$ & $12 /$ setembro & $-15,0$ & 22/outubro & $-41,4$ \\
\hline 25/junho & 185,8 & 04/agosto & $-14,6$ & 13/setembro & - & 23/outubro & $-35,3$ \\
\hline 26/junho & 34,0 & 05/agosto & 16,6 & 14/setembro & $* 1$ & 24/outubro & $-35,4$ \\
\hline 27/junho & 24,8 & 06/agosto & $-20,2$ & $15 /$ setembro & $* 1$ & 25/outubro & $-34,1$ \\
\hline 28/junho & $-8,5$ & 07/agosto & 6,5 & 16/setembro & $* 1$ & 26/outubro & $-21,5$ \\
\hline 29/junho & $-38,5$ & 08/agosto & $-36,8$ & 17/setembro & $* 1$ & 27/outubro & - \\
\hline 30/junho & 17,3 & 09/agosto & $-6,8$ & 18/setembro & $* 1$ & 28/outubro & $* 1$ \\
\hline 01/julho & $-2,0$ & 10/agosto & 9,2 & 19/setembro & $* 1$ & 29/outubro & - \\
\hline 02/julho & 16,6 & 11/agosto & 12,8 & $20 /$ setembro & $* 1$ & 30/outubro & $-11,7$ \\
\hline 03/julho & 29,5 & 12/agosto & $-0,7$ & 21/setembro & $* 1$ & 31/outubro & $-5,0$ \\
\hline 04/julho & 239,3 & 13/agosto & $-44,7$ & $22 /$ setembro & $-26,2$ & 01/novembro & 6,4 \\
\hline 05/julho & $-4,4$ & 14/agosto & 44,6 & 23/setembro & $-26,2$ & 02/novembro & - \\
\hline 06/julho & 60,0 & 15/agosto & 78,6 & 24/setembro & 31,2 & 03/novembro & $-38,0$ \\
\hline 07/julho & 65,5 & 16/agosto & $-15,2$ & $25 /$ setembro & 13,8 & 04/novembro & $-46,2$ \\
\hline 08/julho & 38,0 & 17/agosto & - & 26/setembro & - & 05/novembro & - \\
\hline 09/julho & $-52,9$ & 18/agosto & $* 1$ & 27/setembro & 33,4 & 06/novembro & $-3,2$ \\
\hline 10/julho & 209,9 & 19/agosto & $-22,1$ & 28/setembro & $-25,3$ & 07/novembro & 3,4 \\
\hline 11/julho & 136,0 & 20/agosto & $-43,2$ & 29/setembro & 8,5 & 08/novembro & 63,3 \\
\hline 12/julho & 292,5 & 21/agosto & $-2,1$ & 30/setembro & 24,9 & 09/novembro & $-20,8$ \\
\hline 13/julho & 369,6 & 22/agosto & $-7,2$ & 01/outubro & $-16,2$ & 10/novembro & - \\
\hline 14/julho & 243,8 & 23/agosto & $-29,0$ & 02/outubro & 21,6 & Média & 20,7 \\
\hline
\end{tabular}

*1 - ADR desligado $* 2$ - ADR apresentou valores negativos 


\section{CONCLUSÃO}

As concentrações de material particulado grosso obtidas através do PEM, que utiliza o método gravimétrico, foram superiores as encontradas com o ADR, o qual faz uso da fotometria por espalhamento de luz. A média da razão entre os valores obtidos por esses dois equipamentos foi igual a 3,26; número esse que pode ser considerado um fator médio de correção dos valores obtidos pelo ADR para os valores do PEM.

Apesar do intervalo de diâmetros abrangido pelo material particulado fino corresponder a um quarto do intervalo do material particulado grosso, a porcentagem correspondente a massa do $\mathrm{MP}_{2,5}$ na concentração do $\mathrm{MP}_{10}$ não obedeceu a essa razão e foi igual a $49 \%$. Essa participação "maior" do $\mathrm{MP}_{2,5}$ no $\mathrm{MP}_{10}$ não é algo bom do ponto de vista dos efeitos nocivos à saúde humana, pois esta fração menor de MP é a mais perigosa por ser a única capaz de chegar e se alojar nos alvéolos pulmonares.

As médias obtidas para as concentrações de $\mathrm{MP}_{10}$ e $\mathrm{MP}_{2,5}$, com o método gravimétrico, o qual fornece os resultados mais confiáveis, foram iguais respectivamente a 48,8 e $23,1 \mu \mathrm{g} / \mathrm{m}^{3}$, muito próximas portanto, dos respectivos limites recomendados pela OMS, iguais a 50 e $25 \mu \mathrm{g} / \mathrm{m}^{3}$. A média obtida para o $\mathrm{MP}_{10}$ através da fotometria foi igual a $55,8 \mu \mathrm{g} / \mathrm{m}^{3}$, acima, portanto, do limite recomendado para essa fração de MP. Com relação ao horário de pico, quando aumenta o trânsito de veículos na região do Campus I da USP e consequentemente a emissão de poluentes, a concentração média de $\mathrm{MP}_{10}$ calculada para esse horário foi em média, $20 \%$ maior que a concentração diária.

Considerando-se apenas os dias em que não houve chuva, as médias obtidas através do PEM, para $\mathrm{MP}_{10}$ e $\mathrm{MP}_{2,5}$, e do $\mathrm{ADR}$, somente $\mathrm{MP}_{10}$, se encontraram acima dos seus respectivos limites, evidenciando a importância das precipitações como fenômeno capaz de remover quantidades significativas de material particulado da atmosfera e auxiliar na manutenção das concentrações de MP em valores abaixo dos limites recomendados pela OMS.

As menores concentrações obtidas para o $\mathrm{MP}_{10}$ foram, em sua maioria, verificadas em dias chuvosos, tanto através do PEM como do ADR. As concentrações de $\mathrm{MP}_{2,5}$, obtidas somente através do PEM, também apresentaram os menores valores em dias com chuva. Quanto maior o valor precipitado, menor será a concentração de 
material particulado atmosférico, entretanto essa relação não se comporta de maneira linear e pode ser expressa através de uma equação diferencial de primeira ordem. 


\section{REFERÊNCIAS}

ARTAXO, P.E., 1985. Modelos receptores aplicados à determinação da estrutura de fontes de aerossóis remotos. Tese de doutorado, São Paulo, IF-USP, 188p.

BAIRD, C. Química Ambiental, 2ª ed., Bookman: Porto Alegre, 2002.

BOWER, J.S.; STEVENSON, K.J. et al. Assessing recent surface ozone concentrations in the U.K. Atmospheric Environment, v. 28, p. 115-128. 1994.

Bruno, R. L. Material Particulado Atmosférico na Cidade de São Carlos - SP: Quantificação e Identificação de Fontes. Tese de Doutorado, Universidade Federal de São Carlos, Centro de Ciências Exatas e Tecnologia - Programa de PósGraduação em Engenharia Química, São Carlos, 2005.

BRUNO, R. L., ALMEIDA, A. F., FILHO, V. A., AGUIAR, M. L., GONÇALVES, J. A. S., COURY, J. R. Atmospheric particulate matter in the city of São Carlos/SP, Brazil. Environment and Pollution, v. 22, n.4, p. 477-489, 2006.

CASTANHO, A. D. A., ARTAXO, P. Wintertime and summertime São Paulo aerosol source apportionment study. Atmospheric Environment, v. 35, p. 4889-4902, 2001.

CETESB. Qualidade do Ar no Estado de São Paulo 2010. São Paulo, 2011.

CETESB. Qualidade do Ar no Estado de São Paulo 2012. São Paulo, 2013. 123p.

CONAMA. Conselho Nacional de Meio Ambiente. Resolução nº 03, de 28 de junho de 1990. Dispõe sobre padrões de qualidade do ar, previstos no PRONAR. Publicado no DOU, de 22/08/1990, p. 15937-15939.

COUTO, J.M. Entre estatais e transnacionais: o Pólo Industrial de Cubatão. Tese (Doutorado) - Unicamp, 2003. Disponível em: $<$ http://www.novomilenio.inf.br/cubatao/ch100a.htm $>$. Acesso em 25 dez. 2013. 
EDINBURGH UNIVERSITY. 2013. Disponível em:

$<\underline{\text { http://www.portfolio.mvm.ed.ac.uk/studentwebs/session4/27/greatsmog52.htm }>}$

Acesso em 20 out. 2013.

IBAMA. Portaria Normativa ${ }^{\circ} 348$ - Dispõe sobre padrões nacionais de qualidade do ar e os respectivos métodos de referencia. 1990.

IBGE. Instituto Brasileiro de Geografia e Estatística. In: IBGE: São Carlos/SP. IBGE, 2010. Disponível em: $<$ http://www.ibge.gov.br/cidadesat/link.php?uf=sp $>$

LENZI, E. ; FAVERO, L.O.B. Introdução à química da atmosfera: ciência, vida e sobrevivência. Rio de Janeiro: LCT, 2009, p. 131-135.

MOLNÁR, P.; JANHALL, S.; HALLQUIST, M. Roadside measurements of fine and ultrafine particles at a major road north of Gothenburg. Atmospheric Environment, v. 36, p. 4115-4123. 2002.

ROTIROTI, A. S. Monitoramento da Qualidade Ambiental no Mercado Municipal da cidade de São Carlos, SP: Material Particulado em Suspensão, Temperatura, Umidade e Ruído. São Carlos, 2013. Dissertação de mestrado, USP/ São Carlos, 115p.

SÃO PAULO. Decreto Nº 8.468 - Dispõe sobre a prevenção e o controle da poluição do meio ambiente. 1976

SEINFELD, J.H.; PANDIS, S.N. Atmospheric Chemistry and Physics: From Air Pollution to Climate Change. John Wiley \& Sons, New York, 1998, p. 1326.

SILVA, L. M. Avaliação da Qualidade Ambiental: Mercado Municipal. 2012. 83 f. Dissertação (Mestre em Ciências), Programa de Engenharia Hidráulica e Saneamento, Universidade de São Paulo, 2012.

SZMRECSÁNYI, T, 1994. Tecnologia e degradação ambiental: o caso da agroindústria canavieira no estado de São Paulo, Informações Econômicas, São Paulo, 24, 10, 73-78.

TOLENTINO, M. Estudo crítico sobre o clima da região de São Carlos. Concurso de monografias municipais. Prefeitura Municipal de São Carlos, São Carlos. 1967. 
TORRES, F.T.P.; MARTINS, L.A. Fatores que influenciam na concentração do material particulado na cidade de Juiz de Fora (MG). Caminhos da Geografia (revista on-line), v.6, n.16, p. 23 - 39, 2005.

WATSON, J. G.; CHOW, J. C. Source characterization of major emission sources in the Imperial and Mexicali Valleys along the US/Mexico border. The Science of the Total Environment, v. 276, p. 33- 47. 2001.

WHO - World Health Organization. Health aspects of air pollution with particulate matter, ozone and nitrogen dioxide. Alemanha, 2003. Disponível em: $<\underline{\text { http://www.euro.who.int/_ data/assets/pdf file/0005/112199/E79097.pdf }>}$

WHO - World Health Organization. Air Quality Guidelines. Global Update 2005. 2005. Disponível em:

<http://www.euro.who.int/_ data/assets/pdf_file/0005/78638/E90038.pdf?ua=1>

YONUE, R.Y., 2004. Modelagem numérica da formação, crescimento e transporte das partículas inorgânicas secundárias constituintes do aerossol urbano na região metropolitana de São Paulo. Tese de doutorado USP/São Paulo, 138p. 
APÊNDICE I - VALORES OBTIDOS PELA GRAVIMETRIA (CONTINUA). 
Tabela 1. Dados sobre as duas frações de MP obtidos através do método gravimétrico.

\begin{tabular}{|c|c|c|c|c|c|}
\hline $\begin{array}{l}\text { Dias de } \\
\text { coleta }\end{array}$ & Fração de MP & $\begin{array}{l}\text { (1) Média pré- } \\
\text { coleta }(\mu \mathrm{g})\end{array}$ & $\begin{array}{l}\text { (2) Média pós- } \\
\text { coleta }(\mu \mathrm{g})\end{array}$ & $\begin{array}{l}(2-1) \\
(\mu g)\end{array}$ & $\begin{array}{c}\text { Concentraçãa } \\
\left(\mu \mathrm{g} / \mathrm{m}^{3}\right)\end{array}$ \\
\hline \multirow{2}{*}{$\begin{array}{c}\text { Segunda-feira } \\
(16 / 06)\end{array}$} & $10 \mu \mathrm{m}$ & $185.599,2$ & $185.829,1$ & 229,9 & 47,9 \\
\hline & $2,5 \mu \mathrm{m}$ & $197.361,6$ & $197.472,0$ & 110,4 & 23,0 \\
\hline \multirow{2}{*}{$\begin{array}{c}\text { Terça-feira } \\
(24 / 06)\end{array}$} & $10 \mu \mathrm{m}$ & $193.609,0$ & $193.819,2$ & 210,2 & 43,8 \\
\hline & $2,5 \mu \mathrm{m}$ & $199.561,3$ & $199.649,1$ & 87,8 & 18,3 \\
\hline \multirow{2}{*}{$\begin{array}{l}\text { Sexta-feira } \\
(27 / 06)\end{array}$} & $10 \mu \mathrm{m}$ & $193.920,7$ & $194.200,1$ & 279,4 & 58,2 \\
\hline & $2,5 \mu \mathrm{m}$ & $197.193,0$ & $197.334,1$ & 141,1 & 29,4 \\
\hline \multirow{2}{*}{$\begin{array}{c}\text { Quarta-feira } \\
(02 / 07)\end{array}$} & $10 \mu \mathrm{m}$ & $194.575,7$ & $194.883,9$ & 308,2 & 64,2 \\
\hline & $2,5 \mu \mathrm{m}$ & $191.341,2$ & $191.455,9$ & 114,7 & 23,9 \\
\hline \multirow{2}{*}{$\begin{array}{l}\text { Sexta-feira } \\
(04 / 07)\end{array}$} & $10 \mu \mathrm{m}$ & $202.303,5$ & $202.684,6$ & 381,1 & 79,4 \\
\hline & $2,5 \mu \mathrm{m}$ & $181.849,7$ & $182.000,4$ & 150,7 & 31,4 \\
\hline \multirow{2}{*}{$\begin{array}{c}\text { Quarta-feira } \\
(23 / 07)\end{array}$} & $10 \mu \mathrm{m}$ & $199.064,5$ & $199.292,0$ & 227,5 & 47,4 \\
\hline & $2,5 \mu \mathrm{m}$ & $195.007,5$ & $195.158,7$ & 151,2 & 31,5 \\
\hline \multirow{2}{*}{$\begin{array}{c}\text { Quinta-feira } \\
(24 / 07)\end{array}$} & $10 \mu \mathrm{m}$ & $210.305,7$ & $210.471,3$ & 165,6 & 34,5 \\
\hline & $2,5 \mu \mathrm{m}$ & $201.324,9$ & $201.404,1$ & 79,2 & 16,5 \\
\hline \multirow{2}{*}{$\begin{array}{c}\text { Quinta-feira } \\
(07 / 08)\end{array}$} & $10 \mu \mathrm{m}$ & $191.954,9$ & $192.183,4$ & 228,5 & 47,6 \\
\hline & $2,5 \mu \mathrm{m}$ & $190.014,4$ & $190.120,5$ & 106,1 & 22,1 \\
\hline \multirow{2}{*}{$\begin{array}{c}\text { Sexta-feira } \\
(08 / 08)\end{array}$} & $10 \mu \mathrm{m}$ & $191.005,2$ & $191.242,8$ & 237,6 & 49,5 \\
\hline & $2,5 \mu \mathrm{m}$ & $189.282,7$ & $189.400,8$ & 118,1 & 24,6 \\
\hline \multirow{2}{*}{$\begin{array}{c}\text { Terça-feira } \\
(19 / 08)\end{array}$} & $10 \mu \mathrm{m}$ & $185.534,8$ & $185.650,0$ & 115,2 & 24,0 \\
\hline & $2,5 \mu \mathrm{m}$ & $191.147,5$ & $191.223,8$ & 76,3 & 15,9 \\
\hline \multirow{2}{*}{$\begin{array}{c}\text { Quinta-feira } \\
(21 / 08)\end{array}$} & $10 \mu \mathrm{m}$ & $186.138,5$ & $186.371,3$ & 232,8 & 48,5 \\
\hline & $2,5 \mu \mathrm{m}$ & $190.393,8$ & $190.491,7$ & 97,9 & 20,4 \\
\hline \multirow{2}{*}{$\begin{array}{c}\text { Quarta-feira } \\
(03 / 09)\end{array}$} & $10 \mu \mathrm{m}$ & $193.110,8$ & $193.222,2$ & 111,4 & 23,2 \\
\hline & $2,5 \mu \mathrm{m}$ & $186.647,4$ & $186.689,2$ & 41,8 & 8,7 \\
\hline \multirow{2}{*}{$\begin{array}{c}\text { Segunda-feira } \\
(08 / 09)\end{array}$} & $10 \mu \mathrm{m}$ & $186.435,3$ & $186.662,8$ & 227,5 & 47,4 \\
\hline & $2,5 \mu \mathrm{m}$ & $197.885,3$ & $198.031,2$ & 145,9 & 30,4 \\
\hline \multirow{2}{*}{$\begin{array}{c}\text { Qurta-feira } \\
(10 / 09)\end{array}$} & $10 \mu \mathrm{m}$ & $199.713,8$ & $200.067,6$ & 353,8 & 73,7 \\
\hline & $2,5 \mu \mathrm{m}$ & $193.550,3$ & $193.728,9$ & 178,6 & 37,2 \\
\hline \multirow{2}{*}{$\begin{array}{c}\text { Segunda-feira } \\
(22 / 09)\end{array}$} & $10 \mu \mathrm{m}$ & $202.368,9$ & $202.504,7$ & 135,8 & 28,3 \\
\hline & $2,5 \mu \mathrm{m}$ & $200.683,9$ & $200.775,6$ & 91,7 & 19,1 \\
\hline \multirow{2}{*}{$\begin{array}{c}\text { Sexta-feira } \\
(26 / 09)\end{array}$} & $10 \mu \mathrm{m}$ & $194.967,2$ & $195.155,8$ & 188,6 & 39,3 \\
\hline & $2,5 \mu \mathrm{m}$ & $191.430,1$ & $191.523,2$ & 93,1 & 19,4 \\
\hline \multirow{2}{*}{$\begin{array}{c}\text { Segunda-feira } \\
(06 / 10)\end{array}$} & $10 \mu \mathrm{m}$ & $202.270,7$ & $202.524,6$ & 253,9 & 52,9 \\
\hline & $2,5 \mu \mathrm{m}$ & $191.775,7$ & $191.905,8$ & 130,1 & 27,1 \\
\hline \multirow{2}{*}{$\begin{array}{c}\text { Quinta-feira } \\
(09 / 10)\end{array}$} & $10 \mu \mathrm{m}$ & $192.969,3$ & $193.316,8$ & 347,5 & 72,4 \\
\hline & $2,5 \mu \mathrm{m}$ & $200.662,4$ & $200.787,2$ & 124,8 & 26,0 \\
\hline
\end{tabular}




\section{APÊNDICE I - VALORES OBTIDOS PELA GRAVIMETRIA (CONTINUAÇÃO).}

Tabela 1. Dados sobre as duas frações de MP obtidos através do método gravimétrico (Continuação).

\begin{tabular}{|c|c|c|c|c|c|}
\hline $\begin{array}{c}\text { Dias de } \\
\text { coleta }\end{array}$ & Fração de MP & $\begin{array}{l}\text { (1) Média pré- } \\
\text { coleta }(\mu \mathrm{g})\end{array}$ & $\begin{array}{l}\text { (2) Média pós- } \\
\text { coleta }(\mu \mathrm{g})\end{array}$ & $\begin{array}{l}(2-1) \\
(\mu \mathrm{g})\end{array}$ & $\begin{array}{c}\text { Concentração } \\
\left(\mu \mathrm{g} / \mathrm{m}^{3}\right)\end{array}$ \\
\hline \multirow{2}{*}{$\begin{array}{c}\text { Segunda-feira } \\
(20 / 10)\end{array}$} & $10 \mu \mathrm{m}$ & $195.198,7$ & $195.429,6$ & 230,9 & 48,1 \\
\hline & $2,5 \mu \mathrm{m}$ & $206.331,2$ & $206.473,3$ & 142,1 & 29,6 \\
\hline \multirow{2}{*}{$\begin{array}{c}\text { Terça-feira } \\
(21 / 10)\end{array}$} & $10 \mu \mathrm{m}$ & $191.975,6$ & $192.206,5$ & 230,9 & 48,1 \\
\hline & $2,5 \mu \mathrm{m}$ & $187.979,1$ & $188.088,1$ & 109,0 & 22,7 \\
\hline \multirow{2}{*}{$\begin{array}{c}\text { Segunda-feira } \\
(03 / 11)\end{array}$} & $10 \mu \mathrm{m}$ & $187.869,6$ & $188.171,0$ & 301,4 & 62,8 \\
\hline & $2,5 \mu \mathrm{m}$ & $196.049,2$ & $196.134,2$ & 85,0 & 17,7 \\
\hline \multirow{2}{*}{$\begin{array}{c}\text { Terça-feira } \\
(04 / 11)\end{array}$} & $10 \mu \mathrm{m}$ & $189.541,0$ & - & - & - \\
\hline & $2,5 \mu \mathrm{m}$ & $182.082,0$ & $182.149,7$ & 67,7 & 14,1 \\
\hline \multirow{2}{*}{$\begin{array}{c}\text { Quinta-feira } \\
(06 / 11)\end{array}$} & $10 \mu \mathrm{m}$ & $195.948,5$ & $196.101,6$ & 153,1 & 31,9 \\
\hline & $2,5 \mu \mathrm{m}$ & $185.716,8$ & - & - & - \\
\hline
\end{tabular}


APÊEDICE II - Memorial de cálculo para os valores de $\mathrm{R}^{2}$ utilizando a equação (14) e as precipitações da Tabela 12 . 
Tabela1. Memorial de cálculo de $\mathrm{R}^{2}$ para a equação (14) e precipitação 1 da Tabela 12 .

\begin{tabular}{|c|c|c|c|c|c|}
\hline & $\begin{array}{l}\text { Vo= Valor } \\
\text { ADR }\end{array}$ & & Data & $\mathbf{P} / \Delta \mathbf{t}=34 / 143$ & Ko \\
\hline & $\begin{array}{l}\mathbf{V p}=\text { Valor } \\
\text { equação }\end{array}$ & & $24 / \mathrm{jul}$ & 0,23776 & 34,98 \\
\hline Tempo (t) em (min) & Coeficiente & Valor Equação & Valor ADR & $(\mathrm{Vp}-\mathrm{Vo})^{2}-($ Resíduo $)$ & $\left(V_{0}-M\right)^{2}$ \\
\hline 0 & 0,00000 & 34,98 & 34,98 & $\begin{array}{r}0,00 \\
\end{array}$ & 282,50 \\
\hline 1 & 0,01251 & 34,55 & 32,94 & 2,58 & 218,09 \\
\hline 2 & 0,02502 & 34,12 & 33,36 & 0,57 & 230,67 \\
\hline 3 & 0,03753 & 33,69 & 33,27 & 0,18 & 227,94 \\
\hline 4 & 0,05004 & 33,27 & 33,03 & 0,06 & 220,75 \\
\hline 5 & 0,06255 & 32,86 & 32,24 & 0,38 & 197,90 \\
\hline 6 & 0,07506 & 32,45 & 32,93 & 0,23 & 217,79 \\
\hline 7 & 0,08757 & 32,05 & 32,19 & 0,02 & 196,50 \\
\hline 8 & 0,10008 & 31,65 & 30,89 & 0,58 & 161,74 \\
\hline 9 & 0,11259 & 31,26 & 28,94 & 5,36 & 115,95 \\
\hline 10 & 0,12510 & 30,87 & 29,19 & 2,81 & 121,39 \\
\hline 11 & 0,13761 & 30,48 & 29,8 & 0,47 & 135,21 \\
\hline 12 & 0,15012 & 30,10 & 29,07 & 1,07 & 118,76 \\
\hline 13 & 0,16263 & 29,73 & 28,46 & 1,61 & 105,84 \\
\hline 14 & 0,17514 & 29,36 & 28,27 & 1,19 & 101,97 \\
\hline 15 & 0,18765 & 29,00 & 28,1 & 0,80 & 98,56 \\
\hline 16 & 0,20016 & 28,63 & 27,25 & 1,92 & 82,41 \\
\hline 17 & 0,21267 & 28,28 & 26,65 & 2,65 & 71,87 \\
\hline 18 & 0,22518 & 27,93 & 25,81 & 4,48 & 58,34 \\
\hline 19 & 0,23769 & 27,58 & 24,6 & 8,88 & 41,32 \\
\hline 20 & 0,25020 & 27,24 & 25,13 & 4,44 & 48,41 \\
\hline 21 & 0,26271 & 26,90 & 24,17 & 7,44 & 35,97 \\
\hline 22 & 0,27522 & 26,56 & 25,24 & 1,75 & 49,95 \\
\hline 23 & 0,28773 & 26,23 & 23,53 & 7,31 & 28,71 \\
\hline 24 & 0,30024 & 25,91 & 23,47 & 5,94 & 28,07 \\
\hline 25 & 0,31275 & 25,59 & 23,06 & 6,38 & 23,89 \\
\hline 26 & 0,32526 & 25,27 & 22,69 & 6,64 & 20,41 \\
\hline 27 & 0,33777 & 24,95 & 22,02 & 8,60 & 14,81 \\
\hline 28 & 0,35028 & 24,64 & 23,05 & 2,54 & 23,79 \\
\hline 29 & 0,36279 & 24,34 & 22,27 & 4,27 & 16,79 \\
\hline 30 & 0,37530 & 24,03 & 22,06 & 3,90 & 15,11 \\
\hline 31 & 0,38781 & 23,74 & 22,62 & 1,24 & 19,78 \\
\hline 32 & 0,40032 & 23,44 & 22,78 & 0,44 & 21,23 \\
\hline 33 & 0,41283 & 23,15 & 22,6 & 0,30 & 19,61 \\
\hline 34 & 0,42534 & 22,86 & 22,47 & 0,15 & 18,47 \\
\hline 35 & 0,43785 & 22,58 & 21,94 & 0,41 & 14,20 \\
\hline 36 & 0,45035 & 22,30 & 20,99 & 1,71 & 7,94 \\
\hline 37 & 0,46286 & 22,02 & 20,42 & 2,56 & 5,05 \\
\hline
\end{tabular}


Tabela 1. Memorial de cálculo de $\mathrm{R}^{2}$ para a equação (14) e precipitação 1 da Tabela 12 (Continuação).

\begin{tabular}{|c|c|c|c|c|c|}
\hline Tempo (t) em (min) & Coeficiente & Valor Equação & Valor ADR & $(\mathrm{Vp}-\mathrm{Vo})^{2}$-(Resíduo) & $\left(V_{0}-M\right)^{2}$ \\
\hline 38 & 0,47537 & 21,75 & 21,27 & 0,23 & 9,60 \\
\hline 39 & 0,48788 & 21,48 & 21,73 & 0,06 & 12,66 \\
\hline 40 & 0,50039 & 21,21 & 20,63 & 0,33 & 6,04 \\
\hline 41 & 0,51290 & 20,94 & 20,97 & 0,00 & 7,83 \\
\hline 42 & 0,52541 & 20,68 & 22,89 & 4,87 & 22,26 \\
\hline 43 & 0,53792 & 20,43 & 19,17 & 1,58 & 1,00 \\
\hline 44 & 0,55043 & 20,17 & 19,35 & 0,68 & 1,39 \\
\hline 45 & 0,56294 & 19,92 & 17,89 & 4,13 & 0,08 \\
\hline 46 & 0,57545 & 19,67 & 19,72 & 0,00 & 2,40 \\
\hline 47 & 0,58796 & 19,43 & 20,16 & 0,53 & 3,95 \\
\hline 48 & 0,60047 & 19,19 & 21,81 & 6,87 & 13,23 \\
\hline 49 & 0,61298 & 18,95 & 21,45 & 6,25 & 10,74 \\
\hline 50 & 0,62549 & 18,71 & 21,36 & 7,00 & 10,16 \\
\hline 51 & 0,63800 & 18,48 & 19,75 & 1,61 & 2,49 \\
\hline 52 & 0,65051 & 18,25 & 18,94 & 0,47 & 0,59 \\
\hline 53 & 0,66302 & 18,02 & 21,24 & 10,34 & 9,41 \\
\hline 54 & 0,67553 & 17,80 & 22,84 & 25,39 & 21,79 \\
\hline 55 & 0,68804 & 17,58 & 23,38 & 33,65 & 27,12 \\
\hline 56 & 0,70055 & 17,36 & 23,32 & 35,51 & 26,50 \\
\hline 57 & 0,71306 & 17,15 & 25,19 & 64,72 & 49,25 \\
\hline 58 & 0,72557 & 16,93 & 23,23 & 39,66 & 25,58 \\
\hline 59 & 0,73808 & 16,72 & 22,53 & 33,74 & 18,99 \\
\hline 60 & 0,75059 & 16,51 & 23,94 & 55,15 & 33,27 \\
\hline 61 & 0,76310 & 16,31 & 23,28 & 48,60 & 26,09 \\
\hline 62 & 0,77561 & 16,11 & 26,53 & 108,67 & 69,85 \\
\hline 63 & 0,78812 & 15,91 & 22,54 & 44,02 & 19,08 \\
\hline 64 & 0,80063 & 15,71 & 20,98 & 27,80 & 7,88 \\
\hline 65 & 0,81314 & 15,51 & 21,89 & 40,67 & 13,82 \\
\hline 66 & 0,82565 & 15,32 & 22,13 & 46,38 & 15,66 \\
\hline 67 & 0,83816 & 15,13 & 19,24 & 16,90 & 1,14 \\
\hline 68 & 0,85067 & 14,94 & 18,7 & 14,13 & 0,28 \\
\hline 69 & 0,86318 & 14,76 & 18,15 & 11,52 & 0,00 \\
\hline 70 & 0,87569 & 14,57 & 16,84 & 5,14 & 1,77 \\
\hline 71 & 0,88820 & 14,39 & 16,71 & 5,38 & 2,14 \\
\hline 72 & 0,90071 & 14,21 & 17,7 & 12,17 & 0,22 \\
\hline 73 & 0,91322 & 14,04 & 17,98 & 15,56 & 0,04 \\
\hline 74 & 0,92573 & 13,86 & 17,7 & 14,74 & 0,22 \\
\hline 75 & 0,93824 & 13,69 & 18,88 & 26,95 & 0,50 \\
\hline 76 & 0,95075 & 13,52 & 17,66 & 17,16 & 0,26 \\
\hline 77 & 0,96326 & 13,35 & 20,18 & 46,65 & 4,03 \\
\hline 78 & 0,97577 & 13,18 & 19,72 & 42,72 & 2,40 \\
\hline
\end{tabular}


Tabela 1. Memorial de cálculo de $\mathrm{R}^{2}$ para a equação (14) e precipitação 1 da Tabela 12 (Continuação).

\begin{tabular}{|c|c|c|c|c|c|}
\hline Tempo (t) em (min) & Coeficiente & Valor Equação & Valor ADR & Vp - Vo) ${ }^{2}$-(Resíduo) & $\left(V_{0}-M\right)^{2}$ \\
\hline 79 & 0,98828 & 13,02 & 16,75 & 13,91 & 2,02 \\
\hline 80 & 1,00079 & 12,86 & 17,43 & 20,90 & 0,55 \\
\hline 81 & 1,01330 & 12,70 & 17,04 & 18,85 & 1,28 \\
\hline 82 & 1,02581 & 12,54 & 15,76 & 10,36 & 5,82 \\
\hline 83 & 1,03832 & 12,38 & 13,75 & 1,86 & 19,56 \\
\hline 84 & 1,05083 & 12,23 & 14,1 & 3,49 & 16,58 \\
\hline 85 & 1,06334 & 12,08 & 14,15 & 4,29 & 16,18 \\
\hline 86 & 1,07585 & 11,93 & 14,44 & 6,31 & 13,93 \\
\hline 87 & 1,08836 & 11,78 & 13,98 & 4,84 & 17,57 \\
\hline 88 & 1,10087 & 11,63 & 14,21 & 6,64 & 15,70 \\
\hline 89 & 1,11338 & 11,49 & 14,7 & 10,31 & 12,06 \\
\hline 90 & 1,12589 & 11,35 & 15,07 & 13,87 & 9,62 \\
\hline 91 & 1,13840 & 11,21 & 15,82 & 21,30 & 5,53 \\
\hline 92 & 1,15091 & 11,07 & 16,9 & 34,04 & 1,62 \\
\hline 93 & 1,16342 & 10,93 & 17,27 & 40,22 & 0,81 \\
\hline 94 & 1,17593 & 10,79 & 19,05 & 68,19 & 0,77 \\
\hline 95 & 1,18844 & 10,66 & 19,51 & 78,35 & 1,79 \\
\hline 96 & 1,20095 & 10,53 & 16,72 & 38,37 & 2,11 \\
\hline 97 & 1,21346 & 10,39 & 15,05 & 21,67 & 9,75 \\
\hline 98 & 1,22597 & 10,27 & 15,9 & 31,75 & 5,16 \\
\hline 99 & 1,23848 & 10,14 & 16,79 & 44,25 & 1,91 \\
\hline 100 & 1,25099 & 10,01 & 16,63 & 43,80 & 2,38 \\
\hline 101 & 1,26350 & 9,89 & 15,25 & 28,76 & 8,54 \\
\hline 102 & 1,27601 & 9,76 & 15,3 & 30,64 & 8,25 \\
\hline 103 & 1,28852 & 9,64 & 14,21 & 20,85 & 15,70 \\
\hline 104 & 1,30103 & 9,52 & 13,5 & 15,81 & 21,83 \\
\hline 105 & 1,31354 & 9,40 & 11,66 & 5,09 & 42,41 \\
\hline 106 & 1,32605 & 9,29 & 11,22 & 3,73 & 48,33 \\
\hline 107 & 1,33856 & 9,17 & 11,61 & 5,94 & 43,06 \\
\hline 108 & 1,35106 & 9,06 & 11,44 & 5,67 & 45,32 \\
\hline 109 & 1,36357 & 8,95 & 11,05 & 4,43 & 50,73 \\
\hline 110 & 1,37608 & 8,83 & 11,36 & 6,38 & 46,41 \\
\hline 111 & 1,38859 & 8,72 & 10,85 & 4,52 & 53,61 \\
\hline 112 & 1,40110 & 8,62 & 9,68 & 1,13 & 72,12 \\
\hline 113 & 1,41361 & 8,51 & 10,06 & 2,40 & 65,81 \\
\hline 114 & 1,42612 & 8,40 & 10,6 & 4,82 & 57,34 \\
\hline 115 & 1,43863 & 8,30 & 11,73 & 11,77 & 41,50 \\
\hline 116 & 1,45114 & 8,20 & 10,23 & 4,14 & 63,08 \\
\hline 117 & 1,46365 & 8,09 & 9,66 & 2,45 & 72,46 \\
\hline 118 & 1,47616 & 7,99 & 9,12 & 1,27 & 81,94 \\
\hline
\end{tabular}


Tabela 1. Memorial de cálculo de $\mathrm{R}^{2}$ para a equação (14) e precipitação 1 da Tabela 12 (Continuação).

\begin{tabular}{|c|c|c|c|c|c|}
\hline Tempo (t) em (min) & Coeficiente & Valor Equação & Valor ADR & Vp - Vo $)^{2}$-(Resíduo) & $\left(V_{0}-M\right)^{2}$ \\
\hline 119 & 1,48867 & 7,89 & 9,54 & 2,71 & 74,51 \\
\hline 120 & 1,50118 & 7,80 & 8,18 & 0,15 & 99,84 \\
\hline 121 & 1,51369 & 7,70 & 8,71 & 1,02 & 89,53 \\
\hline 122 & 1,52620 & 7,60 & 8,66 & 1,12 & 90,48 \\
\hline 123 & 1,53871 & 7,51 & 8,07 & 0,32 & 102,05 \\
\hline 124 & 1,55122 & 7,42 & 8,41 & 0,99 & 95,30 \\
\hline 125 & 1,56373 & 7,32 & 7,69 & 0,13 & 109,88 \\
\hline 126 & 1,57624 & 7,23 & 8,13 & 0,81 & 100,85 \\
\hline 127 & 1,58875 & 7,14 & 7,99 & 0,72 & 103,68 \\
\hline 128 & 1,60126 & 7,05 & 8,22 & 1,36 & 99,05 \\
\hline 129 & 1,61377 & 6,97 & 7,77 & 0,65 & 108,21 \\
\hline 130 & 1,62628 & 6,88 & 8,37 & 2,22 & 96,08 \\
\hline 131 & 1,63879 & 6,79 & 8,04 & 1,55 & 102,66 \\
\hline 132 & 1,65130 & 6,71 & 7,14 & 0,19 & 121,71 \\
\hline 133 & 1,66381 & 6,63 & 6,87 & 0,06 & 127,74 \\
\hline 134 & 1,67632 & 6,54 & 6,57 & 0,00 & 134,61 \\
\hline 135 & 1,68883 & 6,46 & 6,66 & 0,04 & 132,53 \\
\hline 136 & 1,70134 & 6,38 & 6,81 & 0,18 & 129,10 \\
\hline 137 & 1,71385 & 6,30 & 5,99 & 0,10 & 148,41 \\
\hline 138 & 1,72636 & 6,22 & 6,57 & 0,12 & 134,61 \\
\hline 139 & 1,73887 & 6,15 & 6,16 & 0,00 & 144,29 \\
\hline 140 & 1,75138 & 6,07 & 5,47 & 0,36 & 161,35 \\
\hline 141 & 1,76389 & 5,99 & 5,46 & 0,29 & 161,60 \\
\hline \multirow[t]{4}{*}{142} & 1,77640 & 5,92 & 5,54 & 0,14 & 159,57 \\
\hline & Média & 16,39 & 18,1722 & 1692,40 & 7728,19 \\
\hline & & & & SQres & SQtot \\
\hline & & & & $\mathbf{R}^{2}$ & 0,7810 \\
\hline
\end{tabular}


Tabela 2. Memorial de cálculo de $\mathrm{R}^{2}$ para a equação (14) e precipitação 2 da Tabela 12.

\begin{tabular}{|c|c|c|c|c|c|}
\hline & $V_{0}=$ Valor ADR & & Data & $\mathbf{P} / \Delta \mathbf{t}=27 / 73$ & Ko \\
\hline & \begin{tabular}{|l|}
$\begin{array}{l}\text { Vp }=\text { Valor } \\
\text { equação }\end{array}$ \\
\end{tabular} & & $02 / \mathrm{set}$ & 0,36986 & 42,23 \\
\hline Tempo (t) em (min) & Coeficiente & Valor Equação & Valor ADR & $(\mathrm{Vp}-\mathrm{Vo})^{2}$-Resíduo $)$ & $\left(V_{0}-M\right)^{2}$ \\
\hline 0 & 0,00000 & 42,23 & 42,23 & $\begin{array}{r}0,00 \\
\end{array}$ & 175,28 \\
\hline 1 & 0,01946 & 41,42 & 40,72 & 0,48 & 154,40 \\
\hline 2 & 0,03892 & 40,62 & 37,72 & 8,40 & 135,20 \\
\hline 3 & 0,05838 & 39,84 & 36,73 & 9,64 & 117,61 \\
\hline 4 & 0,07784 & 39,07 & 35,65 & 11,68 & 101,54 \\
\hline 5 & 0,09730 & 38,31 & 32,38 & 35,22 & 86,94 \\
\hline 6 & 0,11676 & 37,58 & 33,26 & 18,63 & 73,71 \\
\hline 7 & 0,13622 & 36,85 & 33,85 & 9,01 & 61,80 \\
\hline 8 & 0,15568 & 36,14 & 36,06 & 0,01 & 51,14 \\
\hline 9 & 0,17514 & 35,45 & 35 & 0,20 & 41,66 \\
\hline 10 & 0,19460 & 34,76 & 36,04 & 1,63 & 33,31 \\
\hline 11 & 0,21406 & 34,09 & 32,69 & 1,97 & 26,03 \\
\hline 12 & 0,23352 & 33,44 & 33,33 & 0,01 & 19,75 \\
\hline 13 & 0,25298 & 32,79 & 33,98 & 1,41 & 14,44 \\
\hline 14 & 0,27244 & 32,16 & 33,69 & 2,34 & 10,04 \\
\hline 15 & 0,29191 & 31,54 & 35,83 & 18,41 & 6,49 \\
\hline 16 & 0,31137 & 30,93 & 33,91 & 8,87 & 3,77 \\
\hline 17 & 0,33083 & 30,34 & 33,22 & 8,32 & 1,81 \\
\hline 18 & 0,35029 & 29,75 & 31,09 & 1,79 & 0,58 \\
\hline 19 & 0,36975 & 29,18 & 31,71 & 6,42 & 0,03 \\
\hline 20 & 0,38921 & 28,61 & 31,47 & 8,15 & 0,14 \\
\hline 21 & 0,40867 & 28,06 & 32,47 & 19,42 & 0,86 \\
\hline 22 & 0,42813 & 27,52 & 31,69 & 17,37 & 2,16 \\
\hline 23 & 0,44759 & 26,99 & 31,47 & 20,05 & 3,99 \\
\hline 24 & 0,46705 & 26,47 & 29,83 & 11,28 & 6,34 \\
\hline 25 & 0,48651 & 25,96 & 30,22 & 18,13 & 9,17 \\
\hline 26 & 0,50597 & 25,46 & 31,82 & 40,43 & 12,45 \\
\hline 27 & 0,52543 & 24,97 & 30,29 & 28,30 & 16,16 \\
\hline 28 & 0,54489 & 24,49 & 31,08 & 43,44 & 20,26 \\
\hline 29 & 0,56435 & 24,02 & 29,72 & 32,52 & 24,73 \\
\hline 30 & 0,58381 & 23,55 & 29,95 & 40,90 & 29,55 \\
\hline 31 & 0,60327 & 23,10 & 30,4 & 53,28 & 34,69 \\
\hline 32 & 0,62273 & 22,66 & 29,7 & 49,63 & 40,13 \\
\hline 33 & 0,64219 & 22,22 & 31,84 & 92,57 & 45,86 \\
\hline 34 & 0,66165 & 21,79 & 33,11 & 128,13 & 51,84 \\
\hline 35 & 0,68111 & 21,37 & 31,6 & 104,64 & 58,06 \\
\hline 36 & 0,70057 & 20,96 & 29,84 & 78,88 & 64,51 \\
\hline
\end{tabular}


Tabela 2. Memorial de cálculo de $\mathrm{R}^{2}$ para a equação (14) e precipitação 2 da Tabela 12 (Continuação).

\begin{tabular}{|c|c|c|c|c|c|}
\hline $\begin{array}{l}\text { Tempo (t) em } \\
\text { (min) }\end{array}$ & Coeficiente & Valor Equação & Valor ADR & $(\mathrm{Vp}-\mathrm{Vo})^{2}$-(Resíduo) & $\left(V_{o}-M\right)^{2}$ \\
\hline 37 & 0,72003 & 20,55 & 27,33 & 45,90 & 71,16 \\
\hline 38 & 0,73949 & 20,16 & 26,39 & 38,83 & 78,00 \\
\hline 39 & 0,75895 & 19,77 & 25,7 & 35,16 & 85,01 \\
\hline 40 & 0,77841 & 19,39 & 25,86 & 41,87 & 92,18 \\
\hline 41 & 0,79787 & 19,02 & 25,57 & 42,96 & 99,50 \\
\hline 42 & 0,81733 & 18,65 & 24,22 & 31,04 & 106,95 \\
\hline 43 & 0,83679 & 18,29 & 24,68 & 40,84 & 114,51 \\
\hline 44 & 0,85626 & 17,94 & 26,48 & 72,98 & 122,18 \\
\hline 45 & 0,87572 & 17,59 & 28,94 & 128,79 & 129,94 \\
\hline 46 & 0,89518 & 17,25 & 28,12 & 118,10 & 137,78 \\
\hline 47 & 0,91464 & 16,92 & 26,13 & 84,82 & 145,70 \\
\hline 48 & 0,93410 & 16,59 & 26,9 & 106,22 & 153,68 \\
\hline 49 & 0,95356 & 16,27 & 24,43 & 66,52 & 161,71 \\
\hline 50 & 0,97302 & 15,96 & 23,76 & 60,83 & 169,78 \\
\hline 51 & 0,99248 & 15,65 & 23,39 & 59,86 & 177,89 \\
\hline 52 & 1,01194 & 15,35 & 23,41 & 64,94 & 186,03 \\
\hline 53 & 1,03140 & 15,06 & 24,16 & 82,89 & 194,19 \\
\hline 54 & 1,05086 & 14,77 & 25,98 & 125,77 & 202,36 \\
\hline 55 & 1,07032 & 14,48 & 25,22 & 115,33 & 210,54 \\
\hline 56 & 1,08978 & 14,20 & 24,26 & 101,17 & 218,71 \\
\hline 57 & 1,10924 & 13,93 & 25,37 & 130,92 & 226,88 \\
\hline 58 & 1,12870 & 13,66 & 25,24 & 134,11 & 235,04 \\
\hline 59 & 1,14816 & 13,40 & 25,34 & 142,65 & 243,18 \\
\hline 60 & 1,16762 & 13,14 & 24,83 & 136,70 & 251,30 \\
\hline 61 & 1,18708 & 12,88 & 24,69 & 139,36 & 259,39 \\
\hline 62 & 1,20654 & 12,64 & 24,7 & 145,53 & 267,45 \\
\hline 63 & 1,22600 & 12,39 & 24,33 & 142,49 & 275,48 \\
\hline 64 & 1,24546 & 12,15 & 24,73 & 158,15 & 283,46 \\
\hline 65 & 1,26492 & 11,92 & 24,39 & 155,50 & 291,41 \\
\hline 66 & 1,28438 & 11,69 & 24,45 & 162,81 & 299,30 \\
\hline 67 & 1,30384 & 11,46 & 24,03 & 157,88 & 307,15 \\
\hline 68 & 1,32330 & 11,24 & 22,18 & 119,60 & 314,94 \\
\hline 69 & 1,34276 & 11,03 & 22,43 & 130,02 & 322,68 \\
\hline 70 & 1,36222 & 10,81 & 21,94 & 123,77 & 330,36 \\
\hline 71 & 1,38168 & 10,61 & 20,84 & 104,73 & 337,98 \\
\hline \multirow[t]{4}{*}{72} & 1,40114 & 10,40 & 20,3 & 97,97 & 345,54 \\
\hline & Média & 22,77 & 28,9905 & 4578,62 & 8985,78 \\
\hline & & & & SQres & SQtot \\
\hline & & & & $\mathbf{R}^{2}$ & 0,4905 \\
\hline
\end{tabular}


Tabela 3. Memorial de cálculo de $\mathrm{R}^{2}$ para a equação (14) e precipitação 3 da Tabela 12.

\begin{tabular}{|c|c|c|c|c|c|}
\hline & $V_{0}=$ Valor ADR & & Data & $\mathbf{P} / \Delta \mathbf{t}=94 / 75$ & Ko \\
\hline & \multicolumn{2}{|l|}{$V p=$ Valor equação } & $03 /$ set & 1,25333 & 23,01 \\
\hline Tempo (t) em (min) & Coeficiente & \begin{tabular}{|c|} 
Valor \\
Equação
\end{tabular} & \begin{tabular}{|l|} 
Valor \\
ADR \\
\end{tabular} & $(\mathrm{Vp}-\mathrm{Vo})^{2}-($ Resíduo $)$ & $\left(V_{0}-M\right)^{2}$ \\
\hline 0 & 0,00000 & 23,01 & 23,01 & 0,00 & 227,90 \\
\hline 1 & 0,06594 & 21,54 & 22,8 & 1,58 & 221,60 \\
\hline 2 & 0,13189 & 20,17 & 21,24 & 1,15 & 177,59 \\
\hline 3 & 0,19783 & 18,88 & 22,31 & 11,77 & 207,25 \\
\hline 4 & 0,26378 & 17,68 & 22,93 & 27,61 & 225,49 \\
\hline 5 & 0,32972 & 16,55 & 21,54 & 24,93 & 185,68 \\
\hline 6 & 0,39566 & 15,49 & 21,25 & 33,17 & 177,86 \\
\hline 7 & 0,46161 & 14,50 & 19,61 & 26,09 & 136,80 \\
\hline 8 & 0,52755 & 13,58 & 18,85 & 27,80 & 119,60 \\
\hline 9 & 0,59350 & 12,71 & 14,82 & 4,45 & 47,70 \\
\hline 10 & 0,65944 & 11,90 & 14,8 & 8,41 & 47,42 \\
\hline 11 & 0,72539 & 11,14 & 13,22 & 4,33 & 28,16 \\
\hline 12 & 0,79133 & 10,43 & 11,91 & 2,19 & 15,97 \\
\hline 13 & 0,85727 & 9,76 & 10,32 & 0,31 & 5,79 \\
\hline 14 & 0,92322 & 9,14 & 9,58 & 0,19 & 2,78 \\
\hline 15 & 0,98916 & 8,56 & 9,31 & 0,57 & 1,95 \\
\hline 16 & 1,05511 & 8,01 & 8,93 & 0,84 & 1,03 \\
\hline 17 & 1,12105 & 7,50 & 8,98 & 2,19 & 1,14 \\
\hline 18 & 1,18699 & 7,02 & 7,53 & 0,26 & 0,15 \\
\hline 19 & 1,25294 & 6,57 & 7,37 & 0,63 & 0,30 \\
\hline 20 & 1,31888 & 6,15 & 7,19 & 1,07 & 0,52 \\
\hline 21 & 1,38483 & 5,76 & 6,54 & 0,61 & 1,89 \\
\hline 22 & 1,45077 & 5,39 & 6,18 & 0,62 & 3,01 \\
\hline 23 & 1,51672 & 5,05 & 6,75 & 2,89 & 1,35 \\
\hline 24 & 1,58266 & 4,73 & 6,47 & 3,04 & 2,08 \\
\hline 25 & 1,64860 & 4,43 & 6,2 & 3,15 & 2,94 \\
\hline 26 & 1,71455 & 4,14 & 6,25 & 4,44 & 2,77 \\
\hline 27 & 1,78049 & 3,88 & 6,67 & 7,79 & 1,55 \\
\hline 28 & 1,84644 & 3,63 & 5,86 & 4,97 & 4,22 \\
\hline 29 & 1,91238 & 3,40 & 5,53 & 4,54 & 5,68 \\
\hline 30 & 1,97832 & 3,18 & 6,03 & 8,11 & 3,55 \\
\hline 31 & 2,04427 & 2,98 & 6,04 & 9,37 & 3,51 \\
\hline 32 & 2,11021 & 2,79 & 5,87 & 9,49 & 4,18 \\
\hline 33 & 2,17616 & 2,61 & 5,95 & 11,15 & 3,86 \\
\hline 34 & 2,24210 & 2,44 & 5,87 & 11,73 & 4,18 \\
\hline 35 & 2,30804 & 2,29 & 6,08 & 14,38 & 3,36 \\
\hline 36 & 2,37399 & 2,14 & 6,29 & 17,20 & 2,64 \\
\hline 37 & 2,43993 & 2,01 & 5,59 & 12,85 & 5,40 \\
\hline
\end{tabular}


Tabela 3. Memorial de cálculo de $\mathrm{R}^{2}$ para a equação (14) e precipitação 3 da Tabela 12 (Continuação).

\begin{tabular}{|c|c|c|c|c|c|}
\hline Tempo (t) em (min) & Coeficiente & $\begin{array}{c}\text { Valor } \\
\text { Equação }\end{array}$ & \begin{tabular}{|l|} 
Valor \\
ADR \\
\end{tabular} & $\left(\mathbf{V p}-V_{0}\right)^{2}$-(Resíduo) & $\left(V_{0}-M\right)^{2}$ \\
\hline 38 & 2,50588 & 1,88 & 5,11 & $\begin{array}{r}10,45 \\
\end{array}$ & 7,86 \\
\hline 39 & 2,57182 & 1,76 & 5,32 & 12,69 & 6,73 \\
\hline 40 & 2,63777 & 1,65 & 5,23 & 12,85 & 7,20 \\
\hline 41 & 2,70371 & 1,54 & 5,06 & 12,39 & 8,14 \\
\hline 42 & 2,76965 & 1,44 & 5,09 & 13,31 & 7,97 \\
\hline 43 & 2,83560 & 1,35 & 5,28 & 15,44 & 6,94 \\
\hline 44 & 2,90154 & 1,26 & 5,35 & 16,69 & 6,57 \\
\hline 45 & 2,96749 & 1,18 & 5,11 & 15,42 & 7,86 \\
\hline 46 & 3,03343 & 1,11 & 4,9 & 14,38 & 9,08 \\
\hline 47 & 3,09937 & 1,04 & 4,89 & 14,84 & 9,14 \\
\hline 48 & 3,16532 & 0,97 & 5,2 & 17,88 & 7,36 \\
\hline 49 & 3,23126 & 0,91 & 4,98 & 16,57 & 8,61 \\
\hline 50 & 3,29721 & 0,85 & 4,64 & 14,36 & 10,72 \\
\hline 51 & 3,36315 & 0,80 & 4,77 & 15,79 & 9,88 \\
\hline 52 & 3,42909 & 0,75 & 4,89 & 17,17 & 9,14 \\
\hline 53 & 3,49504 & 0,70 & 4,72 & 16,17 & 10,20 \\
\hline 54 & 3,56098 & 0,65 & 4,38 & 13,89 & 12,49 \\
\hline 55 & 3,62693 & 0,61 & 4,63 & 16,14 & 10,78 \\
\hline 56 & 3,69287 & 0,57 & 4,94 & 19,07 & 8,84 \\
\hline 57 & 3,75882 & 0,54 & 4,37 & 14,70 & 12,56 \\
\hline 58 & 3,82476 & 0,50 & 4,52 & 16,14 & 11,52 \\
\hline 59 & 3,89070 & 0,47 & 4,79 & 18,66 & 9,76 \\
\hline 60 & 3,95665 & 0,44 & 4,65 & 17,72 & 10,65 \\
\hline 61 & 4,02259 & 0,41 & 4,17 & 14,12 & 14,02 \\
\hline 62 & 4,08854 & 0,39 & 4,24 & 14,86 & 13,50 \\
\hline 63 & 4,15448 & 0,36 & 4,22 & 14,89 & 13,64 \\
\hline 64 & 4,22042 & 0,34 & 4,4 & 16,50 & 12,35 \\
\hline 65 & 4,28637 & 0,32 & 4,21 & 15,16 & 13,72 \\
\hline 66 & 4,35231 & 0,30 & 4,07 & 14,24 & 14,77 \\
\hline 67 & 4,41826 & 0,28 & 4,21 & 15,47 & 13,72 \\
\hline 68 & 4,48420 & 0,26 & 4,34 & 16,65 & 12,77 \\
\hline 69 & 4,55015 & 0,24 & 4,27 & 16,22 & 13,28 \\
\hline 70 & 4,61609 & 0,23 & 4,42 & 17,58 & 12,21 \\
\hline 71 & 4,68203 & 0,21 & 4,08 & 14,95 & 14,70 \\
\hline 72 & 4,74798 & 0,20 & 4,29 & 16,73 & 13,13 \\
\hline 73 & 4,81392 & 0,19 & 4,15 & 15,71 & 14,17 \\
\hline \multirow[t]{4}{*}{74} & 4,87987 & 0,17 & 3,97 & 14,40 & 15,55 \\
\hline & Média & 4,77 & 7,9137 & 876,08 & 2290,34 \\
\hline & & & & SQres & SQtot \\
\hline & & & & $\mathbf{R}^{2}$ & 0,6175 \\
\hline
\end{tabular}


Tabela 4. Memorial de cálculo de $\mathrm{R}^{2}$ para a equação (14) e precipitação 5 da Tabela 12.

\begin{tabular}{|c|c|c|c|c|c|}
\hline & $V_{0}=$ Valor ADR & & Data & $\mathbf{P} / \Delta \mathbf{t}=41 / 48$ & Ko \\
\hline & \multicolumn{2}{|c|}{$V p=$ Valor equação } & 26/out & 0,85417 & 14,98 \\
\hline Tempo (t) em (min) & Coeficiente & $\begin{array}{c}\text { Valor } \\
\text { Equação }\end{array}$ & \begin{tabular}{|l|} 
Valor \\
ADR \\
\end{tabular} & $(\mathrm{Vp}-\mathrm{Vo})^{2}-($ Resíduo $)$ & $\left(V_{0}-\mathbf{M}\right)^{2}$ \\
\hline 0 & 0,00000 & 14,98 & 14,98 & $\begin{array}{r}0,00 \\
\end{array}$ & 56,49 \\
\hline 1 & 0,04494 & 14,32 & 14,53 & 0,04 & 49,93 \\
\hline 2 & 0,08988 & 13,69 & 12,62 & 1,15 & 26,59 \\
\hline 3 & 0,13483 & 13,09 & 13,1 & 0,00 & 31,77 \\
\hline 4 & 0,17977 & 12,52 & 12,64 & 0,02 & 26,79 \\
\hline 5 & 0,22471 & 11,97 & 11,76 & 0,04 & 18,46 \\
\hline 6 & 0,26965 & 11,44 & 9,52 & 3,68 & 4,23 \\
\hline 7 & 0,31459 & 10,94 & 7,7 & 10,48 & 0,06 \\
\hline 8 & 0,35954 & 10,46 & 8,15 & 5,32 & 0,47 \\
\hline 9 & 0,40448 & 10,00 & 8,12 & 3,52 & 0,43 \\
\hline 10 & 0,44942 & 9,56 & 7,87 & 2,85 & 0,16 \\
\hline 11 & 0,49436 & 9,14 & 6,95 & 4,78 & 0,26 \\
\hline 12 & 0,53930 & 8,74 & 7,56 & 1,38 & 0,01 \\
\hline 13 & 0,58425 & 8,35 & 6,97 & 1,91 & 0,24 \\
\hline 14 & 0,62919 & 7,98 & 8,8 & 0,66 & 1,79 \\
\hline 15 & 0,67413 & 7,63 & 9,45 & 3,30 & 3,94 \\
\hline 16 & 0,71907 & 7,30 & 9,78 & 6,16 & 5,36 \\
\hline 17 & 0,76401 & 6,98 & 10,56 & 12,83 & 9,59 \\
\hline 18 & 0,80896 & 6,67 & 10,75 & 16,64 & 10,80 \\
\hline 19 & 0,85390 & 6,38 & 9,22 & 8,08 & 3,08 \\
\hline 20 & 0,89884 & 6,10 & 7,49 & 1,94 & 0,00 \\
\hline 21 & 0,94378 & 5,83 & 7,01 & 1,39 & 0,21 \\
\hline 22 & 0,98872 & 5,57 & 8,12 & 6,49 & 0,43 \\
\hline 23 & 1,03367 & 5,33 & 7,28 & 3,81 & 0,03 \\
\hline 24 & 1,07861 & 5,09 & 7,99 & 8,39 & 0,28 \\
\hline 25 & 1,12355 & 4,87 & 6,69 & 3,31 & 0,60 \\
\hline 26 & 1,16849 & 4,66 & 6,02 & 1,86 & 2,08 \\
\hline 27 & 1,21343 & 4,45 & 5,77 & 1,74 & 2,87 \\
\hline 28 & 1,25838 & 4,26 & 4,75 & 0,24 & 7,36 \\
\hline 29 & 1,30332 & 4,07 & 4,75 & 0,46 & 7,36 \\
\hline 30 & 1,34826 & 3,89 & 4,65 & 0,58 & 7,92 \\
\hline 31 & 1,39320 & 3,72 & 4,85 & 1,28 & 6,83 \\
\hline 32 & 1,43814 & 3,56 & 6,1 & 6,47 & 1,86 \\
\hline 33 & 1,48309 & 3,40 & 6,35 & 8,71 & 1,24 \\
\hline 34 & 1,52803 & 3,25 & 6,5 & 10,56 & 0,93 \\
\hline 35 & 1,57297 & 3,11 & 7,22 & 16,91 & 0,06 \\
\hline 36 & 1,61791 & 2,97 & 5,47 & 6,25 & 3,98 \\
\hline 37 & 1,66285 & 2,84 & 5,38 & 6,45 & 4,34 \\
\hline
\end{tabular}


Tabela 4. Memorial de cálculo de $\mathrm{R}^{2}$ para a equação (14) e precipitação 5 da Tabela 12 (Continuação).

\begin{tabular}{|c|c|c|c|c|c|}
\hline Tempo (t) em (min) & Coeficiente & $\begin{array}{c}\text { Valor } \\
\text { Equação }\end{array}$ & \begin{tabular}{|l|} 
Valor \\
ADR \\
\end{tabular} & $(V p-V o)^{2}-($ Resíduo $)$ & $\left(V_{0}-M\right)^{2}$ \\
\hline 38 & 1,70780 & 2,72 & 4,45 & $\begin{array}{r}3,01 \\
\end{array}$ & 9,08 \\
\hline 39 & 1,75274 & 2,60 & 5,37 & 7,69 & 4,38 \\
\hline 40 & 1,79768 & 2,48 & 4,69 & 4,88 & 7,69 \\
\hline 41 & 1,84262 & 2,37 & 4,3 & 3,71 & 10,01 \\
\hline 42 & 1,88756 & 2,27 & 4,48 & 4,89 & 8,90 \\
\hline 43 & 1,93251 & 2,17 & 5,13 & 8,77 & 5,45 \\
\hline 44 & 1,97745 & 2,07 & 4,9 & 7,99 & 6,57 \\
\hline 45 & 2,02239 & 1,98 & 4,39 & 5,80 & 9,45 \\
\hline 46 & 2,06733 & 1,90 & 3,65 & 3,08 & 14,55 \\
\hline \multirow[t]{4}{*}{47} & 2,11227 & 1,81 & 3,48 & 2,78 & 15,87 \\
\hline & & 6,28 & 7,4638 & 222,28 & 390,80 \\
\hline & & & & SQres & SQtot \\
\hline & & & & $\mathbf{R}^{2}$ & 0,4312 \\
\hline
\end{tabular}


Tabela 5. Memorial de cálculo de $\mathrm{R}^{2}$ para a equação (14) e precipitação 6 da Tabela 12.

\begin{tabular}{|c|c|c|c|c|c|}
\hline & $\begin{array}{l}\text { Vo= Valor } \\
\text { ADR }\end{array}$ & & Data & $\mathbf{P} / \Delta \mathbf{t}=33 / 24$ & Ko \\
\hline & \multicolumn{2}{|c|}{$V p=$ Valor equação } & 26/out & 1,375 & 13,51 \\
\hline Tempo (t) em (min) & Coeficiente & $\begin{array}{c}\text { Valor } \\
\text { Equação }\end{array}$ & $\begin{array}{l}\text { Valor } \\
\text { ADR } \\
\end{array}$ & $(V p-V o)^{2}-($ Resíduo $)$ & $\left(V_{0}-M\right)^{2}$ \\
\hline 0 & 0,00000 & 13,51 & 13,51 & 0,00 & 58,55 \\
\hline 1 & 0,07235 & 12,57 & 11,7 & 0,75 & 34,13 \\
\hline 2 & 0,14469 & 11,69 & 10,45 & 1,54 & 21,09 \\
\hline 3 & 0,21704 & 10,87 & 8,89 & 3,94 & 9,19 \\
\hline 4 & 0,28938 & 10,12 & 7,92 & 4,82 & 4,25 \\
\hline 5 & 0,36173 & 9,41 & 7,69 & 2,96 & 3,36 \\
\hline 6 & 0,43407 & 8,75 & 7,87 & 0,78 & 4,05 \\
\hline 7 & 0,50642 & 8,14 & 6,41 & 3,00 & 0,30 \\
\hline 8 & 0,57877 & 7,57 & 4,94 & 6,94 & 0,84 \\
\hline 9 & 0,65111 & 7,05 & 4,49 & 6,53 & 1,87 \\
\hline 10 & 0,72346 & 6,55 & 3,52 & 9,20 & 5,47 \\
\hline 11 & 0,79580 & 6,10 & 4,52 & 2,48 & 1,79 \\
\hline 12 & 0,86815 & 5,67 & 5,3 & 0,14 & 0,31 \\
\hline 13 & 0,94049 & 5,27 & 5,92 & 0,42 & 0,00 \\
\hline 14 & 1,01284 & 4,91 & 5,89 & 0,97 & 0,00 \\
\hline 15 & 1,08518 & 4,56 & 4,56 & 0,00 & 1,68 \\
\hline 16 & 1,15753 & 4,25 & 3,84 & 0,16 & 4,07 \\
\hline 17 & 1,22988 & 3,95 & 4,2 & 0,06 & 2,75 \\
\hline 18 & 1,30222 & 3,67 & 3,85 & 0,03 & 4,03 \\
\hline 19 & 1,37457 & 3,42 & 3,3 & 0,01 & 6,54 \\
\hline 20 & 1,44691 & 3,18 & 2,86 & 0,10 & 8,99 \\
\hline 21 & 1,51926 & 2,96 & 2,91 & 0,00 & 8,69 \\
\hline 22 & 1,59160 & 2,75 & 3,48 & 0,53 & 5,65 \\
\hline 23 & 1,66395 & 2,56 & 2,57 & 0,00 & 10,81 \\
\hline & Média & 6,64 & 5,8579 & 45,36 & 198,44 \\
\hline & & & & SQres & SQtot \\
\hline & & & & $\mathbf{R}^{2}$ & 0,7714 \\
\hline
\end{tabular}


Tabela 6. Memorial de cálculo de $\mathrm{R}^{2}$ para a equação (14) e precipitação 7 da Tabela 12.

\begin{tabular}{|c|c|c|c|c|c|}
\hline & $V_{0}=$ Valor ADR & & Data & $\mathbf{P} / \Delta \mathbf{t}=25 / 46$ & Ko \\
\hline & \multicolumn{2}{|c|}{$V p=$ Valor equação } & 26/out & 0,54348 & 11,25 \\
\hline Tempo (t) em (min) & Coeficiente & $\begin{array}{c}\text { Valor } \\
\text { Equação }\end{array}$ & \begin{tabular}{|l|} 
Valor \\
ADR \\
\end{tabular} & $(\mathbf{V p}-\mathrm{Vo})^{2}-($ Resíduo $)$ & $\left(V_{0}-M\right)^{2}$ \\
\hline 0 & 0,00000 & 11,25 & 11,25 & 0,00 & 24,26 \\
\hline 1 & 0,02860 & 10,93 & 10,77 & 0,03 & 19,77 \\
\hline 2 & 0,05719 & 10,62 & 10,45 & 0,03 & 17,02 \\
\hline 3 & 0,08579 & 10,33 & 11,14 & 0,66 & 23,19 \\
\hline 4 & 0,11438 & 10,03 & 10,21 & 0,03 & 15,10 \\
\hline 5 & 0,14298 & 9,75 & 10,34 & 0,35 & 16,13 \\
\hline 6 & 0,17157 & 9,48 & 10,39 & 0,83 & 16,53 \\
\hline 7 & 0,20017 & 9,21 & 9,27 & 0,00 & 8,68 \\
\hline 8 & 0,22876 & 8,95 & 8,47 & 0,23 & 4,60 \\
\hline 9 & 0,25736 & 8,70 & 8,29 & 0,17 & 3,86 \\
\hline 10 & 0,28595 & 8,45 & 8,2 & 0,06 & 3,52 \\
\hline 11 & 0,31455 & 8,21 & 7,77 & 0,20 & 2,09 \\
\hline 12 & 0,34314 & 7,98 & 7,39 & 0,35 & 1,14 \\
\hline 13 & 0,37174 & 7,76 & 7,86 & 0,01 & 2,36 \\
\hline 14 & 0,40033 & 7,54 & 7,58 & 0,00 & 1,58 \\
\hline 15 & 0,42893 & 7,33 & 6,9 & 0,18 & 0,33 \\
\hline 16 & 0,45752 & 7,12 & 7,21 & 0,01 & 0,78 \\
\hline 17 & 0,48612 & 6,92 & 6,85 & 0,00 & 0,28 \\
\hline 18 & 0,51471 & 6,72 & 7,46 & 0,54 & 1,29 \\
\hline 19 & 0,54331 & 6,53 & 6,85 & 0,10 & 0,28 \\
\hline 20 & 0,57190 & 6,35 & 7,18 & 0,69 & 0,73 \\
\hline 21 & 0,60050 & 6,17 & 6,61 & 0,19 & 0,08 \\
\hline 22 & 0,62909 & 6,00 & 6,5 & 0,25 & 0,03 \\
\hline 23 & 0,65769 & 5,83 & 5,77 & 0,00 & 0,31 \\
\hline 24 & 0,68628 & 5,66 & 5,85 & 0,03 & 0,22 \\
\hline 25 & 0,71488 & 5,50 & 5,16 & 0,12 & 1,36 \\
\hline 26 & 0,74347 & 5,35 & 5,14 & 0,04 & 1,40 \\
\hline 27 & 0,77207 & 5,20 & 4,87 & 0,11 & 2,11 \\
\hline 28 & 0,80066 & 5,05 & 4,87 & 0,03 & 2,11 \\
\hline 29 & 0,82926 & 4,91 & 4,48 & 0,18 & 3,40 \\
\hline 30 & 0,85785 & 4,77 & 4,35 & 0,18 & 3,90 \\
\hline 31 & 0,88645 & 4,64 & 4,35 & 0,08 & 3,90 \\
\hline 32 & 0,91504 & 4,51 & 3,67 & 0,70 & 7,04 \\
\hline 33 & 0,94364 & 4,38 & 3,79 & 0,35 & 6,42 \\
\hline 34 & 0,97223 & 4,26 & 3,75 & 0,26 & 6,63 \\
\hline 35 & 1,00083 & 4,14 & 4,34 & 0,04 & 3,94 \\
\hline 36 & 1,02942 & 4,02 & 4,01 & 0,00 & 5,36 \\
\hline 37 & 1,05802 & 3,91 & 3,66 & 0,06 & 7,10 \\
\hline
\end{tabular}


Tabela 6. Memorial de cálculo de $\mathrm{R}^{2}$ para a equação (14) e precipitação 7 da Tabela 12 (Continuação).

\begin{tabular}{|c|c|c|c|c|c|}
\hline Tempo (t) em (min) & Coeficiente & $\begin{array}{c}\text { Valor } \\
\text { Equação }\end{array}$ & \begin{tabular}{|l|} 
Valor \\
ADR \\
\end{tabular} & $\left(\mathbf{V} p-V_{0}\right)^{2}-($ Resíduo $)$ & $\left(V_{0}-M\right)^{2}$ \\
\hline 38 & 1,08661 & 3,80 & 3,71 & 0,01 & 6,83 \\
\hline 39 & 1,11521 & 3,69 & 4,11 & 0,18 & 4,90 \\
\hline 40 & 1,14380 & 3,58 & 3,26 & 0,11 & 9,39 \\
\hline 41 & 1,17240 & 3,48 & 3,46 & 0,00 & 8,20 \\
\hline 42 & 1,20099 & 3,39 & 3,31 & 0,01 & 9,08 \\
\hline 43 & 1,22959 & 3,29 & 3,43 & 0,02 & 8,38 \\
\hline 44 & 1,25818 & 3,20 & 3,38 & 0,03 & 8,67 \\
\hline \multirow[t]{4}{*}{45} & 1,28678 & 3,11 & 3,25 & 0,02 & 9,45 \\
\hline & Média & 6,35 & 6,3241 & 7,48 & 283,74 \\
\hline & & & & SQres & SQtot \\
\hline & & & & $\mathbf{R}^{2}$ & 0,9736 \\
\hline
\end{tabular}


Tabela 7. Memorial de cálculo de $\mathrm{R}^{2}$ para a equação (14) e precipitação 8 da Tabela 12.

\begin{tabular}{|c|c|c|c|c|c|}
\hline & $V_{0}=$ Valor ADR & & Data & $\mathbf{P} / \Delta \mathbf{t}=19 / 40$ & Ko \\
\hline & \multicolumn{2}{|c|}{$V p=$ Valor equação } & 04/nov & 0,47500 & 12,18 \\
\hline Tempo (t) em (min) & Coeficiente & $\begin{array}{c}\text { Valor } \\
\text { Equação }\end{array}$ & $\begin{array}{l}\text { Valor } \\
\text { ADR }\end{array}$ & $(\mathrm{Vp}-\mathrm{Vo})^{2}-($ Resíduo $)$ & $\left(V_{0}-M\right)^{2}$ \\
\hline 0 & 0,00000 & 12,18 & 12,18 & \begin{tabular}{r|}
0,00 \\
\end{tabular} & 23,08 \\
\hline 1 & 0,02499 & 11,88 & 11,34 & 0,29 & 15,71 \\
\hline 2 & 0,04998 & 11,59 & 10,58 & 1,01 & 10,27 \\
\hline 3 & 0,07498 & 11,30 & 10,13 & 1,37 & 7,59 \\
\hline 4 & 0,09997 & 11,02 & 11,15 & 0,02 & 14,24 \\
\hline 5 & 0,12496 & 10,75 & 10,71 & 0,00 & 11,12 \\
\hline 6 & 0,14995 & 10,48 & 10,21 & 0,08 & 8,03 \\
\hline 7 & 0,17494 & 10,23 & 9,62 & 0,37 & 5,04 \\
\hline 8 & 0,19994 & 9,97 & 8,51 & 2,14 & 1,29 \\
\hline 9 & 0,22493 & 9,73 & 9,44 & 0,08 & 4,26 \\
\hline 10 & 0,24992 & 9,49 & 8,91 & 0,33 & 2,35 \\
\hline 11 & 0,27491 & 9,25 & 8,65 & 0,36 & 1,62 \\
\hline 12 & 0,29991 & 9,02 & 8,84 & 0,03 & 2,14 \\
\hline 13 & 0,32490 & 8,80 & 8,18 & 0,39 & 0,65 \\
\hline 14 & 0,34989 & 8,58 & 7,57 & 1,03 & 0,04 \\
\hline 15 & 0,37488 & 8,37 & 7,1 & 1,62 & 0,08 \\
\hline 16 & 0,39987 & 8,17 & 8,86 & 0,48 & 2,20 \\
\hline 17 & 0,42487 & 7,96 & 8,45 & 0,24 & 1,15 \\
\hline 18 & 0,44986 & 7,77 & 8,61 & 0,71 & 1,52 \\
\hline 19 & 0,47485 & 7,58 & 7,8 & 0,05 & 0,18 \\
\hline 20 & 0,49984 & 7,39 & 6,78 & 0,37 & 0,35 \\
\hline 21 & 0,52483 & 7,21 & 7,41 & 0,04 & 0,00 \\
\hline 22 & 0,54983 & 7,03 & 8,05 & 1,04 & 0,45 \\
\hline 23 & 0,57482 & 6,85 & 6,85 & 0,00 & 0,28 \\
\hline 24 & 0,59981 & 6,69 & 7,02 & 0,11 & 0,13 \\
\hline 25 & 0,62480 & 6,52 & 6,18 & 0,12 & 1,43 \\
\hline 26 & 0,64980 & 6,36 & 6,19 & 0,03 & 1,41 \\
\hline 27 & 0,67479 & 6,20 & 5,88 & 0,10 & 2,24 \\
\hline 28 & 0,69978 & 6,05 & 6,09 & 0,00 & 1,65 \\
\hline 29 & 0,72477 & 5,90 & 5,9 & 0,00 & 2,18 \\
\hline 30 & 0,74976 & 5,75 & 6,04 & 0,08 & 1,78 \\
\hline 31 & 0,77476 & 5,61 & 4,56 & 1,11 & 7,93 \\
\hline 32 & 0,79975 & 5,47 & 4,31 & 1,36 & 9,40 \\
\hline 33 & 0,82474 & 5,34 & 4,97 & 0,14 & 5,79 \\
\hline 34 & 0,84973 & 5,21 & 4,63 & 0,33 & 7,54 \\
\hline 35 & 0,87472 & 5,08 & 3,75 & 1,77 & 13,15 \\
\hline 36 & 0,89972 & 4,95 & 3,38 & 2,48 & 15,97 \\
\hline 37 & 0,92471 & 4,83 & 3,42 & 1,99 & 15,65 \\
\hline
\end{tabular}


Tabela 7. Memorial de cálculo de $\mathrm{R}^{2}$ para a equação (14) e precipitação 8 da Tabela 12 (Continuação).

\begin{tabular}{|r|r|r|r|r|r||}
\hline Tempo (t) em (min) & Coeficiente & \multicolumn{1}{c|}{$\begin{array}{c}\text { Valor } \\
\text { Equação }\end{array}$} & \multicolumn{1}{l|}{$\begin{array}{l}\text { Valor } \\
\text { ADR }\end{array}$} & (Vp - Vo) $)^{2}($ Resíduo) & (Vo - M) $^{\mathbf{2}}$ \\
\hline 38 & 0,94970 & 4,71 & 3,55 & 1,35 & 14,64 \\
\hline 39 & 0,97469 & 4,60 & 3,23 & 1,86 & 17,19 \\
\hline & Média & 7,80 & 7,3758 & 24,87 & 231,71 \\
\hline & & & & SQres & SQtot \\
\hline & & & & $\mathbf{R}^{2}$ & 0,8926 \\
\hline
\end{tabular}


Tabela 8. Memorial de cálculo de $\mathrm{R}^{2}$ para a equação (14) e precipitação 9 da Tabela 12.

\begin{tabular}{|c|c|c|c|c|c|}
\hline & $V_{0}=$ Valor ADR & & Data & $\mathbf{P} / \Delta \mathbf{t}=31 / 34$ & Ko \\
\hline & \multicolumn{2}{|c|}{$V p=$ Valor equação } & $04 /$ nov & 0,91176 & 9,56 \\
\hline Tempo (t) em (min) & Coeficiente & $\begin{array}{c}\text { Valor } \\
\text { Equação }\end{array}$ & $\begin{array}{l}\text { Valor } \\
\text { ADR }\end{array}$ & $(V p-V o)^{2}-($ Resíduo $)$ & $\left(V_{0}-M\right)^{2}$ \\
\hline 0 & 0,00000 & 9,56 & 9,56 & 0,00 & 16,52 \\
\hline 1 & 0,04797 & 9,11 & 9,45 & 0,11 & 15,64 \\
\hline 2 & 0,09595 & 8,69 & 9,04 & 0,13 & 12,56 \\
\hline 3 & 0,14392 & 8,28 & 8,39 & 0,01 & 8,38 \\
\hline 4 & 0,19189 & 7,89 & 7,37 & 0,27 & 3,51 \\
\hline 5 & 0,23986 & 7,52 & 7,5 & 0,00 & 4,02 \\
\hline 6 & 0,28784 & 7,17 & 6,77 & 0,16 & 1,62 \\
\hline 7 & 0,33581 & 6,83 & 5,67 & 1,35 & 0,03 \\
\hline 8 & 0,38378 & 6,51 & 5,45 & 1,13 & 0,00 \\
\hline 9 & 0,43175 & 6,21 & 5,82 & 0,15 & 0,11 \\
\hline 10 & 0,47973 & 5,92 & 6,14 & 0,05 & 0,42 \\
\hline 11 & 0,52770 & 5,64 & 6,26 & 0,38 & 0,58 \\
\hline 12 & 0,57567 & 5,38 & 6,54 & 1,36 & 1,09 \\
\hline 13 & 0,62364 & 5,12 & 5,97 & 0,72 & 0,23 \\
\hline 14 & 0,67162 & 4,88 & 5,93 & 1,09 & 0,19 \\
\hline 15 & 0,71959 & 4,66 & 5,16 & 0,25 & 0,11 \\
\hline 16 & 0,76756 & 4,44 & 4,97 & 0,28 & 0,28 \\
\hline 17 & 0,81553 & 4,23 & 4,37 & 0,02 & 1,27 \\
\hline 18 & 0,86351 & 4,03 & 4,1 & 0,00 & 1,95 \\
\hline 19 & 0,91148 & 3,84 & 4,29 & 0,20 & 1,45 \\
\hline 20 & 0,95945 & 3,66 & 3,72 & 0,00 & 3,15 \\
\hline 21 & 1,00742 & 3,49 & 3,65 & 0,03 & 3,41 \\
\hline 22 & 1,05540 & 3,33 & 3,68 & 0,12 & 3,30 \\
\hline 23 & 1,10337 & 3,17 & 4,53 & 1,85 & 0,93 \\
\hline 24 & 1,15134 & 3,02 & 5,09 & 4,27 & 0,16 \\
\hline 25 & 1,19931 & 2,88 & 5,3 & 5,85 & 0,04 \\
\hline 26 & 1,24729 & 2,75 & 4,5 & 3,07 & 0,99 \\
\hline 27 & 1,29526 & 2,62 & 4,71 & 4,38 & 0,62 \\
\hline 28 & 1,34323 & 2,50 & 4,29 & 3,22 & 1,45 \\
\hline 29 & 1,39120 & 2,38 & 4,11 & 3,00 & 1,92 \\
\hline 30 & 1,43918 & 2,27 & 3,73 & 2,14 & 3,12 \\
\hline 31 & 1,48715 & 2,16 & 3,79 & 2,65 & 2,91 \\
\hline 32 & 1,53512 & 2,06 & 3,65 & 2,53 & 3,41 \\
\hline 33 & 1,58309 & 1,96 & 3,34 & 1,90 & 4,65 \\
\hline & Média & 4,83 & 5,4953 & 42,69 & 100,00 \\
\hline & & & & SQres & SQtot \\
\hline & & & & $\mathbf{R}^{2}$ & 0,5731 \\
\hline
\end{tabular}


Tabela 9. Memorial de cálculo de $\mathrm{R}^{2}$ para a equação (14) e precipitação 10 da Tabela 12.

\begin{tabular}{|c|c|c|c|c|c|}
\hline & $\begin{array}{l}\text { Vo= Valor } \\
\text { ADR }\end{array}$ & & Data & $\mathbf{P} / \Delta \mathbf{t}=34 / 45$ & Ko \\
\hline & \multicolumn{2}{|c|}{$\mathbf{V p}=$ Valor equação } & $08 /$ nov & 0,75556 & 7,91 \\
\hline Tempo (t) em (min) & Coeficiente & $\begin{array}{c}\text { Valor } \\
\text { Equação }\end{array}$ & Valor ADR & $(V p-V o)^{2}-($ Resíduo $)$ & $\left(V_{0}-M\right)^{2}$ \\
\hline 0 & 0,00000 & 7,91 & 7,91 & 0,00 & 15,90 \\
\hline 1 & 0,03975 & 7,60 & 7,04 & 0,32 & 9,72 \\
\hline 2 & 0,07951 & 7,31 & 4,88 & 5,88 & 0,92 \\
\hline 3 & 0,11926 & 7,02 & 5,35 & 2,79 & 2,04 \\
\hline 4 & 0,15901 & 6,75 & 5,32 & 2,04 & 1,95 \\
\hline 5 & 0,19877 & 6,48 & 4,29 & 4,81 & 0,13 \\
\hline 6 & 0,23852 & 6,23 & 4,88 & 1,83 & 0,92 \\
\hline 7 & 0,27827 & 5,99 & 6,13 & 0,02 & 4,87 \\
\hline 8 & 0,31803 & 5,76 & 5,88 & 0,02 & 3,83 \\
\hline 9 & 0,35778 & 5,53 & 4,81 & 0,52 & 0,79 \\
\hline 10 & 0,39754 & 5,32 & 5,15 & 0,03 & 1,51 \\
\hline 11 & 0,43729 & 5,11 & 4,45 & 0,43 & 0,28 \\
\hline 12 & 0,47704 & 4,91 & 4,09 & 0,67 & 0,03 \\
\hline 13 & 0,51680 & 4,72 & 7,24 & 6,36 & 11,00 \\
\hline 14 & 0,55655 & 4,53 & 7,14 & 6,79 & 10,35 \\
\hline 15 & 0,59630 & 4,36 & 6,3 & 3,77 & 5,65 \\
\hline 16 & 0,63606 & 4,19 & 6,25 & 4,25 & 5,42 \\
\hline 17 & 0,67581 & 4,02 & 4,33 & 0,09 & 0,17 \\
\hline 18 & 0,71556 & 3,87 & 4,9 & 1,07 & 0,96 \\
\hline 19 & 0,75532 & 3,72 & 3,62 & 0,01 & 0,09 \\
\hline 20 & 0,79507 & 3,57 & 4,21 & 0,41 & 0,08 \\
\hline 21 & 0,83482 & 3,43 & 4,1 & 0,45 & 0,03 \\
\hline 22 & 0,87458 & 3,30 & 3,35 & 0,00 & 0,33 \\
\hline 23 & 0,91433 & 3,17 & 3,93 & 0,58 & 0,00 \\
\hline 24 & 0,95409 & 3,05 & 3,2 & 0,02 & 0,52 \\
\hline 25 & 0,99384 & 2,93 & 2,48 & 0,20 & 2,08 \\
\hline 26 & 1,03359 & 2,81 & 2,36 & 0,21 & 2,44 \\
\hline 27 & 1,07335 & 2,70 & 4,87 & 4,69 & 0,90 \\
\hline 28 & 1,11310 & 2,60 & 6,4 & 14,45 & 6,14 \\
\hline 29 & 1,15285 & 2,50 & 3,3 & 0,64 & 0,39 \\
\hline 30 & 1,19261 & 2,40 & 2,14 & 0,07 & 3,18 \\
\hline 31 & 1,23236 & 2,31 & 2,17 & 0,02 & 3,07 \\
\hline 32 & 1,27211 & 2,22 & 1,83 & 0,15 & 4,38 \\
\hline 33 & 1,31187 & 2,13 & 2,05 & 0,01 & 3,51 \\
\hline 34 & 1,35162 & 2,05 & 2 & 0,00 & 3,70 \\
\hline 35 & 1,39137 & 1,97 & 2,07 & 0,01 & 3,43 \\
\hline 36 & 1,43113 & 1,89 & 2,1 & 0,04 & 3,32 \\
\hline 37 & 1,47088 & 1,82 & 1,9 & 0,01 & 4,09 \\
\hline
\end{tabular}


Tabela 9. Memorial de cálculo de $\mathrm{R}^{2}$ para a equação (14) e precipitação 10 da Tabela 12 (Continuação).

\begin{tabular}{|c|c|c|c|c|c|}
\hline Tempo (t) em (min) & Coeficiente & $\begin{array}{c}\text { Valor } \\
\text { Equação }\end{array}$ & Valor ADR & $(V p-V o)^{2}-($ Resíduo $)$ & $\left(V_{0}-\mathbf{M}\right)^{2}$ \\
\hline 38 & 1,51064 & 1,75 & 1,77 & 0,00 & 4,63 \\
\hline 39 & 1,55039 & 1,68 & 1,72 & 0,00 & 4,85 \\
\hline 40 & 1,59014 & 1,61 & 1,63 & 0,00 & 5,26 \\
\hline 41 & 1,62990 & 1,55 & 1,95 & 0,16 & 3,89 \\
\hline 42 & 1,66965 & 1,49 & 1,79 & 0,09 & 4,55 \\
\hline 43 & 1,70940 & 1,43 & 1,75 & 0,10 & 4,72 \\
\hline \multirow[t]{4}{*}{44} & 1,74916 & 1,38 & 1,49 & 0,01 & 5,92 \\
\hline & Média & 3,76 & 3,9227 & 64,03 & 151,92 \\
\hline & & & & SQres & SQtot \\
\hline & & & & $\mathbf{R}^{2}$ & 0,5786 \\
\hline
\end{tabular}

